\title{
All The Things You Are: Jazz Music, Pathways Analysis, and a Theory of Cultural Flows
}

\author{
by
}

\author{
Tyler Harris, B.A.
}

\author{
A Thesis submitted to the \\ Faculty of Graduate Studies and Research \\ In partial fulfillment of the requirements for the degree of \\ Masters of Arts \\ Communications \\ School of Journalism and Communications \\ Carieton University \\ Ottawa, Ontario \\ Canada
}

July 19,2006

(C) Tyler Harris, 2006 


$\begin{array}{ll}\begin{array}{l}\text { Library and } \\ \text { Archives Canada }\end{array} & \begin{array}{l}\text { Bibliothèque et } \\ \text { Archives Canada }\end{array} \\ \begin{array}{l}\text { Published Heritage } \\ \text { Branch }\end{array} & \begin{array}{l}\text { Direction du } \\ \text { Patrimoine de l'édition }\end{array} \\ \begin{array}{l}\text { 395 Wellington Street } \\ \text { Ottawa ON K1A ON4 }\end{array} & \begin{array}{l}\text { 395, rue Wellington } \\ \text { Ottawa ON K1A ON4 } \\ \text { Canada }\end{array}\end{array}$

Your file Votre référence ISBN: 978-0-494-18269-7 Our file Notre référence ISBN: 978-0-494-18269-7

NOTICE:

The author has granted a nonexclusive license allowing Library and Archives Canada to reproduce, publish, archive, preserve, conserve, communicate to the public by telecommunication or on the Internet, loan, distribute and sell theses worldwide, for commercial or noncommercial purposes, in microform, paper, electronic and/or any other formats.

The author retains copyright ownership and moral rights in this thesis. Neither the thesis nor substantial extracts from it may be printed or otherwise reproduced without the author's permission.
AVIS:

L'auteur a accordé une licence non exclusive permettant à la Bibliothèque et Archives Canada de reproduire, publier, archiver, sauvegarder, conserver, transmettre au public par télécommunication ou par l'Internet, prêter, distribuer et vendre des thèses partout dans le monde, à des fins commerciales ou autres, sur support microforme, papier, électronique et/ou autres formats.

L'auteur conserve la propriété du droit d'auteur et des droits moraux qui protège cette thèse. $\mathrm{Ni}$ la thèse ni des extraits substantiels de celle-ci ne doivent être imprimés ou autrement reproduits sans son autorisation.
In compliance with the Canadian

Privacy Act some supporting forms may have been removed from this thesis.

While these forms may be included in the document page count, their removal does not represent any loss of content from the thesis.
Conformément à la loi canadienne sur la protection de la vie privée, quelques formulaires secondaires ont été enlevés de cette thèse.

Bien que ces formulaires aient inclus dans la pagination, il n'y aura aucun contenu manquant.

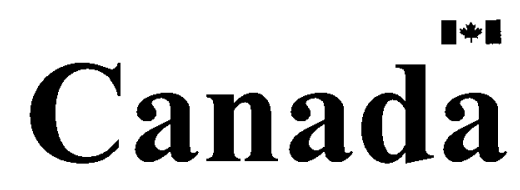




\section{All the Things You Are: \\ Jazz Music, Pathways Analysis, and a Theory of Cultural Flows \\ by Tyler Harris}

\section{Abstract}

This thesis seeks to utilize the history of jazz music to provide an alternative model for the study of cultural phenomena. Traditional histories of jazz music tend to focus exclusively on the role of music and musicians, while neglecting many of the other non-musical factors which have contributed to the development of the music. Jazz music further provides a complicated example of culture, because it has functioned on many different levels of culture: folk, mass, and elite. Historically, there has also been great difficulty in understanding cultural phenomena which operate on more than one level.

These shortcomings can be avoided by paying attention to the pathways through which jazz music travels to reach an audience. An analysis of pathways draws attention to the ways in which messages can be reshaped by factors (media interests, institutions, commercial interests, and critics) encountered along pathways, as well as why certain types of culture operate at certain cultural levels. 


\section{Acknowledgements}

It has been argued that with the onset of rampant digital downloading, most people will stop buying musical albums. One of the reasons I think I will always continue is because I love reading liner notes, understanding some of the supporting cast who has played a role in the realization of the project. And with this in mind I would like to share some of my own debts.

First and foremost, this thesis has been inspired, subject and outcome, by my father. Some of my earliest memories are of watching my father practicing his trumpet; listening with him to jazz and classical records. He has been thoroughly involved in this work from the beginning, and we have shared innumerable discussions about what it is that I wanted to do. His questions of impact have challenged me and will continue to shape my directions.

I would also be remiss if I did not thank the members of my committee for their participation. Paul Attallah has been nothing short of amazing in his editorial coachings. His responses to my chapters and nervous questions have been both quick and incredibly enlightening. He has shown me ways to think and write clearly, and to spend this time with him has been a great learning experience. Charlene Elliott has been a cherished professor during my years at Carleton. I have greatly appreciated her genuine interest in my work, and her willingness to treat me more like a colleague than a student. And I am humbled by the appearance of Will Straw on my committee, who took the time to read and contribute towards an unknown Masters candidate.

Finally, there has been a host of others who have inspired, assisted, and contributed. Mike, my saxophone teacher, has brought me closer and closer to my 
subject material. Royd has aided me with the frustrations of editing, and called out my choices of style and voice. I have valued greatly my discussions with Krista, especially in her sharing with me her own theorizing, and our common questions about the role and future of the arts in our society. And it has been a joy to share the discoveries of this journey and the process of co-miseration with the other MA students in my class (Angela, Kathleen, Lee-Ann, Melissa). 


\section{Table of Contents}

$\begin{array}{ll}\text { Introduction - Complicating Culture } & 1\end{array}$

Chapter One - Abbreviations and Appropriations 17

$\begin{array}{ll}\text { Definitions } & 19\end{array}$

The Narrative Tradition of Jazz $\quad 23$

$\begin{array}{ll}\text { Recent Directions } & 27\end{array}$

Great Men of Jazz $\quad 30$

Solutions $\quad 35$

Chapter Two - Theories of Culture and Communications 42

The Critique of Mass Culture $\quad 43$

Cultural Categories $\quad 52$

The Process of Exchange $\quad 58$

Factors of Influence $\quad 72$

The Importance of Pathways Analysis $\quad 82$

Chapter Three - From Folk To Mass $\quad 86$

Jazz as Folk Culture $\quad 88$

$\begin{array}{ll}\text { The First Cultural Transformation } & 99\end{array}$

$\begin{array}{ll}\text { Chapter Four - From Mass To Elite } & 117\end{array}$

$\begin{array}{ll}\text { Jazz as Popular Culture } & 119\end{array}$

The Second Cultural Transformation 132

Chapter Five - Elite and Everything After 156

Jazz as Elite Culture 158

$\begin{array}{ll}\text { Fusion as a Popularizing Movement } & 178\end{array}$

Neo-Classicism as an Elitist Movement $\quad 188$

Chapter Six - Justifications and Implications 205

Outlining the Theory 208

Limitations and Further Considerations $\quad 230$

Implications 241

Conclusions - All the Things You Are 249

$\begin{array}{ll}\text { Endnotes and Bibliography } & 261\end{array}$ 


\section{Introduction: Complicating Culture}

There are legends of the Orkney Islands that introduce the character of the Selkiefolk. The Selkie-folk are seal people, creatures that can shed their skin and assume human form. However, their transformation into human form is not a complete one; they always long to return to the sea and their original shape. The legend of the Goodman of Wastness is one such folktale. ${ }^{i}$ It explains how a certain gentleman came upon a number of Selkiefolk in human form, playing and basking in the sun. He manages to creep up on them unnoticed and steal one of their skins. The female Selkie whose skin has been taken (and is therefore trapped in human form) follows the Goodman home and begs to have her skin returned. The man falls in love with the seal-maiden and, refusing to return her skin, convinces her reluctantly to leave her people and become his wife. The two live together for years, but everyday, when the man goes out fishing, the seal-maiden searches the house for her seal-skin (which would allow her to resume seal form and return to the sea). Finally one day, with the help of her children, she retrieves the skin and rushes back to the sea, leaving her husband and transforming once again into a seal, with the parting statement: "Fare thee weel, Goodman o' Wastness. I liked thee weel enough fur thoo war geud tae me bit I love better me man o' the sea."

The Selkie-folk of this legend all exhibit an ability to shift back and forth between forms; they can become, completely, another species, though they retain characteristics and longings of their former selves. In other Selkie tales, the Selkie can be seduced away from their original seal-forms to become human by offerings of wealth. However, no matter whether they end up on the human or seal side of the divide, the Selkie are always tempted by a desire to return to the other form. 
These fables can also be interpreted as allegories of the metamorphic nature of cultural phenomena. Much like the Selkie-folk of legend, cultural phenomena can also be seen to exhibit the same transitory properties. Even a cursory history of culture over the last century uncovers many examples of transition. Interestingly enough, however, a particular social group's preferences for a certain cultural form may not remain constant. The various cultural forms, styles, shades, and phrases reviled by one social group can quite suddenly become worthy of praise for another group or at another time. And likewise, certain types of culture celebrated by another group, may become tainted and unworthy. This prompts questions of whether the cultural form changes, or whether it is merely people's flighty preference for the form that changes. Both questions can be answered affirmatively. Taste is not a static formation; rather, cultural fashions have "progressed," "regressed," or changed as a result of the shifting types, ages, and social classes of people who value that form. Additionally, if a more precise history of the cultural form is undertaken, it can be shown that the cultural form itself changes, and in so doing, creates a new audience for itself. Not only is the social meaning of cultural forms de- and re-constructed over time by different audiences, but the form itself evolves.

To draw a parallel with our earlier allegory more closely; the Selkie-folk may be understood to represent one of these cultural forms, while the Goodman of Wastness can be thought of as the embodiment of those social actors who would seek to encourage a cultural form to transform from one state to another. The Goodman of Wastness character exemplifies how certain social actors who desire to keep the Selkie in human form (as a possession) have different motivations for their pursuance. The Goodman of Wastness is initially drawn to the Selkie-folk by their natural form and his own curiosity, but then spies 
their seal-skins lying unattended on the rocks, and quickly seeks to obtain a skin for its value. However, when the human-formed Selkie pleads with him to return her seal-skin, he begins to view her as a possession, and value her transformed figure. She is both human and animal, yet at the same time, neither fully human nor fully animal. The Goodman perceives a human in the form of the Selkie being he first discovers, and under this perception, acts towards her as human, treats her as human, and desires her as a human. And while he is able to keep her in this form for a while, she has her own will, and remains desirous of her former life. So too is culture: able to respond to social influences, yet retaining its ability to change forms.

In addition to the ability to transition between species, the Selkie-folk also exhibit different motivations in each form. As seals, the Selkie are motivated by a desire to be part of their people, to enjoy an inward-seeking philosophy of life. However, they are sometimes seduced by wealth, pleasure, or other means towards becoming human. As such, they have different motivations in their new human form. Likewise, the cultural form also has the ability to transition to a new phase or shape, which is then governed by different rules, values and motivations. However, it is also important to note that both the cultural form and the Selkie character may be seduced to return to their original form; usually by the memory of/longing for what they were.

Examples of the transitory nature of cultural forms abound in popular cultural history. Many of the most convenient examples are traditionally written as the "discovery" of a hip new scene, or the re-discovery of an older one. In the recent history of popular culture, these discoveries would include the swing dance revival, the growth in popularity 
of rap music, the alternative country sound, the rise of skateboarding culture to the mainstream, and the discovery of the "grunge" music scene.

We might examine the grunge phenomenon in a little more detail; during the mid1980s, a small number of bands from Seattle began combining guitar rock with punk and metal to give birth to a new type of musical sound. This local scene remained un-exposed for almost a decade, as bands and independent record labels struggled for economic survival. However, seemingly overnight, exposition by national and international media created a frenzy of public attention directed at the new "grunge" scene. Bands such as Nirvana, Pearl Jam, and Soundgarden promoted platinum albums, performed world tours, and graced the cover of Rolling Stone. Though originally a musical phenomenon, the grunge label exploded beyond its musical characteristics, and grunge apparel (plaid flannel shirts, ripped jeans, and army boots) became the subject of $7^{\text {th }}$ Avenue New York fashion shows. Vanity Fair magazine even featured a Grunge fashion issue. ${ }^{\text {ii }}$ What had begun with an isolated few musicians was now a national phenomenon.

The commercial success of the Seattle sound, or the "discovery" of any new scene, fashion, or music initiates a whole host of questions about the process by which it becomes popular. How is it that a certain genre of music becomes popular? Does the rise in popularity change the music? Who originally participates in the scene/culture? Are they different from the people who participate in the scene later, once it has become popular? Why is it that certain groups and cultures become popular while others lie unnoticed?

An answer to these ambiguous questions points to two general types of explanation. First, one may seek to explain why cultural forms become popular in a general sense; that 
is to say, one may seek to explain why a particular practice acquires value and meaning. Second, however, one may set aside the question of why value and meaning are conferred and seek to instead explain the pathways along which a cultural artifact must travel in order to reach whatever population eventually grants it meaning and value. Obviously, the two types of explanation are not separate. Knowing the circuits through which an artifact travels helps explain why it is popular with a given group of people and knowing which group of people values an artifact helps us understand the nature of the pathways along which it most likely travels. The difference between the two types of explanation is one of emphasis. They are extricated from each other for analytical and illustrative purposes.

If one follows the first type of explanation - the reasons why an artifact becomes popular - one is inclined to look for correspondences between artifact itself and the values of the group which prizes or adopts the artifact. The artifact becomes expressive or reflective of the group's values, aspirations, and self-understanding, and is understood functionally, as something which fulfills a function for the group. Such an approach will, therefore, pay close attention to the 'audience' or group which adopts the artifact or practice, and to its motivations for so doing. This approach has, in recent years, been strongly identified with cultural studies, which seeks to establish correlations or homologies between forms of cultural expression and particular social groups. Cultural studies usually locates the function performed by the cultural form at the level of social class, gender or ethnicity (i.e., the artifact or practice is expressive of impulses rooted in, related to, or explicable by reference to class, gender and/or ethnicity). ${ }^{\text {iii }}$

However, if one sets aside the attempt to explain why a cultural form resonates with its audience, one may turn to the second type of explanation and examine the pathways 
along which a cultural form travels in order to show the types of social actors (peoples, locations, venues, institutions) that the form encounters and how each actor modulates, transforms, transmits, impedes, or refuses the form. If the first type of explanation may be associated with cultural studies, then the second type may be associated with a more traditional approach to communication studies to the extent that it is concerned with pathways and the classic sequence of "who said what to whom through which channel and with what effect.'

The point here is not to cause the study of culture to regress back to some purely linear model of communication drawn from the positivistic 'dark ages' of communication studies. Pathways analysis does not presume that 'messages' or cultural forms travel strictly along straight lines from a single sender to passive groups of receivers. It does not presume that 'messages' or cultural forms remain unaffected by their movement through the pathways. It does not presume that the meaning of the 'message' or cultural form is determined principally, exclusively or primarily by the sender only to be suffered or endured by the receiver. On the contrary, it insists that 'messages' or cultural forms travel along many pathways, often simultaneously; that they encounter people, institutions, other forms and practices, which may alter, encourage, deform, misdirect, ignore, or applaud them; and that the meaning of 'messages' or cultural forms is always undecidable and always the result of the numerous encounters and transformations which occur along the pathways.

This type of explanation, which we may for the sake of convenience call pathway analysis, does not begin with the view that cultural forms are functionally expressive of attitudes, behaviours, and impulses which can be identified under the labels of class, 
gender, and ethnicity. It does not deny that these labels may contribute explanatory elements but it does not privilege these labels or limit itself to them. Since it does not begin with an assumption of functional expressivity, pathway analysis also does not seek out correlations or homologies although, again, it does not deny that such may exist. Instead, pathway analysis seeks to complicate and enrich the explanation of the meaning of cultural forms by drawing attention to the density of the pathways through which all forms travel, and to the work of history as encountered in institutions, alternative practices, human memory, transmission networks, etc. The goal is not to mount an attack upon or rejection of cultural studies, but rather to establish a dialogue between the type of history a cultural studies approach creates and the type of history created by considering other factors. These other contributing factors may be neglected from a cultural studies perspective, but be more visible from another perspective, which may in turn, deepen our understanding of cultural forms.

In fact, pathway analysis may be a needlessly restrictive designation as it seems to draw attention to the circuit or channel or roadway of transmission when it also seeks to draw attention to institutions and their history, the people who inhabit them, their memories, traditions, and practices, their sedimented practices of communication, and so on. Thus, since 'pathway' is the term that will be used throughout this essay, it deserves a closer visitation. The nature of a pathway is that it seeks the path of least resistance; a path may seem to meander but always keeps in mind its goal, where it is going, even if it may seem wayward. Pathways may not appear straight - they follow their own logic. However, for the purposes of this thesis, the term "pathway" indicates a consideration of the entire field of relationships within which cultural artifacts live and die. 
By examining the processes of exchange between audiences, producers, and artists, we begin to understand culture along a more traditional model of communication. Artists function as creators who send out 'messages' (an art form) to an audience of receivers. Of course, the audience is not passive but active in its reception of the 'message.' Various audience members will understand the message from various different standpoints, and may use it in different ways. Additionally, the process of transmission is not characterized by perfect objectivity or clarity. On the contrary, it is affected by various influences which may be commercial, political or social elements; by the actions of opinion leaders (writers, critics, etc.) who all attempt to shape it for their own purposes; by the peculiarities or entrenched habits of the pathway along which culture is transmitted; and by other factors. As Lawrence Kramer says of culture, it must be "understood as communicative action, and therefore as embedded in a continuous texture of psychological, social, and cultural relations." ${ }^{\text {iv }}$ Cultural phenomena must be examined in terms of their own rules, logics, and development. What is required is a multi-dimensional approach to the understanding of culture, which seeks to comprehend the connections between economic, political, social, and cultural dimensions without reducing the phenomenon to any one of these levels. ${ }^{\mathrm{v}}$ Culture is not a static, predetermined object, but a process of negotiation among social actors. A study concerned with cultural forms must not stop at the form itself but must also take into account the creators of the culture (musicians, actors, directors, writers, painters), its audiences (recipients/participants), and its producers, institutions, writers/critics, as well as any other factors/actors which support and play a role in 
popularizing the cultural form. It is the interaction between these participants that shapes the cultural practice and draws it into certain cultural categories.

In this sense, this holistic conception of cultural forms exhibits some characteristics of (and indeed draws upon) Howard Becker's concept of the art world, in recognizing the importance of non-artists in shaping the art form. By 'art world,' Becker means all the actors who fashion the meaning, practice, and success of the art form: the artists, producers, club owners, critics, audiences, and others. ${ }^{\text {vi }}$ Hence, any theory that deals with the idea of cultural change must also answer how the cultural form is influenced by these different actors in order to begin to show how different audiences may interpret it differently.

The creation of culture, therefore, may be viewed as a process of communication. Consequently, the act of cultural transformation, as well as the evaluation and reevaluation of cultural meaning by different social groups are also necessarily communicative processes.

Sorting out answers to the questions surrounding cultural meaning has proven complex. Many cultural theorists have used theories of social class in order to distinguish between different audience groups and art forms. In so doing, not only have they sought homologies or correlations between the groups and their preferred social forms, they have also theorized separate levels of culture. Back in the 1950s, Edward Shils (1951) and Dwight MacDonald (1953) proposed a three-fold cultural division which distinguishes between folk, popular, and elite levels of culture. Understood this way, the refined pursuit of opera is created, informed, and participated in by social elites, while stock car racing exists to satisfy the base sensibilities of the working class. This approach has encouraged 
its proponents to understand culture as a static phenomenon rather than as one that changes (both meaning and participatory group). Yet culture does transform, reinvent, and metamorphize itself. Indeed, there are examples of culture that, at different points in time, fulfill the criteria of each different level of culture identified above. This thesis, therefore, aims to explain how the same cultural form can function within different cultural levels or regimes, and also aims to explore the conditions under which a cultural form may move from one cultural level or regime to another.

In the interests of further delimiting what could quickly become a truly lengthy document; alongside the homological argument of cultural levels or regimes, we also find arguments which claim some affiliation with postmodernism or varieties of cultural studies. In these approaches, authors such as David Brooks, Richard Peterson and Roger Kern have questioned the very notion of cultural levels, distinct genres and segregated audiences. Peterson and Kern propose the notion of the cultural omnivore and the idea of a shift in elite status. ${ }^{\text {vii }}$ According to them, new technologies and the erosion of social boundaries mean that all cultural forms may now be accessed by any member of society. Elites are involved in a wide range of cultural activities which had previously been considered 'low,' resulting in the fact that distinctions between highbrow and lowbrow are no longer valid. Likewise, Brooks argues that a social group he calls the "Bohemian Bourgeois" (a newly-monied class of citizen made up of entrepreneurs, managers, engineers, etc.) has entered the upper classes economically, but without aspiring to the cultural dogma of the previous age. Again, the result has been that many of the traditional 
"high class" cultural practices (and means of exclusion) are no longer valid. People are therefore free to choose from any cultural tradition they like. ${ }^{\text {vii }}$

If this perspective is to be believed, then cultural distinctions are irrelevant, because culture is a purely personal construction; every person selects and utilizes his own forms and readings of culture to construct an individual personal identity, sampling from a private mix of gender, age, geography, ethnicity, sexual orientation, values, and experience. Significantly, while this postmodern approach stands in direct opposition to the homological approach of Shils and McDonald, it nonetheless seeks out new homologies; only now these are located at the individual level of personal lifestyle, taste, impulse, and so on. While it would be foolish to deny that the modern age has been characterized by increasing individualization and personalization, it may also be unwise to abandon all previous reference to societal trends, regularities and structures. Indeed, if the argument is over where the homologies lie - at either the societal or individual level - it may be time to stop thinking of cultural forms first or foremost from a functional perspective and to begin thinking of them from the perspective of the dense networks and pathways through which they travel. Of course, such a shift in perspective does not herald the angry abandonment of the homological approach and the headlong embrace of a purely circulatory metaphor as though the former were entirely wrong and the latter entirely right. It signals, rather, a desire to enrich the conversation between them and to deepen the understanding of cultural forms by bringing more factors into the ambit of analysis rather than by abandoning what has already been achieved.

But to continue; counter to the postmodern line of thinking, mass consumption does not completely erode class differences but merely allows them to assume new forms of 
expression. ${ }^{\text {ix }}$ While it may be socially acceptable for the nouveau riche to participate in what would have formerly been considered "low" culture, "high" culture nonetheless continues to maintain barriers that exclude many portions of the population. Distinct audiences and cultures still exist. Despite a theoretical equality of availability, statistical trends show that symphony audiences are still comprised mostly of aging, educated patrons; that opera is not the focus of commercial radio stations; and that rap music is not performed in concert halls. If a theory of cultural omnivores is to be believed, then social class should be a greatly weakened factor in what culture an individual chooses. Yet social class remains a powerful indicator of cultural participation, and participatory statistics on high art demonstrate an increasing split in audience composition. ${ }^{\mathrm{x}}$ I therefore question the validity of a postmodern theory that eliminates markers of social and economic distinction, and remain convinced that divisions within culture still exist.

If it can be agreed that divisions can be made within culture, and that culture is neither completely monolithic, nor hopelessly individual, I can then proceed to what my thesis proposes to do. In the interests of being absolutely clear, let me lay out all my gathered pre-suppositions before I continue. I am granting that culture does change or transform itself over time. I am also taking as given that one can make distinctions between levels of culture in more than merely an arbitrary manner. And I am also not interested in how meaning is ascribed to culture, but rather in how culture changes itself via the use of specific transmissory circuits which allow it to reach different audiences. Given all these things, it is the plan of my thesis to focus on establishing a theory of cultural flows within an established tri-partite division of culture. The status of a cultural 
form in a specific level, as well as the circumstances under which it may move to another level, are shaped by the cultural creators, the participating and non-participating audiences, and various other social, economic, political, artistic, and/or institutional actors. Parts and various basic tenets of this theory are contained in several texts, yet a comprehensive theory that explains the transition into each of the three cultural categories remains unformulated.

This may be due in part to the problematic fact that the same forces and factors may not be responsible for the transition from folk to popular culture as for the transition from popular to elite culture. In some cases, it may be that reference to an existing cultural theory (such as the Gramscian notion of hegemony) assists in understanding the transition from folk culture into mass culture. However, no one existing theory sufficiently explains how culture transforms into other levels and directions (how mass culture becomes elite culture, how elite culture becomes mass culture, etc.), nor even all the factors involved in the process of transformation (what is the role of artists, institutions, etc.). Hence, for our purposes, a more sophisticated explanation will be necessary. The theory must not only describe the events that bring about the transition of the cultural form but must also separate the elements essential to this transition from those that are more incidental or specific to a particular cultural form.

Ultimately, if one wishes to examine the division of culture into liquid categorizations, one must find an example of culture that belongs (at one time or another) to each level. Jazz music represents a potentially unique case as it has occupied all three positions of folk, popular, and elite culture. It functioned as a folk music in the early 1900s, became a popular music during the Swing Era of the 1930s, and became elite art 
music during the $1950 \mathrm{~s}$ and $60 \mathrm{~s}$. Academic support for the ascendent function of jazz music abounds in the work of Taylor, Gabbard, Marquis, Levine, and many others. To further solidify the metamorphic nature of jazz, since the 1960s there have been several movements within jazz which have sought to shift the music back to the realm of the popular. Though currently unsuccessful, the movements of fusion and neoclassicism represent a conscious effort to position jazz differently within the socio-cultural framework. The question of whether popular culture can truly become folk culture again, and whether high culture can become popular, may be explored through the example of jazz music.

I will argue that a cultural form can move either way amongst levels of culture, but not without dramatically changing its audience, its practices, and its relationship to commercial and popular elements. This, ultimately, is the purpose of my thesis: I will utilize pathways analysis to explore the history of jazz music as a case study in order to extrapolate a theory of cultural flows; a theory that illuminates the conditions under which a cultural form may participate as a folk, popular, and/or elite culture.

The following paragraphs briefly outline the basic structure of my dissertation: Chapter One will serve as an exploration of the current historiographical tradition in jazz. As jazz studies scholars are beginning to realize, the history of jazz has not been a linear progression, and must detail a host of other social actors (besides the musicians themselves) that have an impact on the music and its social meaning. It will serve as the literary review and critique of the literature surrounding the case study. Chapter Two will reflect less on the literature about the case study, but will add a theoretical angle, detailing 
a review of the relevant established literature on cultural theory; in particular, the division of culture into various levels, as well as pointing out some problems with this path of study. A substantial part of the chapter will be a discussion of the proposed theory of cultural flows, and will outline the stages, motivations, and various actors involved in the stages of transition.

Chapters Three, Four, and Five will all be focused on a detailed discussion of various time periods throughout the history of jazz music. Each time period corresponds to one of the aforementioned cultural levels, and fulfills certain criteria of artist, audience, critic, institution, commercial and critical interests. Specifically, Chapter Three will consider the beginnings of jazz music, from a geographically isolated folk music to its rise in the 1930 s as an internationally reknown popular music. Chapter Four will plot the events leading to the commercial downfall of the Swing Era (circa 1940-1945), and jazz music's subsequent "rebirth" through the elitist motivations and practices of bebop (post1945). It will continue to follow jazz as the music becomes an elite art music through a variety of social and academic devices. Chapter Five will then focus on the continued progression of jazz music since 1969, and the way in which the art music establishment fights back against jazz's potential return to popular status. Each of these chapters will be devoted to a different movement in jazz music that seeks to return the music to an alternate position within the cultural structure. Fusion, the attempt to blend jazz with elements of rock music will be the focus of interest (1970s and 1980s) here, but the chapter will also consider the neo-classical agenda (1980s - present), as embodied by the articulate and impassioned philosophies of Wynton Marsalis. 
Chapter Six will then serve as a justification of the thesis; it will formally construct the theory of cultural flows based on the facts unveiled in the previous chapters. From here, it will consider some of the weakness and unexplored theoretical permutations left out by the case study, as well as what future research stemming from this theory might be attempted. It is important to note that, if done successfully, this thesis should be able to show how jazz came to enjoy its current level of functionality. It will be possible to illumine why jazz music in its present form cannot be popular, and can never regain its popular status unless it changes its conceptual makeup and returns to a simpler form and structure, along with all the societal and commercial mechanisms that would be needed to support it as such. And therefore, theoretically, it could be used to suggest what steps might be taken to return it to another level. However, it is not the purpose of my thesis to pitchfork jazz music back into the realm of the popular. Unlike the Goodman of Wastness, I do not wish to keep or make my case study become something she is not. To formulate a theory of cultural flows is the purpose of this thesis, and it is hoped that this theory may prove useful in studying the social meaning of other cultural forms, as well as perhaps suggesting a reconsideration of the ways in which we think of culture. It is to a discussion of jazz history and academic theory that this thesis now turns. 


\section{Chapter One: Abbreviations and Appropriations}

"We are all the great abbreviators; none of us having the wit to know the whole truth, the time to tell it, nor an audience so gullible as to accept it."

- Aldous Huxley

Though the art form of jazz is a young one, it has been the subject of much recent historical scholarship. From critical beginnings in popular jazz journals and magazines, the desire to have a history of jazz has culminated in many substantial jazz texts over the past 50 years. However, many of these texts have themselves been re-examined in academic jeremiads in recent years for their reductionist approach. Their reductionism, it is argued, has caused them to ignore a multitude of social factors which contributed to the development of the art form. In an effort to present jazz as a cohesive narrative, jazz scholarship has reduced the history of jazz primarily to the history of great performers. If an alternate reading of jazz is undertaken, it usually only focuses on one factor (such as race), rather than on a host of them. This is not to say that these alternative texts are completely unusable in the pursuit of current scholarship, rather that they may only represent a partial picture of the rich cultural practice of jazz. The practice of jazz music, as well as its social meaning, has been formed as the result of social negotiation among a variety of factors. It is insufficient to claim that jazz music is the result of the performances of great jazz artists, although they certainly played a role in determining the musical form. Likewise, since the task I will undertake is to understand the social factors and conditions under which jazz music was able to transform itself into folk, popular and elite cultures, it is a different kind of jazz history that I will likely compose. My objective with this chapter is to point out the tendencies and trends in the established body of jazz 
history and to criticize them for their oversights. By widening the scope of jazz history to consider other factors (such as the role of music critics, audiences, the record industry, institutions, and geography) in shaping the definitions and established history of jazz, one is able to understand more meaningfully how the art form of jazz has been disseminated over time.

The irony apparent in my chosen epigraph should also be noted. While I originally selected the quotation in order to suggest that the established jazz history is unnecessarily constrained in scope, were I to attempt a comprehensive jazz history in a thesis of this size, it would be even more lacking in detail than previous texts. Thus, I shall be as guilty as my academic predecessors in creating my own history - just as guilty of leaving out specific facts and factors. However, the difference lies in my adoption of a careful theoretical angle. Standard jazz histories present themselves as objective and consummate, yet in their exclusion of other factors they suggest that these factors are irrelevant. My study of jazz history recognizes that I exclude certain factors, but do so for the specific reason of legitimating the very factors excluded by standard jazz histories. The quotation remains, then, for the purpose of drawing attention to the fact that one will always be forced to ignore certain directions and figures. Indeed, one's theoretical window constrains one to include certain types of facts while disregarding others. Again, it is my aim to develop a history of jazz that will understand the social factors and forces which played a role in altering the cultural form. Thus, in specifically focusing on the transition from folk to popular to elite music, I will be neglecting those artists and events that would not have diverted jazz onto a different trajectory. The counterpoint of this argument is to say that I will construct a version of jazz history that distinguishes itself from the 
established tradition. The established jazz tradition focuses on the musicians; I will focus on all of the social actors that influence the music. The tradition claims that great musicians create new forms of music; I will counter that what is perceived as new music is due, in part, to the establishment of new pathways of social meaning. And where the tradition claims the history of jazz to be a single, linear evolution, I will argue that it is a complicated process of negotiation across various social groups.

\section{Definitions}

Like the history of jazz, the word "jazz" itself represents a disputed tradition. I would suggest three points to take into account in considering a definition of the cultural form. First, jazz is a label that has been applied to a wide range of sounds, performers, and groups. It can be a struggle to understand how the free-form music of John Zorn (recording circa 1995) can be categorically grouped (technically, theoretically, or acoustically) with that of Dixieland trumpeter Louis Armstrong (recording circa 1930), and this fact makes a definition of the overarching category troublesome. Making it even more difficult to draw an objective definition is the fact that the cultural object of jazz (like all current modern art forms) has a history of conscious attempts to break with its own tradition. The end result of these observations is an art form notorious for evolving beyond static definitions.

Second, as Scott DeVeaux points out, the process of constructing a definition of jazz is a language game. By pinning a definition on the art form, the person or institution doing the naming is involved in a game of exclusion; of drawing boundaries of inclusion for certain kinds of the music, while ostracizing or excluding others. One of the best 
examples of this is a quotation from the early jazz trombonist Kid Ory, who, in response to the question 'What is jazz?,' replied "Man, if you have to ask what jazz is you'll never know. ${ }^{\text {xi }}$ This haughty statement recognizes the definition of jazz within a politics of exclusion: "Definition is a powerful weapon...definitions define through exclusion.",xii The definition of jazz requires the insertion of boundaries; the question of what is not jazz is almost as important as what is jazz. It should also be noted that this selective characteristic is a function of higher art and its recognition within academic institutions (a point which will be returned to in Chapter 4). In fact, all definitions, especially in high art, serve to constitute in-groups of insiders who 'know' and out-groups of outsiders who 'don't know.' The pleasure of the definition is bound up with testing who is and who is not an insider.

Third, the definition of jazz has not been static. Much like the cultural form, it is a negotiated process that has changed throughout its history. For example, during the 1940s, a heated debate raged between proponents of "hot jazz" and enthusiasts of "swing" over whether swing music should be considered jazz. One school believed the term "swing" denoted the commercialization and prostitution of "real" jazz, and that its written arrangements performed by big bands contrasted greatly with the improvised type of jazz played by small bands. ${ }^{\text {xii }}$ As framed by historical narratives, this debate concerned forms and styles, rhythms and emphases; however, today, the vast majority in the jazz community have agreed that swing was indeed "real" jazz. might be due to a revision of the formal definition of jazz rather than a cold assessment of where and how jazz circulates. 
It is by understanding that the definition of jazz is a disputed process that we may arrive at a useful, yet unconventional definition. Ostransky offers the following definition: "Jazz is the comprehensive name for a variety of specific musical styles generally characterized by attempts at creative improvisation on a given theme (melodic or harmonic), over a foundation of complex, steadily flowing rhythm (melodic or percussive) and European harmonies., ${ }^{, x v}$ Jazz may include (but has not necessarily been limited to) the following characteristics: a different rhythmic structure from European art music (the symphonic or opera traditions); distinct rhythmic emphases and complex polyrhythms; the use of "blue" notes (flat 5ths, flat 7ths, etc.) not characteristically utilized in Western art music; a vital sense of rhythmic drive (or swing); the use of improvisation by performers; certain instrumentations (especially saxophone); a distinct type of tone performed by the instruments; and many other aspects of the music. ${ }^{\mathrm{xvi}}$ All of these characteristics can be disputed. Is rhythmic syncopation the defining element of jazz? Likely not, since classical composers such as Stravinsky used syncopation in the 1800 s. Is the use of improvisation the defining element of jazz? Again, classical composers such as Bach were very adept at improvising within their own forms. Is it the use of certain instrumentation? Wind bands may use saxophones; pianos, trumpets, guitars, and drums can be found in a variety of types of music, as well as jazz. A definition of jazz that relies on physical characteristics will always be defeated - jazz is simply too diverse.

So where then can we define the music, if not in the music itself? The blending of European and African musical traditions is perhaps one of the only useful commonly-cited characteristics. ${ }^{\text {xii }}$ This is not because the tonal and rhythmic structures of jazz may stem from Africa, while the instrumentation and notation come from Europe, but because this 
characteristic points to an extra-musical factor. It is the struggle over the possession of the definition of jazz, the possession of its history, that is important in defining jazz. DeVeaux states that jazz has been an oppositional discourse, traditionally presented as the music of an oppressed minority culture, shaped by its involvement with commercial processes. In order to escape from this commercial standardization, jazz has sought to develop an intellectual tradition that emphasizes both its universality and its autonomy from commercial forces. Therefore, the tradition of jazz is developed by including certain types of music (presented at certain venues, by certain types of performers, supported by criticisms from certain authors, etc.) to the exclusion of others. The struggle to possess that definition is where certain factors are included and others are excluded. However, despite which factors one uses to limit a definition, in creating a jazz tradition, the music is reified and given a narrative, thus legitimating it as an quantifiable field and object of study. As DeVeaux puts it: "the essence of jazz lies not in any one style, or any one cultural or historical context, but in that which links all these things together into a seamless continuum."

Jazz can therefore exist as a distinct form because it is a culmination of its past; its history is the grouping of functional elements that support each other. If this sense of depth were missing, if a jazz narrative were not constructed, jazz would be indistinguishable from other forms of popular music that combine virtuosity and craftsmanship with dance rhythms. Jazz is a narrative, a struggle to tell the thread of a common story. It is in its construction as a unique tradition that its essence lies. The fact that a definition must go beyond the usual musicological terms of reference is an appropriate parallel for the following research; by defining jazz as a tradition, or a disputed 
common essence, the stage is set for an analysis of the form that will include extra-musical phenomena.

Therefore, it is unhelpful to limit jazz to a narrow set of physical, tonal, rhythmic, or even racial characteristics (although these debates will always exist). Rather, the very fact that jazz scholars and enthusiasts have been able to construct a jazz tradition allows jazz to attain membership as a distinct and deserving modern art form. The struggle over the possession of the definition of jazz is more important than the physical or musical characteristics involved in that definition.

\section{The Narrative Tradition of Jazz}

With the definition of jazz so difficult to develop, it might logically follow that the establishment of a standard history of jazz would be likewise contested. However, even a cursory examination reveals that most jazz histories construct a clear, direct lineage dating from the beginning of the century. ${ }^{\text {xix }}$ Standard jazz history texts, such as those by Mervyn Cooke (1998), Frank Tirro (1993), Graham Vulliamy (1982), and Donald Megill \& Richard Demory (1993) all lead the reader to believe that jazz proceeded in a relatively straightforward progression from Ragtime and Gospel roots to Hot Jazz in the 1920s to the Swing Era of the 1940s to the High Art status it currently enjoys. Details may vary from text to text, however, there is a generally agreed upon path to them all, including a pantheon of great innovators and a canon of recorded works. The creation of a Smithsonian Collection of "Definitive” Jazz (1997), or Ted Gioia's 12-page list of recommended listening (1997) are merely two examples in a long history of canonization. ${ }^{\mathrm{xx}}$ No conventional history of jazz would be complete without references to 
Miles Davis, John Coltrane, Ornette Coleman, Louis Armstrong, etc., but transitory figures who do not fit into one determined style or time period (such as Bela Fleck, Jaco Pastorius, Herbie Hancock, and Bobby McFerrin) are often neglected, or given only brief mention in an extended footnote. For example, it is because Bobby McFerrin has such an unorthodox style (fitting into neither pop music nor bebop nor fusion styles of jazz) that he is condemned to a one-page summary tacked onto the back of a chapter in Megill and Demory's jazz history text. ${ }^{x x i}$ Furthermore, the failure to fit into this history indicates the prior existence of a well-outlined definition into which jazz artists must fit. Other examples can be found in almost all jazz history works.

These types of histories may be correct in an overall sense, but often fail to examine the many different directions explored in each time period. Jazz scholarship has been exclusive in its view of jazz and, although a myriad of different artistic and theoretical directions have been explored by jazz musicians, most scholars have been content to examine only a small range. This approach has focused on continuity in order to lend strength to the argument that jazz has a linear (and more coherent) history. By ignoring elements of discontinuity, this presentation of history undermines the potential of the art form to have been taken in an altogether different direction. Blues, for example, is considered a different genre of music than jazz, despite having shared historical origins and a similar formal structure. In contrast, another stylistic movement, Bebop, was ultimately included within the definition of jazz. Indeed, in the present day, it seems ludicrous to suggest that jazz should not include bebop as this is the form of jazz most commonly cited as having established jazz as an elite 'high' art. ${ }^{\text {xxii }}$ However, at the time of its formation (in the 1940s), the rise of this new style coincided with another movement in jazz, the 
revival of New Orleans "hot" jazz. These revivalists (or 'moldy figs' as they became known) sought to return the dominant path of jazz to an earlier time, feeling that the music played 10 and 20 years earlier was more authentic than the commercially-exploited swing music of the time. To counter this tradition, the supporters of bebop (progressives) attempted to win the loyalty of a younger generation of musicians and a supporting cohort of enthusiasts. What is interesting is that much of the established jazz criticism of the time was primarily in the camp of the traditionalists, who resisted the "modern" phenomenon of bebop. ${ }^{\text {xxiii }}$ Indeed, they sought to brand bebop as a different music altogether, separate from jazz. After all, given the extent to which bebop was dramatically altering jazz music perhaps it ought to have been considered a new genre (hence the title - bebop). Nonetheless, bebop has come to be included as part of jazz, changing the trajectory of the music, but not fragmenting off into a separate genre. Yet the reasons why bebop was included as part of jazz are very infrequently explored in texts; conventional histories have chosen to focus on the commonalities, to align bebop within the subset of one overarching category. Again, conventional histories have insisted on seeing continuities and therefore point to the similarities between bebop and other types of jazz. Many further examples of this fractious past abound: from the gentrification of jazz sounds into classical performance with the work of Paul Whiteman in the 1920s to the proliferation of jazz styles in the 1950 s to the current directions of fusion and neo-classicism. Presenting these elements as wrong turns and dead ends in the story of jazz is not necessarily incorrect - again, our sympathies for time constraints and abbreviation are invoked - rather, the important question concerns the uses to which the selective history of jazz is put. By emphasizing the idea of continuity over the aspects of discontinuity, jazz has invented a linear progression. The invention of 
this linear progression is something that subsequently determines the path of later scholarship.

Therefore, much historical jazz scholarship presents jazz as an easy, coherent whole, an attractive simplification enabling a quick and easy grasp of a complex subject. ${ }^{\text {xiv }}$ Jazz scholarship in the 1960s did not have the luxury of an established academic tradition and consequently sought to invent that tradition. For example, Sterns (1958) argues that the sudden emergence of bebop was "a quick, but logical complication of melody, harmony, and rhythm. European and non-European components merged according to what was increasingly a European pattern. The result was a broader, deeper blend." ${ }^{\times x v}$ This work to begin a jazz tradition was undertaken in order to ensure its survival, after its commercial sustainability declined in the 1950 s and 60 s. In the successful acquisition of cultural prestige (generated by the demonstration of a high art tradition), jazz music could continue to be practiced and heard. ${ }^{\mathrm{xxvi}} 40$ years later, this tradition has been successfully implemented, and the coherent narrative written into contemporary jazz history by academics has vaulted jazz music into the realm of art. Bebop is recognized as the crucial achievement in turning away from the utilitarian values of swing and becoming an autonomous art music. ${ }^{x x v i i}$ In the academic struggle to legitimate the subject area as worthy of high art status, contemporary writers have overwritten many of the other factors which identified with and disseminated jazz music.

For example, there is a clear disconnect between the placid narrative of jazz and the (musically) revolutionary practices and beliefs held by bebop musicians during the 1940s. Bebop music did not serenely attempt to fit in with the established practices of jazz, but aggressively and consciously positioned itself as counter to most of the mainstream jazz 
practices of the time. With its celebration of technical virtuosity and "un-hummable" melodies, its difficulty for dancers, its adoption of an anti-commercial attitude, and its deliberate selections of alternative performance hours, venues, and costume, bebop set itself up against the very nature of "jazz" at that time. Yet when one reads a conventional jazz history, bebop is presented as a "natural" step in the evolutionary progression of jazz music, the vital link between the popular music and the high art. Bebop, as just one musical example, has been claimed by narratives outside of its own social history for their

own, historically inaccurate purposes. ${ }^{\text {xxiii }}$ However, despite the overly simplistic nature of these texts, the "official" version of jazz history continues to be taught at colleges and universities. Victims to the idea of continuity remain unexplained, and a reading of the established jazz history may evoke a feeling that everything doesn't quite fit.

\section{Recent Directions}

An excellent place to understand how the conventional narrative of jazz fails is in its description of jazz from the 1950 s to present. The proud, inevitable march of jazz from its early origins as a folk music to a popular music is confidently presented as progressive and linear. Yet for the more in-depth histories (usually broken into a decade-by-decade examination), the clear narrative thread that was so apparent as jazz 'advanced' during the 1920s and 30s begins to unravel as it approaches the 1950s. Tirro, for example, explains how "at the century's halfway mark, the historical strand that linked contemporary jazz to its roots suddenly began to fray. The cohesive thread had been pulled apart in the 1940s by the bebop musicians." ${ }^{\text {xxix }}$ Jazz is therefore presented as fragmenting into a confusing number of irreconcilable factions: cool jazz, hard bop, modal jazz, Third Stream. ${ }^{\mathrm{xxx}}$ From 
these multiple directions in the 1950s, the counter-poised styles of fusion and free jazz somehow emerge during the 1960 s and 70 s. ${ }^{\mathrm{xxxi}}$ Fusion and free jazz are often positioned as the two philosophical extremes of jazz; where fusion is an attempt to become integrated into rock music, free jazz is the modern philosophical extension of jazz music's attempt to push the art form as far as it can possibly go. Within the established history of jazz then, jazz is presented as a linear progression from its roots as a folk music, to the commercial sounds of the big band era, and then to its flowering as a high art. Because the very definition of high art is to push the boundaries, the multitude of styles seen in jazz since the 1950 s is read as being reflective of the cultural form having reached an intellectuallyprogressive stage in its development.

As the histories of jazz approach the turn of the $21^{\text {st }}$ century, the multitude of styles presented within the art form presents a conundrum as far as determining the future state and status of jazz. The 1980s see the rise of a neoclassical view of jazz, which suggests (while not overtly stating it) that fusion and free jazz are both failed experiments, and that some hypothetical progression of bebop since the 1950 s represents the true spirit of jazz. xxxii Neoclassicism feels that it is the duty of the jazz musician to "reintroduce cultural standards into American culture to counteract the relativizing effects of the mass media," a classic demonstration of high culture values. ${ }^{\text {xxiii }}$ Therefore, current writings in jazz history continue to employ the dichotomy of fusion against free jazz (as two unsatisfactory extremes), while asserting a new debate between these positions and neoclassical traditionalists. If this position on the current status of jazz sounds confusing and unsatisfactory, I would wholeheartedly agree. In fact, as is demonstrated in ongoing debates about the status of jazz today (Is it art? Is it commercial?), the current multiplicity 
of jazz styles prompts a rethinking of the linear historical progression of jazz. As DeVeaux points out, no one has thought to ask whether the earlier cohesive narratives of jazz in the 1900-1930s might also bear conflicting interpretations under similar review. ${ }^{\text {xxiv }}$ Perhaps it is merely that the luxury of time and distance has enabled us to construct a theoretical conglomeration out of jazz' tumultuous past.

An alternate approach used by many jazz texts is to give a very limited treatment of recent jazz history. Once bebop has inevitably asserted itself on jazz music, these other histories skim over the more recent trends. Mervyn Cooke takes nine chapters to bring jazz to the 1960 s, but spends only one chapter on the last 40 years (with a title of "JazzRock Fusion and its Aftermath"). ${ }^{\mathrm{xxxv}}$ In so doing, these approaches actually lend credibility to the neoclassical stance because their exclusion of recent styles forces the reader to assume that jazz has continued since the 1960 s in roughly the same direction (i.e., with nothing worthy of historical note). Neither the abbreviated nor the linear approach to jazz history is satisfactory, but they are indicative of the fact that most jazz history books are written by academics who seek to legitimize their subject matter within academia by ensuring the lineage of a jazz music tradition. (Indeed, Foucault points out how coherent narrative and unbroken lineage are powerful models of analysis available to the field of history. In these models, the world begins to resemble that which we have learned, and historical or cultural discontinuities are passed over in favour of continuity. ${ }^{\mathrm{xxvi}}$ ) Therefore, a different theoretical paradigm will have to be adopted in order to emphasize an alternate reading of jazz history.

Due to its recent origins in popular and folk culture, there is still a common perception amongst jazz professionals that jazz does not have the respect it deserves as a 
high art. During the last 50-odd years, enthusiasts and scholars have sought to elevate jazz music to a place of respect, appreciation, and serious academic study by inventing codes of connoisseurship. Yet today, jazz still occupies a precarious position within academia - it is too close to its popular past, and its complete transformation into an art form has not been sufficiently established. ${ }^{\text {xxxii }}$ As recently as 1982, you could be dismissed from the music program at the University of Alberta if you were heard to be practicing jazz, for example. But by creating a distinct musical tradition, academics and jazz enthusiasts have attempted to demonstrate that jazz music has progressed to the point of high art; worthy of serious intellectual scrutiny, and thereby deserving of a place within high art institutions. The legitimacy of jazz's current position within the canon of high art could be challenged, however, if its progression is not clearly outlined and understood. The multiple, interconnected, and oppositional directions represented by modern jazz make it difficult to understand; both as a singular discipline, and as a demonstration of high art. Rather than present this fractious status, jazz is presented as one united narrative by various historical texts. This subject of the institutional acceptance of jazz and influence upon the subject will also be explored in more depth in Chapter 4.

\section{The Great Men of Jazz}

The creation of an established jazz narrative has also led to a primary historical concentration on jazz performers. Many of the established jazz history texts work their way through the story of jazz based solely on performers. Megill and Demory's Introduction to Jazz History (1993) divides its sections by great jazz musicians (who are seen to embody one particular style), having chapters such as "City Blues: Bessie Smith," 
"Swing: Benny Goodman and Fletcher Henderson," and "Free Jazz: Ornette Coleman." Martin William's The Jazz Tradition (1993), despite being a book made up entirely of essays (each of which discusses key recordings of a particular artist), nonetheless purports to serve as a history of jazz: "It will not take careful readers long to learn that The Jazz Tradition is both a collection of critical essays and a history of jazz."xxxviii What this does, in effect, is invite the reader to conclude that the history of jazz is the history of great men (and I do mean men, as coverage of women in jazz fulfilling any role other than singer are few and far between) who have been able to change the path of jazz by themselves. And while the creativity of artists such as Charlie Parker or Dizzy Gillespie, and their ability to pioneer a new sound, should not be diminished, the fact remains that this approach poses many problems.

One of the problems involved in writing jazz history as primarily the vehicle of great musicians is that this neglects the presence of other social, cultural, and economic factors that play a part in shaping the music. The Great Man theory of jazz history would seek to say that new directions in jazz are the result of one (or a handful of) musical visionaries, who single-handedly imagined a different sound and transformed the genre with their playing. Heroic individuals overcome insurmountable personal obstacles to introduce a new genius to the world. ${ }^{\text {xxix }}$ Vulliamy recounts an interview with Kenny Clarke about his first experience with Charlie Parker: "He was playing stuff we'd never heard before. He was into figures I thought I'd invented for drums. He was twice as fast as Lester Young and into harmony that Lester never touched." Vulliamy sums up the experience in saying: "...Clarke had stumbled upon the man who was later to revolutionize jazz - Charlie Parker.,"xl These types of statements (coupled, as many of 
them are, with few background facts) give the impression that these great artists burst fully formed onto the music scene and single-handedly changed it.

However, even the most gifted and revolutionary artist could not change the genre by himself. For their new musical vision to survive, bebop artists had to have the support of extra-musical factors. If bebop jazz (or any music for that matter) was to spread and influence the widely dispersed jazz scene as a whole, it required a solid audience base, as well as an entire industry of critical and commercial support. Evidence of the strength of these extra-musical factors can be found in the limitations they place upon artists, when their interests are different from those of the artists they support. For example, even an internationally celebrated composer such as Duke Ellington is generally best remembered for the shorter, theoretically simpler pieces that comprise most of his popular repertoire (such as "Cottontail" and "In a Mellotone"), although he also wrote very complex evolutionary pieces (such as "Ko-Ko" and "Harlem Airshaft"). Radio audiences and commercial interests dictated what Ellington's swing band should play, thus influencing them in a direction other than what Ellington would have wished. Collier notes this in saying (about Ellington): "The final effect was that the musicians could not develop the sort of big jazz band they wanted to. Public taste, through the entertainment media, was calling the shots." ${ }^{\text {,xli }}$ Though an essential factor in the direction of jazz, a musician is just one of these factors, and many established histories of jazz do little to consider the other factors at play. Therefore, if artistic production is a dialogue between creators and audiences, why are these audiences excluded from jazz histories?

A second problem with the establishment of jazz history based upon a biographical thrust is that the subject material can often be rather unreliable. Whether merely the 
fallibility of human memory, or a deliberate desire on the part of the subject to claim a specific role or title, interviews with musicians sometimes bring to light factual discrepancies. Jelly Roll Morton, for example, claimed in many of interviews that he invented jazz while playing in 1902. He certainly was an important figure in early jazz, both as a composer and a performer, however, his birth date in 1890 made him only 12 years old when he claims to have invented jazz, and this fact casts some doubt on the credibility of his claim. There are many well-known examples of this throughout jazz history, particularly in the early period, where it has proven difficult to unearth factual evidence in support of, or counter to, an artist's claims. Nick LaRocca, for example, claimed to have composed a piece called Livery Stable Blues in 1912. This was countered by others who claimed that the tune originated with black artists in New Orleans. The piece received national recognition (actually becoming the first piece of music known as 'jazz' to become widely popular) when two of LaRocca's former band mates copied out the tune and published it in 1917. Yet, when LaRocca took them to court for the copyright, the judge held that neither party owned the tune. ${ }^{\text {xlii }}$ The same sort of problems exist in drawing information from recorded albums, as many famous jazz artists were not diligent in reporting exactly all the personnel they may have used for the various sessions it took to produce the album. Artists may be exclusive in their recollections or the type of information they release about themselves, however, even the process of reflection creates a different story. Ralph Ellison wrote about interviewing artists, and his attempts to understand the bebop revolution: "Afterward, the very effort to put the fragments together transformed them; so that in place of true memory they now summon to mind pieces of legend. They retell the stories as they have been told and written, glamorized, inflated, 
made neat and smooth, with all incomprehensible details vanished along with most of the wonder."xliii Even a series of first-hand interviews with historical jazz musicians may not produce a true factual account of the past realities.

A third problem with the focus on individuals comes with those artists whose careers have spanned multiple styles and time periods in jazz. Artists like Charlie Parker or Clifford Brown are ideal from a narrative perspective, as they quickly rose to prominence in a specific stylistic period. Therefore, they can easily be characterized within a categorized narrative as "bebop" players - belonging to one time period and one style of playing. Other performers with longer careers are more difficult to categorize. Miles Davis, for example, was a prominent jazz musician with the bebop movement in the early 1940s, participated in the "cool" jazz movement in the 1950s (while continuing with his bebop playing), was a leading figure in "modal" jazz of the late 1950s and 1960s, and branched into fusion in the 1970s and 1980s until his death in 1993. How can a narrative that separates all of these movements (as the above list has done) hope to explore fully the complex process of evolution as the artist comes to a new point in his playing? The more detailed histories usually break the performer into chunks, the lesser ones merely mention the musician in one conceptual category. The interplay between presenting a cohesive narrative and focusing on individual performers is presented as the two outlying points on the continuum of established jazz histories. On one hand lies the temptation to let the performers tell their own stories in their own words, a more "realistic" history; on the other hand lies the desire to present the history of jazz within a simple, cohesive, evolutionary narrative, which is easy to understand. Therefore, what is seen as a "good" jazz history is one that can compromise between the two extremes, with no thought as to the problems 
inherent with presenting jazz as a uni-directional history. While more difficult to include within a book that aims to cut jazz into separate decades, demonstrating how great players were able to bridge the gap between different stylistic periods strengthens the idea of an overall progression.

\section{Solutions}

All of this is not to say that jazz textbooks which present a linear narrative are historically inaccurate in the sense of getting names and dates wrong. Rather, as has been mentioned previously, it is that a specific theoretical angle or academic predisposition leads them to include certain events and to dismiss others. It is more correct to state that by not acknowledging their biases up front, these jazz histories present one dominant view. By understanding the theoretical angle from which these texts are written, one can understand why they present their specific view of history. DeVeaux's unpacking of the jazz historiography does exactly this, in examining how the "official" version of jazz history is "both symptom and cause of the gradual acceptance of jazz within the academy... as an art music."xliv However, what is left unsaid by DeVeaux is that by adopting a different theoretical angle, or a different term of reference, one can pull out different facts and construct a different type of narrative.

DeVeaux's further writings, as well as work by Thomas Hennessey and Paul Lopes (1994, 2002), offer a means out of the problematic conceptualizations presented by an official jazz history. Working separately, they nonetheless similarly understand jazz music to be the product of multiple social and economic factors, and begin to explore these other influences. They likewise all recognize that it is difficult to understand the history of jazz 
only through the lens of music and musicians. The present work will draw from these approaches in adopting a different theoretical lens to study the phenomenon of jazz.

Hennessey studies the period of jazz between 1890 and 1935, when jazz moves from a series of isolated folk musics into a national phenomenon. ${ }^{\text {xlv }}$ Within each chapter, he breaks jazz down into different regions across the United States, and demonstrates how these regions first had distinct territorial bands, and then evolved into a New York-based scene. In this, Hennessey also examines extra-musical factors such as geography, race, and the rise of the entertainment/popular music industry. Citing the shift in the United States from a rural, home-made cottage society to an urban, mass-produced, massconsumer society, Hennessey views jazz as the product of this transition. Jazz was commercially successful because it was able to embody the new, urban zeitgeist of the industrializing American society. He does not understand this early period of jazz as a deliberately revolutionary music, but rather as a means for musicians of African-American descent to earn a living. He describes the music as being both an art form and a business product, recognizing the fact that jazz in its popular phase could not be separated from its commercial interests. Hennessey goes beyond the standard examination of music and musicians to include examples of urban population and neighborhood growth, and the business practices of jazz bands (length and nature of gigs, places of performance, extent of touring, etc.). In considering these factors and this approach, Hennessey constructs a jazz history that roots the music and musicians within specific geographic areas, as part of a social and economic practice history. This approach does enhance the standard jazz history; however, his survey of the impacts of new technologies such as the phonograph and radio remains very cursory (only a couple of pages devoted to each). Hennessey 
prefers to explain the rise of jazz as a popular music as the result of increasing urbanization, the migration of black classes from the southern United States, and the emergence of a new black middle class.

DeVeaux concerns himself with a different time period, the rise of bebop, from the early 1930 s to roughly $1945 .^{\text {xlvi }}$ While not focusing exclusively on him, DeVeaux uses the transitory figure of Coleman Hawkins to provide one pathway through the complex landscape of jazz. Hawkins is usually identified as a swing jazz player; however, his improvisatory techniques begin to challenge the styles of the Swing Era. By using Hawkins, DeVeaux is able to argue that extra-musical factors were required to vault a new approach to jazz to prominence. DeVeaux's historical approach reaches back into the swing era to find the origins of bebop, and concerns itself with musical, commercial, and racial factors in the transformation of jazz music into a high art. ${ }^{\text {xlvii }}$ He prefers to use the term "genre" to draw attention to the other contributing factors (as opposed to the term "style," which he feels, limits the approach to questions of musical form). He is more concerned with origins, rather than with evidence to support jazz as a high art, and therefore constructs a piece of history that encompasses much of the Swing Era, while breaking off just as bebop begins to gain commercial success. He argues that during the Second World War, the economic structures of the Swing Era remained in place; however, new market opportunities (in anti-swing afficionados and demand for small-combo jazz recordings) allowed musicians to expand what they were doing in private jam sessions to a larger public. This reciprocal relationship between the musicians and their audiences allows for the creation of a new type of jazz music. Thus, DeVeaux demonstrates how musicians operate within a system of power, and while they may make the difficult attempt 
to break out of the established mould, their attempt can never hope to be completely successful. This approach is extremely useful in shattering some of the high art rhetorical illusions as to the demonizing influence of commercialism. Jazz, as DeVeaux clearly details, has always been part of the very economic system that is supposedly so corrupting. Rather, jazz represents an attempt to renegotiate the power within that economic system. $^{\text {xlviii }}$

Lopes finds that DeVeaux has not dug deeply enough in his selection of bebop's history. Lopes has higher ambitions, hoping to explore the impact of the full "art world" on jazz. ${ }^{x l i x}$ Lopes examines the social discussions of jazz as it appears in the press (from specialized jazz magazines such as Down Beat and Metronome to the general newspaper press to academic books). He concerns himself with the quest for cultural legitimacy that both black and white musicians shared; how jazz came to signify various contours of status, distinction and identity in American music. Other questions of the impact of cultural politics on the evolution of $\mathrm{jazz}$, and the transformation of American society (paralleling jazz) are explored. This leads Lopes to examine the way jazz traverses cultural boundaries, and its subsequent creation of art worlds of mixed composition (in terms of class, race, and education). His conclusion is that the introduction of a socially heterogeneous jazz art world to the elite stage of a socially homogenous cultural hierarchy shatters the basic conventions and assumptions active in high and popular art. This is an enticing conclusion; however, it undermines the fact that the basic conventions and assumptions in high and popular art still remain. While high art may now include in its membership musics and audiences of an African-American origin, this is not because they have shattered the conventions of high art, rather they have only created a place for 
themselves at the high art table. Lopes' work remains, though, as a testament to the permeability of these cultural boundaries. The high art genre still exists and still engages in games of exclusivity, but by transporting itself along different pathways, appealing to a different audience, and adapting its own practices, a cultural form may become part of that high art genre. The fact that the once-revolutionary and subaltern music of jazz now enjoys high art status is testament to its ability to mimic high art convention, but not disrupt them. ${ }^{1}$

It stands to reason that it will be of interest to outline specifically what factors I intend to include in my pathways analysis of jazz. Drawing on the work of DeVeaux, Hennessey, and Lopes, one may outline seven basic contributing influences: the audience, the musicians, media interests (or forms, technologies, and types of diffusion), institutions, commercial interests, critics, and the music itself. The seven factors can be aligned in a dialectical process detailed by the following sentence: Who (the musicians) says What (the musics) to Whom (the audiences) through Which Media (venues, media interests, commercial interests) with what Effect (critics, institutions, histories). All seven of these influences can be seen to alter as jazz reaches different cultural phases. However, of these seven, the actual pathways along which jazz travels and mediates its social popularity are limited to four: the media interests, institutions, commercial interests, and critics. These four factors are the ones that influence the progression and diffusion of jazz along different pathways, which in turn, shape the meaning of jazz. The other three function as participants in the communicative process, but are not pathways per se. The emphasis under a pathways model is to consider the effects each pathway has upon these 
participants. This is obviously a very brief discussion of these themes, and these factors will be discussed in much greater depth in the next chapter.

My work hopes to distinguish itself from the writings of DeVeaux, Lopes, and Hennessey in several ways. First, I hope to focus on the specific time periods related to the transition of jazz into both a popular music and into an art form (1900s to $1920 \mathrm{~s}-$ folk music; 1920 s to 1940 s - popular music; and 1950 s to present - elite music). While I will need to briefly confirm that jazz has indeed taken on various different characteristics, the primary focus of my thesis is the periods in which jazz music and its supporting cast undergo substantive transformations. I am specifically searching for the pathways (institutions, venues, media, methods of dissemination, critical scrutiny, etc.) that created new variations of jazz. This will therefore take social, economic, and political factors into account, as they fulfill a specific pathway for jazz. This is not to eclipse the importance of the music and musicians, however, it is to demonstrate how other factors play an influencing role in the development of that cultural form. Second, I will be more overt about the theoretical angle under which I am examining jazz and its social pathways. This is slightly different from the previous works discussed because they are primarily works of history. Therefore, they are mostly concerned with reporting facts. My intent is still to develop a theory of cultural flows, and I am therefore interested in examining the social and technological pathways along which jazz music diffuses itself specifically for the purpose of isolating those factors that caused jazz to change. I am not interested in transitory influences or social contexts specific to jazz, but rather ones that can be mapped onto other social phenomena. This may be countered as limiting, which I will happily grant, however, the spatial ramifications of attempting a comprehensive critique of all 
influencing factors are far beyond the scope of this work. We may all be the great abbreviators, but by sharpening our tools and directions, I hope to be able to extract a theory useful towards other cultural cases. 


\section{Chapter Two: Theories of Culture and Communications}

"It is seeing which establishes our place in the surrounding world;
we explain that world with words."
- John Berger

Much of this thesis will consider the project, culture, and history of jazz. Its history is especially important because jazz has been, at various times, a folk music, a popular music, and an elite music. Jazz and its history, therefore, may point to something interesting about how cultural practices - such as jazz itself - may move from one cultural level to another. Needless to say, many others have written about jazz. Yet most of this historical writing presents itself as objective; that is to say, that it does not consider that it selects its material based on certain criteria, or a certain theoretical point of view. This is what theory does; it provides a conceptual superstructure onto which we can map realworld behaviors, practices, events, and phenomena. Theory aligns historical events, valuing specific types of phenomena while de-emphasizing others. Theory is a tool of perception; to paraphrase Berger, it is a way of seeing. To ignore theory, or deny that one has any theoretical precepts is to claim that one's work is perfectly and comprehensively true. This thesis claims a specific theoretical position that allows it to consider certain influences upon the history of jazz, influence which it feels have been neglected by established histories.

A smaller number of thinkers have thought about cultural levels. These thinkers acknowledge their basis in theory. Some of the most important thinkers on the topic of cultural levels (folk, popular, elite, etc.) are Theodor Adorno, Dwight MacDonald, and Herbert Gans. Adorno is important because of his highly developed aesthetic theory, his 
great distain for mass culture (and defense of high culture), and because he was himself a musicologist who wrote specifically about jazz in the 1930s and 1940s. MacDonald is considered because he developed a description of culture as existing along three main dimensions; the folk dimension, the popular or commercial dimension, and the elite dimension. Gans is included because he sought to split the three dimensions of culture into five, drawing his distinctions from the view that cultural levels rested upon five distinct groups of separate audiences or taste publics.

The interest of this thesis, however, is not merely to repeat what these thinkers have said. It is to use these thoughts in order to put forward what may be called pathways analysis. In this sepse, the thesis is not solely a contribution to jazz history but also to communication study. It uses jazz history and the fact that jazz has moved across cultural levels to advance the proposition that we can understand the reason for jazz's shift across levels by examining the pathways of its diffusion. Such a pathways analysis obviously recalls the work of communication thinkers such as Lasswell and Lazarsfeld who outlined the basic model of communications back in the 1940s and 50s. Pathways analysis will, therefore, be compared and contrasted to other important approaches in the study of jazz and its cultural meaning in the hope of showing that it (pathways analysis) can shed new and important light on cultural phenomena.

\section{The Critique of Mass Culture}

Culture was a very serious issue in the 1800 s, a mindset which continued to prevail through the first half of the 1900s (and even up to today). The dominant writers of the time defined culture as "the best of what has been thought and said," to recapitulate 
Matthew Arnold's famous phrase. Culture was the development of one's human and intellectual gifts, the formation of the spirit and the character. For them, culture was the purpose of humanity's existence. For example, F. R. Leavis, writing in 1930, spoke of the importance of that minority who could understand and appreciate "Culture." This minority constituted the "consciousness of the race at a given time... upon this minority depends our power of profiting by the finest human experience of the past; they keep alive the subtlest and most perishable parts of tradition." "lii Culture was a spiritual activity, one that revived the person and the soul. This is the embodiment of the classic aesthetic defense of high culture: that culture represents a set of self-evidently valuable achievements which make us and our civilization greater in our pursuit of beauty and truth, of happiness and freedom, of sweetness and light. ${ }^{\text {lii }}$

Consequently for these thinkers, culture is not driven by popular taste but is the thing that should shape such taste: "culture indefatigably tries, not to make what each raw person may like, but to draw ever nearer to a sense of what is indeed beautiful, graceful, and becoming, and to get the raw person to like that."liv Arnold's statement here sets up an obvious distinction between what people may like and what they ought to like, and between that which is true culture and everything that is not. Raw, unrefined forms of culture which do not edify and which may merely gratify the individual, are to be cast away. Indeed, proponents of high culture have vociferously defended their territory against what they perceive as its persistent erosion, and have provided scathing criticisms of mass culture. Dwight MacDonald calls mass culture a "parasitic, a cancerous growth on high culture."lv Theodore Adorno writes of mass culture as "a capitalist perversion of culture," responsible for lulling consumers into a dulled state of awareness with its 
saccharine images. lvi The terms "highbrow" and "lowbrow" were first used in the 1880 s to denote intellectual superiority and intellectual destitution, respectively. They come from the $19^{\text {th }}$ century practice of phrenology which used the measurement of cranial geometry to determine racial types and intelligence. These profiles were designed to justify the

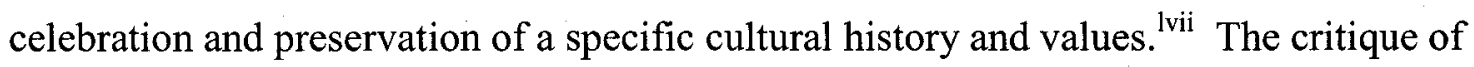
mass culture therefore decries its negative effects on simple audiences, the perversion which it wreaks upon high cultural forms, and its corruption of society at large.

Many of the charges of high culture against mass culture were based on the alienation and reification that the cultural object was presumed to undergo during the process of mass (re)production. In order for a cultural industry to be profitable (motivations which stand in stark contrast to the civilizing mission of High Art), it must appeal to a broad range of people or customers. It must, therefore, create those products with the highest chance of being liked. As such, the craftsman of high art is transformed into the worker of the mass production assembly line and the individual traits of the unique object are transformed into the standardized and formulaic 'product' of modernity. The writings of the Frankfurt School illustrate well this (neo-)Marxist critique of cultural industrialization. The Frankfurt School believed that the process of mass production of cultural objects exerted a standardizing effect which resulted in unproblematic, cliché-like characterizations and status quo obedience from an uncritical public. ${ }^{\text {lviii }}$ Walter Benjamin's work on the "aura" of a cultural artifact, for example, supposes that a vital quality of art is extinguished in its mechanical reproduction. ${ }^{\text {lix }}$

Yet, despite these criticisms, the forms and popularity of mass culture continued to grow. Historically, the democratic and pedagogical impulses which accompanied the 
industrial revolution helped to break down the traditional upper-class monopoly on culture. The newly awakened masses had their own cultural demands, and business entrepreneurs and new mass media technologies made culture a possibility for everyone, even if that culture was more entertainment than enlightenment. At the same time, proponents of high culture were busy drawing boundaries and barriers around their cultural practices. Lawrence Levine's (1988) excellent account of the rise and fall in the popularity of opera in America serves as an example of this type of protectionism. At the beginning of the $19^{\text {th }}$ century, Italian opera was performed in a wide variety of settings, enjoyed great popularity, and was shared by a broad segment of the population. Operatic arias were performed on home pianos and sung by everyone, plebe or preponderate. Opera here was an art form that was simultaneously both popular and elite. As Levine says, "it was attended both by large numbers of people who derived great pleasure from it and experienced it in the context of their normal everyday culture, and by smaller socially and economically elite groups who derived both pleasure and social confirmation from it." ${ }^{\text {, }}$ However, many critics did not appreciate the immigrants who cheered at inopportune moments and drank beer during the intermission. Condescension and contempt were mined to turn opera from a popular art to an elite preserve. Opera began to be associated with "appropriate" behaviors, standards of dress and conduct, etc., in a effort to exclude or eliminate certain segments of its audience. Critics wrote with a growing insistence that opera was a 'higher' form of art which placed demands upon a cultivated audience. Excerpts from operas, always popular with those who lacked the cultivated patience to sit through a full threehour performance, were denounced as undermining the importance of the complete work. ${ }^{1 x i}$ In this way, high cultural defenders were able to distinguish their practices from those of a 
lower economic status, thus creating social exclusion. Hence, had high culture not sought to demarcate itself from popular practice, the divide between high and low might not have been as pronounced as it was at the beginning of the 1900 s.

It was only in the 1950s and 1960s with the writings of Stuart Hall, Raymond Williams, and the Birmingham Centre for Cultural Studies that mass culture began to gain legitimacy as an object of serious scrutiny. The emerging field of cultural studies sought to legitimate the values, institutions, and causes of the dominated working classes.

Cultural studies promoted a different definition of culture, one that was less judgmental. Culture was no longer a process of intellectual and spiritual refinement, but rather a "particular way of life, whether of a people, a period, or a group." "xii This meant that culture could be everything a person did: popular work songs, languages, cooking, etc. Furthermore, it meant that culture was also an expression of self-identity rather than the way in which that identity was raised up to a higher level. Culture is how we negotiate our position within society, how we claim a certain social group and identity for ourselves. ${ }^{1 \text { iii }}$ The everyday cultural decisions that people make, even if they select popular culture, or certain types of popular culture, are rooted in a personal or group notion of aesthetic value. Culture is the meanings and values which arise in certain social classes on the basis of their given historical conditions and relationships. ${ }^{1 \text { iv }}$ The work of scholars such as Dick Hebdige and Stuart Hall justified the consumption of mass culture by endowing it with meaning, and forced a retreat of the high culture purists.

Due to this valuation of all forms and expressions of culture, the discipline of cultural studies has tended to de-emphasize overarching models of explanation in favour of understanding the specific meanings given to particular cultural experiences by specific 
audiences. Yet cultural studies insists, in its emphasis on decoding, that individuals and audiences are located within contexts which themselves require explanation. To do so is to turn from a micro-approach (on individuals) to a macro-approach (on systems of diffusion, or economic conditions of production, etc.).

Due to the many complex facets of culture, the methods for dividing culture into separate categories are also diverse. The old cultural defenders (Arnold, Adorno, and others) distinguish between cultures on the basis of the possibility of edification and the pursuit of perfection. This is obviously elitist and presumes that mass culture produces deleterious effects upon its unsuspecting audience. However, these effects have not been observed by researchers, at least not to the extent that would justify the type of critical onslaught unleashed by high culture purists. Popular culture has not generated atomized, narcotized, escapist citizens. Furthermore, audience research has demonstrated that individuals tend to experience and read cultural artifacts in ways which are hard to thematize and which do not support the view of large, passive, and dully manipulable populations. Therefore, it becomes rather difficult to distinguish between cultures on the basis of the presumed effects which they produce (either spiritual and uplifting, or dull and demeaning). Hence, while the ability to detect different types of culture has not disappeared, the willingness to attach value to those types has been reduced.

Other authors, such as Herbert Gans and Pierre Bourdieu, base their cultural distinctions on notions of separate audiences or taste publics. ${ }^{\text {lxv }}$ Gans uses the notion of taste publics to refer to a division between groups of people with different cultural preferences. Every individual is able to make an aesthetic judgments about what constitutes "good" taste, but this sense of taste is different for different social groups. This 
pluralism of aesthetic taste corresponds roughly with the class distinctions to be found in American society - age and educational levels are the other important contributors. ${ }^{\text {1xvi }}$ Through this system of distinction, Gans is able to come up with generalized taste predictions. For example, he believes that managers and executives are likely to be interested in the type of culture that is substantive but not overly challenging, such as the writings of Tolkien, Hesse, and Vonnegut (the more qualified writers of popular culture), Broadway theatre, and non-abstract art that does not seriously doff formal restrictions.

The most salient feature of Gans' and Bourdieu's approach is their view of the relationship between cultural artifacts and their audiences. Gans believes that people who like one type of cultural experience will also like another type. Bourdieu believes that our experience of culture - the types of culture we enjoy and the types of cultural judgments we make - are embedded within class constraints. For both, then, the question of the audience is important though not necessarily dynamic. For Bourdieu, the audience is essentially another name for the social class and the audience merely expresses the class biases and perceptual/cognitive limitations appropriate to each social class. Gans does not share such a restrictive view of the audience but neither does he make the audience an essential moment in the creation and circulation of cultural artifacts. For Gans, the audience is a type of barometer which tells us to which social category particular artifacts belong and which therefore leads us to expect the presence of certain types of artifacts within certain types of audiences. Both of these approaches seek to establish homological links between certain types of participants and certain types of culture - that culture A is indicative of a person with lifestyle B. 
These are fundamentally sociological approaches to culture which read it as a symptom of something else, of something that pre-existed the culture and that conditions it. They are certainly not 'wrong' in the sense of being factually incorrect or epistemologically unrelated to reality. However, they are also not 'communicative' approaches. They view culture as a medium which reveals something social to us; culture is a proxy for the social. For them, culture tells us about the social class to which its consumers belong and this, in turn, allows us to predict what types of artefacts specific categories of users are likely to prefer. This is certainly an exercise that can be carried out.

A communicative approach, however, would be less interested in predicting broad patterns of cultural behaviour than in examining specific examples of cultural change. It would be less interested in telling us how specific artifacts indicate the class origins of their consumers than in telling us how specific cultural consumers are also part of the process of creation of the artifacts. It would tend less to see culture as a barometer of social impulses and tend more to see culture as a dialogue between creators and audiences dependent upon imagination and invention, the pleasures of discovery and the comfort of familiarity, the chance encounter and the unintended consequence. A communicative approach views culture as a example of contact, a potential answer to the question "how do the ideas in my mind get into your mind, as I intended?" Indeed, unlike the sociological/cultural studies perspective which tends to presume that the ideas in my mind also find their way into your mind because we both share the same cognitive filters based on our class location, the communicative perspective tends to presume that ideas move from one mind to another, if at all, through a much messier process involving chance, 
uncertainty, persuasion, seduction, resistance, and so on. The communicative approach does not eschew sociological insight but neither does it stop there. Therefore, approaches such as those of Gans, Bourdieu, MacDonald, etc., can certainly be part of a communicative approach and can certainly shed light or cause us to ask interesting questions but they cannot be accepted unproblematically.

Hence, while a communicative approach certainly admits that artifacts can be used as indicators of class origin, it is unsatisfied with the view that this insight exhausts the meaning of culture. While people have class origins, they are also able to step outside them, to reflect upon them, to criticize them, to long nostalgically for them, and so on. And part of their intellectual if not their class mobility is dependent upon their encounters with culture of different levels and intensities and intentions. Of course, people may choose to frequent only certain types of culture because of their class-based preferences and prejudices. But they may also choose not to. They may also be surprised by something they had wanted to avoid. And cultural creators can take advantage of this to seduce potential audiences. The distinction is one of nuance or of emphasis. While culture is certainly an expression or indicator of class location, it may also be an expression or indicator of individual volition, choice, or free will.

A communicative perspective, therefore, casts culture into a dance or a dialogue between creators and audiences rather than a litmus test revealing the origin of each. The career of jazz, with its audiences lost and found, its long history at the centre of popular culture and at its margins, its infinite variety and ceaseless novelty, its self-conscious criticism and its fan-based abandonment, suggests strongly that a communicative approach will prove extremely useful. 


\section{Cultural Categories}

This thesis uses a tri-partite notion of cultural levels to study jazz. It argues that jazz has moved through three main cultural levels: the folk, the popular and the elite. These terms are not the only ones available to us to signify different levels, and are worthy of some brief discussion. While "folk" may suggest a certain guileless simplicity, it also aims at the notion of perceived authenticity. The participants in folk culture feel personally close to the culture; it serves no didactic or socially ameliorative function. It serves merely as a vehicle of self-expression which simultaneously asserts group membership. It carries with it, therefore, an affective charge which is characterized by sincerity of intent and reception as well as perceived authenticity. Because it is sincere, it is authentic and vice versa. A non-member of the group, however technically. accomplished or musically gifted, could never be authentic until he had been accepted by the group, at which point his performance would automatically assume the quality of sincerity. Authenticity is a marker of group belonging.

Likewise, "elite" culture may strongly suggest that it is inaccessible. And while I would like to dismiss any suggestion that elite culture is solely for a certain social class or intelligence, the fact remains that such culture remains elite by adopting exclusionary practices. It wants to believe that it can only be understood by a certain level of intelligence or social class. Unfortunately, more-standardized terms such as low and high culture carry with them even more negative connotations, and even "Mass Culture" has been negatively denoted (MacDonald prefers the term because he believes it to be solely an "article for mass consumption, like chewing gum"). ${ }^{\text {1xvii }}$ Other high culture critics such as 
Edward Shils have proposed such unhelpful terms as Brutal, Mediocre, and Enlightened. ${ }^{\text {lxviii }}$

Folk culture is the grassroots variety of culture. As music, it refers to music that is performed and circulated within a very localized or specialized set of organic pathways. Folk cultures are not created and sustained by professional artists. Indeed, because of their limited diffusion, it is very difficult for artists to find enough work to live off folk culture alone. As a result of the part-time status of its practitioners, technical proficiency is rarely emphasized even though it may be attained. Rather, folk culture emphasizes its participatory nature; the line between artist and audience has not been clearly cordoned off. Hence, it is more important that everyone play some music than that a few play it extremely well. Furthermore, folk culture tends not to be subject to the standardizing influences of commercial music. This allows folk music to be surprisingly disparate, eccentric, hard to classify and to track down, etc. It tends frequently, therefore, to be studied by anthropologists as much as by musicologists. It is more difficult to track down the pathways of folk culture than the pathways of other levels because of their small-scale, unselfconscious nature. Folk cultures are also often reluctant to use media technologies. It may be stereotypical to think of folk music being performed on a washboard or with spoons but the image underscores the diffidence towards musical technology. Again, it is more important that everyone may play with whatever instruments are at hand than that the use of specialized instruments become indispensable. At a higher scale of technology, however, folk music also tends not to adopt modern recording and distribution technologies. This is partially due to the impracticality of adopting such large-scale technologies in order to disseminate an artistic form whose following is highly localized 
and very small. However, such technological disinterest is clearly waning as in recent years increasingly miniaturized and unobtrusive recording technologies have begun to permeate even isolated cultural scenes. Folk cultures also do not have a large critical following, again because of the localized nature of the product. Again, though, new technologies such as the internet may provide an opening for widespread critical discourse at the micro-level of folk culture.

The distinction between 'folk' music and country music, for example, should be borne in mind. What we now call country music or country and western music is a spectacularization of folk music carried out principally by Hollywood in the 1930s. The image of Roy Rogers or other 'singing cowboys,' for example, definitely harkened back to an earlier 'folk' music but it bore remarkably little resemblance to that which it referenced. Roy Rogers and his cohorts were acutely aware of 'putting on a show' for money and therefore dressed and acted the part. They refined their performance styles to appeal to ever broader segments of the audience. The folk culture on which they traded, however, lacked that degree of self-consciousness, rarely understood itself as a form of specialized spectacle, and rarely anticipated monetary rewards. Finally, that folk culture also never sought out a mass audience. If it got one, it was by accident or because someone else someone like Roy Rogers - deliberately turned it into spectacle and transformed it in the process.

Because of their small patterns of diffusion, it is usually easier to find phenomena like Roy Rogers which evoke a folk culture than to find the folk culture itself. Indeed, it is often easier to find folk cultures which are no longer folk cultures or already in the process of spectacularization. Such examples include the grunge scene in Seattle, the East 
coast/Celtic music scene, and the roots music revival. For most people, the Seattle grunge scene was only ever a highly commercialized, supremely mediatized musical event. Most people can barely imagine that it was once a 'folk' culture. Folk cultures are hard to pinpoint for the simple reason that by the time one hears about them (through magazine articles, radio, television, etc.), they have already begun to circulate along different, more accessible pathways.

Folk cultures tend to be geographically isolated. They are local 'scenes,' within a city or region, that operate through local pathways. Diana Crane (1992) examines the social organization of culture and suggests that culture is organized along different geographic groupings. She demonstrates how the population base of an urban environment can provide support to the development of a sub-culture to operate outside of the pathways of mainstream culture. She also uses the concept of networks (as opposed to more formalized organizations) to explain how folk cultures operate without a formal legal or organizational structure. Crane's work is an excellent example of how folk cultures operate through local and non-media pathways. ${ }^{\text {lxix }}$ Folk cultures can also be difficult to distinguish because they often operate as a blend or revision of existing styles. They may result in the creation of a unique style by drawing from other cultural forms, either in response or aggregation. For example, the formation of Jamaican reggae illustrates how soul music and electric bass were overlaid with local Jamaican street slang and developed by the local culture into an entirely different musical genre. ${ }^{1 \times x}$

Popular culture is perhaps more easily defined than folk culture. It refers to those cultural objects that circulate along the most widely diffused pathways, such as 
broadcasting, publishing, etc. It is Top 40 radio, MTV, MuchMusic, Ashlee Simpson, and Hillary Duff. Popular culture is geographically disparate and intended to appeal to a large audience from all races, social classes, and ages. One of the central elements of popular culture is its close relationship with commercial institutions. It is characterized by entertainment enterprises that establish structures for the regularized production and distribution of recognizable 'product' in order to maximize return on investment. In the music industry, such close ties bring inevitable aspects of control. In order to please the largest possible audience, popular culture seeks to be immediately accessible. However, as pleasing a mass audience is invariably a risk-filled proposition, the culture industry also tends to rely upon forms and styles with a proven track record. This leads to a process of marginal innovation, or of change within continuity. If a style or 'sound' works, it can be repeated with minor variations until it ceases to work. As Keith Negus states:

It can be reasonably argued that the vast majority of musical production at any one time involves musicians working within relatively stable 'genre worlds' within which ongoing creative practice is not so much about sudden bursts of innovation but the continual production of familiarity. ${ }^{1 \times x i}$

Indeed, popular culture operates on a principle of 'rapid turnover,' that quickly introduces new variations of cultural forms into the market, in order to maximize sales. A cultural artifact is only expected to remain in public favour for a short period, and therefore, new artifacts are required frequently. ${ }^{1 \times x i i}$ In so implementing and creating standards of sound and behavior, the cultural industries act as gatekeepers exercising influence over the artists who reach audiences, the way they reach audiences, and the types of audiences they reach.

Technologically, popular culture tends to use all and any new methods of diffusion it can find. The technology can be a source of distinction and it can respond to cost control measures. It certainly helps popular music reach the widest audience possible. 
Popular culture is also disseminated through the media in non-technological ways through strategies such as pop culture journalism, pop culture magazines and television shows, etc. However, most of this 'writing' has not been given the same type of serious academic criticism as elite culture has. Finally, institutionally, popular music acts may be performed in stadiums, concert halls, or other such large-scale venues, and each of these specialized venues carries with it a specific set of practices and expectations for both performers and audiences.

Elite culture tends to erect barriers to entrance. This may include real-world practical barriers (ticket prices, dress codes) but also refers to the complexity of the code that one must master in order to appreciate the culture. I would postulate that elite culture retains the ability to support full-time criticism of itself because it is sufficiently developed, canonized, and theorized to be the object of sustained, critical scrutiny. Sustained intellectual criticism is a vital feature of elite culture, as it demonstrates the complexity of the art form. Expert criticism is also the marker by which elite audiences are able to judge whether or not the cultural form is truly worthy of elite status. These experts therefore serve as the gatekeepers of elite culture, exercising influence over what counts, how it should be presented, and how it should be consumed. Elite culture is often characterized by a reluctant use of technology, especially newer technologies, because it distinguishes itself by its use of established tradition and canon and of the technology associated with them. Institutionally, elite culture is not able to sustain itself commercially and must rely on institutional support (from both public and private sectors) to sponsor its 
programming. It exists within large, charitable organizations, and academic institutions as an object of serious study and professional practice.

Now acquainted with the distinctions, the purpose of my tri-partite division of culture is to use these distinct levels as guides to the different pathways along which cultural forms travel. At each level, the pathways form a unique constellation of opportunities and pressures for creators to reach audiences. Hence, different cultural forms tend to travel along different pathways not because these forms are expressions of prior social forces - though they may well be - but because the given pathways are the best ways for the forms to reach their intended audiences. Furthermore, these pathways exercise a strong influence on the type of culture that travels along them as well as on the type of audience that consumes the culture. This does not mean that the pathways are a type of invariant structure but rather that they are the most effective way for particular audiences to be able to encounter their desired cultural forms.

By separating culture into three levels, it will be possible to determine that cultural objects can also change levels by changing pathways, though this generally requires that the cultural object rethink itself. This thesis will show that jazz has, at one time or another, fulfilled the criteria and practices of each of these levels and has traveled along very different pathways to reach very different audiences under very different forms.

\section{Process of Exchange}

Much of communications scholarship deals with some aspect of the process of communicative exchange, which can be thought of broadly within a sender-receiver model. 
This model postulates that communication occurs via a process of selection, encoding, transmission, reception, decoding, and understanding. Very loosely, a message is formulated in the mind of the sender, encoded into some form of symbol (words, numbers, gestures, objects), and transmitted. The act of transmission may or may not involve some distortion as may the choice of channel or means of transmission. The communication, however, is ultimately heard, read, or received by a receiver, who decodes the symbols in order to reconstruct the original message. ${ }^{1 \times x i i i}$ The basic formula for the process was captured by Harold Lasswell who described communication in 1948 as the study of the question "Who, says What, in which Channel, to Whom, with What Effect?" The process was often thought to be successful when the receiver understood essentially the same meaning as the sender.

While helpful in identifying the basic process of communication, this model was criticized for its linearity (messages only flowed one way) and for its implicit concern with 'effects' (did the message reach the target with the desired outcome). Finally, it seemed to assume that the goal of all communication was to produce 'effects.' Most damaging in the eyes of some, however, was the model's social 'neutrality.' While it might track the pathways through which a particular message traveled, it apparently had nothing to say about ownership of the channels or about those who got to produce the messages and those who were condemned to receive them. It was accused, therefore, of sociological naiveté and even of ideological misrecognition as it would certainly help large corporations track their operations but would not help the opponents of those corporations topple them. In essence, then, it was accused of being simply 'administrative' when it should have been 'critical.',lxxiv 
It found widespread use in propaganda studies since propaganda seems to lend itself to the straightforward linear pattern involved in the model and in such fields as advertising, public relations, and so on. At its core, though, the model asked a profoundly communicative question: how is contact established between a sender and a receiver, a speaker and a listener, participants in a dialogue, creators and audiences, etc.? Indeed, the question is so fundamental that even Raymond Williams, one of the fathers of modern cultural studies and a devoted neo-Marxist, titled his monumental 1981 history of communication Contact: Human Communication and its History.

Eventually, the model was enriched and updated by Paul Lazarsfeld, Elihu Katz and others who proposed a more sophisticated 'two-step flow' model of communication. Katz \& Lazarfeld's research demonstrated that during the process of transmission, a number of factors could influence, distort, or alter the message. The first of these factors was selective exposure. Lazarsfeld found that far from being mercilessly subject to the imperious power of the media, many audience members simply weren't paying any attention at all. ${ }^{\operatorname{lxx}}$ This finding has subsequently been confirmed by a host of researchers. The problem arose then - how can we even be sure that people are listening? Generally, it is impossible to be certain and so communicators have devised various strategies of seduction to make it as easy as possible for listeners to want to pay attention. Worse though, was the fact that even when they were paying attention, listeners persistently interpreted what they heard in ways that were inconsistent with, uncongenial to, or frankly opposed to the intended meanings of the senders. This has also been confirmed by numerous subsequent researchers. A second question arose: how can we get people to hear 
what we say and not what they think we say or wish we would say or are determined to believe that we say? This is also a largely intractable problem.

If successful communication is characterized by the appearance in the receiver's mind of the idea that had originally been in the sender's mind, then Lazarsfeld et al., had discovered a constellation of intervening variables that were described as noise, distortion, incomprehension, misunderstanding, and so on. Many of the factors of noise could be described in sociological terms by correlating what receivers of messages said about the messages with such markers as age, sex, income level, educational background, and so on.

But there were other intervening variables. Audiences inevitably acquired familiarity with the presentational styles of the various media. They were not naive audiences but increasingly sophisticated ones. Indeed, their media familiarity led them to distrust some media and to trust others. More significantly, audiences were also quite accomplished at taking media messages - even the ones they agreed with - and mocking them or using them in contexts unintended and unanticipated by their senders. They displayed such inexplicable behaviours as a sudden liking for a particular phenomenon followed by its equally sudden banishment. As any film or radio producer well knew, it was infuriatingly difficult to know what would please an audience. And this was evidenced by the fact that 9 out of 10 films, radio shows, television shows, songs, advertising campaigns, etc., were failures. If we really knew how to reach audiences, everything would be much more successful than it was.

In 1960, Joseph Klapper captured the situation well when he said "some kinds of communication on some kinds of issues, brought to the attention of some kinds of people under some kind of conditions, have some kinds of effects." 
The hope that knowledge of the ownership of the channels or the means of production would finally tell us how messages achieve their meanings has likewise been dashed. While the owners of the channels certainly get to be heard more than anyone else, they do not get to determine thoughts more than anyone else. Their views are as likely to be distorted, ignored, mocked, ridiculed, re-circulated, transformed, and occasionally understood as much as anyone else's.

Additionally, audience members do not live in isolation from one another. The media are not their only sources of information. They acquire familiarity with media content and with its style of presentation. They use that familiarity to construct unintended and unanticipated meanings. The media are not their only world. ${ }^{1 \times x v i i}$

Lasswell, Lazarsfeld, and others laid the groundwork for a type of inquiry that I have captured under the term 'pathways analysis.' This is the study of the pathways along which messages travel in order to reach their audiences. Depending upon their pathways, some messages will travel more easily than others. Virtually all messages will have to adapt themselves, perhaps dramatically, to the requirements of the pathways. They will also encounter very different audiences. This approach when applied to jazz gives us the ways in which the music adapts itself in search of audiences. The cultural levels of folk, popular and elite refer to constellations of pathways and, therefore, to various states of jazz, to various networks of circulation, to various types of critical discourse or judgment, and to various audiences.

Lasswell's description of communication as the study of "Who, says What, in which Channel, to Whom, with What Effect?" breaks the act of communication down into 
five parts: (a) the communicator/sender, (b) the message, (c) the channel, medium or vehicle of transmission, (d) the audience, and (e) the impact/effects. According to Lasswell, those concerned with the communicator (the 'who') and his impetus for communication are dealing with control analysis, the study of the considerations that go into the design, selection, timing, and construction of a message. Those who focus upon 'says what' are specializing in content analysis, the study of the objective propositional content of a message and of its primary and latent meanings. Media analysis considers the channels of communication under the view that different channels may reach different audiences, may require different message designs, may result in different impacts, may in fact be part of an oyerall 'media ecology' characteristic of a given place and time (for example, the rise of radio in the 1930s and its peculiar relationship with film). Those who study the 'to whom' are concerned with audience research on the belief that different audiences come together for different reasons, are variably attentive, possess differential defining characteristics, bring dissimilar degrees of familiarity and sophistication to the communicative situation, and so on. Finally, those who study the effects of the message are obviously concerned with effects analysis, which not only validates or invalidates the choices and theories advanced in the earlier steps but also feeds back into control by allowing communicators to refine their contact strategies. ${ }^{\text {lxxviii }}$ Lasswell also notes a distinction between the structure of different channels of communication. Lasswell distinguishes between channels that merely direct messages without content modification from those that affect the content. In this way, he posits the idea that institutions apply doctrines and formulas designed to impact the message. Consequently, communications channels may not be clear points of objective transmission but active agents with a specific 
bias. Lasswell believes that "in every society, values are shaped and distributed according to distinctive patterns (institutions)."lxxix These institutions work to support the network as a whole, enabling it to survive. Lasswell is, of course, a contemporary of Walter Lippmann and, like him, much of his writing focuses on questions of how to guide and encourage democracy. For him, the standard of good communication is found when communication furthers and aids the survival of society; factors that interfere with efficient communication must be eliminated. In this, we can see Lasswell's foreshadowing to an emerging biological/cybernetic paradigm with its concern for homeostasis or systemsstabilizing functionality.

Lasswell's formulation has proven enormously rich and Lasswell himself also suggested directions for future research, focused on how relays (or institutions) operate. Each relay is a vortex of interacting environmental and pre-dispositional factors. In a more contemporary language, we might say that vortices or institutions are producers of discourse or nodes within a network of language games. They do not merely privilege or shape individual messages as they travel through but also represent sedimented forms of knowledge which are applied to the interpretation and appreciation of messages, and they also propose their own messages in order to shift the system one way or another. There is more than simply a hint of hermeneutic interest here. Whoever performs a relay function can be examined in relation to his input and output, and questions of what is passed on, or dropped, or added, or edited become the method for exposing the biases of the relay. In this way, Lasswell outlines the basic model for an examination of the processes and procedures found in the discipline of communications. 
Manning White's 'gatekeeper studies' as well as the entire 'agenda-setting' hypothesis are direct descendants of Lasswell. However, a model remarkably similar model to Lasswell's was proposed in the 1980 s by Stuart Hall. ${ }^{1 \mathrm{xx}}$ This was the 'encoding/decoding model.' Although Hall's model grew specifically out of a selfconsciously neo-Marxist desire to tear back the veil of ideology and finally expose the truth of how messages were subtly distorted, and although his model claimed indebtedness to cultural studies, feminism, and semiotics, it nonetheless broke the steps of communication down into the same elements as Lasswell had proposed, and largely with the same functions. Hall identified a moment of production and a moment of consumption, which correspond to the 'who' and the audience in Lasswell. He likewise identified several intervening steps - professional practices, corporate/institutional expectations, available resources, etc. - which correspond to Lasswell's content and media analysis moments. Finally, both Lasswell and Hall were concerned with impacts, outcomes, and effects. Their main difference centered on how to interpret the outcome and on what to do with it. For Lasswell, the impact was fairly immediate and measurable and tended to serve as a verifier of the previous steps of the model, ultimately allowing the communicator to refine his strategies. This was especially true in the case of propaganda, for example, where behavioural effects should be immediately measurable and should be used to refine later propaganda messages. Of course, knowledge of the propagandist's strategies would also forearm audiences against them. For Hall, however, the impact was essentially co-terminous with the reigning capitalist ideology of the day, that which came to be known as 'Thatcher's Britain.' Since the producers of messages were largely drawn from, and apparently largely sympathetic to, the worldview associated with Thatcherites, 
and since they also oversaw the distribution of resources, established professional practices, exerted their normative judgments, and so on, the messages produced and circulated were heavily-laden with the Thatcherite presuppositions. The impact therefore was long-term and not immediately measurable although it could be glimpsed in such trends as rising support for vigourous police action, spontaneous assumptions of guilt and suspicion directed towards racial and cultural minorities, outbreaks such as the Brixton riots, and so on. Hall found in the effects of messages evidence of the ideology whose existence he had presumed at the moment of production of the messages. The effects served, therefore, as proof of the ideology's existence and as a clarion call for broad-based opposition to Thatcherism. This was complicated by the fact that Thatcher was popularly elected on several occasions. Therefore, the broad-based social action had to take the form of educational campaigns intended to help the populace see what the 'encoding/decoding model' saw, a type of pedagogical false consciousness campaign. Although Hall never made the following claim, it could reasonably be concluded that in the 'encoding/decoding model,' good communication corresponds to communication which reveals the truth of the model's own presuppositions (the ideology we said existed really does exist) and serves to shift the social system towards a state of meta-stability or homeostasis consistent with the analyst's views.

This thesis applies Lasswell's question - "Who, says What, in which Channel, to Whom, with What Effect?" - to the process of jazz. It asks "which musicians (who) perform what music (what) through which venues (channel) to which audiences (to whom) with what effects (popularity, alienation, marginality)?" Following the thread or flow of 
the message along these steps can be called pathways analysis. A pathway is a series of steps leading from one point to another. Each step along the way may act as a gate-keeper, letting some messages flow through while blocking others. Each step may also exert its own specific influence, whether intended or unintended. The influence may result merely from the weight of accumulated experience or from a self-conscious act. The steps are therefore logically and pragmatically related to one another. For example, a message launched first amongst cab drivers is unlikely to find its next step among corporate members of the Trilateral Commission. It may eventually end up there but pragmatically that is not the next likeliest move. Likewise, a message that asserts the reality of ghosts is unlikely to find its next expression at the World Congress of Cognitive Science, although it may eventually end up there. Logically, such a message would seek validation - or would be shunted into an area in which such validation were possible - amongst those who believe in ghosts. The point is: the steps making up a pathway are logically and pragmatically related. There may be a degree of path dependency in the flow of messages.

Furthermore, a single well-known or well-established path - the path that leads from initial garage band tryouts to ultimately lucrative recording industry contracts and global fame - admits of numerous variations within itself. Not every garage band in the world will be discovered on a Tuesday by a disaffected A\&R man. Some will toil in obscurity playing gigs in forgotten clubs before being discovered. Some will never be discovered. Some will be discovered but not signed. Some will be signed and wish they had not been discovered. All will have unpredictable market outcomes. A pathway, therefore, does not describe a rigid, invariant structure but rather a constellation of likely and useful steps. 
For that reason, there exist a number of different pathways. The pathway of the garage band is similar but not identical to the pathway of operatic success. Neither is identical to the pathway of a best-selling novel. And the science-fiction best-seller is unlikely to get Oprah's endorsement whereas Maya Angelou will. Pathways refer to constellations of likely and useful steps. They are multiple and internally variable. A pathway is, ultimately, a way of naming the myriad factors that weigh upon the phenomenon of contact - how does the idea in my head get into yours? It tries to name those factors without characterizing them, without presuming before-hand that they are caught up within, or expressions of, an overarching ideology, for example. That they express the aims and desires of a particular industrial configuration (that they serve to construct audiences in a particularly passive and malleable way, and so on), may prove to be true but such insights would point to factors amongst others rather than to the guiding truths of pathway analysis. Pathway analysis is always open to the unexpected, to the exception, to the unanticipated act of imagination, unintended consequence, the ruse of sophistication or unreason or mockery. It says the system is always undecidable. It reaches momentary states of stability only to take off into new states of instability.

If we now consider Lasswell's model for communication as a means to understand how culture has been studied, the emphasis has been thrown on certain steps in the communicative process. Most established cultural and subject-specific histories focus on the sender, the creator of the cultural form, as well as the cultural content (the 'who' and 'says what' - the music and the great musicians). Most current cultural studies scholarship prefers to concentrate on the audience and its motivations for participating in the form of culture (the 'to whom' and 'with what effect'). Pathways analysis will therefore focus 
principally on the neglected dimension of this process of cultural transmission, the channel along which culture travels in order to reach its audience.

Nonetheless, Lasswell's question can be phrased in many ways in application to the process of music. It could be given as "Which critics (who) offer what criticism (say what) to which audiences (to whom - musicians, other critics, corporations, audiences) through which channels (magazines, books, articles), with what effect (popularity, canonization, university courses, academic acceptance, etc.)?" Alternately, one could ask "Which commercial interests (who) say what (product design and proposal) to which audiences (consumers, musicians) through which channels (media campaigns, advertising) with what effect (popularity, purchase of units)?" The question could even be phrased as "Which audiences (who) say what (approval, acceptance) to whom (commercial interests, musicians, critics) through which channels (purchase, participation, attendance) with what effect (popularity, commercial/artistic viability of specific artist and art form)?"

Each of these transformations of the question points us towards a different pathway, a different constellation of logically and pragmatically related steps. Without presuming to exhaust every possible permutation, this thesis uses the basic Lasswellian question to map out the various pathways along which jazz travelled over the course of the $20^{\text {th }}$ century. It deduces the pathways from a survey of the literature, an assessment of critical debates and historiography, an understanding of the history of jazz, the well-known shifts in the status of jazz, the statements of musicians, and so on. Pathways analysis may help to shift jazz scholarship away from its current academic emphasis on canonization and towards pragmatic questions of jazz's journey towards its audiences. 
Of course, the use of Lasswell may raise some objections. Some will undoubtedly insist that communication studies has come a long way since then and to return to Lasswell is simply nostalgic or naïve. They may reiterate, as many have before, that Lasswell understood communication as a purely linear process whereas it is in fact a non-liner process. They may remind us that Lasswell neglected important aspects of the process because, by focusing on media, he overlooked the importance of social class, gender, and ethnicity, for example.

It is true that Lasswell did not foresee all the developments that would follow him and equally true that he was committed to certain values and orientations which may no longer be sustainable or fashionable. But one might as well object to political economy on the grounds that Marx failed to predict the rise of a management class or the widespread ownership of corporations through shares or the rise and fall of the Soviet Union. Figures of the past are happy in the past. Their failures need not be ours. If Lasswell neglected concerns over the concentration of media ownership, for example, we in the present need not. We do not come to communication studies blindly as though we were ourselves ignorant of everything that fills the gap between Lasswell's original article and the present day. If neo-Kantians can return to Kant with the added knowledge of all that came after, if Marxists can call themselves neo-Marxists, then perhaps the condemnation of pathways analysis and a Lasswellian orientation can be suspended until after the results are in.

The permutations to which Lasswell's question can be put, and the understanding of pathways as constellations of logically and pragmatically related steps demonstrate, at least partially, that the original question need not be as rigid as its opponents imagine. The term "channels," for example, does not have to be media-centric; it need not necessarily 
be read to mean "through which mass medium" and a medium need not be construed only as a component of the 'cultural industries.' A medium can be an institution, a node in a network where knowledge is sedimented and a particular type of discourse produced and circulated. The elements of the Lasswellian question (as surely the developments of cybernetics, systems theory, and Stuart Hall, to name only them demonstrate) are susceptible to considerable expansion and redefinition. Hence, this thesis will expand Lasswell's concept of institutions to include both the media technologies through which jazz is circulated and those factors involved in the creation and transmission of jazz which are often called an 'art world' (in Becker's meaning). The permutations of the question mean that we are npt condemned to imagine the 'who' only as the sender/musician, for example. Furthermore, Lasswell himself notes that the process of communication is not linear but dialectical when he observes that audiences do talk back and that circuits of twoway contact also exist. ${ }^{1 \times x x i}$ It is the process of response which brings the whole into harmonious action - every sender requires feedback from her audience in order to ensure that her message is being received. However, just to be clear, the process of communication cannot be linear because just as musicians say things to audiences, audiences say things back to musicians (by their appreciation, attendance, purchases, etc.).

As the next section reminds us, pathways refer to the set of constraints and encouragements which a cultural form encounters as it leaves the mind of the creator in search of an audience. These constraints and encouragements are difficult to predict, do not act in a constant sequence, are of highly variable importance, may not all be present in all cases, invariably coincide with other events and pressures, and so on. 


\section{Factors of Influence}

There are seven main factors considered in the pathways analysis of jazz: (a) technologies, (b) institutions, (c) commercial interests, (d) critics, (e) audiences, (f) musicians, and (g) the music itself. The first four factors exert obvious control influences whereas the final three tend to be the objects or targets of the first four, they tend to provide indicators of the effects of the first four.

Technologies refer fairly straightforwardly to the techniques, devices and machines used to diffuse a cultural artifact. In the case of jazz, this means radio, television and sound recordings, as well as other writing media. Radio and recording technology (phonographs, LPs, tapes, CDs), the mass media which most influenced jazz, helped disseminate jazz music to a national audience. Historical writings often speak of media technologies in an objective sense, suggesting that they merely record and transmit the cultural object in an instantaneous linking of artist and audience (sender and receiver). This is simply not true. Even at the strictly technological level, each of these technologies has certain built-in biases and limitations, which constrain and influence the cultural object. For example, due to its size and speed, a $78 \mathrm{rpm}$ single could only record about three minutes of a musical performance. As a result, jazz musicians were forced into a specific model of popular music which limited them to a restricted number of choruses and heavily distinguished a recorded performance from a live one (where the band could take as many choruses as it wanted). An examination of this factor is an early indicator that the medium helped to shape the message in a particular way. 
Institutions refer to the physical locations in which a cultural artifact tends to occur; the clubs, bars, speakeasies, concert halls, universities, stadiums, jam sessions, recording studios, and festivals where jazz is played. Again, each of these venues tends to encourage different practices, to attract different audiences, and to exert different pressures upon performers. To the casual observer, this may not be apparent, however, the type of person who attends a speakeasy or bar in order to hear a jazz performance is very likely different from the type of person who attends a jazz performance in an established concert hall (or will bring different expectations and behaviours to each venue). It is acceptable to talk during a jazz performance in a bar or at festival, to move around, order and consume drinks or food, but none of these would be permitted in a concert hall. To the same degree, artists may be much more casual in dress and behavior in certain venues. Therefore, each of these different venues brings with it slightly different codes of behavior, again suggesting how each step in a pathway exerts its own pressures rather than being a socially-neutral or inter-changeable location. The category of institution is my term for Howard Becker's 'art world,' the set of physical venues and practices which shape the performance and creation of jazz.

Commercial interests are those social agents who participate in the process of cultural production with the specific intent of making money. These agents include primarily the music industry; the major and independent record labels which sign, record, develop, and market jazz music and musicians. Their actions are often seen as an external influence, something that detracts from the "art" of music making; however, a commercial presence has always played some part in the process of music creation, and therefore, tirades against commercial interests are more reflective of the values and ideals of the 
objectors than they are incisive descriptions of reality. Nonetheless, because of their need to sell records, commercial interests generally want the largest market possible. ${ }^{\text {lxxxii }}$ From the earliest days, this tendency both encouraged the recording of less-controversial white jazz groups and pushed performers to adopt a more homogeneous sound. Record companies operate on a risk management principle, which means that they are most likely to record and promote acts that sound like previously recorded acts with a track record. This makes them risk averse or unlikely to encourage unproven acts or new directions. ${ }^{1 \times x x i i i}$ Record companies function as gatekeepers; because of their ability to exclude an artist from widespread market diffusion, they effectively have the power to allow an artist to survive. Conversely, if an artist is not recorded, distributed, and promoted by a record company, his impact upon the music scene is likely to be severely limited, at least until he is 'discovered' as an unknown classic or a renegade fierce enough to resist the industry. $^{\text {lxxxiv }}$

Critics, the fourth factor, are not a unified phenomenon but a chorus of critical voices who play a key role in encouraging and legitimating certain cultural objects while minimizing other forms. Critics may come from a variety of backgrounds, with a variety of standards, tastes, and preferences, and therefore do not represent any single entity or ideology. Critics may engage in academic writing, journalism for specialist periodicals or the general interest press, album liner notes, publicity flyers, radio commentary, etc. They also operate as gatekeepers of taste, disseminating opinions about the cultural form which function as reference points for the general public which is thought not to have developed the same trained ability as professional critics. Critics also tell performers when they have done well, when they have lost their way, what they should perform, etc. Critics have 
played an extremely influential role both in the canonization of specific works as well as in developing the canon itself. They create a forum for the observation and assessment of music because of their function as studious listeners. ${ }^{\text {Ixxxv }}$ The critic plays a more prominent role if the cultural form is considered "high art." Indeed, critics may often be more important than the creators themselves because they determine whether a certain cultural object may be considered high culture. Furthermore, it is the critics who master the complex code needed to understand high art, who teach others how to acquire it, who exercise it in order to make determinations of belonging or exclusion, and so on. A critic usually bases his rationale upon some form of aesthetic judgment, and his opinions can often affect subsequent creative works. ${ }^{\text {Ixxxvi }}$ While the critic does not physically stop an audience from listening to an artist, she exhibits both a great power of persuasion as well as the ability to grant exposure to artists of her choosing. Yet because of their formalized relationship with the music as studious listeners, critics may operate differently from their un-studious or utilitarian audiences. Critics therefore often act as re-enforcers of the established canon or as cheerleaders for inclusion within the canon.

The remaining three factors tend to act as indicators of the impact of the first four. As such, they tend to be either the starting or end point of the communicative process, and their identity can tell us much about the type of pathways along which the cultural object travels. For example, different pathways of diffusion will generate considerably different audience types, and require considerably different formal characteristics in the artifact exchanged. This obviously does not mean that musicians or audiences never exert any influence over the nature of jazz music or the collective behavior of jazz enthusiasts; they can and do. The point is that their roles are often reactive within the process of cultural 
exchange, and dependent, at least partially, on the pathways through which the cultural object travels. Within the communicative process, the musicians and the audience both function as senders and receivers, both creating the message/cultural object, and both participating in the cultural practices. After all, attending a musical performance is also a cultural practice. The culture would be incomplete without the musical performance but the musical performance would also be incomplete without the audience to hear it.

The creation of the music by musicians should not be viewed as a process independent of external factors; musicians learn their craft by listening to records, attending performances, meeting other musicians, studying formally, etc. Furthermore, their ability to become successful is based, at least in part, on their ability to mimic previously successful artists, to be knowledgeable of their work and able to perform in a similar (or cognitively dissimilar) fashion. Aspiring musicians must learn a repertoire in order to communicate with other musicians, and must demonstrate an appreciation of the tradition. The artistic institution upholds a system of social roles and norms, deemed 'good,' around the satisfaction of specific artistic functions. ${ }^{\text {lxxxvii }}$ In conforming to the roles and norms, musicians implicitly support the established canon of repertoire and stars, locating themselves within the social context before they may be trusted to develop their own sound and ideas. Behavior is shaped both by established masters and established repertoire, and these two factors function as a system of social control and regulation. Musicians do create the cultural object, but this process of creation is highly circumscribed, even in an art form as independent as jazz.

Audiences, on the other hand, encourage the production of certain types of culture by their participation in that culture. Yet, their knowledge of that culture, as well as their 
access to it, remain somewhat contingent upon the pathways along which the culture travels. Each level of culture carries with it barriers to entry, which make it easier or harder for certain classes of people to participate. A person of low income is unlikely to spend the cultural and economic resources required to attend an opera event: to purchase/wear a dress/suit, to purchase an expensive ticket, to understand the history of the specific work, the language in which it is performed, how to subscribe to the conventions of good judgment exhibited by other patrons, and the conventions involved in knowing when to applaud during the performance, etc. This is an example of how a pathway can exclude certain audience members. It is not impossible or illegal for anyone who so wishes to attend an/opera; however, there is a host of behaviors, codes of conduct, and barriers to entry that must be negotiated. It is also, of course, an example of how participating as an audience member is a cultural practice. This is also why it can be argued that pathways play a primary role in determining the composition of audiences.

Finally, to fulfill the process of communication, the music functions as message, the encoded meaning created by the musician and transferred to the audience. This way of talking about music - as a message - should not make us lose sight of the fact that music is not information. Due to academic and social biases towards quantification and objectivity, the tendency exists to ask "what does the music mean?" This is a misconception because, although music may be intended in a specific way by a musician or endowed with a specific social history by its pathway, any audience member may interpret it as he wishes. If music is a message it does not appear to operate with any single meaning that would be discoverable through repeated listening or more studious inquiry. Indeed, music is often expressive of states of mind - feelings - that are notoriously difficult to put into words. 
Nonetheless, the fact remains that some music does have specific meanings, but this is primarily given to music with lyrics such as national anthems, protest songs, work songs, ritual invocations, and so on. The jazz tradition, however, grew primarily out of instrumental music. Finally, the emotional resonance of music may also be construed as its 'meaning.' These examples of meaning can operate in conjunction with each other or separately. Yet, despite all these instances of attaching meaning to music, it is important to allow that each individual and audience, as well as each performer will likely attach individual meanings and significations to it. The attachment of specific meaning to specific messages is the domain of cultural studies, and it is therefore an important element of pathways analysis that allows this inquiry the flexibility to consider the process of communication without these ideological precepts.

It also worth mentioning at this point the treatment of race within the study that follows. Some will claim that race is a primary factor in the study of jazz and that jazz music is indissociable from the African-American culture that gave birth to it. Indeed, many historical projects have adopted that view. The most prominent treatments of racial factors in jazz understand the music as a history of exploitation, of the expropriation of an indigenous music to serve the commercial interests of a dominant class. Other treatments of racial dynamics in jazz, such as the writings of Amiri Baraka or Frank Kofsky's Black Music, White Business, seek to connect jazz indelibly with its black history. ${ }^{\text {lxxxviii }}$ For these authors, jazz is indissoluble from its ethnic origins, and is itself both a voice and a vehicle of black oppression and extortion at the repressive hands of a dominant white class $^{1 \mathrm{xxxix}}$ 
Consequently, race does appear as a factor through the thesis as a step logically and pragmatically present in certain situations and decisions. As such, it occupies a status similar to that of gender or social class. These are all equally valid (and equally problematic) filters through which to read the history of jazz (though race is probably the cognitive filter most often essentialized within the topic of jazz). Race refers to a cognitive or experiential filter which influences the nature of the encounter with the form of jazz. Yet it would be curious to claim that jazz is as it is because it is expressive of some racial predisposition or sensitivity. Such an argument would amount to the essentialization of race. It would no longer be a cognitive filter - always susceptible of change - but a precondition of existence, forever identical to itself and forever useful as a criterion to separate the true art form from its mere imitators or derivatives.

The history of jazz, however, while confirming repeatedly that race played a significant role in shaping the music, also disconfirms the view that the nature of the music is racially based. Musicians of all races can and do play jazz; singly and in the most various combinations. One might as well argue that European art music is inherently 'white' though there is absolutely no doubt that the experience of white people powerfully shaped it. Yet, it would be counterproductive to claim that only white people could perform it or that the whiteness of the performers were a good criterion for judging the music.

The difficulty here is to acknowledge race as a sociological factor (as a frequently present step within pathways) without essentializing it. Indeed, by essentializing any factor in our analysis we effectively deny the cultural form the possibility of change. To essentialize a factor is to claim that a cultural form always displays one dominant meaning 
or tendency from which it becomes virtually impossible to break away. Yet it is certain that race did provide a particular type of experience for specific types of people.

Musicians of different races have different experiences of jazz (where they can play, etc.), and the same is true for audiences. Nonetheless, in contrast to the types of histories that would claim jazz for their own social narratives, this thesis avoids essentialization and focuses on the potentially infinite combinatorial possibilities of pathways.

When jazz was first developing, it was primarily performed by African-Americans who also tended to belong to disenfranchised social groups. However, after (and even before) it broke onto the national stage in the $1920 \mathrm{~s}$, jazz had been performed and listened to by socially and racially heterogeneous groups. This, therefore, is indicative of the fact that jazz first functioned as the music of a specific subaltern class (comprised of both audiences and artists), but has since expanded to incorporate many ethno-cultural groups (white, black, Cuban, Latin). The very purpose of popular culture (which jazz functioned as in the 1930s and 40s) is to appeal to as broad an audience as possible, making it the purview of many different races. And the high art form of jazz today may be listened to and performed by anyone willing to learn the craft, regardless of race. The games of exclusion utilized by high art discriminate primarily on a basis of either intellect or socioeconomics, not race, although obviously race intersects with these criteria. Furthermore, beyond noting that a cultural object may be the creation of a specific ethno-cultural group in its folk stage, the factor of race is not intrinsic to the process of cultural transformation. Not all folk cultures are black or white. It should be noted, however, that race is an intriguing concept for those who study the subject of authenticity in jazz (just as social class would be a worthy object of inquiry for those studying authenticity in folk music or 
rock'n'roll). However, the politics of authenticity belong to the valuation of music and may perhaps be better addressed by proponents of cultural studies.

Therefore, the seven factors outlined above will guide the historical analysis of jazz. The focus will be directed to the ways in which different aspects of form, or different audience groups, became involved in jazz culture, due to their location within different pathways. In the following chapters, the history of jazz is divided into three discernible time periods that correspond to the music's function/popularity at certain times in the last century. In each period, I will first demonstrate how jazz music fulfilled all the criteria of each corresponding cultural level (folk, popular, and elite). After establishing how jazz operated at a specific cultural level, I will then demonstrate how dialogical developments between the artists/art form and the channels along which the music traveled spurred changes in its ability to function at that specific level. Artists are able to exert a certain amount of influence over their cultural products, much as the channels along which those products traveled also shaped it. The negotiation between these two influences creates the impetus for the cultural form to change levels. Proving this will require an examination of each of the previously-stated factors of influence; and in particular, the degree to which they altered, and the effects this had, upon the cultural form, its audience, and its creators.

Work by scholars such as Simon Frith provides a general model for this type of analysis. For example, Frith studies the process of industrialization surrounding the development of the popular music industry in one of his articles. In his analysis, Frith (1992) considers such factors as the technology required (how the development of the record player required an industry to provide the music in a format to sustain it), the appearance of new professionals to support the industry (A\&R people, record producers, 
sound engineers, disc jockeys, etc.), and other socially-prevalent economic factors (depression-boom cycles). ${ }^{\mathrm{xc}}$ This approach gives Frith a much clearer understanding of the extra-musical factors contributing to the rise in popularity of certain art forms. And while he does not give a thorough treatment of the impact of music industry professionals, nor extend his analysis to consider the role that institutions played in creating/mirroring the changes in music consumption, he nonetheless provides a model for analytical imitation.

\section{Importance of Pathways Analysis}

Historically, there has not been a good theory that can understand cultural phenomena on more than one level. If the cultural form is confined to one specific cultural level, different theories are able to explain its behavior. Aesthetic theory is used to understand high art - a theory of understanding formal perfection within the transcendent piece of art. Because high art is understood as a quest for perfection, it is very rarely understood in terms of its economic relationship with capitalist elements. Indeed, the commercial influences on high art are usually downplayed, ignored, or vilified. On the other hand, popular cultural forms are understood to operate within the constraints of a commercial audience and commercial demands. Popular culture is analyzed in relationship to an audience with utilitarian motivations, and the interplay between creators and gatekeeping media is well documented. However, due to its commercial orientation, it is infrequently evaluated on the same aesthetic scale as high art, rarely thought to be an attempt at technical virtuosity or formal perfection. So we see the difficulty that jazz presents - because it has functioned at both popular and high art levels, it can never be 
understood completely from either a socio-economic (popular) or aesthetic (elite) theoretical perspective.

This is exactly why pathways analysis is so useful. It does not seek to evaluate a cultural form on the basis only of its socio-economic or aesthetic characteristics. Rather, it seeks to explain how the cultural form became popular with different social groups due to its diffusion along different and corresponding pathways. The pathways analysis of jazz therefore provides a benchmark to explain the phenomenon of jazz, despite the cultural level on which the object 'jazz' may exist.

The differences in analytical possibilities between pathways analysis and current cultural theory become apparent in a brief consideration of DeVeaux's work, The Rise of Bebop. DeVeaux begins his book by explaining how, before 1945, jazz was afforded no privileged high art status. Rather, it functioned as "a music created for immediate consumption through commercial channels, it had depended directly upon audience approval." In this 'low art' state, jazz can be adequately evaluated using available socioeconomic cultural models which have little to say about jazz as 'art'. However, in the very next sentence DeVeaux is confronted by the fact that jazz, at one point in its history, abruptly does become art: "Suddenly, with bebop, the terms of the relationship seem reversed: artists, acting on their own initiative, force radical and disorienting innovations upon a reluctant and bewildered audience, in this way guaranteeing a minority role in American culture for jazz as 'avant-garde' art."xci He adds: "We celebrate, literally, these musicians' authority: the ability to create artworks that embody their expressive intent, and their freedom to do so without interference from external restraints. We treat them as composers. The parallel with European art music is obvious." 
Unfortunately, while this sentence captures a very real event in the history of jazz, it also seems to have nothing substantive to say about it. Why did jazz 'suddenly' become art? Apparently because of the individual genius of a few great men. Hence, DeVeaux lapses into a reading of jazz as the history of great musicians determined to combine artistic ambition and economic reward. However comforting that view may be, it neglects the fact that during the transition to bebop, the form of jazz changed dramatically, as did the abilities and goals of the artists, their relationship with capitalism, virtuosity, audiences, etc. In short, it neglects the fact that jazz underwent a total formal change about which the existing socio-economic approaches are enormously discrete, as the turn to hackneyed 'great man' history illustrates.

Consequently, when studying jazz in its high art phase, the former socio-economic models of cultural analysis tend to be abandoned and replaced by a more 'aesthetic' orientation. It is as though jazz were subject to incompatible and incommunicative analytical strategies depending on its current status, either socio-economic and low or aesthetic and high.

Pathways analysis attempts to focus on factors that do not change with the social status of jazz. It focuses on factors that must logically exist at all levels of culture. Hence, while the specific pathway along which music travels to its audience changes, the fact that music must always travel along a constellation of logically and pragmatically related steps does not.

With this type of analysis there is, of course, a temptation to reduce jazz to the sum of the pathways along which it travels. This is not my hope. I seek to emphasize pathways, but not to exclude the importance of other actors. Nonetheless, actors are 
limited in their freedom to act by the pathways along which their cultural form must travel. It is the exploration of the power of these pathways that this analysis may uncover. In so doing, I aim to uncover a theory of cultural flows which will outline the conditions under which an art form may transform itself into a different category of popularity, based on a transformation of the disseminatory channels along which it transmits itself. However, an articulation of this theory will have to wait until Chapter Six to emerge; after the work of analysis has been finished. 


\section{Chapter 3: From Folk to Mass}

"One of the things I like about jazz, kid, is I don't know what's going to happen next. Do you?"

- Bix Beiderbecke

Most people who listened to jazz in the 1940s and 1950s would not recognize the music that was called jazz in the 1890s. After all, jazz from the early 1900s sounded and looked very different from 1940s big band jazz. In the 1940s, 25-piece jazz big bands dressed in tuxedos would play written music in large ballrooms. In the 1890 s, $6-8$ piece groups might perform for a dance in a local community hall in New Orleans. This very different picture prompts at least two major questions. When and where did jazz begin? And how, or in what manner, and for what reasons, did it change?

To answer these two questions, this chapter will also be divided into two parts. The first part will establish that jazz was, indeed, in the 1890s and early 1900s, a folk culture. We should note, additionally, that while a great deal is known about the early history of jazz, much of it remains open to contestation because (amongst other things) the early witnesses are dead or have failing memories, or deliberately mis-remember events. It is also because the very nature of folk music failed to attract a lot of critical attention. It was only later, when jazz had become a phenomenon worthy of sustained criticism, that various individuals went back and sought to reconstruct a history which justified what they believed in the present (rather than one which was faithful to the facts; or if it was faithful to the facts, it interpreted them in such a way as to comfort any contemporary view they might have held). This in turn, guided the topic of study (and resultant neglect of other topics), how they interpreted it, the sequences they made of it, the genealogies constructed, etc. Therefore, this historical examination will consider that the lack of specific facts in 
the history of early jazz acts as an indicator of the type of pathways the music traveled along. The discrepancies in the early literature of jazz are possible because the culture did not travel along mass-mediated channels, did not utilize mass media technologies of dissemination, nor employ critical and commercial interests to deploy itself. Rather, it was a culture of obscurity, sequestered away within specific, marginalized districts of a certain geographic location (New Orleans). It was created and participated in within a specific racial and socio-economic group. It was a culture performed in speakeasies, brothels, taverns, and other rougher centres of society. And it was a culture made and performed by part-time musicians, who had day jobs because they could not make a living strictly performing music.

The second part of this chapter will address the question of change. Using the pathways of Technology, Institutions, Critics, and Music Industry, we can explore the ways in which jazz began to reach different audiences, to be performed by different types of artists, and to adapt itself to a more mainstream process of transmission. The new media technologies of radio and records created a new pathway along which any type of music could travel in order to reach different audiences and venues. However, these technologies proved an extremely important pathway for jazz because they allowed it to be consumed away from its original socio-economic contexts of performance. Eventually, the music industry began to take an interest in the new music of jazz, and began to record, sell, codify, and otherwise exert its own interests upon jazz culture. And from the growing audience, critics and enthusiasts began to spring up, who began to write about and review jazz music in journals, periodicals and newspapers. In these ways, jazz changed from its origins as folk culture as it penetrated alternative pathways that allowed it to circulate 
beyond its local origins. Therefore; in contrast to standard histories of jazz, this chapter will examine the pathways which promoted and sustained jazz, not the creators or receivers of the cultural form.

\section{Jazz as Folk Culture}

As stated in the last chapter, folk culture is an organic, pre-industrial and pre-mass form of culture. Folk music circulates within localized pathways, that is to say in venues and before audiences which are geographically, and perhaps also socially, economically, or aesthetically limited. Folk cultures are characterized by non-professional artists and often emphasize a participatory role for the audience. Much of the material used in folk songs consists of borrowings/variations from traditional songs already known to everyone. Folk culture also has a relatively unsophisticated form - folk music is much less formally complicated than classical music, for example. This ties in neatly with its participatory nature, as formal unsophistication eliminates barriers to collective enthusiasm. Folk cultures are disparate and hard to track down because of their neglect of mainstream media and intellectual channels. They are hard to pinpoint and this is precisely because they come from the blending of a multitude of existing styles. Folk cultures are a blend of unacknowledged and unknown origins. However, folk cultures, when they can be identified, are often geographically distinct, concentrated in one specific location. Folk cultures of the modern era are often noted on the fringes of society, and as an object of study, are often associated with marginalized and impoverished classes and locations. All of these characteristics suggest that folk cultures operate primarily through specific and local pathways, and are unavailable to circulate in the modern mainstream media. And as 
we shall see, the beginnings of jazz music fulfill these criteria of folk culture very well. Now, in the case of jazz specifically, it is certainly worthwhile mentioning its social marginalization as an aspect of the general marginalization of black people in American society. But it is equally important to note that this is an attribute specific to jazz culture rather than an ontological feature of folk culture generally.

Given these characteristics of folk culture, it should come as no great surprise that the beginnings of jazz music are cloudy and filled with gaps, discrepancies, and uncertainties. It is difficult to know precisely the moment that jazz was first performed, or by what musician or group of musicians. There are many disputed characteristics of jazz music, but one that is undisputed is its undeniable link to African-Americans. This was the social group from which jazz emerged. As a result, in its folk phase, jazz shared many of the characteristics of this group. At the turn of the century, especially in New Orleans, music fulfilled a multitude of functions in the life of African-Americans: church, work, entertainment, and social events were all characterized by the sound of music. New Orleans also had a very strong tradition of instrumental marching bands, which played their own boisterous renditions of marches, ragtime, and hymns at picnics, dances, parades, and funerals. And New Orleans had many of them. ${ }^{\text {xcii }}$ The city was also famous as a city of vice, particularly the red-light district of Storeyville (created in 1897 to satisfy the desires of sailors at the nearby Naval Base). Storeyville had many brothels, cabarets, and speakeasies, which hired musicians to perform in them. ${ }^{\text {xciii }}$ Most of the people who lived in Storeyville were African-American, but there were many other Black ghettos and slums in New Orleans as well. Hence, jazz was born into a context which existed at some distance from the mainstream forms of elite and respectable culture. It had little direct 
contact to forms of culture outside of its immediate geographic setting. Additionally, in this early period, only a thin line separated artist from audience. With both amateur musicians and public displays of music everywhere, it was relatively easy to go from being a spectator to being a participant. Some musicians even went so far as to make their own instruments, further suggesting both the impoverished conditions, and the non-technical or non-specialist nature of the music. xciv $^{\text {. }}$

There are not many names widely celebrated as practitioners of jazz music from the early turn of the century, and this is because there was no commonly-defined form of jazz. For there to be stars of jazz, there must first be a form recognized as jazz of which it is conceivable that there might be stars. Playing music for most was a part-time occupation. Almost all jazz and popular musicians at the turn of the century had day jobs; from barbers to brick makers. And this was because they could not make a living entirely from playing music. $^{\text {xcv }}$ Furthermore, most of them would play whatever type of music was required they weren't specialists or purists as there was no 'pure' form of jazz to hold to. However, for all these definitive difficulties, Buddy Bolden (1877?-1931) is often called the first jazz musician. However, the title was bestowed upon him later, after his death, rather than during his lifetime. There are likely many other contenders for the title. Nonetheless, it was only 4 years after Bolden's death that jazz enthusiasts began to dig into his history as well as that of New Orleans jazz. Bolden was certainly well-known around New Orleans as a popular trumpet player and leader of various bands. And his elevation to the status of the "first jazzman to earn the title "King",xcvi is itself enlivened by the legends surrounding Bolden's life; the excesses of women and alcohol ("women once fought for the honor of carrying Buddy's cornet"xcvii), the legendary power of his sound (Jelly Roll Morton 
claimed you could hear Bolden's horn 12 miles away), and his spectacular public demise (Bolden went insane during a parade and was committed to an asylum). ${ }^{\text {xeviii }}$

However, the identification of a 'first' jazz musician, besides undermining the work of other musicians who may be equally deserving of the title and besides being assisted by an appropriately colourful backstory, is, in itself, less important than the impulse to construct a history. It is much more likely that around 1895 , a growing body of musicians in New Orleans began to play a new type of music, and that this new type of music was itself an amalgam of much that had gone before. This new type of music blended other musics both remembered and forgotten, but was adapted to new circumstances and sought new audiences and/uses. Our constructed historical tradition allows us now to look back, from the vantage point of the present, upon this music and to grant it a consistency and continuity which we call jazz. ${ }^{\text {xcix }}$ Other examples of uncertain origins abound in the early days of jazz, and it may be less important to claim a singular innovator or innovation than to recognize the collaborative efforts involved.

What jazz had in the early days was a scene; a ferment of local activity, a multiplicity of musical styles, and an openness to experimentation with borders and boundaries. There was no one particular club, party, band, or dance hall where jazz suddenly appeared. Rather, it was the blending of musical styles that resulted in the new music. Jazz brought together the traditions of European music with the influences of African-American and Creole culture. In fact, as a non-canonical form of music, jazz was naturally open to syncretic influences, but these influences and practices were primarily contained geographically within New Orleans. What has formally been codified as "jazz" appeared after blues and ragtime became popular, and the influence of these forms is also 
noted in the development of jazz. ${ }^{\mathrm{c}}$ There were also the popular songs of the day that musicians played, work songs, folk songs, quadrilles, marches, tunes from minstrel shows, religious hymns, and popular Tin Pan Alley melodies. ${ }^{\text {ci }}$ Much like any oral culture, where there is no great reliance upon a detailed system of notation, early jazz began to distort, syncopate, and alter popular music tunes of the day: early jazz practices were more adaptation than raw invention. ${ }^{\text {eii }}$ When this capacity for invention was mixed together with an inability/disregard for written notation and a practice of collective and melodic improvisation, the new cultural form of jazz was the result. ${ }^{\text {ciii }}$ Parenthetically, the failure to write down music tended to exclude jazz from the music industry of the day, which was organized around the sale of sheet music (and which will become an important fact later). Therefore, the new folk culture of jazz came about as the result of the blending of the popular cultural forms of the day.

Early jazz was also often incidental music, more of a way of life than a formal performance. Musicians were hired to play for new store openings, dances, weddings, funerals. Many of these gigs lasted long hours, and improvisation helped fill the time, fleshed out another repetition of a standard tune, and relieved boredom. As with many other types of popular music, music here was functional - it was music to do things by. It was background entertainment at saloons and stores. Bars would make sure there was music playing 24 hours a day. ${ }^{\text {civ }}$ This fits into a folk culture definition of music as part of everyday life, with no clear distinction between artist and audience.

The pathways upon which the new folk culture traveled must also be considered.

First, critics' involvement with early jazz is interesting to note, particularly because there was so very little of it. The beginnings of early jazz as played by brass bands within 
the city of New Orleans were well covered by the local press, but were given little critical appraisal. Most of the coverage was merely descriptive, informing people that there would be a parade or concert happening at a certain time. Attending jazz performances was a perfectly legitimate pastime for African American families. For example, the New Orleans Picayune cordially reported in 1881 that "At Spanish Fort next Sunday a musical concert will be given in the park from 2:30 until 6:00 PM by the Onward Brass Band. These concerts are free and are being liberally attended by the best families of the colored people of our city." It was not until jazz music began to gain in popularity and make inroads into the protected high culture of whites (during the 1917-1919 era) that critical reviews became more apparent. However, critical attention did not necessarily mean social acceptance; it would take some time before jazz was respectable. As a result, the editors of the Picayune actually ran an article in 1918 in an attempt to dissociate themselves from the claims that jazz music had begun in their city:

"In the matter of the jass, New Orleans is particularly interested, since it has been widely suggested that this particular form of musical vice had its birth in this city - that it came, in fact from doubtful surroundings in our slums. We do not recognize the honor of parenthood, but with such a story in circulation, it behooves us to be last to accept the atrocity in polite society, and where it has crept in we should make it a point of civic honor to suppress it. Its musical value is nil, and its possibilities of harm are great."cvi

This is very interesting when this type of press is juxtaposed with the factual descriptions contained in the New Orleans papers. This type of coverage indicates how the folk culture of jazz was seen as everyday, a pastime of the lower classes, and unworthy of critical attention.

Much like the factor of criticism, the factors of media dissemination and the music industry also treat jazz in its folk cultural phase with neglect. Aside from the publication 
in local papers of show times and band names, the early forms of jazz were of little interest to either the mass media or the popular music industry of the day, certainly not as a form to invest money into. Now it would be easy to suggest that this was because these Africaninfluenced practices were merely a local cultural form, confined to a specific geographic area and a low socio-economic class. This is simply incorrect. Indeed, at the elite cultural level, the influence of African musical traditions had spread far and wide, and many of the major classical composers of the early $20^{\text {th }}$ century utilized these techniques. A partial list of composers who incorporated African musical or rhythmic elements into their compositions includes Erik Satie, Igor Stravinsky, Darius Milhaud, Arthur Honegger, and Paul Hindemith. ${ }^{\text {cvii }}$ At the popular level, the music industry was aware of distinct AfricanAmerican traditions and practices. As Eric Hobsbawm has noted, the widespread adaptation of Black minstrelsy, the promotion of ragtime and blues music (as other African-American forms of music), and the transitory wanderings of many musicians made an experience of African-American musical influences commonplace around the United States. $^{\text {cviii }}$ Yet, curiously, jazz music remained un-promoted, for now. So it was not for lack of awareness that the African-American practice of jazz remained un-transmitted by the music industry in the early $20^{\text {th }}$ century. Consequently, it was another factor that enabled jazz to rise to national popularity.

To conclude that jazz was originally ignored by the music industry overlooks the key fact that the music industry in the early 1900s was constructed around a different format than jazz presented. The popular music industry around the turn of the century was focused on the printing and selling of sheet music. There were no record players, no radios, and therefore no ways of hearing music unless it was played or sung live. 
Industrial efficiencies had begun to produce cheap, reliable upright pianos, and from 1870 to 1910 , the average number of families with pianos in the United States rose from one in every 1,500 to one in every $250 .^{\text {cix }}$ Music was played in homes, churches, schoolrooms and meeting halls. Enterprising music publishers recognized that millions of Americans had pianos in their homes and began producing popular songs for voice and piano accompaniment. $^{\mathrm{cx}}$ Popular songs were made popular by their transmission through printed sheet music. And this was a pathway that jazz could not access. Jazz music was live, improvised, raw, unrehearsed, and otherwise very inhospitable to printed sheet music. Not only was the practice of improvisation and adaptation impossible to recreate on a printed sheet, but jazz music used a bevy of rhythms, techniques, half tones, and effects that were utterly impossible to reduce to a score. Jazz therefore was not able to become popular through the established channels of the popular music industry in 1900.

Evidence of this incongruity can be found in a quick examination of ragtime, another African-American-influenced music which became widely popular between 1890 and 1910. Ragtime was the first black music ever to achieve widespread popularity, and even more importantly, commercial distribution. ${ }^{\text {cxi }}$ The name denotes the sense of syncopated rhythm that formed the unique feel of the music, and stemmed from a simplified version of the more complex rhythms African-Americans would use in their folk songs. ${ }^{\text {cxii }}$ Both ragtime and blues were common African-American forms of music at the time, but it was ragtime that became a national craze. Scott Joplin's composition, The Maple Leaf Rag, sold over 100,000 copies when it was published in 1899. Ragtime was played by piano players all over the United States, and was even showcased at the World's

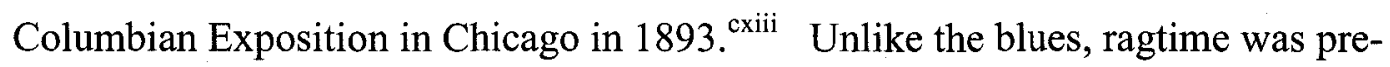


composed, arranged, and could therefore be rendered in standard musical notation.

Furthermore, ragtime did not contain any of the "blue" notes and vocal effects that were often employed by blues musicians; it was confined to the tempered scale. MeGill and Demory summarize it as follows: "Where the blues lent itself to individual interpretation and improvisation, ragtime was formally structured, and its composers intended that it be played exactly as written." ${ }^{\text {"cxiv }}$ Ragtime then was a blend of African rhythmic influences within a European scalar system, but more closely tied to the Western European musical tradition than the blues. ${ }^{\mathrm{cxv}}$ The fact that ragtime became much more popular than blues, and rose to popularity so quickly reveals how it was well suited for transmission along the main mass mediated pathway of the day. And it was the lack of such a sympathetic pathway that kept the more improvisational styles of African-American music out of the popular spotlight, at least for a while.

It was also the local practices and institutions of New Orleans that sanctioned the creation of jazz music as a folk culture. While I am not bold enough either to completely support or deny the claim that New Orleans was "the" birthplace of jazz, solely responsible for the creation of the art form, I do think that this presupposition offers some very interesting insights into the type of institutions that allow folk cultures to exist. As has already been pointed out, New Orleans was a mix of different socio-economic groups and ethnic cultures. It functioned as a major trading port for both upriver traffic and oceangoing traffic from other continents. As a result, there were many immigrant populations: Italians, Spaniards, French, and British. This also included the African-Americans who were living in the city, as well as the white populations. In particular, the AfricanAmericans made up almost $25 \%$ of the population of New Orleans. Because they were 
clustered in ghettos and separated from whites, they enjoyed a greater sense of autonomy than many Blacks living in the Southern United States at the time. But it also included a mix of French descendants (Creoles), who operated as a sort of in-between class, neither white nor black. ${ }^{\text {cxvi }}$ Each of these groups brought its own cultural and musical influences to the sounds of New Orleans.

Both Black and Creole minority groups had strong musical traditions, as demonstrated by the many brass bands and parades that regularly performed in New Orleans. The marching bands performed in many social functions, from weekly dances to Saturday night fish fries to funeral parades to parties. On Sundays, black residents of New Orleans would migrate to the shores of Lake Pontchartrain where they would be entertained by as many as 30 or 40 bands. Mondays and Wednesdays would feature lawn parties, much like the later private fund-raising rent parties of New York. ${ }^{\text {cxvii }}$ Music was everywhere. In fact, one prominent New Orleans musician, Jelly Roll Morton, claimed that there were from two to eight parades every Sunday. ${ }^{\text {exviii }}$ Many of the histories of jazz point to the fabled Storeyville vice district as the place where jazz first began. ${ }^{\text {cxix }}$ And while the brothels and speakeasies in the ghetto would have hired musicians who would have also filled out the ranks of the brass bands, the music that became known as jazz was not only performed in these places. Certainly, the club setting may have encouraged the use of different instrumentation better suited to small environments than parades, but that instrumentation was itself carried over into other venues. Indeed, parade bands celebrated their use of improvisation and adaptation of arrangements, and the necessity of playing without written music encouraged this practice. ${ }^{\mathrm{cxx}}$ 
However, I do find it interesting to point out that New Orleans was not alone in its mixing of cultures nor in the prevalence of African-American traits in its folk music. The growth of the Mississippi-style Delta Blues occurred in a different state than Louisiana, as did the earlier craze of Ragtime (which was centered around St. Louis). ${ }^{\text {cxi }}$ Both these musics also featured the blending of African and European influences. Therefore, it seems that the ability to blend cultures is a key distinction for the creation of new folk musics, but not a characteristic unique to the birth of jazz in New Orleans. Neither is the clustering around urban centres. While it is tempting to say that new folk cultures spring forth from the mixing of cultures in close-proximity urban environs, this would ignore the development of rural folk cultures, such as the barrelhouse piano style of popular music (which developed in black lumber camps). Other rural folk cultures also exist, from the development of country blues to the East Coast Celtic music.

To adopt Diana Crane's terminology, the cultural scene in New Orleans was a lower-class network-oriented culture world. This means that the culture of jazz that was created did not structure itself either around profit-orientations or around formal structure. ${ }^{\text {cxii }}$ Jazz as a folk culture did not structure itself into a firm producer-consumer relationship but acted more as a lifestyle. While the bands still performed for money, it was not as financially-straightforward a relationship as opera or symphonic music. As well, the jazz scene in New Orleans did not seek out formal organization. Jazz bands did not set up legal or organizational structures, relying instead on the support of audiences. They operated on loose affiliations of single musicians, freely changing groups, performance venues, and styles of performance. 
So after all this discussion, it may prove of assistance to understand whether this culture of jazz fulfills all the criteria of a folk culture. First, jazz music in the early 1900s was not performed by professionally schooled musicians. Most of the musicians had other sources of employment. Second, jazz music was characterized by a lack of media transmission; its non-written nature was not conducive to transmission along the pathways of the time. Third, there was not a lot of critical speculation about jazz. What coverage there was in the news media of the time was factual rather than aesthetic. Fourth, the culture of jazz took place within a specific geographic area; it was a local scene which blended elements of existing cultures into a new form and unique practices. To back all of this up, our established histories of jazz find many gaps in the early story of jazz. This is perfectly in line with a culture that did not transmit itself easily along established mainstream pathways, and so many of the earliest artists are unknown and details are sketchy. Therefore, the early structures and scenes of jazz music fit the definition of folk culture well. Jazz was a folk culture at the turn of the $20^{\text {th }}$ century. But this was about to change.

\section{The First Cultural Transformation}

From the folk culture that it was in the early 1900 s, jazz was to change dramatically in meaning, practice, scope, form, and audience by the 1920s. Primarily, this was realized in a dramatic broadening in scope of artists and audiences, and a re-definition in terms of artistic product. Jazz went from being a local scene to a national one; with artists, audiences, and music covering the entirety of North American, and even reaching into Europe. To give an idea of the general time frame, the expansion of jazz began in 1917 
and reached the heights of its popularity by the late 1920 s/1930s. I have previously laid out the pathways along which jazz traveled in its folk phase. Now, an examination of the changes in the existing pathways, and the development of new pathways, will demonstrate how these changes prompted a transformation in the valuation and popularity of jazz music. We must therefore turn to examine the four contributing factors to understand this. As regards Media Technology, two new pathways opened up the possibility for jazz to transform itself. I have shown previously the barriers that confronted early jazz music due to its failure to conform to the standards of musical notation. However, the invention and rapid social diffusion of recording technologies and radio broadcasting created a new type of pathway for the transmission of music to new audiences, which in turn opened up the possibility of more widespread dissemination for the music of jazz.

Though the technology of sound recording that would permit sound recording was invented in 1877 , disputes over a common technological format reigned for a number of years, and it was not until 1906 that the Victrola appeared. ${ }^{\text {cxxiii }}$ The Victrola provided a common format (the recording disk) and launched the popularity of recordings for the home. Interestingly, jazz music did not emerge on recording for home consumption until the very late 1910s. The first jazz recording to become a legitimate hit occurred in 1917. ${ }^{\text {cxiv }}$ Nonetheless, it is interesting to consider the nature of this delay. If Victrolas were first marketed in 1906, then only 11 years separated the market introduction of the new technology from the first recording of jazz, a socially-marginalized music. Given the relative expense of the new technology, Victrolas were probably purchased first by the category of listener least likely to seek exposure to jazz. This, in combination with the existing inertia of the music industry - naturally, they would have recorded the hits of the 
day first - seems to account for the time lag. Laing (1991) furthermore suggests that the concentration of the existing popular music industry upon the format of sheet music explains the slow growth of genre selection in the sound recording business. Sheet music was a $\$ 4$ million a year industry by 1900 (over 10 million units), and the mechanisms of Tin Pan Alley firmly invested the industry in this format. ${ }^{\mathrm{cxxv}}$ However, the lag between technological emergence and national popularity mitigates the importance of new technology as the sole contributing factor in the national exposure of jazz, and suggests other factors played a role as well.

Regardless of the time frame, it is hard to overstate the importance of this technological development for the culture of jazz. Jazz development in most areas of the United States can be linked to the availability and diversity of jazz recordings. ${ }^{\text {cxxvi }}$ Recordings finally make it possible to review the jazz players, works, and styles of the past. It must be noted, however, that recordings also possess certain 'shortcomings' which themselves exert an influence upon jazz performance. This purely technological influence is quite separate from the pressures emanating from the commercial music industry or from the artistry of the performers. For example, until the technology improved in 1927, recording microphones were unable to pick up very high and low frequencies or soft volumes. These limitations made it very difficult to record the low sounds of drum sets or string basses. As well, the soft sounds of guitars were not picked up, and so, guitars were often switched for the more percussive banjo, while tubas were exchanged for basses. Additionally, the size and speed of the record players limited a performance to only three and a half minutes (which was one side of a record). And this in turn set a specific constraint on the length of a song, usually only two or three choruses of a 32-bar song. ${ }^{\text {cxxvii }}$ 
Additionally, the fact that recording technologies faithfully reproduced the sound of a performer was a disservice to some musicians. Artists such as Freddie Keppard refused to record because they were afraid that some other musician would usurp their personal style. cxxviii Consequently, their influence and impact upon the world of jazz are only given a partial picture, because we have no other means of accessing their art. Jed Rasula articulates the problem of recordings in asking whether they are an acoustical conduit through which we can understand the past, or an obstacle to overcome in understanding the past. $^{\text {cxxix }}$ This pathway reaches across time, as well as to different populations in its own time.

Yet despite any negative limitations, the recording technology did allow for the separation of time and space. This permitted a much wider dissemination of the cultural object - one no longer had to be a resident of New Orleans to hear jazz. Beyond geographical limitations, it also separated jazz music from the physical venues where it was originally performed. People who would never go to a seedy bar or mingle with black people to hear jazz music could still access the cultural form in the safety and comfort of their living rooms. This technology therefore allowed for distance between the performers and the audience, giving the audience more control over the performance (audiences could decide volume, as well as turning the music off if it displeased them at any time). And this separation also resulted in the eventual dissolution of some of the anxieties surrounding the art form's close proximity to vice-laden venues. Perhaps equally importantly, the technology of sound recording allowed the music of jazz to be captured and reproduced in an aural form. Records could capture the sound and spirit of jazz (including all of its unnotatable effects and techniques) in a way that sheet music never could have. 
The new technology of radio also had many of the same effects upon the audience of jazz. Invented in 1901 by Marconi, radio did not really reach critical mass until after World War I, when national radio networks began to set up across the continent. ${ }^{\text {cxxx }}$ National networks in the United States began in the late 1920 s, creating both profits for jazz bands, and national prestige. Local stations and national networks had airtime to fill, and took up the practice of broadcasting live from jazz concerts in hotel ballrooms and nightclubs. Again, as with recording technology, Hennessey (amongst other authors) places the influence of radio technology on the jazz music scene later (1929-1935) than the original uptake of the technology by the general public (1922). This is indicative of some of the impacts the technology would have on the practice of jazz. Radio broadcasting was live, and it reached an audience which was by definition 'massive' or non-select. With few national networks to chose from, the audience for radio was very diverse, and networks had to be careful not to broadcast material that would have been considered offensive. As a result, jazz music was not broadcast in the early 1920s, when it was first breaking into the mainstream market. Rather, it was only broadcast after most of society had decided it did not represent the same threat to social cohesion and impressionable youth that it once had seemed to. ${ }^{\text {cxxi }}$ For example, Marshall Stearns points out that by 1927 - by which time he considers the jazz age to be 'finished' - jazz had effectively penetrated all of the United States and the exciting practices of 'hot' black jazz bands were being adapted and covered by white bands. This illustrates the fact that jazz ceased to be perceived as a threatening form thereby paving the way to its diffusion via radio. ${ }^{\text {cxxii }}$ Furthermore, the national range of broadcasts began to set a standard for the sound and style of jazz, what "good jazz" sounded like. While creating a widespread demand for the music, national distribution of 
certain select names and sounds also encouraged a select type of jazz, one that was less improvisatory and more controlled. As we shall see in a later section, the local scenes where jazz had flourished began to sound much more alike. ${ }^{\text {cxxiii }}$ Some scholars have labeled the tendency for popular musics to sound similar as an expression of the corrupting influences of commercialism. However, this should not be viewed as corruption, but rather a natural result of the 'professionalization' of a genre. When jazz functioned as a series of folk musics without any common standard or regional exposure, it was consequently very diverse. However, with national diffusion comes a sense not just of the local style (which artists would have access to), but the very best that the world has to offer. The broadcasting of jazz music had the effect of creating a sound, a benchmark for jazz artists in local venues to subscribe to.

Therefore, the new media of radio and recording had a number of impacts upon the course of jazz music. It allowed for the separation of time and place, of performance and performer, of performer and audience, allowing for the dissociation of jazz music from its original class and context. It encouraged the creation of a professionalized, national sound. It also grew an audience across the country, which enabled musicians to establish greater names for themselves, and allowed them to sustain national or regional tours. And, of course, both technologies also introduced the idea of gatekeepers into the process of jazz transmission, which will be dealt with in the next section.

The popular Music Industry also dramatically influenced the transformation of jazz music as it entered mainstream culture. Unlike its reduced role in the life of folk cultures, the music industry plays a huge role in the development of jazz in the $1920 \mathrm{~s}, 30 \mathrm{~s}$, and $40 \mathrm{~s}$. It inserts its own set of influences and priorities into the cultural pathways and these values 
are reflected in the cultural products and practices created. The processes involved in the manufacturing and distribution of records are expensive and require a whole system of production and financial backing. However, with this financial investment comes the introduction of a profit motive - corporations would not be willing to commit money to a recording if they did not think they could make money on it. Therefore, the decisions over who and what to record become mixed with considerations of profit. ${ }^{\text {cxxiv }}$ Indeed, the same separation of artist and audience enabled by the record and radio now required the insertion of a middleman or gatekeeper to reconnect a sound performance removed from its time and space with a potential audience equally removed from the performance. The music industry is this gatekeeper; it re-connects audiences and artists.

This should not be construed to imply that commercial influences are unknown within folk cultures. This is a popular view, especially with Marxist historians, who often romanticize the folk culture as a time when artists made art purely for self-satisfaction, away from the corrupting evils of commerce. However, jazz has always been entangled with profit motivations. It has never realized the Rousseauean ideal of the Noble Savage, a time when musicians was performed strictly for pleasure without hint of economics. Jazz musicians always played for money; it was a job, earned some money, and maybe some hope to one whose occupational mobility was limited. ${ }^{c x x x v}$ The innovation which I wish to underscore is the emergence of the 'gatekeeper,' of a mediating body or process which reconnects artists and audiences and which becomes necessary as a result of the types of separations between performer and performance, performance and venue, and venue and audience enabled by the new technological pathways which become jazz's privileged means of social diffusion. 
The pathway of the music industry affected jazz music in two ways. First, the industry was accustomed to certain types of music and images. It is important, but should not be surprising that the first group to become commercially successful playing the new music of "jazz" was a group of white musicians. In 1917, the Original Dixieland Jazz Band (ODJB) in New York was the first group to record jazz music, achieving widespread popular recognition for the cultural form. Their first "out and out" jazz recordings sold in the millions for the Victor label, garnered newspaper headlines from coast to coast, and made the word "jazz" a piece of household vocabulary in a matter of weeks. Over the years, their work (in particular the Livery Stable Blues) has been seen as less-representative of the "true" jazz music of the time, and as a novelty act based on effects. ${ }^{\text {cxxxvi }}$ (The song uses instruments to imitate barnyard animals). The fact that they were white goes a long way in explaining why they were recorded instead of some black jazz band from New Orleans. Primarily because of their skin colour, the ODJB were able to successfully negotiate the pathways of the music industry by offering a product and an image that was in line with the industry's habits. This bias towards white performers continued for years. Benny Goodman's breakthrough popularity in 1935 when jazz bands fronted by black leaders had already been playing the same thing for upwards of 7 years suggests the continuation of this bias.

Second, the music industry encouraged the formalization of one dominant style and model of jazz music. The fact that jazz now reached audiences via radio and recordings resulted in a more standardized sound. This was an adaptation of the "hot" black jazz music into a more controlled, arranged "sweet" style. Whereas hot jazz retained the collective, disruptive, improvisatory style of New Orleans, sweet jazz was written down 
and reproduced at a much hushed volume level with less rhythm. Early jazz hits like the ODJB or the Mound City Blue Blowers (1924) were given great distribution by the industry, but as novelty records. The Blue Blowers played many high society clubs, toured Europe, and generally 'became the darlings of society people who didn't know one tune from another but were thrilled by those 'freak instruments.",cxxxvii But in 1924, other black artists such as King Oliver, Fletcher Henderson, Bennie Moten, and others were playing a distinct form of hot jazz and making records, but to much less popular success. The number of prosperous dance bands multiplied, but the amount of hot jazz played by these bands was not considerable. Most bands would employ one or two "get-off' soloists who could improvise, but the rest of the band could not swing and would merely play the arrangements. Paul Whiteman hired Bix Beiderbecke for exactly this reason in 1927; Bix could swing but the band could not. Fletcher Henderson's Orchestra is another example of how a band sought to negotiate the racial and stylistic biases of the music industry. Henderson's arranger, Don Redman, found a formula that would please both dancers, musicians, and music managers by blending the written harmonies of European classical music with the African-American improvisational tradition, underscored by a danceable beat. Redman infused the standard voicings of jazz tunes with the rhythm and exuberance of the New Orleans-style black bands, and allowed a soloist to improvise over top of the melodies. ${ }^{\text {cxxxviii }}$ With the addition of incredible soloists Louis Armstrong on trumpet and Coleman Hawkins on saxophone, the Orchestra was rewarded with success in New York City in the 1920s, playing the Roseland, Alabam, and Manhattan clubs. ${ }^{\text {cxxxix }}$ Many white bands borrowed from Henderson's model of arrangement and composition. And the result of all this was the development of a more uniform sound standard for jazz. By 1926, Doc 
Cheatham, arriving from Chicago noted that: "New York had its own style of music. It was more sophisticated. They had bandstands, music stands, and books all full of stock arrangements."cxl Radio broadcasts of New York jazz bands helped solidify this model of sound and New York was privileged because the radio networks were all headquartered there. In fact, the industry in the early 1930 s became much more centrally organized, and included a much greater concentration on the booking of musicians. This allowed the industry a much greater degree of control over who and what types of bands worked than the previous industrial structure allowed. This new approach to the industry also brought jazz into greater conformity with the established conventions of Tin Pan Alley and dance orchestras, and in turn, gave rise to the "sweet" sound of jazz.

Contrary to their minor role in a folk culture, critics and the criticism they leveled at jazz music helped shape and direct it during the 1920s and 1930s. Although there are always two sides to every argument, much of the early critical responses to jazz were extremely negative. Critics of jazz in the 1920 s stuck to the established traditions of classical music and opera, and understood jazz as corrupting of moral virtues, or at the very least, as a negative influence on artists' technique and musical values. Criticisms flew with eloquence and imagery. Theodor Adorno, for example, saw in those who listened and danced to jazz some "convulsive aspects reminiscent of St. Vitus' dance or the reflexes of mutilated animals." "xli Equally condemnatory is an article published in the Ladies Home Journal in 1921, titled: "Does Jazz put the Sin in Syncopation?" which suggested that jazz music had evil effects and encouraged loose living, indecency, and savage instincts. Some traditional critics equated the music with alcoholism, while others, such as Francis Toye, a writer for the New England Review went so far as to claim that syncopation caused 
permanent brain damage, and cited "scientific evidence" in support of her point. This music would "stagnate the brain cells and wreck the nervous system.",cxlii These criticisms were launched by two groups of opponents. One included people who were economically dependent upon or ideologically committed to traditional classical music. This included music critics, music teachers, dance teachers, classical musicians, and patrons of the high arts. $^{\text {cxliii }}$ The second group was composed of the traditional guardians of morals and manners: clergymen, educators, community leaders, and various politicians, businessmen and doctors. ${ }^{\text {cxliv }}$ Most of the reactions against jazz associated the music with either the black culture that gave it birth, or the vice-related venues where it was originally performed. In the process, they sought to show that jazz was inextricably linked with various undesirable social practices. This included drinking, wanton sexual behavior, crime, vice, racial miscegenation, and a general moral degradation of youth and society. Some of these connections would have been easier to make than others, as the venues and neighborhoods where jazz was originally performed were also the same places where many of these illicit activities took place.

Of course, not all critical response to jazz in the 1920 s was negative. For those who defended jazz, like the journalist Gilbert Seldes, jazz was the "expected, wonderful arrival of America at a point of creative intensity." "xxlv Jazz was the first truly "American" music, an art form in its own right, and a music that expressed the energy of a new country. This patriotic motif was very common in many defenses of early jazz. Significantly though, the defenders were not pointing to the hot jazz of black musicians as examples of good music but rather to the highly successful, and highly symphonic, jazz music of Paul Whiteman or Vincent Lopez. It seemed to them that this direction more closely embodied 
"art" (as opposed to vernacular gimmickry). Therefore, while they defended jazz, their defense looked to traditional Euro-centric models of art approval. It should be also noted that while many of the most critical reviews appeared in conservative journals (such as the Ladies Home Journal), the mainstream press such as the New York Times were generally favorable in their coverage of jazz music, as were literary magazines such as the Literary Digest and Music Trade Review. Newspapers have never been in the habit of attacking events that their readers enjoy. ${ }^{\text {cxlvi }}$

It is worth unpacking these negative responses to jazz, especially since jazz seems to have continued to become part of the American nightlife despite hostile reactions. For the most part, this can be distinguished between the levels from which the reactions emerged. Most bastions of elite culture and polite society denigrated the music of jazz during the 1920s. This would include radio networks, who, not wanting to take a risk of offending their clientele, erred (if you'll pardon the pun) on the side of caution. For example, NBC's musical director in the 1930s, Frank Black consciously kept dance bands and jazz music out of primetime slots because he believed they were not refined or wholesome enough. However, at the level of popular society, jazz enjoyed a continued popularity and moved within the ethos of the cityscape. Movies were filled with images of jazz, and cabarets and nightclubs became an acceptable part of civic nightlife. ${ }^{\text {cxlvii }}$ During the Depression, the free-spending attitudes that characterized the 1920s evaporated, negatively affecting the nightclub scene, and the hot jazz performed in them. Popular music and the radio networks were overcome by crooners, and the jazz that was played was a heavily arranged style of jazz or sweet jazz; music that was designed to soothe or provide escape. When they could, hot jazz bands escaped to Europe, but in America, it 
was the sweet, white dance bands that dominated the airwaves. ${ }^{\text {cxlviii }}$ Yet in 1935, the "swing era" hit the nation, popularized by the sounds of Benny Goodman's band, and ushered in a new demand for big bands and jazz players. Not surprisingly, it was a white band that led the charge. This is not to neglect the black bands that were operating at the time but to point out that although hot jazz stars such as Louis Armstrong continued to play and record throughout $1929-1935$, it was not until a white band copied their style that they were rewarded with success. Again, the biases of the pathways allow for certain representations of culture to be transmitted while neglecting others.

This new swing craze met with much less critical resistance than the earlier jazz craze of the 1920s. As Neil Leonard argues, this change in perception was the result of a process of assimilation and acceptance, wherein professional musicians and the music industry succeeded in cultivating jazz into a less-threatening cultural expression. ${ }^{\text {cxlix }}$ If there were two sides to a critical debate, it was over the issue of hot versus sweet jazz. The new music market and the Great Depression had led to a shift to a more arranged, smoother, "sweet" jazz which often featured crooners such as the bands of Hoagy Carmichael or Guy Lombardo. Whereas hot jazz featured a cacophony of noise, blaring multi-instrumental soloing, sweet bands used stock arrangements, less improvisation, and less rhythm. Dubbed "mickey-mouse bands" by jazzmen, the dance music they turned out was melodious and did not interfere with the conversations of their patrons. ${ }^{\mathrm{cl}}$ And while swing music was not "hot" jazz, it was able to incorporate more of the rhythmic enthusiasm of hot jazz, and was much more exciting to listen to. Hence, while still not as loud or exciting as hot jazz, swing bands were viewed as a return to a more "authentic," more emotional sound of jazz, a strike against the polished sweet jazz bands. Swing bands 
were much more exciting to listen and dance to, and, while still subscribing to written arrangements, they struck a balance that was much closer to the original sounds of hot jazz.

So where was the battle ground for all of this sweet versus hot rhetoric? While some of it occurred in the mainstream press, by the 1930 s, specialty magazines were developing for jazz. Prior to 1934 , most jazz criticism in the United States was journalistic, but general opinion magazines would occasionally run longer interest pieces. The Swing Era changed this, inaugurating an American jazz press. The two best known magazines were Metronome and Down Beat. Metronome had a history of covering classical music, but was transformed into a swing magazine in 1935. Down Beat began in 1934, adopting a more risqué slant. But both publications had a large section of record reviews, and both used slang-filled headlines, argumentative columnists, and a large letters department. Both publications adopted a populist cultural attitude, feeling that jazz was a music of the people and represented a great benefit to the country. ${ }^{\text {cli }}$ In so doing, they created a scene for enthusiasts of jazz to encourage each other and begin to invent the language and standards of jazz criticism. This development of specialty journals was to pave the way for a new group of jazz enthusiasts, to set the stage for the development of critical jazz culture. The development of specialty journals created a forum, a space that enabled and encouraged the serious discussion of jazz music. While specialty jazz magazines were not read by a large contingent of the population and were not a pathway for the general public to access jazz, they nonetheless played an important role in organizing the legitimizing forces of jazz, a development that hadn't occurred with the earlier craze. 
Finally, there were significant changes in the types and places of venues where jazz was performed during the years between 1915 and 1935. These changes developed on at least two levels. As far as geography goes, the period between 1914 and 1920 was one of tumultuous activity in the Southern United States. More than half a million black Americans moved from the rural South to the Northern United States in the hopes of finding employment in urban centres. ${ }^{\text {clii }}$ This migration was concentrated in three distinct movements: one from the Carolinas, Georgia, and Florida up the eastern seaboard to New York, Boston, and Washington; a second from the Deep South to the Midwest (Cleveland, St. Louis, and particularly, Chicago), and a third from the Southwest (Texas, Arkansas) to Kansas City. Black neighborhoods in these areas (Harlem in New York, Southside in Chicago) skyrocketed, but still left most in impoverished living conditions. However, the move of so many African-Americans also brought the influences of their music and culture. This is significant, because the three cities (New York, Chicago, and Kansas City) each developed their own unique style of jazz music. Hennessey is able to base his analysis of early jazz by dividing the country into six distinct territories, each with its own sound, influences, and star bands. ${ }^{\text {cliii }}$ The significance here is to show that without the standardizing influences of radio and recordings, the national jazz scene was fragmented into different spheres. Jazz could not develop a national sound until the industry developed.

On a second level, within a city, the venues where jazz itself was played also changed, allowing a less-dodgy association for the music. While jazz may have been played in parades, outdoor parks, and other less-threatening venues (as well as saloons and bars) in its early days in New Orleans, in these Northern cities, none of these practices 
existed. Therefore, jazz developed in a bit of a different environment; different in the first sense because it was now primarily performed for a fee inside commercial clubs and venues. Yet it is very interesting to note how certain developments in New York both encouraged the development of a distinct style, and encouraged the spread of jazz music within the city and throughout the country. The most important aspect was that jazz musicians of both races had access to a more lucrative white audience in New York. ${ }^{\text {cliv }}$ This was enabled by the development of Broadway shows and cabaret culture. Ballrooms operated in both Black and White districts, and offered longer-term gigs, which kept bands together and facilitated greater artistic development. Cabarets also offered more freedom for bands, who could vary the tempos of their pieces with much greater control than in a dance gig (where all the pieces would have to be in the same range). Additionally, the new urban culture of the Roaring 20s celebrated what would have previously been considered vice. People flocked to cabarets such as the Cotton Club, 400 Club, or the New York Roof, which stayed open as late as $4 \mathrm{AM}$, and required entertainment. ${ }^{\text {clv }}$ Furthermore, the company headquarters for all the major recording labels was in New York, which meant that the New York bands were well recorded and had a larger national name. The effect of all these factors was an increased penetration of jazz to all areas of the population, especially the white audience. The jazz scene in New York took off in the 1920s; New York became the home of the national bands, and set the standard for what jazz should sound like.

These characteristics become more pronounced when the scene in New York is compared to the scene in Chicago during the same years of 1923-1929. In contrast to New York, bands in Chicago would very infrequently play for upper and middle class clienteles. 
Instead, bands would play for white working class audiences in ballrooms, the black community in the vaudeville theatres, and for a mixture of blacks and whites in the underworld cabarets. The upper class clientele were played by white dance bands, which meant little exposure to jazz. This meant more restricted job opportunities for jazz musicians, as they were primarily confined to black-only gigs. Furthermore, the vast majority of cabarets in Chicago were run by the Mob, and so, retained the association with vice and violence. ${ }^{\text {clvi }}$ As a result, jazz in Chicago remained primarily a music of the lower classes, and did not enjoy the widespread popular scene of New York. The contrast between the two cities demonstrates how a shift in venue can alter the popular success of a music.

\section{Conclusions}

This chapter has shown both the existence of jazz as a folk culture around the turn of the century and the fundamental ways in which it changed over the next thirty years. The changes in popularity, audience demographics, and geography happened as a result of changes in the pathways along which jazz traveled. Jazz began the century as a local and isolated phenomenon, and by the 1920 s, it enjoyed national attention. It began with little interaction with the commercial music industry, but in the 1920s, developed and capitalized on a new relationship with industry. This relationship brought about national exposure through radio broadcasts and record distribution. These new technologies also reinforced the popularity of jazz, because of their ability to separate performer from performance, performance from venue, and venue from audience. Jazz's upbringing and association with the lower classes and lascivious venues proved a detriment to the 
popularity and respectability of the music. Its new relationship with the industry and media technologies helped elevate jazz beyond this condescension. The newfound popularity of jazz music in the 1920s and 1930s gave rise to a number of specialty journals about the music and its culture. These journals also assisted to instill a better-perceived moral character in jazz, but more importantly, they began to refine and hone a language and standard of criticism for the burgeoning art form. The new pathways explored by jazz in the 1920s and 30s transformed the artists, audiences, and even the cultural product itself. The commercial success of jazz bands and jazz musicians enticed more performers, and jazz became performed by professional musicians instead of amateurs. This in turn elevated the technical standards of the music and the complexity of the musical arrangements. All told, the development of new, alternative pathways allowed for jazz to expand, grow, and redefine itself as something different from the folk culture of its origins. The next chapter will seek to explain exactly what this new form of jazz music was. As the Beiderbecke quotation about jazz's uncertain direction implied, jazz was on the beginning of a long journey. 


\section{Chapter 4: From Mass to Elite}

"For ambitious youth my advice is: Sell out if you can, since if you can, you don't have anything of value and you might as well cash in on it."

- Dwight MacDonald

By the 1930s, some claimed that jazz had 'sold out.' That is to say that it had ceased to be an authentic folk music and had become nothing more than commercial music, virtually indistinguishable from any other type of commercial music available at the time. The reason for thinking this was simple: the hot jazz of New Orleans - which had been the dominant form of jazz since about 1910 - had been replaced in the 1930s by, first, sweet jazz, and then, by swing. Both of these (sweet and swing) were performed not merely by black jazz musicians but frequently, and most successfully, by white jazz musicians who catered to a largely white, middle class audience. This was especially obvious with the rise of Benny Goodman and 'swing' music as of 1935. Swing music was a type of jazz arranged for orchestra and intended purely for dancing. It rapidly became the dominant form of jazz music as well as the very definition of popular culture and rose to enormous fame and success. Young Americans flocked to dance to the sounds of orchestras such as Goodman, Count Basie, Glenn Miller, Stan Kenton, and Duke Ellington. Eventually, though, even the tremendous popularity of swing music declined and its place in the jazz pantheon was disputed by a new type of jazz music, bebop. The rise of bebop, as of about 1945, however, brought a long festering controversy into sharper view. Indeed, as early as the 1930s, those who felt that swing was a 'sell-out' had maintained that hot jazz was the only authentic form of jazz and that the music should return to its roots in order to develop them. Bebop, however (which also positioned itself against swing), 
nonetheless rejected hot jazz as well. Hence, three streams of jazz contended with one another over the claim to represent true or authentic jazz: New Orleans hot jazz which had been dominant from approximately 1910 to 1930 , swing which had been dominant from approximately 1930 to 1945 , and bebop which became dominant after 1945 until about 1960. The proponents of hot jazz called swing a 'sell-out,' the proponents of bebop called the proponents of hot jazz 'moldy figs,' the proponents of swing considered bebop unpopular and undanceable, and few could agree on what type of jazz represented the authentic soul of the music or the direction along which it should develop. Indeed, contrary to the overarching narrative presented by many jazz histories, in the wake of bebop, the disputed terrain of jazz was to fragment further.

This chapter will focus on this process; the evolution and self-conscious development of jazz music, and how the new style and practitioners of bebop chose to align themselves intellectually with pathways consciously separate from previous practices. We will examine the same factors as in previous chapters: critics, media technologies, the music industry, and institutions/venues/geographies/practices, and how the selection within these factors influenced the participating audience, artists, and the cultural product itself. The chapter will be divided into two sections. The first section will detail how jazz functioned as a form of popular culture and the pathways along which it was disseminated. The second section will examine how these pathways changed, creating a different conception of participation, a different type of popularity, and a different audience. The examination of these pathways will show why jazz changed in popularity during the 1940 s from popular culture to something more elite. 


\section{Jazz as Popular Culture}

Popular culture has several distinguishing traits. First and foremost is the fact that it assumes an industrial form. Popular culture is an industry dependent upon large and satisfied audiences in order to ensure its continued operation. Consequently, it is overwhelmingly concerned with popularity, which is to say with its commercial success. For popular culture, the audience, its preferences and its vagaries (to the extent that these can be captured in an industrial form permitting regularized contact) are paramount. Concern with the audience is concern with commercial success and concern with commercial success is concern with the audience. This is not to say that folk or elite cultures are untouched by commercial factors, but within popular culture, industrial considerations are inseparable from the cultural form. Additionally, the industry acts as a gate-keeper, disqualifying some performances and performers but also, crucially, linking others to audiences. In so doing, the industry seeks to maximize its profit-generating potential by consistently selecting for the most commercial (i.e. the most popular) performers and performances with the best chances of longevity and mass appeal. An important index of the industry's success in this regard is its ability to sell as many recordings (or cultural products) as possible and this drives it to design and market products that will appeal to as wide an audience as possible. In an effort to achieve that goal, the industry uses all and every media form available in order to disseminate its product, from specialized channels to mainstream publications and promotions. As mentioned, the audience for popular culture is large and covers as many segments of society as possible. Ideally, a popular audience will transcend class, race, age, and whatever other barriers are considered relevant at a given time. Needless to say, however, 
the audience of popular culture is not 'particularized' in the sense of catering to the individual desires of individual members but is a 'mass' audience catering to a roughly average taste of all members in general. The temptation is, of course, great to denigrate such an audience and to remark that the industry which caters to it merely caters to "the lowest common denominator." While such an outcome is, of course, entirely possible, to leave the analysis of popular culture at that point seriously underestimates the extent to which even popular audiences acquire sophistication, use their familiarity with forms both for reassurance and renewal, drive innovation on the part of creators, undergo generational shifts and transformations, etc.

The cultural form which appeals to a mass audience frequently begins as an expression rooted in a particular geographic/philosophical/socio-economic position and appeals to a quite small audience. However, once it is transformed into popular culture, the form can become a marker of cultural identity recognized and adopted by many different types of people. In keeping with this sense of scope, popular culture events usually occur in larger venues because of their ability - indeed, their specific intention - to draw larger crowds and generate larger revenues. Yet, as regards music specifically, the venues in question also tend to induce performance practices based more on showmanship than on musical craft. For example, costumes, lighting, gesture, advance publicity, and skillfully placed newspaper interviews, may count as much as musical ability. Maintaining and selling the popularity of the cultural form is of primary importance. When these traits are constituted together, the form in question will function as popular culture. As we shall see, jazz music in the 1930 s fulfilled these criteria. 
The recorded music industry played a key role in the 1930s in spreading and marketing jazz to a mainstream audience. This is significant because, at the end of the $1920 \mathrm{~s}$, the recording industry looked like it was about to collapse. This was due to the rise of radio. Indeed, 1928 saw a considerable rise in radio consumption and a corresponding decline in record sales. Furthermore, the financial collapse of 1929 further dampened sales of recorded music. Of the 70 to 80 recording labels active in 1925 , only four were left in 1931. However, recording sales rebounded in the 1930s as the result of the creation of jazz band superstars. ${ }^{\text {clvii }}$ Importantly, the rise of jazz superstars coincided with the repeal of Prohibition in 1933 which once again allowed hotels, nightclubs, and public dance halls to host drinking and dancing legally. Working in synergy, national radio broadcasters would pipe hotel music to their audiences who would then flock to dance halls to hear their radio favorites live, whenever the bands toured. Broadcasters could then sell the band music to sponsors who wanted to associate their products with the "name bands." Hotel jazz bands provided content to radio broadcasters who further popularized the jazz bands who became name brands attractive to advertisers who supported the broadcasters who relayed the hotel jazz bands. Clearly, there was money to be made in jazz music. And this level of promotion had great effects upon the jazz bands. "The combined efforts of the national broadcasters, the hotel industry with its allied service industries, the recording industry, the advertising business, and the entertainment industries in general made band leaders as well known as major-league baseball players and Hollywood movie stars." ${ }^{\text {"clviii }}$ Millions of dollars in radio equipment sales created a natural market for the musical content industry which therefore became increasingly lucrative throughout the 1930s. Indeed, the recording and broadcasting industry strove to increase 
its role in all aspects of music production, and began to intertwine itself within the matrix of technology and artistic production. ${ }^{\text {clix }}$ Popular music was completely enveloped by the music business. The fact that it was commercial not only freed jazz from its folk roots but also subjected it to new types of constraints (as we shall explore below). Peretti notes this in saying that "to a great extent the musicians were Janus-faced, drawing inspiration from pre-industrial folk musical practices while they were confronting a dynamic industrial society that rationalized their music."clx The process of industrialization helped sever the connections between jazz music and the remnants of its folk traditions.

Furthermore, the industrialization of jazz inserted 'gates' between bands and their audiences. For example, only a few years after the swing craze first took hold of America, dance orchestras generated nearly $\$ 100$ million annually, and employed 30-40,000 musicians, as well as 8,000 managers, bookers, promoters, and support personnel. During the 1930s, a national tour network consisting of one-night performances in small towns and major cites all across America was forged, leading to an enourmously expanded dance hall industry, and the possibility of making a living as a touring band. ${ }^{\text {clxi }}$ However, bands, especially black bands, needed to gain access to the increasingly centralized entertainment industry which could only be done through the hiring of a professional intermediary. Additionally, publicity networks created a demand for dance music as well as musical celebrities who usually needed their own acoustic trademarks. ${ }^{\text {clxii }}$ Most of the swing bands had their own self-consciously adopted gimmicks and distinctive theme songs, such as Shep Field's "Rippling Rhythms" and Kay Kyser's "College of Musical Knowledge."clxiii The marketing of celebrity, while an integral part of the popularization of music, also accelerated the concentration of power in the hands of national broadcasting networks, 
who were the only corporate bodies able to generate and guarantee media exposure. ${ }^{\text {clxiv }}$ Because of the level of detail and professional marketing required to make a swing band known nationally, intermediaries or gate-keepers became an integral part of the music scene. The importance of the industry can be further noted when one considers the spread and penetration of radio technology.

Obviously, if the technology of radio had not spread so widely within American society, broadcasts of jazz music would not have been so effective in popularizing the form. In 1926 and 1927, the national radio networks were being put together.

Fortuitously, they then required endless hours of content to fill their broadcasts. One of the easiest ways for radio stations to fill their air time was to broadcast live concerts from ballrooms and dance halls, which could be accomplished with a microphone and an announcer. The fancier the venue, the better, as listeners were drawn to the mystique of large clubs and extravagant locales. The Cotton Club in New York was one such venue from which radio broadcasts became common. Duke Ellington and his orchestra were broadcast live from the Cotton Club during 1927 to 1930 at least three times a week. The radio broadcasts also naturally increased the group's popularity. Collier notes that these radio broadcasts made Ellington so famous that he was invited to meet President Hoover in 1931 as part of a group of "Negro Leaders." also explained Benny Goodman's famous reception in California in 1935. Goodman had recorded the 'King Porter Stomp' in July of 1935 and it had sold well nationally. Additionally, Goodman's broadcasts on the Let's Dance radio show had built up a sizeable following such that, during a tour to California in August of 1935, Goodman hit the 
jackpot. $^{\text {clxvi }}$ The youthful crowds that had heard his music on radio and on disc went crazy by the time Goodman's tour reached California and he became a huge musical celebrity.

Radio technology not only facilitated but also shaped the rise of jazz music. In the earliest days of radio, the medium naturally lacked an audience as wide and enthusiastic as the one that it eventually acquired. For instance, in 1921, only $\$ 11$ million of radio equipment were sold in the United States. But that number rapidly climbed to over $\$ 850$ million by 1929. Consequently, a "listening public" developed as the technology of radio evolved from a novelty to a household necessity. ${ }^{\text {clxvii }}$ Because the number of radio stations from which listeners could choose was relatively limited, certainly as compared to the number of individual recordings from which record purchasers could choose, radio technology proved effective in generating specific tastes around certain bands and styles. Radio audiences were receptors of content, unlike purchasers of recorded music who were more active selectors of forms. Therefore, radio played a large factor in helping jazz to become popular. The mechanical reproduction of music, now combined with easy and relatively inexpensive radio access, enabled young fans, as well as fans all across the country, to gain firsthand knowledge of the cultural form of jazz. ${ }^{\text {clxviii }}$

It is also important to note that the increasingly close working relationship between jazz musicians and the 'music industry' - now consisting of broadcasters, record labels, managers, publicists, networks of hotels and other venues, etc. - also eventually resulted in greater racial openness. The process was not immediate, however. As Lopes notes, white swing bands had far greater access to the mass media of radio and recording than most black swing bands. White musicians also won the top spots in the choice venues all over the national market, and enjoyed the greatest prestige. However, much of the swing style 
was derived from the work of black artists, and many successful white swing bands either had black arrangers or bought arrangements from black swing bands. This dichotomy between black originators and white practitioners was especially noticeable in the popular opinion polls conducted by the jazz magazines. White swing musicians and white swing bands consistently won top honours in these polls, revealing the greater ease with which white musicians rose to celebrity. For example, Bix Biederbecke won the 1936 Down Beat readers' poll although he had already died, over the legendary Louis Armstrong, while the highly influential Duke Ellington never finished higher than fifth on lists of favorite swing bands during the 1930s. ${ }^{\text {clxix }}$ But while strongholds of exclusion remained, jazz music also represented an upwardly mobile social path for black musicians, offering the chance of financial reward, increased status, and public recognition. ${ }^{\text {.lxx }}$ Jazz music therefore functioned as an engine of popularity for black musicians; it was an area of society where blacks could be admired.

The impact of the industry on the music and the debates surrounding it must also be examined. One of the major debates over form was the question of sweet versus hot jazz. The cyclical adoption of black styles, their dispersion within white music industry practices, the resultant popularity of the new form, its eventual over popularity, and the subsequent transition to yet another new form had marked the history of jazz, as well as of popular music generally. In fact, this process of discovery, saturation, and transition to a new style is an important characteristic of popular music. ${ }^{\text {clxxi }}$ Popular music is full of ceaseless transition as companies constantly struggle to produce the "next big sound." Within the history of jazz, a dichotomous negotiation between black artists and white standards emerges. When jazz first became popular in the early 1920s, it was hot, wild, 
and improvised. But to become a full-fledged cross-over success (a music originally marketed to black audiences but which also became a success with white audiences), it had to be tempered with standardized influences and adapted within established industrial practices. Audiences wanted something different, but not too different. In jazz, this plays out in the formation of the sweet style of performance. Jazz goes from being a wild, improvised style, to something smoother, straighter, and written out (i.e. composed using standard notation). The difference can be heard by comparing the sound of Jelly Roll Morton's 1926 recording of “Grandpa's Spells” to Jimmie Lunceford's 1936 recording of “Organ Grinder's Swing." Furthermore, hot jazzmen could often not read music, and the result of having more than four or five of them in a larger ensemble was chaotic. Sweet jazz was slower, used straight eighth note rhythms, little improvisation, and many vocalists or 'crooners.' It was melodious and was not performed loud enough to interfere with the conversations of club patrons. Between the hot jazz bands and the sweet jazz bands, the sweet jazz bands began to dominate the music industry by the end of the 1920 s. Metronome magazine summed this up in 1931 by stating that: "Blaring jazz music consisting mostly of noise - is being replaced more and more by soft and subdued melody."clxxii Sweet commercial bands such as those led by Guy Lombardo, Rudy Vallee, and Wayne King survived and prospered, whereas those hot jazz bands led by Duke Ellington and Louis Armstrong folded or moved to Europe. Many black musicians did not appreciate the sweet style of music, feeling that it left no room for improvisation or rhythmic excitement. ${ }^{\text {clxxii }}$ However, sweet jazz was dominant only from roughly 1929 to 1934 , and with the rise of a new generation of music fans in the 1930s, came a renewed interest in the hot style of jazz. Swing was to many a "revolt against the commercial sweet 
dance bands that dominated radio and the top band rooms." was popularized by Benny Goodman, who considered sweet music to be inadequate in comparison with the "real music of America." By 1934, he had bought 36 arrangements done by a black arranger, Fletcher Henderson. Henderson's idea was to harmonize a hot solo line for an entire section of instruments (4 trumpets or 4 saxophones), who then used the old West African pattern of call and response to trade the line or "riff" back and forth. A soloist would blow over top of all this, and this became the standard form of swing. Swing bands would also very frequently use a thirty-two-bar AABA form, whose overwhelming popularity can be noted in the fact that many tunes using this form are known even today as jazz "standards." Hammerstein standard "All the Things You Are." Therefore, swing cultivated hot jazz practices while still carefully negotiating between hot and sweet jazz. Hence, Goodman retained the white practice of playing "straight" notes in the manner of a formally trained classical musicians, cutting out the black practice of bending notes. Goodman would hire hot soloists such as Lionel Hampton or Teddy Wilson to play over top. The result was that Goodman "tamed the black big band sound of its more African-based features, but kept the rhythmic swing. This was just the combination that white teenagers wanted."clxxvi Goodman's use of 'swing' techniques that black bands had used ten years earlier proved conducive to the music industry as it existed in 1935 , thereby sparking not only his own tremendous popularity but also the latest phase of popular music. It was new to most of the audience, but not too experimental, and it was presented by a white bandleader who was easy to market. Goodman bent the conventions of the day, but did not shatter them. 
Jazz also functioned as popular culture as a result of the coverage it received in national daily newspapers. Newspapers played an important role in acknowledging and popularizing the cultural form of jazz. By the 1930s, and certainly after the swing explosion of 1935, jazz was written about in many mainstream newspapers and magazines. Contrary to press attitudes in the early 1920 s which claimed that jazz fostered the "baser" elements of human nature, much of the coverage of the 1930s was positive. A 1938 Newsweek article declared that "Swing has always been here and will always stay." Another 1938 article, appearing in Life magazine, spoke of swing music as the "Hottest and Best Kind of Jazz;" one which was approaching its golden age. ${ }^{\text {clxxvii }}$ Swing was, in the words of the New York Times, "the tempo of our time. Swing is real. Swing is alive."clxxviii This positive press was, of course, supported by the specialty jazz magazines (Metronome and Down Beat), which were read by jazz fans. As previously noted, the specialty magazines also helped make jazz a credible object of study. However, for the most part, while jazz was covered in the mainstream press, it did not involve a high degree of academic scrutiny. The informal and unsystematic nature of the written criticism appearing in magazines was not analytic but ran heavily to attacking or defending either musicians or critical positions. ${ }^{\text {clxxix }}$ The culture was primarily one of fandom - that is to say the setting forth and defence of preferences, the foregrounding of trivia and obscure knowledge - rather than one of scholarship. Both fans and critics possessed the same tools of analysis and the division that exists today between analytic critics and enthusiastic fans remained unspecified. Jazz magazines invited active critical participation through lively letter columns, but in the letters, "critics often acted as glorified fans and fans as incisive critics." ${ }^{\text {clxxx }}$ Finally, the effect of so much mainstream coverage was that swing began to 
appear interesting to all sorts of people, not just to one category. For example, in an October 30, 1938 article about a performance of Benny Goodman's band at the Waldorf Astoria, The New York Times said that Goodman's presence was being carefully gauged by the "trend-watchers" and therefore endorsed by both youth and "the more polite folk." Goodman himself noted that even the "literary set" involved itself with swing music, as his band was introduced on radio by book critics, novelists, and writers for The New Yorker, who came to his show in New York every Saturday night. ${ }^{\text {clxxxi }}$ Summarily therefore, widespread coverage of swing allowed the form to become embraced as the popular music of its time by men and women of all strata of society.

During the Swing Era, jazz was performed primarily in concert halls and hotel ballrooms. The brothels and speakeasies that initially housed jazz performances had clearly been left behind. Several reasons account for the change in venues. First, the popularity of jazz meant that larger venues were required to house all the patrons, especially dancing patrons who required a large floor. The popularity across a broad range of social classes also enticed white musicians to perform jazz, thereby helping to remove the any remaining barriers which prevented jazz from being performed in clubs and higher class venues. Additionally, the social context for young people had changed. Erenberg points out that the 1920 s saw the creation of a culture of nightlife and dancing. Breaking away from Victorian home values, Americans began to go out more often. From the 1920s onwards, nightclubs were no longer considered 'risqué,' and the emerging culture of youth created a widespread interest in popular culture. ${ }^{\text {clxxxii }}$ Ballrooms and theatres catered to the 
new music and its clientele, and the strength of associations with hotels, made jazz safe, clean, and, most importantly, accessible to a wide variety of patrons. ${ }^{\text {clxxxiii }}$

The dancing crowd also created different needs within the instrumentation of the jazz band. Jazz bands of the 1920 s usually were no larger than 7 pieces, and the sweet dance bands of the late 1920s consisted usually 8 or 9 men. However, the standardization of the riff (as discussed earlier, involving the formation of saxophone and trumpet sections of players performing in harmony) allowed bands to expand to 12 or even 20 members without creating acoustical chaos. The interest here was that a larger band could also pack a louder punch (important when there was no electrical amplification as in the 1930s), which excited dancers more. The louder music of swing also caused some changes in the choice of instrumentation. With the larger band size, the drummer became the driver of the band, ensuring that a constant beat was always provided for the dancers. Likewise, the bass lines most often performed by a tuba or other low wind instrument in early jazz, were now performed by the string bass which did not require great amounts of breath and could more easily sustain long lines. ${ }^{\text {clxxxiv }}$ These modifications in members, size, and instrumentation allowed jazz to become more suited to the dance venues and their patrons, in turn allowing jazz to become more popular.

The result of the new channels for jazz in the 1930s were nothing short of remarkable. A 1938 "Carnival of Swing" in New York brought out more than 23,000 dancers. The New Century Committee of Chicago presented a free Swing Jamboree at Soldier Field on August 24, 1938 involving twenty big-name white and black jazz bands on three separate stages. The response was enormous; around 100,000 fans poured into the stadium. The gates were closed to try to prevent over-crowding, but a crowd rivaling the 
size of the one already inside gathered outside, pushed, and collapsed the stadium gates. It was, the Chicago Daily News noted, the "world's largest crowd...for a musical event." The Chicago concert was attended primarily by youth of both black and white races, and jazz became championed as the music of a new youth generation. Jazz had reached its mass audience by becoming the favorite music of young Americans. ${ }^{\text {clxxxv }}$ However, while popularized by youth, its popularity was not confined to that demographic. The best swing of the era was popular not only with youth, but with the educated and moneyed people as well. While it might originally have been marketed to a specific socio-economic segment of the population (via the sale of "race records"), swing music was popular with most everyone. ${ }^{\text {clxxxvi }}$

Jazz during the Swing Era of 1935-1945 can therefore be seen to function as popular music. In fact, it was the popular music of the day; sales of swing music carried the music industry. It enjoyed huge audiences, drawn from a number of socio-economic backgrounds. It benefited in popularity from a close relationship with the commercial industry, especially radio broadcasting, which spread the musical form to every household in America. The recording industry also played a part in formalizing the sound of jazz music. The negotiation between hot and sweet jazz delivered a specific formula that audiences admired and bands developed. Jazz music also benefited from extensive media coverage, both in specialized jazz journals and mainstream presses. Critical scrutiny of jazz had not developed much at this point, and the line between enthusiast and critic was uncertain. The end result of this negotiation of pathways was that jazz music was the popular music of the 1930s and 40s - it was enjoyed by everyone, accessible to everyone, and indelibly inked on the minds of a generation. 


\section{The Second Cultural Transformation}

However, jazz's role at the top of the popular music industry was not to last. A number of crucial developments forced jazz into a new trajectory; away from popular enjoyment and towards a more critical spectrum. After 1945, jazz was confronted with a new philosophical direction which sought to push the boundaries of the music and distance itself from commercialism. This was Bebop, which emphasized technical virtuosity and drew away from the pathways of popular music. Consequently, bebop also sought different pathways along which to travel that did not possess the same biases as popular music. It was assisted in this development by the formation of a critical lexicon, a series of more elite venues, and the emergence of new entrance barriers to the pathways of the popular music industry.

A traditional recounting of the coming of bebop goes roughly as follows. By 1945 , the commercial appeal and close relationship with the music industry frustrated many young black musicians. They wanted more space to solo away from the constraints of written arrangements. And so, a group of young black jazz musicians began playing at jam sessions, after hours in a club called Minton's Playhouse in Harlem. The musicians wanted to "create something that they (the other - music industry, white musicians) couldn't steal, because they couldn't play it," and began to push tempos, develop new, faster techniques, and experiment with unconventional rhythms. But it was the technical genius of Charlie Parker that finally coalesced the movement of bebop into a revolution. Parker was supported by trumpeter Dizzy Gillespie and pianist Thelonius Monk. Bebop is traditionally rendered as a revolutionary music; a revolution in musical and social style 
against the white establishment which had repressed the creative forces of jazz

musicians. ${ }^{\text {clxxxvii }}$ Or as Vulliamy puts it:

Young black musicians were fed up with the way previous jazz developments had been commercialized by white musicians. They were tired of playing the same old stuff in swing bands. They were also disillusioned, having wrongly thought that problems of racial prejudice would be solved after traveling north from the south. No longer did they want to entertain large audiences with a kind of watered-down jazz music they did not enjoy playing. Instead, they wanted to create their own music and make it so difficult that the whites couldn't steal it. This was, for the first time in jazz's history, a revolt by the musicians against the public."loxxxviii

Again, it is not that this type of historical rendition is necessarily incorrect. But rather, it lacks a treatment of the supporting factors that played an integral role in allowing this new, complicated form of jazz to emerge. It is these factors that bear a further examination.

The first factor to be examined here is the music industry. This is a very interesting topic because it is marked by a distinct, but not unprovoked, shift during the years of 19451950 away from the music of jazz. Indeed, from the beginning of the century until the 1930s, the popular music industry had been moving towards concentration into enormous networks. The Big Three recording companies (Victor/NBC, Columbia/CBS, and Decca) controlled the vast majority of record distribution ( $85-90 \%$ in 1941), and retained an incredible ability to 'make' certain artists. They were interested primarily in mainstream entertainment, and specialty markets on the fringes (such as hot jazz or hillbilly music) did not generate enough return to interest them. The choices available to today's cultural consumer did not exist in the 1930s, and the result is what DeVeaux calls "something close to a unitary popular culture." ${ }^{\text {,lxxxix }}$ Indeed, the swing phenomenon itself was the result of this drive towards a unitary culture. But the extension of the bebop movement during 1940-1945, along with several other factors (discussed below) began cracking the monolith 
of popular culture that was swing. The economic and institutional structures of swing remained in place through WWII. Most jazz musicians still worked with swing bands, as can be noted by recordings featuring the young Charlie Parker with strings in the early 1940s. Yet while bebop began to rise in popularity amongst musicians, the record industry increasingly turned to the sweeter sounds and star power of big singers. By 1944, singers like Frank Sinatra had asserted their independence from bands, and within a few years, the Swing Era had been overcome by the era of the "big singer. ${ }^{\text {,cxc }}$ Major record companies were able to consolidate production with singers, by using a small number of bands tied directly to the label to back up their entire stable of artists. They were also able to control the product through the use of artist and repertoire personnel, who arranged the recordings and chose the singles. ${ }^{\text {cxci }}$ The industry's disconnect with big bands cut off the broadcasting, recording, promotional, and touring pathways through which the big bands had connected with a large audience. At the same time, wartime conditions had increased the earning power of black Americans, and so the race records that had previously been a fringe market began to become more economically viable. And these fringe markets were assisted by the development of new musical idioms. The increasing viability of the fringe markets encouraged the evolution of hillbilly music into country music, the emergence of R\&B and soul music, and the youthful embrace of the new rock n' roll genre, which in turn rapidly fragmented the cultural marketplace. ${ }^{\text {cxcii }}$

Also contributing to the fall of the swing bands during the 1940 s were a number of economic conditions that made it very difficult to maintain big bands. The economics of WWII dealt a severe blow to the big band scene. In 1942, the Office of Defense Transportation issued a ruling forbidding the use of buses, both to save rubber and 
petroleum supplies, and restricting their use to transport troops. This was immediately protested by a number of people who worked with black bands - from Cab Calloway, booker Joe Glaser, record producer John Hammond, and even the executive secretary of the National Association for the Advancement of Colored People. They argued that the effects of this ruling would be to threaten the very survival of the black band's ability to tour. It was an interesting case. Black bands were still barred from many venues (hotels and theatres) in many towns and they therefore had to tour extensively to make a living. The private automobile was the method of choice, but it was too expensive for most black bands, and also left them in danger of harassment in the South. The train was another method, but it made it difficult to co-ordinate a series of one-night performances, especially in towns where trains did not visit regularly. The end result of this disruption to the transportation network eliminated many swing bands, a disproportionate number of them black. ${ }^{\text {excii }}$ For those proven bands such as Tommy Dorsey or Glenn Miller, who could work in any venue, the lack of competing bands created an increase in wages. But overall, the number of bands actively performing fell dramatically. Lopes reports how just before the US entered the war, Down Beat's listings of bands peaked at over 800 . By 1945 , there were only 92 active bands reported. ${ }^{\text {cxciv }}$ The bands that were first affected by this were naturally operated at the margins of society. This meant that black swing bands were the first to feel the effects of the reduction in transportation pathways.

Another significant factor in the transition of jazz during the 1940s was the ban on recording called by the musician's union in 1942. Contrary to many historians' views, the ban ultimately allowed new industry pathways to develop that would begin the exposure of the fledgling movement of bebop. James Petrillo, president of the American Federation of 
Musicians (AFM) had been threatening the music industry with strikes over pay scales in the late 1930s. However, by 1942 almost every professional musician in America held a union card. With this power, Petrillo turned to confront the longstanding issue of recordings. He felt that the use of recordings encouraged presenters to substitute canned music (such as jukeboxes, which were responsible for $44 \%$ of record sales in 1942) instead of live musicians, and that therefore, if a musician was going to make a record that could put him out of work, he should be compensated for it. Naturally, the record labels disagreed, and the AFM banned any union member from making a record in August of 1942. The strike effectively silenced the recording industry for a year, and shook the major labels dramatically. Of the Big Three companies, the Decca label was the only one without ties to a radio network, and therefore had no alternative source of income. It was the first to capitulate to the union's demands in September of 1943, whereas the Victor and Columbia labels held out until late 1944. But the market had been fundamentally altered, creating room for a different model of recording to emerge.

From an historical standpoint, the recording ban proves frustrating for present day scholars. On one side of the divide, the Swing Era is still going strong; on the other, the small-combo voices of a developed bebop style begin to emerge. The time between, based on interviews with musicians, was one of vigorous experimentation. Before 1942, the recordings of Charlie Parker and Dizzy Gillespie are of soloists with swing orchestras. After November 1944, Parker and Gillespie are in control of a fully realized, radically different conception of jazz. ${ }^{\text {cxcv }}$ And frustratingly, there are no records of the transition, no recollection of the experiments in style that were going on during the time period. Some have thought that this period allowed bebop to develop in isolation. ${ }^{\text {cxcvi }}$ However, other 
scholars have gone so far as to blame the recording ban for denying bebop a quicker transition into the vernacular awareness, so much so that it has become a cliché. For example, Tirro states that bebop "might have taken place more quickly, but an AFM ban was imposed... and a major medium for the transmission of new ideas among the jazz musicians was temporarily denied them." "xcvii

However, if one examines the effects of the AFM ban more closely, a different conclusion may be reached. The time in between Decca's acquiescence and the settlement with Victor and Columbia, allowed for a multiplicity of independent record labels to jump into the business. These independent labels knew that they could not compete with the major labels and, with the exception of Capitol Records, did not try. So they specialized in different types of recordings, with small-combo jazz being one of the most available and attractive options. The audience for these small-combo bebop offerings was a group with a disproportionate representation of true enthusiasts who were willing to pay premium prices (and whose appetite had been greatly intensified by a fifteen-month ban). And the artists were available all over New York, where they had become concentrated in hopes of finding work under the shelter of the big recording labels. Furthermore, the growth of independent recording labels during the ban meant that the major labels were not able to completely dominate the market as they had before. They now had a popular mainstream that was beginning to fragment into a number of different demographics. With a climate like this, it was only a matter of time before small recording firms like Savoy would record Charlie Parker and Dizzy Gillespie, and turn their music loose in 1945. But it was the combined effects of the hiatus of the major labels from the recording scene and the 
fragmentation of the market that created pathways which suited an alternative presentation of jazz.

Now, lest we get too isolated in our examination of jazz, it is important to mention the rise of bebop within the context of the larger music industry. While bebop is an incredibly important event in jazz music, and in our understanding of music pathways, it is not a big event in the music industry. In fact, counter to the Swing Era in which jazz music represented the majority of sales for the industry, bebop marks the disappearance of jazz from popular music, replaced by other forms of popular music more suited to the established pathways and prejudices. Therefore, a cursory examination of the increase in popularity of other genres of music is important to understand as well. One of the impacts of the AFM recording ban was the music industry's increased reliance on singers. So much so that the ten-year period following the end of World War II (1945-1955) is often called the era of the "big singer." During these years, popular song and the popular music industry were populated by star singers, rather than by big bands. Singers developed a closer relationship with recording labels, were much cheaper to promote and tour, and did not have union ties. A ranking of the top ten recording artists based on sales for the period 1940-1955 includes only two jazz bands (Glenn Miller's, and the lighter jazz combo of Nat King Cole). The other eight are singers, from Bing Crosby and Perry Como to Patti Page and Jo Stafford. ${ }^{\text {cxcviii }}$ Swing big band music was no longer the economic powerhouse it had been in the pre-War era; it had been eclipsed by the crooner. And while some academics feel that the public's focus on jazz music had shifted to bebop during this period, the music was most often mentioned as a fad. For example, Life magazine explained bebop as an easily-mocked society of ritual handshakes, berets, dark glasses, and 
goatees (much taken from Dizzy Gillespie's appearance). ${ }^{\text {cxcix }}$ Jazz in both the form of swing and bebop was beginning to slip away from the role of popular music.

To move jazz music even further away from the mainstream attention it enjoyed in the 1930s, the genre of rock'n'roll quickly became a legitimate contender for popular music in 1953-1955. ${ }^{\mathrm{cc}}$ While smoother singers would continue to play a large sales role for the music industry during the course of the 1950s, the 1940s extension of Billboard magazine's charts of hits into the "hillbilly," "race," "folk," and "gospel" categories promoted the exposure of other types of vernacular musics. ${ }^{\text {cci }}$ Radio disc jockeys such as Allan Freed helped construct a new system for the exposure of record singles, a national network of hits. Additionally, they opened up pathways for cross-over hits from other genres and vernaculars (black pop, gospel, country), enabling new types of music to access a new market and more widespread audience. It was this adaptation of popular pathways that gave rise to rock'n'roll, and created a new popular music for America, thus relegating jazz music to another status. ${ }^{\text {ccii }}$ Bill Haley's recording of "Shake, Rattle, and Roll" sold one million copies in 1954, and by 1955 , rock had become exciting, mainstream, and very popular. Now a further exploration of the rise of the big singer and, later, rock music under the auspices of pathways analysis would be interesting, but is outside the scope of this paper.

Critics were an extremely important factor in the transition of jazz music during the 1940s and 1950s. They were responsible for developing a critical lexicon that could be used to judge and sort jazz music. But even more so, they were the first people who really tried to make distinctions about jazz. Whereas many musicians were content with just 
playing music, critics went to great lengths to define and distinguish that music. Asked to define bebop, Charlie Parker was uninterested in being precise: “It's just music, it's trying to play clean and looking for the pretty notes."cciii This was the opposite stance of the music critic who thrived on distinctions and classifications. While bebop musicians may have striven to renegotiate their music and their relationship with the music industry, it was the critics who defined and outlined the terms of their movements.

A growing community of young, white jazz enthusiasts had begun to develop in the 1930s. These enthusiasts were avid supporters of hot jazz (1920s), which they perceived as genuine or real, and they began a collective effort to preserve this authentic jazz vernacular. Their attitude is captured in the words of Robert Goffin who wrote: "Melodic jazz (referring to Paul Whiteman) has contributed nothing to music and will only be remembered for its insipidness; whereas hot jazz is a creative principle which can scarcely fail to affect the music of the future in the most original and unexpected directions."cciv These enthusiasts asserted a measured difference between the cultivated jazz of professional swing musicians and the original hot black styles. Likewise, these people set themselves up as distinct from the popular swing market of teenage fans and jitterbugs (teenage swing craze dancers). They were self-proclaimed "connoisseurs" who felt that jazz deserved serious effort and appreciation. ${ }^{\mathrm{ccv}}$ And their level of interest in jazz led them to begin writing about jazz in various fan periodicals which would, in turn, develop into the first jazz criticism.

Enthusiasts embraced records wholeheartedly as a means to experience real jazz. Collectors would rummage for select discs in junk shops and black neighborhoods to find old "race records" from the 1920 s. Furthermore, the jazz collector delighted in arcane 
knowledge and detail, feeling that it was not enough to know who the leader of a group was, but also important to know various jazz labels, all personnel within a band for a specific recording, and even the serial and pressing numbers of records. ${ }^{\text {ccvi }}$ With this type of specialized knowledge, it was no wonder that discographies were quickly compiled. Discographies were categorical and exhaustive lists of jazz recordings, dating from modern (1930s) back through the 1920s. Interestingly enough, the most prominent discography was compiled by a Frenchman, Charles Delaunay (five editions by 1946), and indeed, the first round of jazz criticism was primarily formed in Europe. Fellow countryman, Hugues Panassié became the first serious critic of jazz, publishing the first works of serious scholarship on the subject in 1934 (Le Jazz Hot). Many modern critics have lambasted this first round of jazz scholarship, claiming it was historically inaccurate. These criticisms have pointed out that it was very difficult for French collectors to uncover a compendium of information about the jazz that they studied because of their distance from both the original market demographic as well as from any firsthand experience of the jazz scene itself. And it is true that Delauney did not even visit the United States until he was editing the fifth edition of his discography (Down Beat notes this in a 1946 article when it claims Delauney became "the greatest research scholar on American hot music without having crossed the Atlantic." A 1940 edition of Down Beat acclaimed an earlier edition of the discography as "the greatest jazz work ever published"). ${ }^{\text {cvii }}$ However, it is possible to understand the removal of these people from the immediate creative circumstances merely as engendering the possibility to adopt a different approach to the music. Given the lack of access to the hot jazz performances they identified with, the French response was to develop a more self-reflexively critical approach to the music, enshrining the important 
recordings within a categorized discography. And it is this very distance that critics began to appeal to. Barry Ulanov believed that fans corrupted musicians if they did not maintain a critical distance between their judgment and the object of their affections. Adoring fans revered jazz musicians, and this almost religious devotion (as Ulanov thought) could influence a musician to cater to public taste instead of his own artistic ambitions. Adoration merely fettered one's ability to know the subject. ${ }^{\text {ccviii }}$ Ultimately, the white critics of the jazz specialty journals did not belong to the same musical subculture that they idealized, and this distance became normalized as a function of criticism itself. It should also be noted that this critical distance can be noted elsewhere in other disciplines of established criticism. Hence, criticism marks itself off as its own 'universe,' while these early critics, with their discographies, lists, pressing numbers, trivia, etc., functioned more as enthusiasts. To be a 'scholar' requires detachment and systematic inquiry guided not by one's preferences and interests but by the requirements of the object under study, a desire for systematicity, a willingness to debate method, etc. Music criticism is, ultimately, the use of objective language to further a specific set of ideals. And further, it requires a critical establishment to support these ideals.

The enthusiasms of jazz collectors developed beyond discographies as well, turning into a national network for trading and selling which included hot jazz shops, record catalogs, magazines, collectors clubs, and hot jazz record labels. Some jazz enthusiasts organized themselves into "hot clubs," which were places where enthusiasts could gather to share record finds and exchange liner notes and appreciations. The creation of hot clubs dated back into the 1920 s, but some of the clubs attained a high degree of organization and financial dedication. Some hot clubs were even involved in the reissuing of old, out of 
print recordings, leasing the masters from major labels to reprint the albums. These reissued albums of hot 1920s jazz did not become bestsellers but demonstrated that there was some commercial viability in specialized jazz markets, a fact which would be exploited by independent labels in the later 1940s. As a networking opportunity, the United Hot Clubs of America was founded in 1935 as a national network for hot jazz clubs, and expressed a missionary zeal in supporting the appreciation and increasing the prestige of jazz music. ${ }^{\text {ccix }}$ It had chapters in most major American cities, but included many college students, elite, white, and educated. John Hammond and Marshall Stearns both began their interests in jazz while at Yale, and Stearns' doctorate in English literature equipped him with the scholastic tools he would need to run a series of pieces on the history of jazz from 1936 to 1938 in Down Beat, which linked jazz from African beginnings to the Swing Era. ${ }^{\text {ccx }}$ This historical bent caused critics to paint jazz at a crossroad, which is the origin of our current narrative tradition of jazz. Barry Ulanov, again writing for Metronome: "No longer does the jazzman stand alone, uncluttered technically, emotionally constricted. Behind him is a history and a tradition. Before him is an art." ${ }^{\text {"cxi }}$ And to expand the reach of this new art form, critics began writing beyond specialist magazines, in general interest magazines such as Harper's, Esquire, New Republic, Town \& Country, and Mademoiselle. By 1944 Esquire had even taken to publishing an annual Jazz book supplement. Magazines would offer articles about jazz, as well as record and concert reviews, and played a large part in leveraging jazz into the national mainstream consciousness.

The role of Hot Clubs and original jazz aficionados in the 1930s also demonstrates a key crux in the history of jazz. First, they demonstrate the separation of critic and 
musician. Many critics were uncomfortable with both the vapid, adoring jitterbugs and the musicians themselves. Critic Ted Locke responded to the tension between critics and musicians by saying "critics must necessarily be far more cultured than the people whose work they review... we must conclude that intelligence isn't necessary to produce great art, but it can't be denied that intelligence is necessary to appreciate it."ccxii This is very similar to Gans' notes on high culture whereby critics become more important than creators because of their ability to determine the worth of a cultural product. ${ }^{\text {cxiii }}$ Critics serve as important gatekeepers in elite culture. For their part, musicians increasingly chafed at those who would criticize their efforts without being able to play the music themselves. ${ }^{\text {ccxiv }}$ It is not vital to explore the resolution of this tension, however, this tension is important in recognizing that critics had their own agenda as independent agents who shaped the pathways and purposes of jazz music. ${ }^{\text {ccxv }}$

Additionally, Hot Clubs and traditional jazz enthusiasts in the 1930s and 40s represent what could have been a turning point in the history of jazz. During the $1940 \mathrm{~s}$, a heated debate began between the proponents of hot jazz and swing. Jazz traditionalists sought to return jazz music to its earlier form, as embodied by the Dixieland hot jazz performed by black musicians in the 1920 s. They felt that swing music was an attempt to insert jazz into a network of capitalist commodity exchange, whereas hot jazz was pure and untainted by commercial pathways. Dubbed "Moldy Figs" because of their "corny" traditional leanings, many of the swing periodicals began attacking their exclusive pretensions. The swing periodicals articulated their own positions as indicative of modernism and progress in jazz. This was the battle scene that bebop stepped into in 1945 , when it began to gain attention in the press. Bebop quickly redrew the boundaries of the 
traditionalist/modernist debate, with swing music now counted in the traditionalist camp. The Dixieland war transposed itself with great subtlety into the bebop war, such that many critics did not even notice it. As the commercial appeal of swing was gradually superseded by rock and other popular vernacular musics, bebop became the remaining dominant form of jazz. $^{\text {cexvi }}$

On one level, these debates between traditionalists and modernists required a level of thought and articulation that prepared the way for the emergence and critical acceptance of jazz as an art music. Due to the level of sophistication demanded in the defense of either camp, they naturalized the reference to jazz as an art form. What was being constructed was an/aesthetic discourse, which Bernard Gendron defines as a set of concepts which fix the limits within which discussions about jazz could occur. ${ }^{\text {cexvii }}$ As Gendron demonstrates, the debate before 1945 between the swing modernists and the Dixieland revivalists had sufficiently delimited the discourse that when bebop entered and turfed the swing defenders into the traditionalist camp, the same discourse was applied with very little variation despite a major upheaval in position. The modernists sought to subscribe to precise technical standards of analysis as well as more complex chordal and melodic figures. The revivalists responded that an approach grounded on technique was shallow and appealed to the soulful aspects of the music. The modernists rejected emotional symbols and ecstasies while the revivalists championed emotion over an intellectual exercise. ${ }^{\text {cxviii }}$ Interestingly, the position articulated by each camp is perfectly indicative of the respective levels of folk and elite culture. Remember that as a result of its non-professional practitioners, folk culture does not emphasize technical mastery. In 
comparison, the highly professionalized nature of elite culture requires years of indoctrination to correctly learn all the codes of performance.

One other point bears further discussion. By enshrining the older types of jazz, the traditionalists were attempting to return jazz to a folk culture. To assist themselves, these jazz scholars (led by Hugues Panassié and Robert Goffin) subscribed to a romantic ideal of what former jazz was like; authentic jazz was a primitive culture and authentic artists were primitive artists. ${ }^{\text {ccxix }}$ Likely unconsciously, in the construction of this primitivist ideal, writers did not describe the music itself but the practices, the venues, and the ways of exchange. In so doing, they sought to idealize the pathways alongside the music, an unconscious recognition of the importance of these pathways in defining the experience.

Were the Moldy Figs doomed to fail in their attempts? Many scholars note the eventual eclipse of the traditionalist movement, but do not satisfactorily explain why. Our chosen path of analysis provides some answers. I would argue that the Moldy Figs' attempts to return jazz to its "authentic" origins were inconsistent with their chosen methods, namely, the development of cohesive scholarship. If folk cultures are characterized by insignificant critical attention, the creation of a formalized lexicon does not bode well for the return of a popular form of culture to a folk status. It is difficult for an established pathway to untrack itself. More importantly, the revivalist critics who sought to return jazz to its "pure" state were unable to transform any other of the pathways. They were unable to convince the music industry to forget jazz, they could not return jazz music to its isolated beginnings, and they could not undo the work of recordings (indeed, it was primarily through recordings that they were able to construct their views). And therefore, without help from any of these other factors, the traditionalists were ultimately 
defeated by the modernist movement. ${ }^{c c x x}$ While the Dixieland movement would continue in isolated pockets, it did not win the war of criticism.

Nonetheless, despite launching a failed attempt to return jazz to its origins, jazz enthusiasts were integral in laying the framework for the modernist future of the art form. Jazz enthusiasts had undertaken a project to build an audience for hot jazz music through recordings, writings, radio, and criticism. Lopes notes that the "dreams of jazz enthusiasts in building a large hot jazz movement did not materialize as they had hoped." But the aesthetic standards and educational mandate of jazz critics demonstrated this commitment, and their work laid the foundations of a jazz art world. Jazz critics developed and defined criteria to measure jazz music in comparison with existing elite cultures. They consciously aspired to elevate jazz music to recognition as an art form, based on the existing European models of criticism. Paul Edward Miller stated in Down Beat that the time was "ripe for jazz music to be judged according to the standards of all legitimate music and for it to be put on an equal basis of comparison with the best classical selections... The genuine artistic level of music, regardless of form can be recognized solely by the application of the test of all superior music." ${ }^{\text {,cxxi }}$ Other critics pointed to the commonalities between classical music and jazz. This application of objective aesthetic standards required a working body of critics, and in so doing, also elevated the critic above the creator. For the jazz critic, bebop was never supposed to replace swing as the popular music of the day. It was about changing the public perception, changing the pathway of jazz, making jazz intellectually accepted amongst the elites instead of the masses.

And for the most part, this critical effort was successful. The new audience for bebop was "not made up of lowbrow morons, but highbrow jazz connoisseurs."ccxxii The 
effects of the adoption of an "educational" mandate and critical methods furthermore suggest the creation of a specialized audience. Critics made a point of distancing themselves from the wide-eyed "swing kids." The critic was further to play a role in suggesting the correct response for audience members, a point that will be explored later. Listening was preferred to dancing and the development and success of listening-oriented performance venues demonstrates the control that critics had over the access of jazz, as well as the change in audience composition.

It is also worth briefly discussing the work of artists in creating the new movement of bebop. While most historians have painted bebop musicians as a group who consciously turned away from commercial structures, this is somewhat misleading. After all, the vast majority of bop pioneers were committed to careers inside the commercial dance band system. They were integrated professionals (to use Becker's term), not rebels. ${ }^{\text {cxxiii }}$ Bebop was produced, distributed, and marketed within the same commercial network that had given popularity to swing. Now the bebop founders did have some elitist attitudes in their construction of the art form. Bebop artists sought to exclude those performers who could not meet their technical standards, and erected barriers and codes in their practices and performances. Harmonic obstacles, modulating into different keys on each chorus, and brisk tempos were the chosen method of eliminating the unqualified from the performance sphere. Dizzy Gillespie once remarked that "the modulations we manufactured were the weirdest, especially if some new cat walked in with his horn and tried to sit in with us." ${ }^{\text {"ccxiv }}$ But the anti-commercial phrases invoked by some musicians dovetailed nicely with the prevalent bohemian attitudes of the day. ${ }^{\mathrm{ccxxv}}$ However, bebop 
artists did consciously seek to distinguish themselves from mainstream culture. But they did so by redefining the pathways along which they presented their music. Part of the genius of bebop was the renegotiation of relationships between artists and audiences, as well as between artists themselves. And this renegotiation took the form of different venues and practices that bebop artists used to create a space for themselves. This was the jazz club and the jam session.

Jam sessions are at the centre of the bebop movement, and arguably, the fulcrum of jazz's thrust into a legitimate art form. Jam sessions begin their roots as far back as the 1890 s, when bands in New Orleans would have 'cutting contests,' where bands would try to play louder than another band in order to drive them away from a certain territory. ${ }^{\text {ccxxvi }}$ By the 1920 s, cutting contests had become more for individuals, a chance for players to pit their technical prowess against each other. By the 1930s, the culture and practices of jam sessions (more or less the same thing as cutting contests, if somewhat less openlycompetitive) were established all across the US - Chicago, Detroit, Kansas City, St. Louis, Los Angeles. The small combo settings, emphasis on improvisation, distain for written notes, and the spectacle of musicians playing for their own enjoyment offered a compelling alternative to the formal big band arrangements. Yet jam sessions are a very exclusive, highly elitist situation. A performance takes place with the briefest exchange of cryptic phrases ("blues in A," "rhythm changes") with no obvious clues for the listener's response. As DeVeaux points out, they were never meant to be public spectacles, separating themselves both physically and temporally from the audience. ${ }^{\text {cexxvii }}$ Jam sessions were most often held in seedy, small clubs, and usually took place very late at night, after the regular clubs had closed (anywhere from 2AM to 8AM, though some legendary stories talk 
about marathon sessions that would run right into the afternoon). ${ }^{\text {ccxxvii }}$ Jam sessions therefore embodied an alternative type of pathway for jazz to travel. Their exclusive codes and heavy reliance on pre-ordained knowledge mark them as specialized, difficult to appreciate without an insider's knowledge.

The specifics of this code meant that jam sessions were not appreciated by the general public, especially swing audiences. Rather, this exclusive format gave rise to a new group of educated participants. Aided by enthusiasts, jam sessions also enjoyed support from the intellectual elite. A 1936 Variety report noted that "jam sessions have become quite 'ultra' here with the swank mob and the intellectuals in for the 'new modes' in music."ccxix Jam sessions have been immortalized by jazz enthusiasts who saw them as glimpses into a world uncorrupted by commercial pursuits - musicians playing together for each other, without pay or concern for audience. This again is a romanticism: as Lopes persuasively details, jam sessions were often also a competitive affair, where musicians pitted their skills against each other, established their status, and played their way into commercial jobs. ${ }^{\text {ccxxx }}$ The jam session is, of course, where bebop was first created. Though somewhat hackneyed, it should come as no surprise that an environment so reliant on exclusive codes gave rise to the "art" form of jazz.

Jam sessions happened in any number of convenient locations, from players' houses to dance halls. However, certain small jazz clubs became known as centres for jam sessions where musicians would go to sit in and improvise with other musicians. Like the jam session culture, jazz clubs also pre-dated the rise of bebop. New York had a number of venues in operation in the $1930 \mathrm{~s}$, particularly in the districts of $52^{\text {nd }}$ Street and Greenwich Village. ${ }^{\text {ccxxxi }}$ The two New York clubs that have become canonized as 
birthplaces of bebop are Minton's Playhouse and Monroe's Uptown House, due to the fact that they first featured bebop pioneers like Dizzy Gillespie, Charlie Parker, Kenny Clarke, and Thelonius Monk. ${ }^{\text {ccxxxii }}$ Of course, many of the clubs existed before bebop became a cohesive musical style, therefore suggesting an alternative reading of history in which the venue acquires renewed status in that it creates a physical space for musicians to explore new musical directions. (This also, of course, underscores the importance of pathways analysis). The impact of the jazz club becomes more apparent when considering one record collectors' recollections: "The Village was phenomenal as a center of around-theclock activity...every kind of music available at the numerous clubs you could walk into just about anytime of the day and night.,"ccxxxii A vision of the jazz scene in the 1930s begins to come into focus: jazz clubs where anyone and everyone was playing, cutting, jamming at all hours. This is the environment that gave rise to bebop, not the isolated actions of a few visionaries. Jazz clubs (much like independent record labels) were notoriously unstable, popping in and out of existence with little notice. It was not until the later 1940s and 50s that jazz clubs became a more feasible and stable economic proposition, once the art world for bebop and other experimental forms of jazz had solidified. But the jazz club and jam session played an integral role as a new pathway which allowed a new vision of music to coagulate.

An additional point of interest in determining how the venue of jazz shifted in the 1930s, allowing for a larger dissemination of the cultural product, comes with the consideration of the rise of the jazz "concert." As DeVeaux has noted, the concert carries with it a rich set of associations, practices, and prestige. The concert is a solemn ritual, which imposes a strong degree of social credibility upon the object of performance. 
Attendees need to respect certain formalities of dress and decorum, and participation is limited to specific "correct" moments for applause. ${ }^{\text {ccxxxiv }}$ Interestingly, the history of early jazz in the 1920s and 1930s was marked by the introduction of the cultural form at two very important concerts that reflect how the music was socially perceived. One of these concerts was put on at Aeolian Hall by Paul Whiteman in 1924. Whiteman pretentiously titled his concert "Experiment in Modern Music," as an attempt to demonstrate how jazz music was a new beginning in the world of art music. He deliberately set out to combine classical music and jazz, and presented one offering of jazz in its "true, naked form" (the Original Dixieland Jazz Band's Livery Stable Blues) before showcasing his own symphonic jazz style. Whiteman had George Gershwin's Rhapsody in Blue commissioned for the concert, but the musicians played elaborate arrangements exactly according to the score. ${ }^{\text {ccxxxv }}$ While the concert was reviewed quite favorably, it did not alter the course of jazz music at all. DeVeaux concludes that this was because "it was an attempt to impose a concert form on jazz 'from above' that had little immediate effect on the musical scene."ccxxxvi This can be contrasted with the types of jazz concerts that emerged in the 1930s. While Benny Goodman's 1935 concert in Los Angeles prompted the beginnings of the Swing Era, it was his 1938 concert at Carnegie Hall that further presented jazz as an acceptable elite pastime. If it was worthy of Carnegie Hall, jazz music must really be an American art form, distilled from folk traditions. ${ }^{\text {cexxxvii }}$ Presenting jazz at Carnegie Hall directly mapped jazz music onto a plethora of existing elite practices. Following Goodman's success, jazz musicians began to hold regular concerts at Carnegie Hall.

Rather than the novelty of the music, the public during the swing era was fascinated by the basic musical elements of jazz, the improvised solos and rhythms of the music. 
This interest was stoked by jazz enthusiasts who promoted concerts in classical venues in an educational format. This programmatic format was designed to educate the audience and often featured printed programs that outlined the significance of the event and provided background history of the groups and pieces performed. As the jazz promoter John Hammond recollected in 1977, these concerts were designed to showcase "Negro music from its raw beginnings to the latest jazz," which further demonstrated the nowcultured nature of jazz music. ${ }^{\text {ccxxxviii }}$ It had become the common jazz concert format by the end of the 1930s. Furthermore, DeVeaux notes that regular performances of jazz in theatres endowed audiences with the habit of listening while sitting, instead of the frantic dancing made famous by swing fans. ${ }^{\text {ccxxxix }}$ One of the important oppositions between swing and later jazz clearly focuses on the role of dancing. Dancing is directly bodily and therefore, not intellectual. A traditional way to demonstrate one's intellectualism is precisely to underscore one's immobility, one's physical passivity; it happens specifically in the mind and does not require the external display of motion. Dancing - specifically jitterbugging - was one of the things that Adorno hated most about jazz. He thought it reduced the listener to the status of an animal. ${ }^{\text {ccxl }}$ This then, was the reason that jazz concerts became successful after Benny Goodman and not Paul Whiteman. By the 1930s, an educated audience was in place that understood how to hear jazz through the behaviors required by the concert hall. The concert was a new pathway for jazz that utilized existing practices to cultivate a public perception of cultural legitimacy. Alongside jazz clubs and jam sessions, jazz music itself came to represent a serious object of study. 


\section{Conclusions}

By 1955 (and even earlier), bebop musicians noted that their efforts to "establish a proper place in society" for their music had begun to be received. They had begun to be recognized by musicians and musicologists who previously had been interested only in symphonic music. The artistic promise of bebop trumpeted the fact that jazz had finally transcended its squalid social origins and taken a place of respect as an autonomous art form within the American cultural hierarchy, one that could be governed by its own laws and judged by its own criteria. But while jazz did not completely die a commercial death under the dominant refrain of bebop, it certainly did not thrive. ${ }^{\text {cxli }}$ While many jazz enthusiasts discuss the transition of jazz from swing to bebop as a magical revival of authenticity and a break from crass commercialism, it can be shown that this transition was actually a renegotiation of the relationship between musicians, audiences, critics, and the industry.

This transformation can also be understood as the adaptation of the music into a series of specialized channels. Jam sessions, jazz clubs, and jazz concerts enabled the development of a more complex, studious, and listener-oriented form of music. The work of critics in developing autonomous standards and vocabulary for jazz permitted the application of aesthetic judgments and intellectualized jazz as an art form. And the music industry itself went through a number of events which discouraged the continuance of jazz within the established channels of diffusion. While the musical product itself changed during this time period, it did not do so completely at the whim of musical visionaries, but rather as a result of the creation of new opportunities for musical exploration and valuation. It should also be noted that an exploration of the influences played by 
technological developments in transforming jazz during the 1930 s and 1940 s has not been undertaken in this chapter. This is because the technologies did not really change during this time, and no new technological pathways or biases were developed. Jazz music developed as an art form despite a lack of change in this factor.

Therefore, the triumph of bebop as the dominant form of jazz in the late 1940s marked the transition of jazz from a folk music to a form of popular culture, and finally to an elite art form. As jazz critic Reed Dickenson said in Harper's, "simple in its essence, jazz has now become an intensely complex, highly developed art."ccxlii The next chapter will put the finishing touches on the history of jazz, bringing it closer to its present-day place within the cultural pantheon. 


\section{Chapter Five: Elite and Everything After}

"Jazz is America's Classical Music. It is both a way of spontaneously composing music and a repertoire... Though it is often fun to play, jazz is very serious music."

- Billy Taylor

Taylor's comments which open this chapter were delivered at a conference in the 1980s and they underscore the myriad of changes that jazz music underwent after the fall from popularity of swing music in the late 1940s. If jazz had been America's popular music during the 1930s and 40s, it became America's classical music during the 1950s and 60s. The bebop movement of the 1940s marked the beginning of jazz's transition into elite art. It was not, however, the only step. During the period 1949-1955, jazz rapidly began to fill out its modernist pretensions, expanding its styles and technical virtuosity, in what Lopes calls a "modern jazz renaissance.”"cxliii If bebop sought to distinguish itself from swing music, then the multiplicity of styles in the 1950 s sought to explore every different technical and musical direction possible in jazz. Interestingly, this experimentation was, for the most part, supported by an economic boom in live and recorded jazz music; albeit for a niche market, instead of a mainstream one. Hence, the basic economics of the jazz art world - created initially by bebop - remained commercial, supported by independent recording labels, jazz clubs, and live festivals. But the art world of bebop and all that followed soon moved jazz beyond the borders of popular music, such that, by the end of the 1960s, jazz was a music that could no longer survive easily in the marketplace.

In the 1960 s and beyond, the elite jazz art world continued to develop and to enshrine itself within institutions and academia. Its growing hegemony, however, as the definitive version of jazz was also subject to challenge. These challenges were brought to a head by two jazz movements: a) jazz-rock fusion and b) neo-traditionalist classicism. 
Fusion is associated principally with the efforts of musicians such as Miles Davis and Chick Corea who, in the 1970s, began to combine elements of jazz and rock music in order to reach a newer, younger audience. Neo-traditional classicism is associated principally with the work of Wynton Marsalis who became popular in the 1980s and who sought to reject the fusion experiment and return jazz to its bebop and pre-bebop origins. Each of these challenges struggled (with differing degrees of success) to bend the dominant discourse of jazz to its own ideals. Each of these challenges was met with scorn and distain from certain critics and institutions who preferred that jazz remain within the pathways it had established for itself as a result of bebop. And each of these challenges did meet with a certain degree of success, both commercial and critical. In short, then, the world of jazz as created by bebop and the experimentation which followed became entrenched in academia, critical circles, and with a small but loyal following. Any challenge to that art world would have to overcome the hostility and indifference of academic institutionalization, critical hostility, and audience loyalty.

This chapter examines the ascension of jazz into a fully legitimized art form, within the American pantheon of respected art musics. It will consider how the movements of Fusion and Neo-Classicism sought, unsuccessfully, to create new practices and pathways for the music. The same factors as in previous chapters will be examined: critics, media and musical technologies, the popular music industry, and institutions/venues/practices, as well as how the use of these pathways enable the creation and participation of new audiences, artists, and music. The chapter is divided into three sections. The first section tracks the establishment of jazz music as a form of elite culture during the $1950 \mathrm{~s}$ and $60 \mathrm{~s}$. The second section considers the challenge of fusion, along with the new approaches with 
which it sought to distinguish itself from previous forms of jazz. The third section examines the neo-classical movement, and its use of certain institutional and critical pathways through which it also attempted to carve out a niche for itself. The consideration of these pathways will enable a more thorough understanding of why jazz retains its current market and levels of popularity.

\section{Jazz as Elite Culture}

Elite culture is characterized by specificity and specialization. It erects barriers that reduce the ability of the general public to easily access, attend, or understand it. It is therefore characterized by mastery of the specialized code necessary to its understanding. The barriers ensure that access to the culture is granted only to those who have made an effort to educate themselves about the particularities and aesthetic judgments appropriate to the cultural form. Barriers may come in the form of physical barriers (such as high ticket prices or exclusive venues concentrated in larger urban centres) or in the form of a complex behavioral code that participants must understand and master before they feel comfortable attending a performance. If these barriers are not learned and negotiated, a neophyte is likely to misunderstand the performance and/or feel alienated, unwelcome, and excluded. Such barriers therefore limit the type and number of audiences to those with the time and resources to consciously seek out and identify with the cultural forms. In order to support the development of complex behavioral audience and performance codes, the elite culture itself must be complex; and sufficiently developed, canonized, and theorized to be a worthy object of sustained critical scrutiny. Therefore, criticism plays a vital role in the life of elite culture. It is the marker by which elite audiences are able to judge if a cultural 
offering is good or not. It adjudicates new cultural works on the basis of sometimes difficult aesthetic criteria and places them within a canonized system of established elite works. Typically, aesthetic criteria intellectualize the process of enjoyment such that overt displays of 'getting it' (such as dancing, singing along, hand clapping, etc.) are deliberately eliminated in favour of more passive behaviour patterns indicated by sedentary listening, intent concentration, philosophical talk, staying up very late to hear the performance, etc. Critics thereby act as gatekeepers of the exclusive status of elite culture and may be better positioned than even the artists themselves to render judgments of suitability (because the critics will have heard so much and have exhibited the sedentary concentration to such a high degree). Elite/culture also often prides itself on its distance from commercial relationships, justifying its inability to support itself through commerce as evidence of its important aesthetic purpose. As a result, elite culture relies on institutional support (public grants, private patronage) to continue its operations. This close relationship with formal institutions also extends to its relationship with academia. Established elite cultures are entrenched within academic institutions; taught at universities and colleges, constitutive of a specific discipline, possessive of a distinct narrative (which justifies their place amongst other recognized elite cultures), and supported by a canon of examples, works, methods, and traditions. Finally, elite culture is often characterized by a reluctant use of new technologies, primarily because of its pride in and discourse upon the established tradition and canon. If all of these traits are exhibited by a cultural form, that form can be said to operate as elite culture. Since the 1950s, jazz music has become elite culture. 
As previously noted, the music industry's relationship with jazz music in the period following 1945 was marked by a general withdrawal of support for big band swing music. For a complex series of reasons, the music industry eventually preferred to offer its mainstream audiences lighter singers as well as other vernacular forms of music such as R'n'B, Gospel, Country, and especially rock'n'roll (which all gained popularity throughout the 1950s). All these helped accelerate the industry's shift in focus away from jazz. Due to the decline in industry support during the years between 1945 and 1955 , the market for jazz clubs, big bands, and jazz labels became more unstable. Many jazz clubs and jazz bands could no longer support themselves and collapsed. However, this was not to be the "death of jazz" as some periodicals proclaimed. Instead, by the mid-1950s, jazz again experienced a growth in live and recorded music. However, this 'rebirth' of jazz occurred under very specific circumstances which required that jazz become a new type of musical category within the music industry. ${ }^{\text {ccxliv }}$

Mid-50s jazz was not the same type of music that had captivated teenage dancers ten years before. It was now specialized and intellectual, often drawing upon classical music in both form and influence. Furthermore, it was no longer a unitary phenomenon just 'jazz' - but now consisted of a number of styles. And bebop was considered merely one of these many styles of jazz, often a point of departure. These other styles included cool jazz, third stream, West Coast jazz, Hard Bop, Modal jazz, and so on. These streams can generally be divided along two general directions. One direction drew its influences and practices heavily from classical music (Cool Jazz), while the second direction drew its influences more directly from within the bebop idiom (Hard Bop). 
Cool or West Coast jazz was primarily a softer version of the swing ensemble and used European classical traditions to construct musical form, harmony, and arrangement. Cool jazz reduced improvisation and emphasized written melody and arrangement. Its biggest stars were mostly white musicians, such as Stan Getz, Lee Konitz, Chet Baker, and Gerry Mulligan. Cool jazz began to develop as early as 1949, but reached its zenith of popularity with artists such as Dave Brubeck and the Modern Jazz Quartet during the years between 1954 and 1959. ${ }^{\text {cxlv }}$ The first group to achieve success with a new type of jazz music was, again, one that fit well into the established pathways. Hence, while cool jazz and hard bop were both being played in the late 1940s and early 1950s, it was cool jazz which first emerged as a popular new jazz style. ${ }^{\text {ccxlvi }}$ In 1954, Dave Brubeck appeared on the cover of Time magazine, demonstrating the increased intellectualization of jazz. His quartet achieved widespread success during the 1950s, particularly with the college crowd, for its brand of cool jazz. Furthermore, Brubeck sought acceptance on the same terms as classical music, an aspiration underscored by his well-groomed image and the widelycirculated news that he studied music with French classical composer Darius Milhaud. ${ }^{\text {ccxlvii }}$ It should come as no surprise that jazz's third wave of popularity was again led by a white musician playing in a style close to established European traditions, as it had been years earlier by Paul Whiteman and then by Benny Goodman. Lopes notes that although only a minority of jazz musicians actually played cool jazz, it nonetheless enjoyed a large portion of popularity in the $1950 \mathrm{~s}$, due to the preferences of jazz critics. ${ }^{\text {ccxlviii }}$ This is not noted to demonstrate the in-egalitarian operations of the music industry, but rather to note that a product which more closely resembled the music already transmitted by the industry was more likely to garner critical and popular approval. Brubeck's appearance and public 
image were a much closer match to the type of existing pathways which had achieved great success in reaching a distinct and faithful (if intellectual) college audience.

The bebop-inspired direction (for simplicity's sake, termed Hard Bop) was also recognized as a popular style of jazz during $1955-1960$, but to a lesser degree. Unlike cool jazz, however, it continued to rely on improvisation and looked more to African-American traditions for inspiration. ${ }^{\text {cxlix }}$ Although hard bop also used European compositional tools and theoretical concepts, it did not make jazz subservient to them as the cool jazz tradition did. Instead, hard bop bent the European compositional tools to its own jazz-specific ends such that these tools became elements within a jazz tradition which they did not dominate or define. Hence, whereas cool jazz made jazz sound like a European composition, hard bop made European composition sound like jazz. Further, hard bop musicians did not confine themselves solely to the techniques of bebop itself. For example, bebop musicians typically relied on musical standards to form the core of their performance repertoire, but the hard bop musicians who came after them did not necessarily. Instead, hard bop musicians experimented with various chord progressions, and other black vernacular influences (R'n'B and Gospel, in particular). However, concentration on chord progressions itself became moot as some hard bop performers began to pursue lesser compositional complexity so that a performer could improvise without focusing on rapid chord changes. This resulted in three major approaches within the hard bop direction.

First, some artists (such as Horace Silver) looked back to blues and gospel, giving rise to what was called Soul Jazz or Funky Jazz (which often used simpler chord progressions based on black vernacular musics). Silver recorded several excellent examples of this style of playing in 1955 and 1956. Second, other musicians further 
reduced the formal complexity of their music by adopting a theory that allowed them to play one scale over a number of chord changes. This approach was called Modal Jazz and Miles Davis' 1959 recording Kind of Blue remains the quintessential example. Third, the movement known as Free Jazz eliminated any sort of chord progression at all, preferring to base its performances on complete collective spontaneity. Ornette Coleman's work in the $1960 \mathrm{~s}$ is usually the most-cited reference. ${ }^{\mathrm{ccl}}$

Unfortunately, a chronological recounting is not the best method for understanding the styles of jazz during the 1950s. This is because many of them were in popular practice at the same time. Therefore, regrettably, this section may prove challenging to the reader. It has certainly done so for many jazz authors, who remain divided on the number of styles in the 1950s and the importance of each of these. However, all of these myriad styles embodied the modernist approach taken by many jazz musicians in the 1950s. Moving in opposite directions of increasing formal complexity and formal simplicity, the work of jazz musicians in the $1950 \mathrm{~s}$ and 60 s set the outside parameters of possibility for experimentation within jazz. If modernism strives to push the boundaries of what is considered art, to reflect self-consciously on the process of its own creation, to propose a new standard of evaluation, and to question its own tradition, jazz had fully signed on to this mandate.

What is interesting that, as has been previously demonstrated, this was not the first time that jazz had presented a number of divergent, competing styles. After all, the debates between hot, sweet, and swing jazz represented a variety of styles; and Hennessey's division of the United States into 6 distinct territories and bands (each with their own unique sound) in the years between 1914 and 1929 demarcates a variety of styles, too. ${ }^{\text {cli }}$ 
However, for the first time in jazz history, the proliferation of styles is noted and even emphasized by jazz historians; "recent" jazz music becomes defined as a multitude of styles. Significantly, these different directions were encouraged and supported by a decentralized music industry that favoured them. They were also assisted by a functional critical discourse that strove to categorize and articulate the different styles.

The popularity of multiple jazz styles also resulted from shifts in the organization of the jazz music industry. The music industry that marketed and sold jazz in the $1950 \mathrm{~s}$ was significantly different from the music industry that popularized swing in the 1930 s. Rather than a few monolithic corporations that dominated the recording and selling of jazz, the new jazz music industry was much more decentralized. It consisted of a large number of independent artists, small producers, and specialty record labels. With no central authority in place to limit or promote one dominant style, a myriad of styles was allowed to flourish. The increase of jazz sales in the mid-1950s certainly indicates that major labels participated in the promotion and dissemination of jazz music, but they did so primarily in a reactive role. Major labels would let independent labels sign new jazz artists, and would only take them on after they had already proven themselves. ${ }^{\text {cclii }}$ According to Down Beat in 1961 , of the $188 \mathrm{jazz}$ ensembles listed by the magazine, $78 \%$ were signed to independent labels, while the remaining $22 \%$ were with one of the major labels. Independent labels constituted a new pathway through which jazz musicians could reach audiences. And this in turn was reflected in the distinct market status of jazz music.

While jazz remained popular in the 1950 s, it only took the solidification of rock music as of the mid-1950s to bump jazz off the popular radar. Rock emerged in the $1950 \mathrm{~s}$ 
to become the dominant voice of the popular music industry, and the general public moved on from jazz..$^{\text {cliii }}$ Furthermore, as free jazz increasingly became recognized as a significant contribution to the jazz idiom, the distance between its complexities and dissonance, and the easy utilitarianism of rock music only intensified the distance from the new youth audience. Additionally, by the $1950 \mathrm{~s}$ and $1960 \mathrm{~s}$, jazz would have been the preferred music of thirty-year-olds, who had enjoyed swing while growing up in the 1930s and 1940s. If one of the defining characteristics of a new youth audience was rejection of cultural forms favoured by its parents, then teenagers in the 1950 s and 60 s were even less likely to identify with their parents' preference for jazz. The debate over free jazz led to significant changes in the place of jazz within US culture. Jazz's unstable or multiple identity during the 1960s interacted with changes in arts funding, audience composition, and career choices of performers. From an industry perspective, free jazz was suicide; the harmonic and philosophic freedoms embodied by the music, as well as its political ties to the civil rights movement, made it very unattractive to the music industry. Free jazz was distinguished by its absence of melody, rejection of any familiar harmonies or tonalities, great length and absence of repetition; all creating an extremely difficult listening experience that could only be approached intellectually, and which cast itself as the antithesis of those values that the music industry transmitted. By offering itself as a pure intellectual experiment, free jazz adopted forms that would cause the music industry to find it unmarketable. Free jazz demonstrated its inability to survive within the marketplace, which transformed the funding basis of jazz. During the late 1960s and 1970s, jazz moved into the non-profit funding arena; its musicians became reliant on private foundation and public sector funds, such as National Endowment for the Arts (NEA). ${ }^{\text {ccliv }}$ In order to 
qualify for NEA grants, jazz had to prove itself akin to other high arts which received funding (such as opera, ballet, museums, etc.). The selection of this pathway increased jazz's desire to compare itself to high art alongside other established recipients, and to construct a similar rationale for funding, that of an art form which was less-tainted by commerce, and therefore, more worthy of public subsidy. ${ }^{\text {cclv }}$ This rationale was assisted by musicians like Lee Morgan, who actively pushed for the subsidization of jazz, rationalizing it by comparing it to another established art form: "See, Leonard Bernstein plays to a minority audience, too, because everybody can't like symphony orchestras. But symphony orchestras are subsidized. And jazz should be subsidized."cclvi This rationale to include jazz as another elite art was also assisted by both new institutions and new critical approaches.

During the $1950 \mathrm{~s}, 60 \mathrm{~s}$, and $70 \mathrm{~s}$, the venues in which jazz music was performed also underwent a significant transformation. These new locations were more conducive to a fine art appreciation, and the architectural configuration of the spaces was designed for a listening audience. Jazz music moved out of the urban nightlife scene where it had formerly been established, and into a different set of pathways, those of the special concert setting, the festival, colleges, and universities. Commercial jazz clubs did not cease to exist, but they were much diminished as commercial opportunities. ${ }^{\text {cclvii }}$

The festival provides an interesting case study. In 1954, the East Coast resort town of Newport hosted its first jazz festival, to great media acclaim. ${ }^{\text {cclviii }}$ Much like Benny Goodman's 1938 Carnegie Hall concert, the Newport festival was celebrated in the mainstream press as an elite art form embraced by high society. "The fine art of American 
jazz, which rose from humble beginnings in the bordellos of New Orleans... has now reached the fabled social lawns of the Casino at Newport." ${ }^{\text {,cclix }}$ Clearly the selection of the resort town demonstrated to members of the general public that jazz was part of elite culture. Other jazz festivals included a New York Festival in 1956, and the Monterey Jazz Festival in 1958. In 1959, Down Beat magazine covered festivals in 11 different North American locations. The festival emphasized the type of appreciation accorded high art performances, since it was a venue specifically designed to bring patrons together to listen to jazz. Audiences were able to devote their attention wholly to listening to performers, as opposed to nightclubs, where conversation, dancing, and other distractions were tolerated. ${ }^{\text {cclx }}$ In this way, jazz festivals represented a new type of pathway that encouraged consumption in the manner of high art. Furthermore, the festival implies an audience with leisure time to devote to jazz. A quick preview of the Newport festival on TV - PBS shows it - reveals a celebration of whiteness, yachting, noticeable tans, long blond hair, and excellent attention to nutrition.

The jazz concert also became a significant venue for performance during the $1950 \mathrm{~s}$. Norman Granz's touring "Jazz at the Philharmonic" concerts grossed more than $\$ 1$ million dollars annually in the late 1950 s (though they folded in the $1960 \mathrm{~s}$ ). ${ }^{\text {cclxi }}$ Other jazz concerts were regularly held at traditional bastions of high culture such as Carnegie Hall and the Museum of Modern Art in New York. Jazz promoters aimed to identify their jazz music product with established high cultural art forms. Musicians and critics alike recognized the importance of altering the pathway along which jazz music was offered and "actively sough locations for jazz performance outside the club scene for reasons of status, aesthetics, and money."cclxii Like the festival, the concert encouraged the presentation of 
jazz as a serious art form for a listening public. Concert-goers were seated in rows, facing the stage, and therefore both convention and architecture discouraged conversation and any overt physical response (like dancing). In contrast, nightclubs were structured around table settings, which promoted conversation, and dancing was often permitted, if not encouraged. In this way, a shift in venue suggested a different behavioral response, and by presenting itself according to established high culture concert conventions, jazz musicians offered a musical culture suggestive of an elite pathway.

A third venue to consider is the isolated beginnings of the jazz camp, which created a new pathway for musicians to access and understand their art more thoroughly. The Lennox School of Jazz was only in operation from 1957 to 1960 but had an enormous influence on the future direction of jazz. A partial listing of the impressive cadre of students and teachers included Bill Evans, Dave Brubeck, George Russell, Ornette Coleman, Don Cherry, Freddie Hubbard, Don Ellis, and Steve Kuhn, among others. It was set up within walking distance of Tanglewood (the famous summer home of the Boston Symphony Orchestra) and prided itself much on the same model as the classical music summer camp, where students would study with established professionals. ${ }^{\text {cclxii }}$ The camp became an important step in the formal study of jazz, as it began to lay pedagogical foundations for jazz. Whereas before, jazz had always been taught through performance, jam sessions, and practical experience; the jazz camp now began to explore the more studious aspects of "teaching." Perhaps the most important aspect of this camp was the dissemination of a new approach to jazz performance. One key plank that made an intellectual approach to chord structures and scale choices possible was laid out by George Russell, a theory teacher at the Lennox camp, who had published a book in 1953 entitled 
The Lydian Chromatic Concept of Tonal Organization. The book articulated all the mathematical possibilities and variations of note combinations that could be played over a chord. Basic theoretical exploration had begun in jazz already, but what was still lacking in the 1950 s was a self-contained, systematic theory of tonality and harmony that methodically explored all the possibilities for harmonization. ${ }^{\text {cclxiv }}$ This was what Russell's book offered. Its effects were widespread. John Coltrane, Miles Davis, and Ornette Coleman (who would serve as extremely influential experimenters in the 1960s) all cited the book as responsible for their understanding of music theory. ${ }^{\text {cclxv }}$

The transformation in musical conceptualization represents an irreversible development in jazz; indeed, this complex theoretical approach to jazz has become the dominant form of the music even to the present day. As the result of their studies, two Lennox students, David Baker and Jamey Abersold, went on to create multi-million dollar publishing empires based on practical methods for learning jazz. This idea is encapsulated in the Lennox School prospectus, which offered a "conception of the history of jazz, the development of its styles and idioms, and its relationship to music as a whole... a point of view toward jazz as a significant and vital art form of our time." ${ }^{\text {"cclxvi }}$ This mission clearly outlines what would become the first foray into what might be termed the "pedagogicalization" of jazz music. Other examples of the jazz camp began to spring up in the 1950s, and the first national college festival (which brought together recreational college jazz bands to perform) was held in $1956 .{ }^{\text {clxvii }}$ In this way, the jazz camp reflected and anticipated many of the changes that would happen to jazz as it entered the university institution. 
Significantly, jazz music in the 1960 s became too complex to pick up by ear. It now required formal theoretical training. The expansion of the theoretical approach to jazz was pushed to its furthest extreme by the free jazz movement and the work of Ornette Coleman. In 1964, Coleman and his octet recorded Free Jazz, which was improvisation with no rehearsal, no planned chord progressions, and no planned structure. Of course, Coleman's music may not be what it appears to the first time listener; it is not complete and utter noise. Free jazz still has many rules, and Coleman is only able to play what he does because he has the technical capacity to play bebop and is aware of the very conventions he is striving to violate. ${ }^{\text {cclxviii }}$ (His solo on Lonely Woman, for example includes variations of Charlie Parker licks). Rather, free jazz is the jazz equivalent of Avant-Garde contemporary classical music, which seeks freedom from traditional approaches to music making. Free jazz is more about the intellectual awareness of convention than about melody; it is more philosophical in approach than pleasure-driven. Listeners used to traditional music find this approach mere chaos, with no meaning. But those who can listen in other ways may be able to explore an amorphous conception of music, which changes with each hearing as one concentrates on different instruments. However, as such, the music exists to divide an audience into those who can intelligently disconnect themselves from their expected conceptions, and those who cannot derive any form of intellectual pleasure. Free and Modal jazz therefore represent jazz music as a highly formalized elite music, one that no longer allows for dancing, and assumes patient, sophisticated listeners with an appreciation of musical theory. ${ }^{\text {cllix }}$ Furthermore, the quest for academic legitimation also created a new audience for jazz; of elite, college-educated participants, who had often taken a course in jazz history. Therefore, the theoretical 
possibilities offered by Russell's publication ensured the creation of an elite club of professional musicians and educated audiences. (In other words, this is the definition of the complex code of which one must have mastery in order to listen to jazz.) This was a critical pathway that allowed jazz to entrench itself within a cohesive modernist theoretical tradition, on par with all other established elite musics.

The final venue through which jazz sought to establish its high art status was the college centre. In seeking to enter the university, jazz music placed itself directly alongside other established elite musics (classical and opera), and would have to appeal to their standards, if it was to be judged worthy of elite status. This was not a quick process and required the adpption of a new set of pathways that would allow jazz music to develop itself for an elite group of specialized practitioners. Cool jazz quickly became popular with the college scene in the early 1950s. In 1953, Dave Brubeck released "Jazz at Oberlin," which was the home of one of the oldest classical music conservatories in the country. The significance of the performance was evident, as the album liner notes spoke first of the Oberlin conservatory's close adherence to established classical literature, then of jazz music's "firm and comfortable" acceptance within the structures of the college. ${ }^{\text {cclxx }}$ However, beyond being a venue for concert appearances, jazz music was now making slow inroads into academia as a scholarly discipline. Music conservatories for jazz were established in the 1950s, including those at Berkelee in Boston, and Westlake in Los Angeles. North Texas State introduced a major in jazz as early as 1950, and by 1975 , it was one of six North American colleges to offer a post-graduate degree in jazz. In the earlier part of the century, apprenticeships as sidemen allowed musicians to learn to perform jazz. Learning was based on the ear, instead of written music; more the lived 
experience of the music than any abstract concepts. This has been changed by jazz education in colleges. This movement away from informal institutions (jam sessions, band apprenticeships) towards more formal courses, workshops, and college classes had a number of effects on jazz musicians. ${ }^{\text {clxxi }}$ It encouraged burgeoning jazz musicians to seek out formal training in technique and theory, instead of the loose, practical training that had sufficed during the Swing Era. ${ }^{\text {cclxxii }}$ Furthermore, as they accepted tenured positions, musicians were no longer required to continue with developing an art form, but could instead concentrate on theorizing and historicizing, without worrying whether the market or a record label approved of their work (what Alice Goldfarb Marquis pessimistically calls the "steep price of respectability"). ${ }^{\text {clxxiii }}$

From a critical angle, in order to be accepted fully by academia, jazz music would have to demonstrate that it was truly an elite music, that it operated along the same pathways, and with the same forms as other elite musics. In order to be taught as a formal subject or discipline, the practices of jazz required many elements of routinization. Again within an academic setting methodology, theory, and history were all required, as were formal methods to teach them. ${ }^{\text {cclxxiv }}$ A vitally important aspect of this was the development of an official history and a canon of established repertoire, both of which classical music had. The canon advances jazz's status as an original art form by providing an aesthetic and ideological framework for judging the legitimacy of past, present, and future achievements. And by the 1970 s, a basic jazz music repertoire of standard tunes had been formulated. ${ }^{\text {clxxv }}$ The uniformity of this canon was further standardized by the 1974 creation of a bootleg fake book called The Real Book by two Berkelee College students who endeavored to 
notate the types of tunes and chords that jazz musicians played at the time. ${ }^{\text {cclxxvi }}$ They did not have the money to protect their investment, and so the book was published without any legal copyrights for the tunes. Because of its idiomatic representation and great breadth of tunes, this book was to become a biblical reference work to young musicians, an immense underground success, and a generally-held prerequisite for jazz performance. Knowledge of the tunes contained in the book is a requirement for all young jazz musicians even today, and the keys in which the tunes are rendered in the book are the standard keys in which they are performed. One can go to any jam session in any town in North America or Europe and find a copy of the book. The creation of this book therefore has canonized the repertoire, despite being only two people's ideas of what was important. However, even more interestingly, because of its copyright violations, the book remains illegal. One can get the book at some music stores in most cities, but it will be under the counter, and must be asked for specifically by name, often with a reference from an established player in town. This key piece therefore demonstrates both the canonization of a selection of jazz repertoire, as well as the rather difficult pathway that one must travel in order to have access to that repertoire.

As far as a distinct methodology for jazz, Charles Beale states that "the need to justify jazz education as worthy of institutional and cultural attention led to a clear, if in retrospect, slightly limited, definition of a single jazz style and related set of skills.”,cclxxvii Methodologies of jazz have canonized bebop music as the basis of modern jazz, and a comprehension of bebop serves as the basis for most jazz performance programs of study. Some have argued that this turn in jazz has alienated its audience, and become too specialized. They say that a concentration on bebop as the basic calisthenics of jazz 
improvisation causes jazz to lose its audience. It makes technical and interpretational demands that are simply beyond the capabilities of the mass of students and can therefore be socially exclusive. ${ }^{\text {cclxxviii }}$ And while this may be an interesting point worth arguing, for the purposes of this paper it perfectly illustrates jazz music's development of elite, exclusive pathways that are only accessible to musicians and audience members who are educated enough to understand the complexities of the code.

Another aspect in the development of jazz was the development of a history of the art form. Jazz in the 1950s was confronted with attempts by critics to produce a comprehensive history of jazz. Early attempts by writers such as Hugues Panassie (Le Jazz Hot, 1934) or Rudi Blesh (Shining Trumpets, 1946) were incomplete because the parameters of jazz had not yet been defined; the music was still in formation. However, by the 1950s, the presentation of a basic evolution of jazz from folk to popular to high art music had become standard. This was accompanied by what Lopes calls the "literation" of jazz; the increased importance of the written word and the written note. ${ }^{\text {clxxix }}$ The written word became increasingly important in understanding jazz, and the plethora of jazz histories published in the 1950 s and 1960 s testified to this increase. ${ }^{\text {cclxxx }}$ Later histories canonized earlier arguments. Histories written in 1977 (like Frank Tirro's), for example, incorporated free jazz without revealing many of the contentions the movement had previously unleashed. Therefore, jazz critics were able to actively construct a jazz tradition. And much like literacy rates within the general population, literation in jazz suggests the development of a specific and complex code. Within jazz periodicals, jazz began to take on inevitable high art leanings. Down Beat, which had begun in a tabloid format (often publishing pictures of women in swimsuits or popular singers) changed its 
content quite dramatically. It dropped its coverage of popular music completely, and began to explore the future of jazz as a recognized high art genre. Jazz critics since the early 1950 s had been castigating commercialism and trying to explain the difference between jazz and popular music. But by the 1960 s, this rhetoric had expanded to include a discussion of the importance of classical music in jazz innovation and growth, and the struggle to find venues and support for jazz performance as a high art form..$^{\text {cclxxxi }}$ Through these discussions, critics were able to find autonomy from fans by creating a metalanguage. Everyone could opine, but only professionals could speak a language and brandish mastery of a paradigm.

Technology also played a small part in reinforcing the elitist pathways that jazz was traveling. The introduction of the LP record presented an alteration of a pathway for jazz. The LP extended the length of a record side from roughly four minutes to roughly twentyfive. Introduced in 1948, it quickly divided the music industry into the full-length album and the single..$^{\text {cllxxxii }}$ Interestingly, popular record producers did not exploit the longer format, confining popular music to the single format until the 1960s. The LP repertoire was therefore the territory of classical music (which could finally record entire symphonies) and the surviving dance bands and their singers. ${ }^{\text {clxxxiii }}$ So the technology was available for making longer recordings, and the possibility of listening to jazz in a longer format was in place. All that remained now was for artists to begin to record longer takes of songs. The LP allowed artists to record a ten, fifteen, or even twenty minute song, which jazz artists began to exploit in the 1950s by taking longer and longer solos. These solos were, again, increasingly complex, and, lacking in melody and repetition, required 
more concentration from an audience. Therefore, the separation of LP and hit singles in both technological and industrial formats also encouraged the consumption of jazz along a specialized pathway.

The impacts of all these elite specializations of pathways and vocabulary were felt by the jazz audience. Though diminishing throughout the 1940s and 50s, jazz audiences were still a large part of the American public and the recording industry. Yet this popularity camouflaged the fact that jazz had become a music to be listened to, instead of danced to. Contrary to the swing era, audiences were no longer able to easily identify a catchy tune, or a simple rhythm, because artists were aiming to enrich and complicate exactly these aspects. Tirro notes that beginning in the 1950s, "those members of American society who came to jazz for entertainment and relaxation were beginning to turn away from the newer forms because of the increasing levels of musical and intellectual sophistication now being demanded of them." "clxxxiv The distancing of jazz from a commercial focus did not necessarily mean a great decline in popularity. The jazz audience throughout the 1950s was smaller than the swing public of the 1930s and 40s, but remained stable. It became, as Gary Giddens put it, "smart music for smart people. The masses don't get it? That's a good thing -1928 all over again. We're hip and you're not." "clxxxv One particular market that became very interested in this "smart" jazz was the college concert scene. While hiring jazz bands for dances had been popular at colleges and universities since the $1920 \mathrm{~s}$, the university increasingly became important as a venue for jazz concerts. As jazz moved into the academy, it enjoyed a popularity with collegeeducated people and students. Dave Brubeck's highly successful college recordings and 
concerts in 1953-1955 led to the emergence of a college circuit. ${ }^{\text {clxxxvi }}$ The changing of jazz's pathways into more elitist streams led to the construction of a different, specialized, educated audience.

Therefore, through the adoptions of all these different pathways, jazz music was moving closer towards the norms of elite culture, as set out by other established musics. Venues for jazz were becoming less commercial in orientation; they were performance halls, college concerts, and workshops or summer camps. Critics played an established and important role in judging new pieces and artists, acting as gatekeepers for the general public. Jazz musicians relied less on selling a commercial product to a mass market, and more on a model of public-sector patronage. A self-conscious aesthetic code was elaborated and circulated. The music industry had fragmented and no longer promoted a single jazz style but favoured several competing styles. And the jazz audience was becoming more educated; the complexity of the music demanded an audience that could make an intellectual connection. ${ }^{\text {clxxxvii }}$ Therefore, because of the creation of jazz traditions that mirrored other high arts, jazz became known as a formal discipline of study within academia by the 1970 s. Though still sometimes tempered by resentment and a lack of respect from other music scholars, jazz became further and further entrenched within academia. $^{\text {cclxxxviii }}$ Academics could now theoretically examine and understand the development of jazz, situate it within a unique high art history, aesthetically and objectively critique jazz works on their own self-referential merit, compare a jazz tune against an established canon of great works, and feel comfortable in comparing jazz to other high arts. Jazz music had ceased to function as popular music, it was now elite music. 


\section{Fusion as a Popularizing Movement}

The blend of rock and jazz sounds explored by the fusion movement in the early 1970s was one form of backlash against the establishment of jazz music within the circles of elite culture. Jazz musicians adopted electric instruments, effects, and sounds popularized by rock in an attempt to create a style of jazz that would be more accessible, more hip. Though it is usually presented as an attempt by jazz musicians to incorporate rock music within their sound, it can also be read as an attempt to utilize different pathways in order to return jazz music to the level of popular culture. In both tellings, fusion can be presented as a failed experiment, but the reasons for its failure are different. If fusion is just the use of rock sounds to reclaim a larger audience, there can only be speculations as to why it failed as a popular music. It may have failed because rock already did what it aspired to, and did it better. Or fusion may not have gone far enough to overcome the alienating aura that clung to its jazz remnants. However, if fusion is the attempt to utilize different pathways to return jazz to the status of popular culture, then the success or failure of the movement can be judged on how successful a pathway was adapted for the musical product. Fusion failed because it was not able to garner enough critical support to overcome the alienating elitist aura that clung to jazz.

The usual presentation of fusion is as follows: As jazz neared the end of the 1960s, it was pronounced dead by a number of critics. The Avant-Garde free jazz explored by Ornette Coleman, Albert Ayler, Don Cherry, and Roland Kirk had no viable future in the marketplace, and fans and sales numbers dropped. Debuted by musicians such as Elvis Presley, Jerry Lee Lewis, and Bill Haley as early as 1954, rock music was gaining in 
popularity, especially with youth. And with the onset of Beatlemania in 1964, rock established itself as the dominant form of popular music, further decreasing the share of the marketplace occupied by jazz music. However, many jazz musicians sought to return jazz to the mainstream by adopting elements of rock music. Ever the innovator, Miles Davis began to blend his jazz ideas with electronic instrumentation, specifically the electric piano, electric bass, and electric guitar. His 1970 album, Bitches Brew, set the stage for the growth of fusion, selling over 400,000 copies and becoming a mainstream hit, despite being critically condemned for "selling out" by many jazz critics. Other fusion acts began to surface in the 1970s: Joe Zawinul and Wayne Shorter's Weather Report, Bob Mintzer's Yellowjackets, and/Chick Corea's Return to Forever. ${ }^{\text {cclxxxix }}$ Herbie Hancock's Headhunters produced a best-selling pop single in 1973. Fusion mixed jazz improvisation with the instrumentation and rhythmic conception of Rhythm \& Blues. It was the most commonly performed jazz music throughout the $1970 \mathrm{~s} .{ }^{\text {ccxc }}$ The commercial success of fusion garnered critical disapproval from many jazz writers, who accused fusion of "selling out," of deliberately catering to a commercial audience instead of performing more "artistic" jazz. ${ }^{\text {cxci }}$ Fusion continued to a degree into the 1980 s, with a new label, "crossover" to signify its expansion to include other cultural and ethnic musics. However, in the $80 \mathrm{~s}$, the critical backlash continued, claiming that fusion innovations were not a part of the jazz tradition, and that they distorted the true meaning of jazz, as developed by Louis Armstrong, Duke Ellington, and other early jazz greats. The fusion movement had become codified by the late 1970 s, smoothing off its rough edges into a more palatable pop-jazz that paved the way for commercially successful New Adult Contemporary Jazz, such as Spyro Gyra, Geoff Lorber, and Kenny G. ${ }^{\text {ccxcii }}$ For these sins, fusion was expelled from the 
canon of jazz; rejected by the dominant tradition because of its ties to commerciality and mainstream pop sounds. Or so the story usually goes. Yet an examination of the four key factors can do much to explain why this movement/experiment failed to be included within the already diverse definition of jazz.

The factor of technology was the first pathway through which musicians sought to renegotiate the position of jazz. Much of the fusion project was carried out by jazz musicians surrounded by speakers amplified by solid-state electronics. They performed on instruments that were electric (pianos, basses, electric guitars) and used a host of electronic effects (fuzz boxes, moogs, wah-wah pedals, etc.). These were not merely a different set of instrumental choices; they were deliberately favoured for their established use by rock artists. $^{\text {ccxciii }}$ Rock artists had built their distinction from other streams of music through the use of electric instruments, as well as the volume that an electrified instrument could produce. Therefore, in using these instruments, fusion artists were not just experimenting with a new type of sound but were deliberately choosing to create a type of sound that already contained a certain image and enjoyed a certain type of popularity with a specific audience. This sort of thinking can be noted in Miles Davis' 1968 references to the influence of rock musicians such as Sly and the Family Stone, James Brown, and Jimi Hendrix leading to his creation of the seminal Bitches Brew. In particular, Davis notes long jam sessions with Hendrix in 1968, a working musical relationship, and a deep respect for the other's music. Given this environment, it is small wonder that Davis created an album which mirrored his respect for this type of music. ${ }^{\text {ccxciv }}$ Davis began basing his own musical riffs on Hendrix's sound. He began to use electric pianos and 2 or 
3 electric guitars in his groups to create the throbbing sound of a rock band. Even more specifically, Davis began using electronic effects such as the wah pedal on his trumpet's sound to imitate Hendrix's wah guitar effects. This type of imitation, and interplay between rock and jazz artists, was certainly noted in the early 1970 s. $^{\text {ccxcv }}$ Other examples include notable jam sessions between Jimi Hendrix and jazz saxophonist Roland Kirk, and Lou Reed's compilations with Ornette Coleman. ${ }^{\text {cxcvi }}$ Therefore, jazz fusion artists deliberately chose to align themselves and their sounds along technological pathways that had a different set of associations than the established jazz tradition. This provided a musical product that would be accepted and accessed by a different audience than jazz previously had.

Of course, the dissemination of this different sound was assisted by the utilization of a different institutional pathway. Throughout the 1960s, jazz had continued to align itself with the University, thus projecting a serious and intellectualized image. If it was to succeed as a popular music, it would have to dissolve this association. Artists such as Miles Davis attempted to break with the intellectual traditions surrounding jazz by performing in stadiums and clubs alongside other rock bands instead of in concert halls. After releasing Bitches Brew in 1970, Miles Davis began touring in a different sort of manner at the insistence of his label president, Clive Davis. ${ }^{\text {ccxcvii }}$ Miles was encouraged to perform at the legendary rock auditorium, the Fillmore, in San Francisco, opening for the Grateful Dead. His performance in a rock music venue, coupled with his association with an established rock band, was able to access a new type of audience (one that was young, white, and enjoyed the popular music of the time). In an interview, Miles recounts his impressions and the effects of this exposure: 
That was an eye-opening concert for me, because there were about five thousand people there that night, mostly young, white hippies, and they hadn't hardly heard of me if they had heard of me at all. We opened for the Grateful Dead, but another group came on before us. The place was packed with these real spacey, high white people, and when we first started playing, people were walking around and talking. But after a while they got all quiet and really got into the music. I played a little of something like Sketches of Spain and then we went into the Bitches Brew shit and that really blew them out. After that concert, every time I would play out there in San Francisco, a lot of young white people showed up at the gigs. ${ }^{\text {excriii }}$

In this quotation, the access to a different audience can be clearly noted, as well as the positive effects. Miles continued to tour with rock groups, opening concerts for Santana, the Band, Laura Nyro, Crosby, Stills, Nash, and Young, and others. He performed at the Isle of Wight Pop Festival in front of a crowd estimated to be 400,000. Other early jazz musicians who utilized the rock stadium venue included the saxophonist Charles Lloyd (who performed at the Fillmore in 1967-1968, and recorded a live album there in 1967), Wayne Shorter and Joseph Zawinul's group Weather Report, and others. Through this combination of new pathways in technology and venue, jazz groups were able to access new, popular audiences, and as a result, realize commercial success reminiscent of the days in which jazz functioned as popular culture.

This commercial exposure was further assisted by the use of the commercial music industry. Again, during the 1960 s, jazz music, as a genre, had noticed significant decreases in commercial sales, and had begun to explore other pathways by which it could realize a continued existence (such as public funding and NEA grants in the 1970s). However, fusion was to move again back into the realm of mainstream popularity, and so, would again return to the pathway of support through the music industry. As the 1960 s wore on, radio programming became less about individual disc jockeys and more reliant on standardized format programs. These formats were designed to appeal to specific 
demographic audiences, but had the effect of solidifying distinct genres of popular music. The more popular music formats were the ones that would attract the widest audience, which is what appealed to the commercial interests of the music industry. Market research firms who conducted audience testing created high rotation playlists which ensured recordings were popular with the "broadest possible appeal." "cxccix It was therefore very unlikely to hear avant-garde jazz played on the radio as it simply did not meet the requirements of any popular music radio formats. Fusion changed this. With a marketable sound (akin to rock), fusion was able to successfully navigate the pathways of commercial factors and encourage growth in jazz sales. In the early 1970s, jazz radio programming became dominated by soft jazz and fusion jazz as radio musical directors hoped to attract larger demographics. Likewise, major record companies shifted their interests away from modern jazz to jazz which incorporated rock practices. ${ }^{\mathrm{ccc}}$ And as previously noted, labels began to encourage fusion bands to perform in rock venues. Rock bands such as Chicago and Blood, Sweat, and Tears began to prepare the music industry and set a musical precedent for other jazz-influenced sounds with their use of horns and improvisation, while not in themselves (according to most critics) constituting a true jazz-rock fusion band. The dramatic increase in sales by artists such as Miles Davis and Herbie Hancock worked as proof that the new fusion sound was successfully accessing a large new audience. ${ }^{\text {ccci }}$ Further "commercial refinement" during the 1980s and 1990s produced "smooth jazz," an updated form of fusion. It was specifically designed for FM airplay, with musicians writing tunes and solos specifically to fulfill rigid format requirements of FM radio stations. Jazz musicians such as Jeff Lorber, Spyro Gyra, David Sanborn and Kenny G generated huge amounts of commercial revenues with their simple, melodic tunes. While 
never demonstrating blockbuster hits and the phenomenal popularity of rock, fusion in the form of commercial jazz has been comfortably successful in commercial circles. By the end of the 1990 s, there were over 200 radio stations across the US that specialized in fusion/smooth jazz. ${ }^{\text {cccii }}$ If rock was the pathway, the format of preference to the popular music industry, by creating a sound similar to this format, jazz would be able to utilize this pathway.

The final factor to examine in regards to the jazz fusion movement is the critics. This is an interesting factor, because, like all new directions in jazz music, fusion was hotly contested. For the most part, the critical approach to fusion has been one of rejection. Peter Watrous, for example, summarizes the elitist passions and standard critical summary of fusion when he states:

While the early attempts at fusion were often musically sophisticated, the music quickly faltered, losing its complexity and experimental vigor, and by the late 1970 s, it barely existed. Within a handful of years, jazz fusion became a sort of instrumental pop music, using pop's melodic ideas, rhythms, instruments, and textures. And with that, a dream vanished; like any mule idiom, it was barren. ${ }^{\text {cciii }}$

Here, what Watrous obviously values is complexity and experimentation not melody, rhythm, texture, etc.; placing him as a defender of jazz music's elite position. Fusion was quickly labeled as a simplification of jazz by other critics, a sound that was much more defined by the commercial fashions of the day than by the serious action of making music. A common theme of elite culture throughout the ages has been the setting of a divide between commerce and art. ${ }^{\text {ccciv }}$ Art is seen as being autonomous, created to realize formal perfection and transcendence, whereas popular culture is created with commercial motivations; and therefore, fusion, with its simplified chord changes and reliance on popular electronic effects of the day could not hope to be high art. Music could be high 
art, or it could be popular, but could not be both as the fate of fusion suggests. Pianist Horace Silver postulated that jazz artists "are either propelled into a certain direction by record people, or they follow what the masses are doing, in order to make more money. Few have the courage to stand by what they believe in" (which would presumably be the pursuit of high art). ${ }^{\mathrm{ccc} v}$ Even the compilation of jazz texts reveals this critical bias against fusion. For example, Robert Walser's selection of readings about jazz covers every decade in the 1900s. However, while its selections from the 1980s outline the traditionalist agenda, its selections from the 1960s and 1970s are completely devoid of fusion, preferring to focus instead on jazz as a progressive social force (indicative of racial equality and opportunity). ${ }^{\text {cccvi }}$ Of course, the critical reaction against fusion is not so much an accurate or factual account of the music's quality or value (ever subjective) as it is a desire on the part of jazz critics to maintain their authority. What fusion points to is a relative decline in the status and role of critics within the constellation of jazz aficionados. The audience for fusion was not the audience for cool jazz and it did not value critical input in the same way. The rising popularity of fusion was, therefore, also a challenge to the status of criticism. The critics' authority rested on their ability to adjudicate the value of overtly 'artistic' jazz style such as cool jazz. Any non-overtly artistic jazz style, such as fusion, therefore had to be attacked and denigrated.

The other critical response, which has been heard increasingly in the last decade recognizes that jazz has incorporated popular sounds and styles since its early days in New Orleans. Examples are given from the 1920s (jazz and ragtime renditions of Tin Pan Alley songs), and it is usually pointed out that even the bebop masters utilized popular standards. ${ }^{\text {cccvii }}$ However, these arguments neglect the vast and vested interest that critics 
have in continuing jazz as elite culture. Critics and academics have spent an enormous amount of time since the 1920s developing a lexicon specific to jazz, a canon of standards, and a set of aesthetic justifications. With this level of critical scrutiny commonplace by the 1970s, it becomes difficult to turn away from it. Once a specific, identifiable history of jazz is in place (especially one that has constructed a narrative on the progression of jazz from a folk music to an elite music), it is very hard for fusion to undo these definitions..$^{\text {cccviii }}$ In essence, the defenders of 'art' jazz have become this generation's Moldy Figs, clinging to a past that is irrevocably slipping away. Yet it is important to note that the new Moldy Figs have power, authority, and inertia, and can act to entrench their preferences much more vigourously than the Moldy Figs of the 1930s could.

So why did fusion fail to establish itself as the dominant form of jazz? It had demonstrated that it could succeed in the commercial marketplace by adapting itself to the pathways of technology, places of performance, and the music industry. It was commercially successful, enjoyed by a large section of the population. It seemed to represent a realistic future for jazz, returning to thrive as a popular culture. The only factor it did not adequately negotiate at the popular level was the critical factor. And with the increased importance of the critic within elite culture, it was the critics who ultimately held the power to define what was part of their elite culture of jazz. And they cast fusion as a failed experiment. It was the critics who expelled fusion from the jazz narrative, by explaining that it was not "real" jazz, that it did not fulfill the criteria of autonomous art (which jazz had become). The evidence of this failure is contained in the struggle over the definition of what is jazz and what isn't. From a music industry perspective, fusion (and other crossover artists) were labeled as jazz, and consequently were seen to bolster sales of 
the genre as the movement successfully navigated the pathways of the popular music industry. However, from a critical and academic perspective, fusion (with a few exceptions for great masters) was considered too simple and too commercial to constitute "real" jazz, and so, was cast out of the canon of recognition. Therefore, the bifurcation of jazz can be seen to be evidence of fusion's failure to turn the dominant narrative of jazz towards a popular music again. This struggle over definition re-affirms the importance of DeVeaux's claims that much of jazz criticism is the struggle over the possession of jazz history. However, unlike DeVeaux's open-ended questioning of jazz definitions, pathways analysis enables us to understand exactly why it is that certain perspectives are able to win over the ability to define jazz history.

Now it should be noted that jazz-rock blends, and fusions with different types of popular music, are still attempted by jazz musicians today. Jazz and rap fusions with different degrees of balance have been attempted by groups such as US3, Guru, The Brand New Heavies, and Groove Collective. What became known as the Acid-Jazz scene (featuring groups such as Medeski, Martin \& Wood, and The Greyboy Allstars) attempted to reconnect jazz with the urban dance floor. Jazz and Electronica/DJ combinations have resulted in popular success for groups/artists such as St. Germain, Koop, DJ Logic/Metalwood, DJ Spooky, and The Herbalizer. But the critical perspective towards all of these movements remains similar. As Stuart Nicholson puts it: "This is not music of substance, it is deja-vu jazz with a backbeat." "cccix Therefore, from the perspective provided by pathways analysis, it seems unlikely that these attempts will be able to reclaim jazz as a popular music without the unlikely support of critics and withdrawal of jazz from the halls 
of academia. Jazz fusion would require a much greater sustained level of popular support to disenfranchise jazz from its position as an elite music.

\section{Neo-Classicism as Elitist Movement}

Jazz history textbooks have categorized the 1980s and 1990s as characterized by a Neo-Classical movement within jazz. Most texts attribute the neo-classical movement to the work of Wynton Marsalis. Marsalis deliberately set himself up against the continuing fusion attempts of Miles Davis in the early 1980s; one man representing a return to conservative values and a 'purer' definition of jazz, the other representing the ability of jazz to morph into new styles. Marsalis' popularity grew quickly, bolstered by his clean, handsome, intelligent, and articulate appearance. ${ }^{\text {ccx }}$ In 1984, he was the first artist in history to win a Grammy for both classical and jazz recording in the same year. Marsalis' virtuosic abilities in both classical and jazz won him legions of fans, and built a new standard for jazz musicians. His artistic abilities were importantly accompanied by an outspoken philosophy concerning the state, practices, and history of jazz. Jazz, for Marsalis, is greater than pop music. It is not pop music, but rather, a full-fledged art form with a distinguished history. Pop music is basic, for teens, and not serious; something that one doesn't "really have to know too much to know about." The purpose of pop music is to "sell records that appeal to people on a level that they want to accept it on.",cccxi But whereas pop music is a celebration of ignorance, Marsalis' neo-classical beliefs are a conscious attempt to stimulate some kind of intellectual realization. It is art, and specifically the art form of jazz that tries to make life meaningful. Marsalis feels that one cannot "improve" on jazz without being schooled in its history. ${ }^{\text {cccii }}$ Notice how this 
sentiment recognizes the importance of tradition, a key distinction of elite culture. It is also indicative of a modernist philosophy, in that Marsalis specifically pursues artistic “improvement." Marsalis was featured in a Time magazine cover story in 1990, proclaiming that straight-ahead jazz was being revitalized by a new generation of talented young musicians who were rescuing jazz from its near-death experience in the 1970s by returning to its roots. ${ }^{\text {ccxiii }}$ Textbooks usually conclude with a note about the potentially controversial nature of Marsalis' claims, but counter that his approach has revivified a host of "young lions" who seek to follow this neo-classical creed; studying and idealizing the past works of jazz musicians of the bebop era and other "elitist" jazz composers who advanced the art form of jazz (such as Duke Ellington, Tadd Dameron, Max Roach, Louis Armstrong, Dizzy Gillespie, Charlie Parker, Thelonius Monk, and Bud Powell, to name just a few). Neo-Classicists generally shy away from endorsing the more commercial works of the Swing Era, while supporting the more "artistic" musicians. Miles Davis' early works, modal and cool styles are celebrated, but Davis' later fusion work is frowned upon, for example. Marsalis' authority over the traditions of jazz can be noted in programs such as the PBS Jazz documentary (2001) in which he was the guiding narrative voice. The fact that it was Marsalis who was chosen as narrator demonstrates his authority, and the fact that it was a public educational undertaking indicates the level to which he has become a gate-keeper on the subject.

Many observers have difficulty in understanding the specific trajectory of the neoclassical movement. Does it seek to return jazz to the status of a folk culture, the music of its New Orleans past? Or does it seek to return it to the time of the jazz renaissance of the 1950s, when jazz still enjoyed a higher profile and greater cultural centrality with the 
general public? Neo-classicism clearly opposes the blend of rock and jazz found in fusion, and is very discrete on the subject of swing, the moment of jazz's greatest popularity. Furthermore, neo-classicism is often accused of condemning jazz to its past, instead of projecting a forward vision. Finally, neo-classicism is traditionally referred to by jazz history textbooks as something new. Yet, when the pathways along which neo-classical jazz travels are analyzed, they do not differ from the elite pathways utilized by jazz culture during the $1960 \mathrm{~s}$. Therefore, upon a careful examination of the effects and pathways that the neo-classical movement employs, it can be said to be a movement that seeks to reinforce jazz music within the pathways of elite culture. This is also the reason for its success. While there still remains some critical debate over the direction of jazz, and whether the neo-classical approach allows jazz the freedom to continue to evolve, this movement succeeds because of its re-affirming use of elite pathways. It does not need to establish new critical, institutional, technological, and industrial pathways, but rather, can simply expand and establish its role within the already utilized pathways.

Technology also performed a role in reinforcing jazz music as an elite pursuit and niche market under the Neo-Classical jazz movement. The switch in the presentation of audio recording media from cassettes to compact discs took place during the $1980 \mathrm{~s}$, and the change in medium created a desire for the re-issue of "classic" albums. ${ }^{\text {ccxiv }}$ The question of why jazz bebop albums were re-released instead of jazz fusion albums is a further testament to the ascension of jazz as an art form. Popular music is characterized by unrelenting transition, new styles quickly seem old and lose favour within the industry and the popular market. The jazz fusion works of the 1970s were attempts at popular music, 
and so, therefore, the vast majority of them would quickly drop out of public consciousness by the 1980 s. However, those works of jazz which resided in the jazz canon remained required touchstones for practitioners and enthusiasts alike, and would therefore be desired in a new, improved medium. Old and new collectors alike rushed to replace their old vinyl LPs with new, clear-sounding CDs. Record labels (assisted by the knowledge that it was cheaper to reissue an old session than pay for a new recording) began to issue sets of old albums, often with the "classic" label or series theme. ${ }^{\text {cccxv }}$ These series were able to introduce new audiences to the jazz tradition, but also helped solidify the canon of established material. Even further, labels like Columbia, Verve, and Blue Note went into their past catalogues for previously un-issued historic sessions. The result is that more recordings from the bebop and other classic jazz eras are available now than at the time they were recorded. Audiences and musicians today have an immediate availability of traditional knowledge, perhaps even "more opportunity to learn about the past than about the present," as Art Lange puts it. ${ }^{\text {cccxvi }}$ This has made present-day sales of jazz records heavily reliant on past catalogues.

Yet despite these technological improvements, and the availability of a large number of recordings, overall, jazz remains a niche market. Jazz record sales account for roughly $3-5 \%$ of all record sales, close to the numbers for classical music, and roughly the same proportion of audiences rate jazz as their first choice in music listening. The total number of people who annually attend a jazz event is slightly less than for classical music ( $10 \%$ of the US public in 1992), however, a small percentage of the jazz audience forms a disproportionately large share of the total number of attendees. This lends credibility to the statement that jazz is participated in by a smaller number of dedicated fans, enthusiasts, 
and concert-goers. Furthermore, over $75 \%$ of annual jazz participants have had at least some college education, and in this, the audience profile for jazz resembles that of the other arts activities, who realize higher levels of participation from the most affluent and educated. Jazz is therefore a niche market, primarily accessed by those members of the elite with education or a history of contact with the art form. Demographic surveys conducted by major jazz specialty magazines find a disproportionately demographical representation of both male and African-American supporters, further suggesting a select and specialized nature of the audience. ${ }^{\text {cccxvii }}$ Jazz has become recognized by the general public as an elite culture.

The neo-classical movement also recognized the importance of continuing jazz inside of academic and serious performance institutions. It seeks to keep the culture of jazz firmly elevated and entrenched within refined practices. The poster boy for neoclassicism, Marsalis, was appointed the artistic director when New York's Lincoln Center for the Performing Arts became the first elite arts organization to establish a full-time jazz department in 1991. The Lincoln Center maintains a full-time big band on its payroll, and specializes in presenting what it and its artistic director understand to be "classic works of the jazz canon," most notably, a pronounced appreciation for the music of Duke Ellington. Hence, Marsalis has become a gate-keeper - he is not just a performer, he is also the embodiment of the critical function with the power to enact his judgments - just as in classical music. Following the Lincoln Center's lead, other national concert venues began taking a more serious look at jazz. While jazz had been presented at varying times during the century at Carnegie Hall, it was in the 1990s that elite arts institutions such as Carnegie 
and the Smithsonian Institution began to promote regular jazz programs. ${ }^{\text {ccexviii }}$ With a more permanent place in these established elite venues, jazz gained a sense of legitimacy as "America's Classical Music." Marsalis has encouraged the intellectualization of the music both through the presentation of the music in serious concert settings, but also through a conscious attempt to educate the audience (suggesting that jazz is best appreciated by those who can understand the nuances and historical significance of the art form). The Lincoln Center Big Band annually presents a series of concerts billed as “Classic Jazz," which re-enacts and promotes canonized jazz works. Furthermore, Marsalis feels the concert notes (a common practice in classical concerts) further allow the audience to comprehend the jazz performance within a "proper" socio-historical context:

While enjoyment and entertainment are paramount matters in the Classical Jazz series, it should be clear that we also feel a need to help promote understanding of what happens in jazz. An important part of the series, therefore, are the program notes... Although jazz can be enjoyed on many levels... we feel that the proper presentation of notes, song titles, and even small discographies will help audiences better understand the essential elements of the music and thereby enjoy the music even more. ${ }^{\text {ccxix }}$

Here, the leading proponent of the Neo-Classical movement demonstrates his belief in the separation of jazz from popular music. While popular music functions as immediate entertainment, Marsalis aims to align jazz appreciation along pathways such as the other classical high arts, suggesting that a further appreciation of the art form is only possible through study and serious intellectual bearing.

Additionally, Marsalis has demonstrated distain even for jazz festivals, because he feels that they represent as jazz what should not be considered jazz. Jazz festivals often book popular music acts, and bill them as jazz, which, according to Marsalis, dupes the audience. "The promoters of these festivals readily admit most of the music isn't jazz, but 
refuse to rename these events 'music festivals,' attempting to piggyback on the achievements of others." "ccxx Because of the commercial element involved with festival promotion, Marsalis feels there is a temptation to cater to the popular, instead of the artistic. Though jazz festivals were once a venue that assisted jazz in becoming understood as serious music, this venue had now been outgrown. According to Marsalis, jazz should be promoted along other pathways (such as the concert) that encourage the education of an audience. These comments again support the use of elite pathways.

The result of the neo-classical movement is that jazz has become increasingly entrenched as a fixture within the elite pathways of the university institution. During the 1990s, jazz became accepted in hundreds of music departments at universities and colleges across North America and the world. ${ }^{\text {cccxxi }}$ Likewise, the increase in jazz programs has presented an attractive alternative source of income and security to many jazz musicians. Most of the best jazz performers in North America are now teachers at colleges and universities, which again, reinforces the importance of education in an up-and-coming jazz musician's career, and requires the use of an elite pathway to access the music. ${ }^{\text {ccxxii }}$ Whereas 20 years ago, if you wanted to become a jazz musician, you moved to New York, took lessons, and hung out with the established musicians; now you must take a degree in jazz performance from an established institution. ${ }^{\text {cccxxiii }}$ And the neo-classical movement has done everything to encourage the use of the formalized academic pathway. Lewis Porter concludes his book on jazz with the statement that jazz is more accepted by universities, governments, foundations, and concert presenters than ever before. ${ }^{\text {cccxxiv }}$ Porter claims this as good news, which I am not confident all critics would agree with. I believe that this may be either good or bad news, but it is certainly very indicative of the 
fact that the neo-classical movement has succeeded in firming jazz within the elite pathways of the university institution.

The music industry has also responded with some encouragement to the neoclassical movement, but its role in the production and promotion of jazz has been somewhat marginalized. It should be underscored here again that the industry operates under commercial motivations, and a political economic disdain often colours much of the commentary about the music industry. And while the music industry is often looked upon unfavourably by elite cultural circles, it is not as easy as locating all those who prosper within the music industry as pop fodder, while those artists confined to non-commercial pathways can be seen as elite musicians. However, concurrent with their status as practitioners and defenders of an elite art, many neo-classical artists and critics now view transmission (and/or success) via commercial pathways as evidence of "selling out." Saxophonist Joshua Redman offers one example. Signed to Warner Brothers Records in the 1990s, he released several albums, and attracted a large popular following. Yet by the end of the decade it was difficult to determine if Redman's success was, as Peter Keepnews puts it "a positive sign for jazz or simply a triumph of marketing.,"cccxxv Redman received massive promotional support, and even a sponsorship from a clothing designer, but critics pointed out that his music seemed to be turning to less challenging offerings, and his stage performance seemed to be more about showboating than playing jazz. Thus, the critical response to an artist's successful adoption and dissemination along the pathways of the music industry demonstrates that many feel jazz to be worthy of different treatment and status. 
Nonetheless, the music industry itself has struggled with understanding how to market and sell jazz. To this end, it has seen two types of jazz sales, and has striven to categorize jazz in two ways. With the rise of neo-classicism, Billboard magazine recognized the differentiation between two streams of jazz (contemporary and traditional jazz), creating a new sales chart to document the split. The "traditional jazz" category remained for the avant-garde and those practitioners who would seek to draw on more immediately on bebop influences. ${ }^{\text {cccxxvi }}$ Of course, within this category, there are more and less commercially successful artists, determined by their ability to negotiate the pathways of the music industry. Within this category, the music industry prefers to promote artists who either are established artists, or have a sound that resembles an established sound. This is why new renditions of classic tunes are also encouraged by the music industry, the one point where the industry desire for formulation corresponds with the high art demand for tradition. Lighter jazz fare usually sells to more people, as do acts with vocals in them. Artists/Crooners such as Michael Bublé, Norah Jones, Diana Krall, and Harry Connick, Jr. have become the niche market equivalent of superstars because they present a product that most closely resembles the popular culture formula. As André Mayer puts it: "crooners allow casual listeners to experience something 'jazzy' or 'jazz-like' without having to suffer through all those fancy chord changes and tedious, squawking solos."”ccxxvii This closer relationship with popular pathways, and separation from academia is also noted in critical reviews of Diana Krall, for example. Noticing her commercial tie-ins and use of her music in Chrysler advertisements, Greg Buium perceptively recognizes that this type of popularity is what allows the casual consumer of jazz to be able to refer to Krall on a first name basis. He also summarizes her albums as being characterized by a "single-minded 
devotion to the soft centre of jazz," noting that her music is "never something you couldn't pipe into a Hudson's Bay showroom." Buium also mentions the fact that "snobs may see Krall as musical fossil fuel," again demonstrating her distinction from the high culture jazz tradition. ${ }^{\text {cccxxiii }}$ Significantly, for all the press he received in critical jazz journals, Wynton Marsalis' debut CD sold only 100,000 copies. This had been unheard of for acoustic jazz, especially in 1984, but Diana Krall's "When I Look In Your Eyes" album has sold over 2,000,000 copies worldwide. ${ }^{\text {cccxix }}$ Therefore the traditional jazz category functions primarily as a niche market, representing a small number of record sales and consequent promotional interests, except for the occasional cross-over artist. Apparently, one's jazz credibility appears to be inversely proportional to one's music sales and the better one's music sales the more likely one is to attract negative critical commentary.

Apart from the "traditional jazz" category, the other category of jazz was dubbed "contemporary jazz" by the music industry and included all the more overtly commercial types of jazz-oriented instrumental music. This is the world of adult-contemporary radio formats, music which completely adapted itself to coincide with the established music industry channels. The music often draws strong critical parallels to the sweet jazz of the 1920 s and 30s. Jazz musicians such as Jeff Lorber and Kenny G have generated huge amounts of commercial revenue with their quiet, peaceful tunes. Some crooner acts such as Michael Bublé, or Norah Jones might seem to reside more in the contemporary jazz category than in the traditional jazz category; indeed, Bublé's recent award of the 2006 Juno for Best Pop Artist suggests this. Artists such as Diana Krall and Chris Botti draw more frequently on jazz standards than on their own material, and this may support a distinction between the two types. However, the distinction is often clouded: Jones and 
Bublé also sing jazz standards, while artists such as Terrance Blanchard write their own material, but are categorized as traditional. This is the nature of "crossover" hits - artists that are able to sell well in more than one market category. Regardless of the nuances of categorization, contemporary jazz far outsells traditional jazz, but has been completely ostracized by the vast majority of established jazz practitioners. ${ }^{\text {cccxxx }}$ But the vast majority of jazz artists do not do well commercially, and as a whole, the music industry is not a pathway that easily corresponds with the ideals, philosophies, and operations of elite culture.

Finally, the neo-classical movement had the effect of illustrating the role of critics in jazz, albeit with a variety of contentions. This movement illustrates a separation between two levels of criticism; that of the popular press and that of an academic intellectual with a fully-grown technical vocabulary. Some popular music critics have praised the work of Wynton Marsalis, calling him a virtuoso, and a champion of jazz's proud legacy. They feel his work reflects the new priorities of jazz; reclaiming jazz tradition from a modern perspective. ${ }^{\text {ccxxxi }}$ They point out that revivals in jazz are nothing new; artists such as Lu Watters and Turk Murphy in the 1940s tried to recreate the hot jazz of the 1920s. Others (and to a certain extent, the majority of popular music writers) have responded with uncertainty to Marsalis. They appreciate his craft and technical ability but are uncertain that jazz can sustain itself by merely recycling its past great performers. Peter Watrous states that; "as much as the constant revivals of past glories make for satisfying, historically important listening, the danger is that if looking backward becomes jazz's prime activity, the music becomes embalmed, lifeless." ${ }^{., c c x x x i i}$ The flood of tribute 
albums and remembrances is viewed as moving jazz into the museum, making it an archaic relic of a past era. Jazz is losing its long history of invention in the name of revivalism. ${ }^{\text {ccexxxiii }}$

Understandably miffed by criticisms such as these, Marsalis was given a chance to respond to his critics; more specifically, he wrote a 1994 article in the National Jazz Service Organization Jazz Journal in response to a very pointed attack from a journalist, one Kevin Whitehead. While his opinions still remain his own, the way in which he responds calls to attention a very developed understanding of musical theory. In his article, Whitehead claims that a Marsalis performance of Thelonius Monk's music was full of improvisations which ignored the structural quirks and awkward silences that characterized Monk's playing (and substituted by more conventional 'blues changes'). Marsalis vehemently challenges Whitehead on this point, questioning his accuracy, as well as his ability to comment on such matters:

...how does one run blues changes? Does he mean by playing on dominant seventh chords or superimposing the form of a blues on an unrelated song? Well, a majority of Monk's songs feature the dominant seventh chord with a flat five. So he can't mean that. As far as anyone imposing the 12-bar blues form on a 32 bar song like Evidence, I can assure you - as will the tape - that this never happened.

Marsalis here is invoking an elite behavioral code. He is saying that unless one can understand the music from a level of technical specificity and mastery, one is not worthy of commenting on it. This response therefore demonstrates the importance of an elite code, making the practice of jazz an elite one. Further evidence of these complex codes can be seen in other journals, but it is important to point out that these types of responses are no longer found in popular and specialty magazines, but in serious peer-reviewed academic journals (both specific to jazz and more generalized). In fact, it is from these 
academic journals that many affirmative responses of the neo-classical tradition come, supported by highly nuanced readings of individual performances. One example is Samuel Floyd's article on the signifying processes of jazz musicians through reference, gesture, and interaction to create multiple meanings and dialogue with both past and present within a single performance. ${ }^{\text {ccxxxy }}$ Another example is Alan Stanbridge's work on Miles Davis' use of non-standard performance techniques as a deliberate attempt to question established renditions of his chosen repertoire, and suggestion of a rich intertextuality within the performance. Stanbridge suggests that jazz musicians are very cognizant of past performances of their pieces, and their chosen methods of performance, use of style, quotation from other songs, etc., reflect a post-modern jazz performance practice. ${ }^{\text {ccxxxvi }}$ Again, and obviously, these are highly nuanced readings of jazz, which demonstrate the use of complex and elite language. On a second level, by suggesting that there are multiple levels within a jazz performance, these examples actually support a neo-classical rendering of established standards. This is for the specific reason that the same link to the past and levels of intertextuality (understanding, recognizing, and parodying past performances) would not be possible on a new work, one without an established history. Now, I am not seeking to argue that Stanbridge and Floyd are neo-classicists, but rather that the use of elite language and complexities demonstrates that jazz music is able to travel along elite pathways (that of critical scrutiny and interpretation). Marsalis obviously believes jazz to be worthy of elite status, and whether they agree or not with the verdict, Stanbridge and Floyd demonstrate jazz to be worthy of this acclaim as well. Therefore, neo-classicism in jazz is ultimately supported and confirmed by academic critics, who are the only ones able 
to access and master the complexities of the elite music. This type of subtlety and intellectual bearing are indicative of an elite pathway.

So has the neo-classical movement succeeded in winning the dominant narrative of jazz history? Well, counter to those who would suggest that the neo-classical movement is merely a passing fashion within jazz, an analysis of the movement's use of certain pathways suggests that it will (if not already) become the dominant means through which jazz is understood. Unlike the fusion movement which preceded it, because of its utilization of the same pathways upon which jazz was already established, the terms of its success cannot be measured by its ability to get the dominant narrative of jazz to conform to different standards. Instead, it seeks to prevent jazz from adopting new standards. It should rather be understood as a re-affirmative movement, one that would have jazz stay within the same elite pathways it has become adapted to. The neo-classical movement has sought to insulate itself within the bounds of academic thought, preferring the use of serious concert halls and other elite practices (such as program notes and discographies). It has allowed and upheld a place inside universities and colleges for jazz musicians to teach and work. It has defined itself at a critical distance from the commercial influences of the music industry, viewing any who make concessions for the sake of record sales, or adapt their music for commercial pathways, as lesser artists. Instead, neo-classicism has tried to legitimate itself as a serious object of study, and has used many complex codes of theoretical, historical, and philosophical perspectives to rationalize this status and define itself as an exclusive and elite culture. This line of argument has even sought to insulate 
itself from the popular presses, who are forced to analyze and argue on a less technical level.

Anecdotally, it is interesting to briefly consider the similarities and differences between the present-day positions of the neo-classicists and the latter-day positions of the Moldy Figs (operating in the 1940s). Both viewed the past of jazz as the authentic place of reference, the time in which the music was greatest. Both had a previous era of jazz to point to, what they considered a renaissance of cultural activity. Both were critically lambasted by modernists, who accused them of holding jazz ransom to its past, of not allowing the art form to continue to evolve, as it always had. So from this position, with the arguments normally used in textbooks, it is difficult to understand why one movement failed and one succeeded. However, with the tools of pathways analysis we can understand that the neo-classicists ability to sequester themselves within academic institutions and use critical language allowed them to repel other critical attacks, whereas the Moldy Figs of the 1930s and 40s, did not have this pathway available to them. Therefore, from the perspective provided by pathways analysis, it seems likely that the neo-classical movement in jazz will succeed in further enshrining jazz within the bounds of elite culture.

\section{Conclusions}

As jazz continues to establish itself within the Academy, it will continue to make jazz an elite music, and if previous indications bear any weight, it will continue to use other established elite practices and pathways to legitimate itself as an elite culture. As elite games, jargon, lexicon, and theory become more established, jazz loses its ability to 
relate to a popular audience. Specialized channels of distribution, perceptions, and exclusivities have set themselves up and are now the dominant pathways along which jazz transmits itself. The elite promises suggested by bebop have finally parlayed themselves into jazz music's acceptance as an elite music; within elite institutions, supported by elite critics, and established as a specialized niche market within the music industry. Within this elite culture, free jazz (Avant-Garde) will be able to continue, to a small extent. Protected by the institution, free jazz will be able to continue to push the very limits of what is considered jazz, but will function primarily as an intellectual experiment instead of a popular music. This is fundamentally counter to the pathways through which popular music is transmitted. Secondly, the fusion movement represents a challenge to the dominant narrative of jazz as an elite culture. It seeks to use popular pathways of music industry, technological, and institutional support to return jazz to the status of a popular music. However, if jazz as an elite culture was able to resist this challenge as early as the 1970 s, it is unlikely that fusion will be able to transform these pathways. If it does obtain a greater level of popular support, it is likely that fusion will be defined as "not jazz," leading to a fragmentation away from the existing narrative. It is a much trickier battle to bend the dominant narrative of jazz to a different direction without completely splitting off. To be successful, fusion would have had to return the overall culture of jazz to the popular level, without being discredited as a separate music or musical category. Thirdly, the movement of neo-classicism can be understood as a re-confirmation of jazz along its existing elitist pathways. Neo-classicism suggests a re-reading of earlier jazz through intellectual and academic pathways. It seeks to protect jazz within elite institutions and venues, and render jazz an elite activity, which should be participated in in certain ways, 
with certain precepts. Therefore, we can understand the current position of jazz as functioning as an elite culture; relying heavily on serious critical scrutiny, drawing support from academic and other elite institutions, positioning itself within elite venues which have certain requirements and codes to access the culture, and positioning itself within the music industry as an established niche market for certain types of consumers. While possible to change this position within the cultural hierarchy, it is unlikely that any current movement within jazz has the power to redefine the pathways along which it operates. 


\section{Chapter Six: Justifications and Implications}

"All art is at once both surface and symbol. Those who go beneath the surface do so at their own peril."

- Oscar Wilde

Although occupying a large part of this paper, the focus has not solely been jazz, or jazz history, or even debates within jazz historiography. Rather, jazz has been used as a case study to illustrate something slightly different from itself, and it is now time to understand what we have obtained during this historical consideration. My goal has been to develop a theory of cultural flows within a tri-partite notion of culture. This theory would help to establish the status of a given cultural form - such as jazz - as it operates within various cultural levels. It would establish the status by examining the pathways along which the cultural phenomenon travels in order to connect its artists with their audiences.

The theory of cultural flows as elaborated in this thesis therefore relies upon the following assumptions. First, while cultural forms can certainly be approached as examples of artistic expression amenable to a semiotic analysis and possessed of an aesthetic dimension, they are also a communicative phenomenon. That means that in order for a cultural form to have an existence as a cultural form, for its creators to want to make it, for its audiences to want to experience it, it must first solve a simple communicative problem: it has to reach its audiences, it has to find some way to travel from where it is produced to where it is experienced. In short, it has to answer Lasswell's famous question: "Who says what through which channel to whom and with what impact?" The first assumption, therefore, is that attention to the channel or pathways along which cultural phenomena travel helps us understand the form which a phenomenon assumes as different 
pathways are likely to link different types of creators with different types of audiences and therefore to affect the semiotic organization or aesthetic dimension of different types of cultural phenomena.

The second assumption of the theory of cultural flows derives closely from the first: there exists a multitude of pathways and therefore a multitude of variations within a given cultural form. This is why jazz is such an exemplary case study. Jazz has moved through all sorts of 'variations.' It has gone from being a relatively marginal music at the beginning of the $20^{\text {th }}$ century to occupying the very heart of popular culture between the late 1920 s to the early 1950 s to a new type of 'artistic' marginality from the late 1950 s to the present.

The third assumption of the theory of cultural flows grows closely out of the study of jazz: the multitude of pathways tends to undergo relative stabilization into a small set of major pathways. In other words, although a cultural form could be (and frequently is) diffused along innumerable pathways (many of which will remain hidden from critical scrutiny or not even self-recognized as pathways of diffusion), that 'infinite multitude' tends to resolve into a few larger categories that can be named and examined. Jazz illustrates this clearly and, indeed, the standard division of culture into 'folk' or 'vernacular', 'popular' or 'commercial', and 'elite' or 'restricted' corresponds fairly well to the general organization of pathways. In this sense, the third assumption is not new and tends to confirm or to coincide with what others have already said. There does appear to be some broad sedimentation of pathways into high, middle and low culture although the specific categories will receive many different names. 
The validation of the theory of cultural flows has rested upon a demonstration of the difference in pathways at various cultural levels. In other words, the thesis has attempted to show, using jazz as its case study, that although the communicative problem remained the same at all three cultural levels - the music always had to connect with or somehow reach its audiences - the specific mechanisms by which that happened were different. In other words, the pathways were different depending on the level of culture under analysis.

Finally, because the theory of cultural flows seeks to understand the pathways along which cultural forms travel, it finds itself able to diagnose at least some of the circumstances under which a cultural form may shift from one level to another. A cultural form, as the case of jazz abundantly illustrates, can move between cultural levels, but only if it alters the commercial, critical, institutional, academic, and technical pathways through which it transmits itself. Indeed, the situation may be stated more positively: as a cultural form adopts new pathways of diffusion, its commercial, critical, institutional, academic, and technical characteristics will undergo a corresponding transformation, thereby also transforming the audience, the artists, and the cultural form or practice itself.

As the Wilde quote at the beginning of the chapter suggests, our examination of art has led to something deeper. Our abridged history of jazz has allowed us to use the information gleaned in order to illustrate the theory. This theory has allowed us to understand culture as a product of certain conditions and channels. We are therefore now in the position to ask the question: what are the implications of this theory? How can it be used and applied in a more general manner? 
This chapter will be divided into three sections. The first will recap the developments of jazz as it has transformed itself from a Folk culture to a Popular culture to an Elite culture. In so doing, it will outline the factors which contribute to the construction of the theory and will highlight those details which illustrate how cultural forms shift from level to level. The second section will be concerned with the limitations both of this thesis and of jazz as a case study. It will suggest that the application of the theory of cultural flows to other cultural phenomena may be helpful not only in validating the theory itself but also in understanding those particular cultural phenomena. The third section will consider the implications of the proposed theory of cultural flows. It will argue that the theory can do two main things: (1) diagnose the level at which a cultural form operates and (2) demonstrate why a cultural form can or does change levels. This means that pathways analysis offers an alternative set of questions which construct a different view of culture. It does not mean that pathways analysis provides the "correct" method of understanding culture but rather that the competing models for understanding culture are governed by their own sets of questions of which it may be useful to gain some awareness.

\section{Outlining the Theory}

It is useful to think of the Theory of Cultural Flows as a process consisting of four parts. The artists are the cultural creators, those who produce the cultural product or who play a key role in the activation of the cultural practice. They may have many years of formal or professional training or may be entirely self-taught. The cultural product or form is the artifact or practice itself; it is the music, art, painting, sculpture, or work, to which audiences attend, which captures their interest, provides them with an aesthetic or cultural 
experience, and forms the object of their later discourse. It is the object around which creators and audiences unite, the pretext for their 'dialogue,' the 'thing' that travels along the pathways. The audience is the target of the cultural form, the receiver of the artifact, the participant in the process or practice, the thing without which the practice would not be undertaken, the necessary partner in the dialogue with creators. The audience may be small and distinct or large and diffuse, educated or uneducated, specific or general, localized or diffuse, sophisticated or unsophisticated, appreciative or rancorous, attentive or distracted, etc. All audiences, though, grant or withhold their assent in varying degrees and through different mechanisms: applause, hurling fresh fruit, hasty dismissal, compulsive return, disdainful refusal, etc. The audience's response is usually a clue to creators of how well their communicative act has succeeded and often an indicator of whether they should alter their behaviour or strategy in future creative acts. It is the manifestation of a dialogue or exchange between creators and audiences and it is susceptible to all sorts of transformations. Audiences may learn to appreciate something which they had formerly rejected or to reject something which they had formerly appreciated. Creators may learn new strategies from audiences. Critics may seek to instruct both, to show audiences what they should attend to or to tell creators what and how they should create. The exchange or dialogue is always the occasion for the emergence of a 'critical vocabulary,' the setting into words of attitudes or judgments or preferences which exercise the critical and rational faculties and leak into other aspects of life. This 'audience activity' is an important locus for the elaboration of argumentative strategies, the setting out of norms and ideals, the determination of acceptable proofs and arguments, etc. Finally, the pathways, or channels, are those institutions, technologies, industries, and 
critical dimensions through which the cultural form travels on its way to audiences. The pathways refer, therefore, to 'sites' (both physical and ideational), and to the ways in which those sites operate (the way they act as gate-keepers, letting some phenomena through and restricting others, the way in which they highlight some features, aspects or details and overlook others, the way in which they admit some participants and exclude others, favour some arguments or attitudes and disallow others, etc.). Each pathway exerts a measure of influence over the type of cultural form created as well as an ability to assist in the dissemination of a form to certain types of audiences. The corollary is that each channel possesses a bias towards certain types of cultural products and against other types. These barriers may/prohibit, delay, or downplay the ability of a cultural form to access a certain audience. The cultural form may adapt itself to become more palatable to the specific pathway, or it may find another means of transmission.

Together these four parts (audiences, artifact, artist, and pathway) make up the elements of the theory of cultural flows. Each of these components functions as a critical lens which reflects the status, popularity, and dissemination of the cultural form. And each of these parts also refers to its own distinct indicators.

The theory of cultural flows also divides culture into three main levels: Folk, Popular, and Elite. Each level corresponds to different pathways, artefacts, creators, and audiences. A cultural form may shift between levels. In making a change between each level, the pathways along which the form travels will also shift. Hence, the transformation of the pathways marks a transformation of the cultural form as it assumes the characteristics appropriate to each pathway. The result of the change in pathways will also be access to new audiences, and sometimes, activity by different types of creators. 
Therefore, given this division of culture, one can understand why and how a cultural form operates at each of the three levels of culture by studying the pathways along which the cultural form travels. Likewise, it is possible to understand how the cultural form changes between levels by studying changes in the use of pathways.

I will now review each stage of change in my case study, outlining those factors which first marked the level at which the cultural form operated and then caused it to change levels.

During the early 1900 s, the emerging cultural form of jazz operated as a folk culture. It was primarily contained within a specific geographic area which came to be represented primarily by New Orleans, though there were also important contemporaneous developments elsewhere in the United States. Within New Orleans, jazz was primarily a music of the marginalized classes, performed in brothels, speakeasies, and the vice district. Institutionally, the jazz scene did not seek out formal organization nor was it centered specifically around profit orientations. It functioned primarily as a lifestyle rather than as a formal occupation. Jazz culture received little critical attention; what little coverage of the jazz scene made it into the New Orleans newspapers was merely informative, understanding jazz to be the product and purview of the African-American classes but certainly not worthy of serious critical scrutiny. Furthermore, the music industry essentially ignored jazz because it did not assume a form conducive to the technology or the industry of the day. Jazz music was a raw, improvised, live music which used all sorts of un-European effects and which was therefore difficult to transmit via the system of European-notated sheet music that made up the popular music industry in the early 1900 s. 
The many bands and parades formed a sound and a culture that was very popular among certain categories of New Orleans citizens (marginalized African-Americans) but that was essentially uninteresting to a larger audience. The artists involved in the early scene reflected its folk status; they were largely self-taught amateurs with little professional musical training (certainly not training in jazz). They were amateurs not because they were inadequate musicians but because they were unable to earn a living solely from the performance of their music. Consequently, they had other means of deriving income. The audience also consisted of a select group of specific persons, drawn from a particular location and often a marginalized socio-economic background. In these ways, the pathways along which jazz music did or did not operate demonstrate its folk culture status in the early $1900 \mathrm{~s}$.

From this example, we can also see what tends to characterize the pathway along which folk culture travels. Folk culture tends to be local, disparate, and hard to pinpoint. Its localness tends to mean that it does not aspire to assume a shape that will make it congenial to outsiders or distant listeners. It is satisfied with its audience and current status and seeks to change neither. Its localness also means that it tends not to be performed exclusively or predominantly by stars (certain performers who have widespread popular recognition and come to represent the style). On the contrary, folk music tends to be performed by almost anyone with the requisite skill. Furthermore, the performances are not confined to specialized performance venues and not usually linked to revenue generation. The performances can and do occur informally; at the end of a day's work, in kitchens and church basements, at weddings and funerals, etc. The point is not that folk music occurs outside of, or with disregard for, venues; on the contrary, it has high regard 
for its venues. The point is that the venues are not specialized venues set aside exclusively or predominantly for the performance of the music. They are venues which are often occasions (weddings, funerals, barn raisings, rent parties) in which the music is accessory to the social gathering rather than the cause of the gathering. Hence, the lack of star performers means that folk music is not only local but also disparate in the sense of being performed by almost anyone.

The fact that it can be performed by almost anyone also works to keep its level of aesthetic and technical 'sophistication' relatively low, precisely in order to make it available to all-comers, and to prevent its appeal beyond its immediate circle of consumers. This disparateness, therefore, makes folk music hard to pinpoint in the sense that it seems to emerge from everywhere simultaneously and to have no predominant locus of origin. It is not focused on a single performer, on a particular venue, on a highly elaborate style. As a result, folk music tends to be harder to commodify or less congenial to the strategies and channels of the commercial music industry. All of these characteristics conspire to make folk music difficult for the standard strategies of music inquiry to grasp. Hence, there is relatively less concrete knowledge about folk music than about other types of music. This lack of concrete knowledge should not be taken as evidence that the folk culture is lacking in form or style but rather as evidence of its non-transmission along media channels.

The way in which folk music is codified by its performers and audiences - the values systems which guide their evaluations of performance, the features which they choose to highlight - tends to be difficult for standard musical strategies to understand. Often, the performers and audiences of folk music are not self-conscious about their music. They therefore are not interested in defining it or in reflecting upon it (potentially in order 
to alter it). Often, they are not concerned with its place and status within the larger world of music. Their attitude towards their music affects knowledge about the music or, more specifically, it helps to explain the lack of knowledge about the music. Indeed, music critics who are often caught up in the process of defining and codifying music tend to neglect folk musics. In some cases, critics may simply not know about it. Yet its insignificance may be the reflection of our own snobbery, rather than of something inherent in the music. Folk music often possesses characteristics that the broader public does not care about because folk performers and audiences themselves do not care about inserting themselves into a broader world of music. Sometimes, the characteristics of folk music are simply compared unfavourably to other types of music, and seen to hearken to an earlier state of society that we are anxious to forget. Its performers may hail from a socially devalued class and its audience may lack attributes of urban sophistication. Folk music tends therefore to be deemed unsophisticated and insignificant. As a result, folk cultures are not normally subject to an established critical pathway.

Finally, the music industry is often lukewarm to folk music. The music industry tends to codify music which it distributes in ways which make the music suitable to its established distribution mechanisms and audiences. This codification is often understood as a process of standardization or commercialization or diminution of the original authenticity of a given musical form. Whether such characterizations are helpful or not, the music industry is certainly very successful at codifying sounds. However, folk music, as suggested above, tends not to be very self-conscious and therefore tends not to work at elaborating its style. It may be more repetitive than innovative. Additionally, one of its primary values appears to be its functionality within the context of the venues in which it is 
most often performed. Hence, it has relatively limited appeal and is not a good candidate for distribution by the music industry. Conversely, without the standardizing influences of the music industry, folk cultures are able to remain flexible and undefined.

For these reasons, folk cultures travel along local pathways; there are barriers to their transmission along other, more cosmopolitan/commercial channels. Likewise, the audience that participates in folk culture will likely come from more marginal socioeconomic groupings.

During the late 1910 s and 1920 s, the folk music of jazz began to change, due to the opening of new pathways. The new media of recording technology and radio broadcasting enabled jazz to reach an entirely new type of audience, as well as expanding the scope of the audience far past the limitations of a folk culture to national awareness. These new technologies did not contain the same barriers to entrance for improvisational jazz music as had printed scores. Working with these new technologies, the popular music industry inserted itself as a major pathway in the practice of jazz, using its influence to connect jazz music with a widespread audience and generate national popularity. However, as we have seen, the music industry had its own preferences as far as sounds, image, and style of jazz that was performed. While the industry would encourage the transmission of anything that would sell, it had certain proclivities towards softer sounds, white artists, and arranged music. Therefore, this pathway was more successfully negotiated by some artists (such as Benny Goodman, Paul Whiteman, and Glenn Miller, who realized more immediate success) who were affected less negatively by the biases. Critics also played a role in the popularization of jazz music. Unlike its neglect when it operated as a folk culture, jazz 
was now noticed by many social and music critics. While some critics (particularly those writing for more socially-elite publications) originally demonstrated contempt for jazz music, such attitudes had generally dissipated by the 1930s. The institutional and technological separation of jazz music away from its original socio-economic circumstances and performance sites began to erode negative opinion. The new venues for jazz performance helped pave the way for much more positive popular and critical opinion. In the creation of hot clubs, jazz enthusiasts were to play a further role in fostering a positive attitude toward jazz. Therefore, as with technology, jazz had to negotiate and adapt itself in order to be allowed access to a new audience (controlled by the critics). Finally, jazz had long been associated with places of vice, but the development of public nightlife in the major cities and of a cabaret culture encouraged the performance of this music in places that were more socially sanctioned. This use of more publicly-accepted pathways further increased the penetration of jazz music into the mainstream American audience. The effects of these new pathways were noticeable in the dramatic broadening in the scope of artists and audiences who participated in jazz and in the re-definition of the cultural product. Jazz mushroomed from a local scene contained in New Orleans and a few other cities to a national one. Artists all across the United States, from Kansas, Chicago, New York, Los Angeles, and even reaching to Europe, began learning and performing jazz. Likewise, the audience for jazz diversified and increasingly came from all walks of American life: black, white, rich, and poor. Jazz had managed to transcend its status as a folk culture.

These were the important points of adaptation and discovery that allowed jazz to become more than a folk culture. From them may be distilled certain catalytic rules 
governing the process of transformation from one cultural level to another. Obviously, some of the phenomena under observation may be applicable to jazz only, and so we must discern if the event analyzed is general or case-specific. As regards the technological factor, while the incongruity of folk jazz with the established technologies of musical dissemination succeeded in delaying the spread of jazz, an initial incompatibility is unnecessary for the development of a folk music. Folk music does not have to be incompatible with the technological channels of popular culture in order for it to develop as folk music. There have been plenty of examples of folk musics which have developed/been maintained since the invention of recording technologies (grunge, bluegrass, celtic, etc.) where this barrier was not in place. To put it more simply, incompatibility with recording technologies is not a defining characteristic of folk music but a unique historical circumstance of jazz. Rather then, we can only say that if there is a technological barrier to the folk music, it will greatly curtail the spread of this folk music until such time as the barrier can be overcome.

The role of venues is perhaps more characteristic of all folk musics. Folk musics are usually characterized by their association with more impoverished socio-economic classes and are performed in venues connected with unseemly or unvalued elements of society. As a result, they are often considered to contain dangerous elements and spurned by mainstream audiences as a result. Therefore, the negotiation of new venues which do not imply this unfortunate perception allows the music to reach new audiences which may value it differently. Folk music must move from lower class venues (such as brothels or speakeasies or farm kitchens) to more accepted places (such as cabarets, clubs, theatres, etc.) in order to become more popular. Hence, the music must become increasingly 
sensitive to the pathway constituted by critics (both social and musical). This is achieved both through the eventual dissolution of older, negative associations and the eventual creation of new, positive legitimacies. New venues assist in the dissolution of old presumptions, as does the work of enthusiasts who are found in the new venues and who champion the culture as a legitimate, authentic, and creative culture worthy of interest.

Finally, the music industry plays an enormous role in the transformation of a folk culture. This pathway strongly influences the formalization of the culture by creating a more specific or codified sound, a product which can be promoted across different media, venues and audiences, and stars or celebrated practitioners who can serve as the focus of the style and the culture, as role models, as likeable personalities or ego ideals, etc. The music industry can also regularize production of the music, maximize the financial benefit to be derived from it, nurture new stars for its continued success, negotiate its placement in or alliance with other cultural industries (i.e., music in movies, in advertising, in Broadway plays), provide a framework within which innovations can be championed, contained or suppressed, and so on.

By the mid-1930s, jazz had become established as the Popular culture of the day. It functioned as popular culture because the music had negotiated certain pathways which brought it access to the majority of citizens in North America and in many parts of the world. Recordings and radio broadcasting allowed for easy, mass dissemination. These forms of transmission were also greatly tied into the popular music industry, which promoted the musical culture to many different social classes and locations. The popular music industry also acted as a gatekeeper, controlling access to audiences and venues, 
promoting some styles over others, frequently favouring established acts over newer ones, etc. In short, it helped ensure that bands would perform the style of jazz most consistent with the industry's notions of saleable music.

The negotiation over the styles of jazz that were promoted by the music industry was reflected in the critical and artistic debates over "hot" and "sweet" jazz. While critical debates were one important factor in shaping jazz, another equally important factor was the ongoing effort to present jazz as a "real," "hip," and "alive" music to a broad cross-section of audiences. Critics, whether journalists and enthusiasts, sought to define and present jazz as an interesting and legitimate pursuit to millions of people. Their actions enabled jazz to spread still further.

Additionally, jazz music's use of festival grounds, hotel ballrooms, and dance theatres enabled large crowds to hear, as well as respond to the music through dance. Overall, jazz music's great popularity during the 1930s is evidence that it had successfully negotiated new pathways and now functioned as popular culture.

Popular music can therefore be understood as music that is transmitted along various popular pathways. This fact gives popular music certain formal characteristics. Because popular music is concerned with profitability, the industry acts as a powerful gatekeeper disseminating preferentially those styles of performance with a proven track record or which it hopes will appeal to a broad audience. The goal of the music industry, therefore, is not just to reach an audience but to reach a large and profitable audience. This goal is often interpreted as the commercialization of music but whether or not that notion is helpful, there is little doubt that jazz in its popular phase was commercially successful and profitable. 
Additionally, in this phase, jazz tends to be performed in larger venues that allow for bigger crowds. An ancillary characteristic is the fact that in this phase of its existence, jazz is also strongly associated with dancing whereas in its later, elite phase, it will be just as strongly associated with studious listening and the display of cool. It is therefore tempting to conclude that popular culture is marked by physical audience response in the form of dancing, whereas elite music is marked by cerebral audience response in the form of studious listening. However, this may be a tendency rather than a hard-and-fast rule as there are many venues - such as concert halls/stadiums - which make it difficult to dance and therefore do not necessarily elicit a physical response. They may elicit a more 'ecstatic' response which depends on the display of pleasure or appreciation through the striking of poses, overall posture, micro-gestures such as applause or waving cigarette lighters, private dancing or agitation, the affectation of a drugged-out, dreamy state, and so on. These are externalizations or physicalizations of presumed inner states and, in this sense, some instances of popular music may therefore resemble the response of audiences to elite music.

Critics also help to shape jazz in its popular phase simply by paying attention to it. In the popular moment, critical attention tends to be marked by positive enthusiasm around the novelty of the music rather than by sustained intellectual criticism. In this way, critics assist in the dissemination and public awareness of the culture.

Finally, technology helps disseminate the music through all available channels both specialty and mainstream. These may be recordings, radio, television, movies, newspapers, specialty publication, and so on. Though often governed by economic considerations, the music becomes available to as many as possible. 
The primary characteristic of jazz in its popular phase, therefore - and of popular culture generally - is that it removes as many barriers to participation as possible. It is open, easy and freely available. It seeks to be like the air we breathe: omnipresent. It seeks to be the stuff of everyday conversation and therefore avoids elaborate or restricted codes of communication. It offers itself as self-evidence and is therefore abundant, celebratory, always self-same and always slightly new. It wants to be desired and is therefore fronted by stars and special personalities, surrounded by glamour and wealth, and so on.

But with the introduction of bebop, jazz would again shift cultural levels and become an elite form of music. Consequently, jazz would also adopt new pathways along which it reached its new elite audience. Again, a change in the music was correlated with a change in pathways. As we have seen, the music industry itself, considered as a pathway which exerted its own particular pressures, began to change in the early 1940 s by moving away from jazz music towards more vocal music. The culture industry generally, of which the music industry is an important component, is noted for its continual search for the next big "thing," and by 1940, that had ceased to be jazz. ${ }^{\text {ccexxxvii }}$ Its shift towards crooners in the 1940 s was amplified even further by the rise of rock'n'roll in the 1950 s. At the same time, bebop's disdain for the established practices of the big band belied an unwillingness on its part to conform to the established pathway of the music industry which had worked so well for swing music up till that time. Further, other 'environmental' factors such as World War II and the AFM musicians' strike reduced the ability of bands to access the same widespread audience as in the past. Likewise, the rise to prominence of the jam session as 
a vehicle for the experience of "authentic" jazz assisted in the public perception of jazz as an elite art form, due to the elaborate behavioural codes required of both musicians and audiences in order to appreciate the music. Through jam sessions and jazz concerts, jazz became a culture which emphasized a more cerebral, serious and studious demeanor and which de-emphasized a more immediately physical response. The increasing cerebrality of jazz appreciation was further consolidated by the development of an increasingly complex critical lexicon which distinguished ever more finely amongst types of jazz and promoted alternative methods of aesthetic interpretation. The critics, therefore, understood as a pathway, encouraged the shift to elite culture by developing specific critical jazz language and promoting an intellectual separation of the connoisseur from the fan. Finally, it would be incorrect to suggest that the function of jazz music changed completely as a result of the new pathways. Many artists certainly played an integral and conscious role in transforming the status of the music and certainly struck a deliberately philosophical pose that put them at odds with the function of jazz as a popular music. However, they would not have been able alone to change jazz into an elite music without the concomitant development of a critical vocabulary and the eventual drift of jazz into the academic world. Therefore, the development of jazz as an elite art form occurs at the intersection of artists, audiences, and the new pathways along which the music travels. If they want to reach different publics, and be considered as something greater than popular acts, artists must choose to utilize different pathways, along with all the requirements they entail.

The shift of jazz music from a popular to an elite form is marked by a transition that removed jazz from the popular, accessible pathways it had used in the 1930 s to pathways of a more restricted nature. From this example, we can draw some general 
lessons concerning the process of transformation from popular to elite culture. Barriers to entrance into the culture are deliberately and elaborately constructed, which reduces the audience and the artists who are able to participate. Within the industry, the transition is marked by a separation of bebop from the production and promotional networks through which jazz and swing had previously accessed a mainstream audience. This occurred because bebop eschewed the previously-established promotional and production practices of the music industry. A movement away from the popularizing effects of the culture industry may be assisted by any number of external conditions. While a recording strike is not likely a necessary condition for any popular music to become elite, the creation of specialized, niche markets for the consumption of an intellectualized version of the form does help. Likewise, a ban on rubber tires that stopped the touring buses of big bands is probably not a necessary condition for all cultures, but it significantly denied the cultural form in question easy access to a popular audience, thereby creating a space for other cultural forms. The creation of a critical language is another element required of all upward cultural mobility. If elite culture is marked by barriers to entry, then a language that can define and exclude certain types of participants and responses is a necessary step. In tandem with the critical tendency towards rarefication or inaccessibility of the form, the creation of defined performance spaces which have their own elite codes of behavior encourages the perception of the cultural form as a serious pastime. Venues that permit the somber consideration of the cultural form mark the form as different from its cultural predecessors (who typically were marked by a more physical response). Additionally, the use of complex behavioral codes and the ostentatious display of technical mastery by performers help to separate both the performers themselves and their audiences from any 
immediate sense of gratification. The very fact of these elite codes encourages the development and application of intellectual (and eventually, academic) thought, which in turn, lends legitimacy to the notion that the music under consideration really is a form of elite culture. Finally, technology considered as a pathway is significantly absent from the bebop moment. This is not because elite culture shuns the use of technology or because bebop could magically be transmitted without technological mediation but because the very ubiquity of recording technology and the ease of transmission of music via radio, records, and so on, do not fit well with a tendency towards exclusion. In the bebop moment, music technology works to ease access to audiences whereas the music imagines itself as more exclusive, harder to understand, not immediately available to just anyone. There is, therefore, a mismatch between the music technologies of the day and bebop. The technology simply does not create enough barriers. Hence, during its bebop moment, jazz will tend to be less recorded - because of inconvenient recording schedules, inaccessible venues - and to be distributed in a much more restricted fashion through fewer outlets and on less well-known labels.

Throughout the 1950s, 60s, 70s, and into the present, jazz music has increasingly transformed itself into an elite music. It has done so on the strength of a renegotiation of its relationship within three types of pathways. The music industry, which played such a central role in the establishment of jazz as a popular culture is marked by a significant withdrawal of support. The industry shifts its focus onto other forms of vernacular (soon to be popular) musics. Jazz music therefore is relegated to a specialized market status; the majority of jazz (especially new artists) is recorded by independent labels for a select yet faithful niche market of jazz consumers. The move to independent labels allows for an 
increase in diversity, as jazz begins to function away from the hit-making machine. Small labels can specialize in 'small' styles which appeal to small audiences. Jazz performance venues also assisted in the legitimation of jazz as an elite art form. The use of "serious" venues such as the concert hall (and, to a lesser extent, the festival and the university circuit) promote a listening public and draw from responsorial practices, established by other elite musics. Furthermore, the drift of jazz from the commercial arena to the academic arena further helps the process of formalization and systematization of jazz performance and response. This transformation of jazz into an academic discipline meant the creation of a jazz narrative, the establishment of a canonical repertoire and artists, and the development of a methodology for the systematic investigation and teaching of the subject; all complex codes that verify the status of the culture as elite. Inevitably, these developments in the life of jazz (tradition, establishment within academia, use of elite venues) eventually encouraged the comparison of jazz to other elite musics. Therefore, as with other elite musics, the nature of jazz criticism also began to change. Jazz magazines become more specialized and more serious, dropping any ties with popular culture content and concerning themselves with the serious study of their chosen art form. Furthermore, as jazz music progressed into the academy, an increasing reliance was placed upon academic critics, and a distinction between jazz journalists and jazz intellectuals became apparent.

From these developments, we can again glean the principles and pathways by which elite cultures operate. The elite culture tends towards pathways that erect barriers which reduce the ability of the general public to access and understand it. These barriers require knowledge and mastery of a specialized code in order to know how to respond 
appropriately and which evaluative criteria to apply. Barriers, therefore, are both physical and behavioral and occur along all the pathways through which elite cultures transmit themselves. As an elite culture, jazz patterns itself on other elite cultures and therefore seeks alliances with the academy and other serious performance and scholastic institutions. Elite cultures will utilize established elite performance venues as a pathway to encourage a specific audience. Likewise, the culture will begin to establish itself within the institution of the university. The move to establish itself within the university will further require the culture to develop certain aspects which would allow it equal status with the other enshrined elite cultures. These developments facilitate a full-fledged intellectual exploration of the qulture and include the creation of methodologies of teaching, formalization of a canon of performers and works, and the creation of an official history. However, the effect of all these 'traditions' is the creation of complex codes, the mastery of which eludes many members of the general public. As a result of the transition into academia, the importance of the industrial pathway is diminished. As an established elite culture, the culture is increasingly maintained as a niche market; it becomes a stable but fairly minor fragment of the overall cultural industry. Though some often claim that the music may be dying, it is usually in no danger of complete collapse. Rather, it is usually financially supported through other means such as institutional, private, and governmental donations (as well as the commercial culture industry which still plays a reduced role), all of which require the culture to establish itself as an "art form." Taking up the slack from the reduced role of the industrial pathway, critics establish themselves as the new gatekeepers of the elite culture. Critics function within elite culture as the arbiters of whether a work is good, based on a formalized set of evaluative criteria. Therefore, the 
cultural form itself must be developed enough to withstand this type of critical scrutiny. Finally, again, technology plays a diminished role in the creation and sustenance of elite musics. Its main role is to reduce barriers - anyone who can afford the recording, for example, can access the music - in a context in which the reinforcement of barriers is the order of the day. This leads to the typical posture of critics who bemoan the unsophistication of the public which, despite relatively easy and affordable access, nonetheless fails to appreciate the art form. Paradoxically, therefore, the very ease of access of the technology helps to solidify the critical view of the music as elite, difficult, relatively inaccessible, and reserved for knowing tastes. Therefore, through the use of elite pathways, the new cultural form models itself after other elite cultures, constructing barriers to entrance and reducing its utilitarian approachability.

Lastly, we come to jazz's fusion moment, which sought to turn jazz back into a popular music. It permits us, therefore, to explore how and if elite musics can become popular musics through the use of different pathways. First, fusion jazz used new technology which brought it into conformity with popular music. Hence, fusion performers experimented with electronic instruments and electric amplification, mimicking the practices of rock music in order to create a sound that was similar to rock music. Second, fusion sought distribution through the same networks and outlets as rock music. Fusion musicians performed in rock clubs, stadiums, pop music festivals, and shared the stage with rock musicians. Third, fusion musicians relied on the popular music industry for marketing cues. Hence, fusion modeled itself on rock in terms of marketing, promotion, and even audience composition (as it sought a younger, more popular 
audience). Fusion artists worked closely with their record labels, trying to develop and market a sound that would appeal to a wide audience. With the use of these popular music pathways, fusion was able to realize solid commercial success and reach a broad audience. However, for all these successful negotiations of popular music pathways, the fusion movement failed to make jazz the popular music it had once been. Several factors account for this and they must be treated carefully. Within the established community of jazz critics, fusion was largely cast aside, outside the official jazz narrative. The critical jazz establishment successfully defended its aesthetic, theoretical, and technical standards and was able to show that fusion did not measure up. Evidence of fusion's failure to turn jazz into popular music can be found in the creation of distinct genres, further codifying one type of music as "jazz" and the other as "not jazz." Fusion was defined separately from jazz, as noted by Billboard's designation of subcategories for "crossover jazz." However, within the non-jazz community, composed of fans, and general audiences, fusion found considerable success. Nonetheless, here too, fusion failed to become the dominant popular music simply because it entered a situation in which competing popular musics rock, disco, rap - had already established themselves and because, despite its best efforts, it brought with it the whiff of jazz's exclusionary past. Hence, there are at least two big responses to fusion. A response from inside the jazz community, which rejects fusion, and a response from outside the jazz community, which gives fusion a reasonably favourable though hardly dithyrambic welcome. Neither response returned jazz to the status of dominant popular music but neither do they signal the utter failure of fusion.

Nonetheless, the example of fusion may teach us useful lessons about elite musics more generally. The fusion moment demonstrates the enduring power that certain 
pathways can exercise over a cultural form and their willingness to defend their standards, norms and criteria, their operational procedures, their networks of references and performance venues, their accumulated critical lexicon, etc. It shows, in a sense, the inertia of the critical pathway in a certain phase of its development. In elite cultures, critics have a great interest in maintaining a form's elite status. After all, that status both flows from and buttresses their philosophical orientation and their functioning livelihood. Elite critics have spent gigantic amounts of time and effort to develop a lexicon and criteria specifically for the elite cultural form; a canon of standard works and artists, a set of aesthetic justifications, and a set of practices that favourably draw from (and compare to) other established elite cultures. They have instituted mechanisms from the preservation and transmission of these criteria to new generations and other mechanisms for the verification of the successful transmission. While critics would not likely have had the same ability to determine the narrative of jazz in its popular or folk phases, the importance of the critic in elite cultures is such that he can significantly shape the discourse on the cultural form and protect it from unapproved developments. This may be comparable to the influence of the music industry during jazz's popular phase. At that moment, the music industry retained the bulk of the control over the cultural form. However, some differences in the nature of the control may be noted between the two pathways. Whereas critics use language and definition to exert control, the music industry exerts control through the promotion of acts. In either case, though, the gatekeeper status of the pathway can greatly influence the ultimate outcome of the cultural form. If the gatekeeper pathway is not successfully negotiated, the artistic direction will not succeed in bending the culture's dominant narrative to the new direction. 
This, then, is the theory of cultural flows. It can be used for at least two purposes. First, it can diagnose the level at which a given cultural form operates by examining the pathways along which the culture travels. The thesis has demonstrated the role played by pathways in the creation and valuation of cultural forms. Second, the theory can help to show how and why a cultural form may transition between cultural levels. This thesis has argued that a shift in pathways coincides with shifts in form and philosophy. The new pathways put the new form in touch with new audiences. We will turn now to some of the limitations and implications of this theory of cultural flows.

\section{Limitations and Further Considerations}

This section examines one primary question. This section will examine the limitations of the current case study and ask whether the theory can be applied to other examples of music. It is obvious that my case study neglects certain aspects of the proposed theory of cultural flows because it is not possible to address all potential transformations. The thesis argues that jazz was able to change as a cultural form from folk to popular to elite music. This raises two sub-questions: (1) Can the process as described in the case of jazz be replicated in the case of some other types of music? (2) Do cultural forms (either musical or non-musical) always change in this sequence? Can a cultural form shift, for example, from popular to folk or from elite to folk? Both of these questions can be answered through the consideration of other examples of transitory culture, both musical and non-musical. The first set of examples will re-affirm the same process of transition as illustrated in my case study. The second set will explore the other 
possible iterations stemming from my theory, but not explored by my case study (elite to popular culture, popular to folk culture).

I am interested in exploring these questions because I am inclined to believe that the process of cultural transformation between levels is not merely one of uni-directional ascension (from folk to popular to elite). In principle, any culture is able to re-negotiate the pathways along which it travels, and in so doing, to transform itself into a new type of culture with new formal characteristics and new audiences. Of course, things that are possible in principle may nonetheless be very difficult and exceedingly rare in reality. Like all good scientific work, an experiment must be duplicated in order to be confirmed as fact. The answer to the question, however, is 'yes' and, fortunately, there are many examples at our disposal which also exhibit some, or all, of the traits of jazz music; they may move merely from folk to popular cultural levels, be shown to exist as an elite culture, or perform a transition between all three levels.

Rap music, for example, has distributed itself along popular pathways, functioning as a popular music for a number of years. Like jazz, its popularity has come in waves, from its original "discovery" in 1984 (artists such as Run DMC) to its extraordinary mainstream success in the late 1990s (Eminem, Jay-Z, Nelly, Tupac Shakur, etc.). Yet the style of rap popular in the early 2000 s was quite different from its earlier incarnations. Naturally, styles change over 20 years, especially in a music industry focused on novelty, and Kalefa Sanneh has shown how current rap styles emphasize melody and accompaniment rather than lyrics (which have traditionally been a distinguishing characteristic of rap). This adaptation suggests that rap has become a form of popular 
music, removed from its historical street/ghetto origins. The genre has since frequently been derided by both artists and critics for "selling out." However, new forms of rap and new artists, possessing additional "street cred" or authenticity are perpetually unearthed and breathe new prosperity into the form. ${ }^{\text {ccxxxviii }}$ This cycle between discovery, rise to popularity, separation from folk origins/operation via popular culture pathways, and subsequent popular revitalization through new, underground artists illustrates well the process of transition from folk pathways to popular pathways although the process may be more condensed and rapid than was the case with jazz.

There are other examples of folk cultures becoming popular cultures. Bluegrass/roots music, with its characteristic banjo pickin' has enjoyed great success in recent years due in part to the promotion provided by the film, O Brother, Where Art Thou? (2000). As a result of its widespread promotion and subsequent \#1 soundtrack, bluegrass enjoyed widespread popularity despite operating unabated in isolated rural pockets for most of the century. And as mentioned in the introduction, what became known as the Grunge movement in Seattle languished in economic obscurity before being "discovered" in the mid-1990s. Signed by major record labels and promoted heavily through the media, the grunge sound became extremely popular amongst many teenagers in the US.

The transformation of folk cultures into popular cultures is probably the most prevalent form of cultural change. Some of these cultural examples may even demonstrate a cyclical longevity, as the culture returns to function as a folk culture, and then returns to utilize popular culture pathways (becoming a craze again). Yet a distinction between a transformation to folk culture and a shift in popularity to a sub-culture is also worth 
making. A popular culture that suddenly drops in popularity with all but a select few social groups does not necessarily mean that it has become a folk culture again. Only if all the folk pathways are negotiated, is it possible for a popular culture to return to that status. The problem is, of course, that once a culture has developed an elaborate code, and established itself along certain pathways, how does a culture unlearn these activities? Is it really even possible? This question of course, is one that would require more research. However, the process of examining other types of music opens some interesting interrogations which are not central to this thesis but which could form the basis of an extended research into culture generally.

It is also relatively simple to find examples of cultures seeking to become elite. These attempts may be either successful or unsuccessful. An example of a successful transition to elite culture can perhaps be observed in current circus acts. Acrobats, jugglers, and tumblers have existed at least since medieval times. By the late $1800 \mathrm{~s}$, this disparate folk culture had been industrialized through the popularizing channels of the Big Top Circus (Barnum \& Bailey's, The Ringling Brothers). Circuses enjoyed great popularity for many years, but have generally been replaced by other forms of popular entertainment. However, companies such as Cirque du Soleil pursued the artistic angle of their performances, developing an understanding and appreciation of the professional training required to perform in such a manner, as well as introducing an elaborate code of acrobatically-based performance. The circus arts (note the new title - use of 'art') are beginning to utilize other pathways, away from the commercial industry. The Government of Canada, for example, has defined many circus performers as "professional artists" and the Ecole Nationale du Cirque receives government funding from programs designed to 
support arts organizations. Yet at the same time, Cirque du Soleil enjoys great popularity at its shows in Las Vegas (hardly an elite venue). Through the use of elite pathways, the culture of circuses (a term that still retains lower-class connotations) is beginning to move into elite cultural circles $-\mathrm{a}$ transition in process.

But a movement into elite culture may not be successful. An example of an unsuccessful attempt may perhaps be provided by the art rock movement. Prevalent in various forms in the 1970s through groups such as Frank Zappa and the Mothers of Invention, and Emerson, Lake, and Palmer (ELP), the art rock movement sought to elevate rock by adapting and incorporating many classical music ideas within its music. ${ }^{\text {cccxxxix }}$ ELP wrote many of their works in movements, a classical device that resulted in longer pieces requiring longer attention spans. For example, the group transcribed the classical work Pictures at an Exhibition by Modest Mussorgsky for rock trio. Art Rock musicians used longer pieces and more formal compositional elements to prove that rock had matured and could stand alongside other elite musics. ${ }^{\mathrm{cccxl}}$ Ultimately, the movement in the $1970 \mathrm{~s}$ was unsuccessful in leveraging the dominant narrative of rock into the elite level because of its inability to penetrate the academic institution and an inability to separate itself from the commercial ties of the popular music industry. However, many universities have begun to include rock music in their curricula, but not yet within music programs (thus recognizing the music as an equal to other elite musics). ${ }^{\text {ccxli }}$ The art rock movement is embodied today through Avant Garde rock artists such as Sonic Youth and Sigur Ros, suggesting that there will continue to be attempts to move the musical form into elite channels. The recurrence of these types of movements within many forms of popular 
culture suggests that there may be a tendency within popular culture to aspire to elite status.

Additionally, some types of culture may exhibit no movement at all. These, it may be postulated, remain creations of one cultural level and have shown no interest in other pathways. For example, one might consider the popular music industry's current fancy with so-called "boy bands." Groups such as the Backstreet Boys, N'Sync, 98 Degrees, and the Spice Girls (girl band - same formula) are creations of the popular music industry and have no folk music past. They exist to sell records for the industry and do not claim to elevate their art form or use other pathways to access new audiences. These types of groups wax and wane in popularity over time, but have an established history (dating back as least to the Monkees in the 1960s) of returning to favour with the music industry.

The second set of cultural examples will explore the possibility of elite cultures becoming popular again, and popular cultures becoming folk cultures. To this end, the example of Gregorian chant may prove useful. In 1993, recordings of Gregorian chants by the Benedictine monks of Santo Domingo de Silos experienced a moment of remarkable popularity. For analytical purposes, let us begin by examining the fact of this outburst of commercial success rather than its underlying causes. It should be noted that the sixth century choral music of Gregorian chant is characterized by a monophonic vocal sound, the use of a dead language, and the notable absence of instrumentation or any recognizable attempt at syncopation, rhyme, rhythm or beat. These factors distinguished it sharply from virtually every other popular music of the day. Nonetheless, the 1993 album, Chant, climbed to the top of the pop charts in Spain, realized sales of over 3 million copies, and 
became the $30^{\text {th }}$ highest grossing album in the US in 1994. The monks' success was greatly boosted by an extensive publicity campaign coordinated by the record label which included advertising, profiles in USA Today, and an MTV music video. Other labels immediately scrambled to find their own Gregorian hit-makers and the sound eventually came to rest as a cross-over hit in the "New Age" category. Although the monks became a hit, they ultimately proved unable to establish Gregorian choral music as the new popular music of the day. Elite critics, who had long been the guardians of this type of music, were perplexed. They expressed both bemused satisfaction at its popularity and lingering suspicion that such popularity simultaneously devalued the form. Interestingly, the Gregorian moment of the early 1990s, in its measure of relative success, suspicion within elite circles, and display of a 'new' genre of popular music is akin to the fusion moment within jazz. It provides an example of an obviously elite music form suddenly becoming popular.

Another potential example of a shift from elite to popular music might be found in the genre of orchestral film music which enjoys both commercial success with large parts of the audience and enduring critical disdain from classical music critics. It is, therefore, another example of a high cultural form - or of a cultural form inspired by high origins attaining popular success. Of course, being a "hit" (i.e. successful use of popular pathways) does not necessarily mean that the dominant narrative of the elite cultural form will suddenly veer towards the popular. Rather, if critics can exert their influence and demonstrate how this new "crossover" phenomenon is not really a worthy example of the elite culture, then the hit and all its progeny can safely be defined as separate from the elite 
culture which they merely imitate in an impotent gesture of aspiration and degradation. Again, as DeVeaux notes, definition is a powerful weapon. ${ }^{\text {ccxlii }}$

Nonetheless, taken together, these two examples seem to strengthen our earlier conclusion that an elite cultural form can only become popular at the price of severing its ties with the critical establishment and probably offering itself as a new type of culture. Critical inertia is such that if critics have been able to champion a cultural form as elite, it is then exceptionally difficult to dislodge this culture as a whole. Artifacts in the style of the elite culture but obtaining popular success will tend to be cast out of the magic circle. Perhaps if an elite culture has only recently established itself and not yet confidently entrenched its canon, traditions, and norms, the transition from elite to popular would be smoother.

Another non-musical example may seem to represent the prospect of a popular culture returning to the status of a folk culture. Skateboarding has gone through at least four major waves of popularity. Invented in the 1950s, skateboarding became a national craze in the 1960s (international contests, movies, specialty magazines) but crashed in 1965. It then retreated to underground status, appearing only in isolated pockets, such as Santa Monica, California. Here skateboarding functioned as a folk culture, participated in by amateurs in localized pockets, without the benefit of preferential venues. It reached widespread national popularity again as a fad in 1973, with better product design, but the growth of the sport was halted in 1980 , due, at least in part, to the restrictive insurance costs of building skate parks (where the dominant form of the sport was practiced). Finally becoming popular culture, skateboarding emerged in 1984 with a new style of street skating, which allowed it to be practiced anywhere, by anyone. With the help of industrial 
support, it finally entered the mainstream of youth culture; skateboard manufacturers realized huge profits, and skateboarding clothing, footwear, and expressions (championed by stars such as Tony Hawk and Rodney Mullen) became a staple for many teenagers. However, aided by the principle of rapid transition within popular culture pathways, skateboarding was considered "sold out" by the late 1980s, and the industry turned downwards. Assisted by a new breed of practitioners who shunned media attention and mainstream popular channels (different styles, different methods of practicing the sport, etc.), skateboarding descended from the public consciousness. It became a folk culture again, only practiced by a small minority of people. However, skateboarding was not to languish as a folk culture forever. It re-emerged as a popular culture in 1995, again becoming extremely popular, participated in by many people of many different walks of life, with a new blend of stars such as Bob Burnquist and Mike Vallely. Yet the sport had changed and now had as its focus a vast array of enourmously difficult technical tricks that required years of practice. ${ }^{\text {coxlii }}$ What is interesting about this history is that skateboarding, after functioning as a form of popular culture or teenage subculture, manages to distance itself from the channels of popular culture and return to its underground roots. As a folk culture, skateboarding was again able to transform itself without the constraints of popular definition. ${ }^{\text {ccoxliii }}$ Therefore, albeit from a preliminary examination, it appears possible for a cultural form to move from functioning as a popular culture to functioning as a folk culture once again, if it can re-negotiate the pathways it operates on.

This example gives rise to one further consideration; with the example of skateboarding I may be accused of confusing what is a youth subculture with a true folk culture. Yet because skateboarding has attempted (however successfully or 
unsuccessfully) to transform itself through the use of alternative pathways, I would argue that it benefits from an examination of pathways analysis. However, it is perhaps worth noting that the splintering of styles across all areas of music tends to turn all music into pseudo-elite manifestations. In a sense, the argument could be made that rap music, for example, functions simultaneously as popular and as elite music. Some rap artists get very wide distribution, others are known only to the initiated. It may be that within every popular culture there is an internalized tendency towards 'elitization.' After all, every popular culture is also constructed around the demonstration of difference. The fact that some popular cultures - usually youth cultures - reach large audiences could be merely a function of the size of the youth audience. Nonetheless, within the youth audience there have always been clear tendencies towards further distinction, towards the breakdown of the 'big' youth culture into ever smaller and more refined subcategories. Right from the very beginning, rock splintered into white and black, rock and pop, mods and rockers, etc. It may be held that it is only retrospectively that we imagine the unity of musical culture when for those living it, on the ground, all that one can see is an infinity of microdifferences. Perhaps these micro-differences would be apparent even in our case study of jazz. If one were to go back to swing, would one really find a unitary popular culture or would one find swing fans making fine distinctions - important to them - between the fans of Benny Goodman and those of Louis Jordan (for example)? Hence, one may observe what appears to be a built-in tendency towards elitization (via increasing distinction). However, it is of equal importance to note the distinction between a form of culture which hopes to transform itself by utilizing different pathways, and a form of culture which merely attempts to use different styles to distinguish itself. While fans of Benny Goodman 
might be insulted to be lumped in with those of Louis Jordan, the fact is that both artists utilized the same popular commercial pathways. Therefore, a distinction between the two camps can not be upheld via pathways analysis, but only if we consider the valuation of the message by certain audiences and the creation of elite identity groups by those members (a task well handled by the cultural studies perspective). Likewise, youth culture is not a level. Youth culture is by definition bound up with notions of the 'popular,' it is a means by which teenagers attempt to construct identities. Pathways analysis is not about the construction of identity, it is about understanding the means by which certain messages reach certain audiences. Therefore, the idea of youth culture adds a degree of subtle nuance to our theory, but in the sense that we must carefully consider what are actual attempts to change pathways, and what are attempts to use subtle formal discrepancies to create identity groups amongst like-minded audience members. Nonetheless, the effects and penetration of this tendency are certainly an idea which further research should explore, or at the least, they constitute a suggestion for how a new question could be posed to cover old cultural material.

Therefore, from these previous explorations, while difficult, it seems possible for a culture to transform itself from a popular culture to a folk culture through the deliberate use of non-popular pathways, especially when the critical establishment is weak. The transformation of an elite culture to a popular culture (through the separation of the form from the protection of academic institutions and critics) seems much more difficult to accomplish if the elite culture is firmly entrenched within a critical and academic tradition. If the elite culture is too entrenched in these supporting pathways, attempts to move it back to a popular form are more likely to result in a fragmentation of culture, a new genre of 
popular culture that only retains certain elements of its elite parent. However, a further indepth consideration of cultural examples which exhibit these trends would be required to more fully understand this process of transition, but will not be attempted within this paper. Therefore, there is no shortage of examples to illustrate the theory of cultural flows. Cultural movements exist which have attempted to move from each of the levels to another one, either successfully or unsuccessfully. In this way, it will be necessary to examine other cultural examples in order to strengthen the theoretical model proposed.

\section{Implications}

A second major set of questions would seek to understand the implications of the theory beyond its mere applicability to additional case studies, and out to the disciplines of cultural studies and communications. Where does this thesis lead us? It proposes a theoretical model of cultural flows but what are its implications? What might it mean for cultural studies and communications?

Fundamentally, the theory of cultural flows and the pathway analysis upon which it relies provide a different set of questions to supplement "standard" approaches to music or cultural analysis as commonly proposed by cultural studies or jazz studies. The standard approach asks questions such as "how did musicians change jazz music?" It delivers answers such as "Charlie Parker invented bebop, which changed jazz into an art form." This approach focuses on music and musicians, the cultural form and the cultural creators. The pathways approach asks such questions as "how do pathways influence jazz music?" It delivers answers such as "jazz music changed its popularity with certain types of audiences because of its increased or decreased exposure through the use of specific 
pathways." This approach focuses on gatekeeping intermediaries - the institutions, industries, and interlopers - who are involved in the process of transmission between artist and audience

Pathways analysis does not claim to be 'better' than the standard approach or even wish to replace it. It claims only to provide other questions which may enrich our understanding of the phenomenon under study. In this respect, then, while the standard approach levied by cultural studies focuses on aesthetic and psychological factors, pathways analysis is clearly more attuned to institutional and sociological factors. It is rooted in the world of communication studies rather than the world of musicology.

Within the world of communication studies, pathways analysis also makes a claim. The approach clearly derives from Lasswell's famous question "Who says what to whom through which channel and with what effect?" However, over the years, the Lasswellian approach and its transformations through Lazarsfeldian functionalism, effects studies, uses and gratifications studies, have been increasingly condemned and marginalized. Lasswell and his successors have most famously been condemned as examples of 'administrative' research. Their outlook was said to be unidirectional, linear, static, and, most significantly, in the service of corporate, state or unacknowledged ideological interests. It was argued that a focus on the steps of the Lasswellian approach deflected attention from other, more important questions which are usually called 'critical'. Hence, while Lasswell wondered through which channel messages traveled, other better informed and more astute critical scholars inquired into who owned the channels. Lasswell claimed modestly that sending a message through different channels might affect its effectivity or its form or its audience reach. Critical scholars claimed, more grandly, that knowledge of the channel's ownership 
told us volumes about what any message could possibly mean. Ownership or control of the channel coloured or very nearly exhausted everything we needed to know about the message. Hence, Lasswell might modestly prefer one means of delivery over another; his critical colleagues were armed with a program for total media reform.

The goal here is not to revisit the communication wars of the last 70 years. May it suffice to say that some very enriching and some not very inspired things have been said from almost any perspective one can imagine. The approach promulgated by this thesis does not hope to undo or criticize the explorations of power relations. Within communication studies, however, pathways analysis is an attempt to 'rehabilitate' a neglected tradition, an attempt to revisit it and to ask whether it may not be rescued, at least partially, from the criticism directed against it. Modestly, the claim of pathways analysis is that, yes, the so-called administrative tradition contains valuable elements worthy of re-examination. Pathways analysis provides a high degree of insight into culture in that it invites us to consider carefully all the steps involved in the transmission of a message. Even further, it invites us to consider a cultural act as, first and foremost, a communicative act (the encounter of an idea/message with a receiver/audience) rather than an exercise of power. It also insists that the channel of delivery actually impacts on the form/shape/content of the message, whereas the so-called critical tradition is much less interested in such questions because it believes that the shape/form/content is secondary to the fact of control. The critical tradition would argue that if we know control, we do not need to know the shape of the cultural form, because this shape is completely accounted for by the fact of control; whatever particular shape is involved, it can only be an attempt 
to disguise the control. Therefore, this thesis contributes to both the music/cultural analysis perspective, as well as communication studies.

However, though significantly different, even these two approaches are not the only paradigms through which one might seek to understand culture. The dynamic of racial factors and their impact on the development, valuation, and spread of jazz is another window or set of questions, yielding a still different angle, implications and answers.

What also becomes apparent is that by adopting a different paradigm, we can also understand the way in which the standard defenses of culture are constructed. Pathways analysis does not merely provide a different perspective or set of questions, but provides insight into the way in which other perspectives are constructed and the reasons for which they are invoked. If the focus of our cultural understanding is based on the cultural artifact itself, then its place within the cultural hierarchy is warranted by the form of the artifact. An artifact gains attention and becomes worthy of inclusion within a cultural hierarchy because of its particular constellation of formal features. But if the focus of our cultural scrutiny is transferred to the process by which the cultural form gains access to different audiences (mass, elite or folk), then the appraisal of cultural levels becomes a much more neutral display of identifying pathways through which the form travels.

Let me explain a further implication of this approach. I want to make a contrast between the questions of scrutiny leveled by the approaches of cultural studies and communications studies. Pathways analysis transfers scrutiny from formal features to the process by which an artifact encounters its audience. It renders the meaning of the artifact dependent upon its success as a communicative act. The cultural studies approach makes the meaning of the artifact dependent upon its place within a system of formal features. 
Pathways analysis also legitimates and encourages scrutiny of the role of the audience as an essential moment in the circuit of meaning. However, cultural studies sees the audience as an expression of its class origins or of its social location. This is certainly a good way to think of the audience. Cultural studies also sees culture as homologous with the class origins of the audience. It is also a good way to think about culture. But pathways analysis sees the audience as a moment in a process of communication or contact (and an unstable moment, at that). If an audience expresses its social location, then the audience only changes if the social location changes. It therefore means that the process of communication within such an audience is fairly stable. We will always know what the audience thinks, why it chooses some artifacts over others, or how it responds based on the long-term stability of the overall social system (within which social location is fixed). However, from a pathways perspective, the audience is always changing. The pathway may or may not connect with it. And if it does connect, it does not guarantee that the audience will be receptive. Nor does not exclude the possibility that other pathways may be reaching the same audience at the same time or that groups such as critics are attempting to exert influence on the functioning of the pathway. Indeed, pathways analysis asserts that pathways are not neutral conduits but rather active machines which shape the meanings of messages. The cultural studies perspective tends to view the pathway linking the media (for example) with the audience as fairly stable and consistent; it always delivers the same ideological outcomes. This is the difference. Cultural studies takes a view of the audience as much more stable, as consistently expressive of a stable class-based identity, and as a consistent, reliable moment in the process of communicative exchange. It is that 
very consistency which makes ideological interpretations possible. Pathways analysis does not make those assumptions.

Yet, by studying communicative acts, then we also have something important to say about the cultural studies approach. We are able to identify its focus on formal features and their location within an overarching system of classification; we are able to predict which artifacts will be deemed significant and, therefore, show what types of investigative strategies will be used to explore those artifacts. Further, we are able to show that because this strategy makes meaning dependent on the organization of formal features, it will view audiences as either "worthy" or not, as either able to appreciate the sophistication of certain formal features or not; it will understand creators as worthy manipulators of the formal features or not. This approach then, naturally contributes to the history of 'great creators' producing 'great artworks' which require 'great audiences.' Pathways analysis, on the other hand, asks "what does the cultural object mean from the point of view of the user?" If art is a communicative act, then the artist does not simply manipulate features from a vast storehouse of manipulable features (although this certainly happens), the artist asks "what effect do I want to achieve? To what audience am I speaking? How can I be sure that my message will be understood?"cccxlv From the pathways analysis perspective, an artifact becomes valuable if it is pragmatically successful, not if it represents a noble assemblage of formal features. So, from a pragmatic or pathways perspective, bebop is interesting not because of its formal or semiotic density - which certainly exists - but because of its failure to elicit an identifiable response from a mainstream audience. And swing is valuable not because of its formal or semiotic density - which is certainly less than bebop's - but because of its ability to communicate. Dancing 
becomes noteworthy not because of its freakish displays (as Adorno would claim, jitterbugging shows us the true degradation of mass man under the reign of popular culture alike to the reflexive jerking of severed insect limbs) but because it is the externalization, the physicalization of an internal state. Dancing is the evidence that the artist got it right, the response that allows the artist to know that she has communicated with the audience. And, as we can plainly see, this approach turns the relationship between creator and audience into a dialogue - creator says one thing, audience says something back - and to be interested in dialogue is to be interested in communication. Stepping outside one theoretical paradigm therefore allows us to understand how the adoption of that paradigm affects our viewpoints, beliefs, and research focus.

There is still another conclusion to discern. Each of our sets of questions begets certain related answers. If we truly understand this, there is no possibility to have one over-arching theory that can explain all cultural phenomena. Every set of questions concentrates on a slightly different object of study; every set of questions requires a new set of answers. All we truly have are competing and overlapping sets of questions $-\mathbf{a}$ potentially infinite series of case studies and points of view to consider. This is the secret of pathways analysis; it is concerned not with providing definitive answers but with generating good questions that allow us to play the game of research and dialogue. It depends on the individual skill and imagination of the players, not upon their inscription within systems of power and domination (though that certainly happens). It is, therefore, extremely hopeful towards future research. This then, is the implication I would like to take out of my research - I would like to promote a meta-cognitive understanding of cultural studies; one that would incorporate many different models of understanding. It is 
not a question of finding the "right" way to understand culture. It is a question of being able to understand culture from many different perspectives, each perspective containing a unique set of questions and values, as well as the types of judgments and defenses that an adoption of each perspective entails. If there must be a recommendation, it would be to have students of culture attempt to understand their object of study from a variety of views, each with their own set of questions and thematic emphases. 


\section{Conclusions: All the Things You Are}

So all that remains is to volley a few concluding remarks. I would like first to begin briefly with another story, the story of another cultural object which has exhibited degrees of transition. George Boas has written a fascinating history of a specific work of art that traces what critics have said about it through its history. ${ }^{\text {ccxlvi }}$ The art work he has chosen is, intriguingly, the Mona Lisa.

To Leonardo's contemporaries, the work was nothing special. Many contemporaneous accounts of the painter's life fail to mention the work. Others merely glance over it, mentioning it in passing as a simple portrait which was bought by the king. The one critic who does cover it in detail, Vasari, lauds it for its faithfulness in imitating nature, and credits Leonardo with great skill as a craftsman. Leonardo's ability to reproduce a lifelike picture is praised rather than his skill in creating an artwork that produces emotion in the observer. This is indicative of a Renaissance society which celebrated the arts which helped humans understand the things of nature. As Foucault notes in The Order of Things, in the Renaissance, resemblance guided exegesis and textual interpretation, organized the play of knowledge and symbols, and made knowledge possible. ${ }^{\text {ccxlvii }}$

For a hundred years or so after the Renaissance, there is little discussion of the Mona Lisa. Presumably, this is because the painting belonged to the king, and not many people had the chance to see it (especially if it was not immediately thought to be one of the painter's better works). This is, of course, a demonstration of the effectiveness of controlling pathways of access. However, the Mona Lisa resurfaces again in the middle of the $17^{\text {th }}$ Century. Critics begin to contribute to the legend of the Mona Lisa by 
exaggerating the time it took Leonardo to finish the portrait (anywhere from 4 months to 4 years). So the legend of the Mona Lisa grew, but it was not until the $19^{\text {th }}$ Century that critics took another angle.

With the rise of Romanticism, the character of the femme fatale began to emerge as a critical theme; sensation and feeling passively marking themselves against male rationality. Romantic critics understood works of art to be hieroglyphics; bearers of a hidden meaning which only the initiated could understand. Reflectively, comments on the Mona Lisa began to change from fidelity of lifelike reproduction to the eternal feminine. The Mona Lisa now recalled past lives, loves, and experience, mocking you with her strangely familiar smile. What was now lacking was an explanation as to the mysterious character of this face; quickly found (according to romantic procedure) in the romantic life of the painter. The Mona Lisa became the mistress of the painter, Leonardo. These were the clues to the 'true' meaning of the picture, only decipherable by a critic.

This ability of critics to understand the perspective of the artist was further strengthened by the popularity of the psychology of Sigmund Freud in the $20^{\text {th }}$ Century. Freud believed artists to be those who symbolically release sexual frustrations cathartically through the creation of art. Using his theory of the Oedipus complex, Freud considered the Mona Lisa to be Leonardo's mother, legitimating a critical exploration of her life and other implications. Another critic found Leonardo's possible homosexuality to be concealed disguised in the painting. This is possible only if one accepts the Freudian theory that art is a symbolic rather than a literal satisfaction of repressions. Currently, the Mona Lisa and Leonardo are subject to a different sort of critical revisionism. Based on a plethora of recent books and television specials, the scientific and philosophical side of DaVinci is 
more in demand these days, and the worth of the Mona Lisa is the primary point of interest in the painting nowadays.

Boas draws a conclusion from this examination of the critical history of the work. He points out that the search for aesthetic standards usually presumes that the work of art is an unchanging object and may always be judged in the same manner, with the same criteria. Boas goes on to demonstrate that the judged 'beauty' in works of art does indeed change over time, even if the physical work itself (the words of the play, or canvas of the painting) does not. ${ }^{\text {ccxlviii }}$ The physical basis of the work is perhaps less important than what critics and audiences have looked for, and found within the work. If it is argued that the work of art should be judged strictly on the artist's intent in creating it, we struggle in vain to recapture exactly what that intention is. The work of art therefore is the focus of different sets of values determined by the perceptions of each new critic. The old adage about life reflecting art is perhaps less true than art reflecting life. Boas submits that works of art which "withstand the test of time" change their value and even perceived purpose, as they travel through history. ${ }^{\text {cccxlix }}$

Therefore, Boas demonstrates both the influence that other (extra-artistic) factors can have upon the understanding of the work, as well as the important fact that the judgments of art do change over time. A cultural movement can mean different things, even if the object does not change. My own selection of jazz as a case study is slightly more complex than Boas' reading of the Mona Lisa simply because I am choosing to follow a cultural movement (jazz), rather than a specific example of culture (such as the many different renditions of "I Got Rhythm"). In selecting the more general movement, I have chosen a subject that evolves over time. This is no longer a static object of study, but 
a dynamic form that adapts itself to the circumstances in which it finds itself, and may be adapted to access different audiences and evoke different social responses.

The bulk of this thesis has been focused around three main analytical tools or theoretical constructs that have undertaken the task of understanding the popularity and prevalence of certain types of cultures amongst certain types of audiences. The first of these is the tool of analysis I have taken to calling Pathways Analysis. Pathways analysis focuses on the question of how certain types of cultures resonate with a certain audience, and considers the different ways in which a cultural form may transmit itself to a particular audience. Pathways analysis studies the work of institutions, critics, industries, practices, and technologies in creating the popularity of cultural movements. Counter to many models of culture which focus on the homologies between forms of culture and particular social groupings, pathways analysis instead considers how the cultural form accesses certain types of groupings. This tool of analysis therefore enables a different conception of culture - that of culture as a process of communication - which may serve as an alternative means of exploring culture. With this tool of analysis, we ask a different set of questions (questions of the role of the entire field of relationships within which cultural artifacts exist) than previous models of cultural understanding (as postulated by the school of cultural studies).

The use of pathways analysis has taken place within a Tri-Partite notion of culture, the second tool. This division supposes three basic levels of culture (folk, popular, and elite), each of which can be taken to signify a particular set of channels which allow for access to a different type of audience. While traditionally divided on the basis of either 
cultural content or social class, these divisions in level maintain their distinctiveness when the focus is shifted instead to the pathways through which the culture is communicated. In saying that culture can be divided on the basis of form or social class, we draw homological links between the culture and the audience. In adopting this stance, we say that audience A likes artifact B because of audience A's social location. And if this is true, than I know everything I could possibly want to about artifact B and audience A. Yet beginning an analysis from a homologizing point of view constrains the analysis. The point is not to deny the existence of homologies - of course they exist. I do not deny that audiences have preferences, but I do contest that all of these preferences can be explained through the artifact. Instead, I have argued that in order to understand audience A's liking for artifact B, we must study not the composition of the audience or the formal features of the artifact, but rather the pathways which permitted artifact B to come into contact with audience A. Preference exists because of the pathways which connect audiences to artifacts. The divisions we can see in culture are not divisions based strictly on class, but suggest that there are multiple factors and actors that influence who is able to participate in a certain type of culture. Pathways are not neutral conduits; they exert pressure. Nor is this division subject to static categorizations that would see culture as functioning permanently at one cultural level; rather cultural movements can shift from level to level. This is where the third tool comes in - the theory of cultural flows.

Pathways Analysis coupled with this Tri-Partite notion of culture gives rise to our Theory of Cultural Flows. This theory recognizes that culture is not a static object, but functions through a process of negotiation amongst social actors. The process shapes the cultural form and aligns it within one of the three cultural categories, but the form may also 
change as a result of further negotiations or developments. Pathways analysis points us towards the factors which enable a cultural form to operate at a certain level. The theory of cultural flows therefore prescribes the conditions under which a cultural form may exist at one of the three levels, as well as the conditions under which a cultural form may metamorphize into a new level from the one it has previously occupied. It allows us to more fully understand the actors who contribute to the popularity of the cultural form, and opens the door to further study of the ability of culture to transform. The understanding of culture, ever a complex and complicated object, may be enriched through the creation and application of this theory.

Conclusions are usually marked by a demonstration of what types of further research might benefit the current work, and I will not deviate from this standard. One direction for future research looks to prove further the validity of the theory of cultural flows, and expand it through all of its possible iterations. Though the one case study I have dealt with in this thesis seems to support the development and use of the theory, it will be necessary to reproduce these same results with other case studies. Further work will need to suss out exactly what types of cultural movements and forms can be explained by the tools of pathways analysis and the theory of cultural flows. The case study of jazz has demonstrated how folk culture can become popular and then elite culture. Further work could explore the requirements of cultural forms to transform themselves from elite to popular, or from popular to folk levels. In examining the potential for transformation from elite to popular culture, future research must explore the work of critics in the canonization and definition of elite culture, and the degree to which elite traditions, norms, 
and practices have to be entrenched in order to retain control over the definition of what exactly constitutes the elite culture. These are the conditions which allow critics to maintain the position of the cultural object within established elite pathways, and they are also the conditions which must be overcome in order for the cultural form to function at a different cultural level. In examining the potential for transformation from popular to folk culture, future research will have to consider the ability of cultural forms to pursue transmission along pathways other than the commercial channels of popular culture. In shunning commercial channels of transmission, the cultural form will access a different audience, and the potential for it to redefine itself as something other than popular culture may exist. Although given a cursory treatment in the preceding chapter, a more in-depth explanation of these theoretical permutations can be undertaken by further research in order to fill out the diagnostic tools of pathways analysis and the theory of cultural flows. A future researcher may also be interested that certain behaviors seem to suggest that a cultural form can operate at differing levels of popularity within one cultural level (popular culture, elite culture). The popularity of a certain form of popular culture may become more or less extensive (in fashion, seen as 'cool') over time without altering its content dramatically. This behavior may be explored and explained by the Lazarsfeldian concept of membership groups. Membership groups are the outcome of a mass society. Diverse groups of people find themselves clustered together, enjoying similar things because of common interests or situations. They are not consciously created from the culture, especially with any specific revolutionary intent, but are the byproducts of a diverse society with many features. ${ }^{\text {ccl }}$ A membership group may be easily confused with Hebdige's better-known notion of the subculture. ${ }^{\text {cccli }}$ However, the two are different in at 
least one important way. A subculture typically polices entry to its magic circle and is characterized by highly coherent internal practices, beliefs, etc. A subculture is, in fact, a membership group. But whereas membership groups are simply features of a pluralistic society (according to Lazarsfeld), subcultures are heroically resistant bands of oppressed consumer citizens bravely seeking out an authentic identity against the capitalist depredations of mainstream culture. To speak of subcultures is to speak of the use of culture in creating meaning, and thus, to draw a homological link between a cultural form and an audience. But to speak of membership groups is to allow for a distinction in audience groups without requiring a singular reading of cultural meaning. If we set aside subcultures and speak instead of membership groups, we would say that a membership group might "constitute" a niche market, or might connect with a certain pathway or might allow entrance to a certain type of message. A cultural form may therefore be subject to different popularity fluctuations without changing the pathways along which it accesses its audience. Though an intriguing idea, not every change in the popularity of a cultural form is due to a renegotiation of the pathways it is transmitted along. And it is this fact that demonstrates why pathways analysis is important. To study pathways is only to discover how artifacts are made available to an audience; pathways do not guarantee their meaning or their success. But further research is needed to compare if and how these membership groups use alternative pathways in order to mark their chosen cultural distinctions as separate from other cultures that operate on the same level.

The existence of various types of membership groups also suggests the possibility of a quest within the level of popular culture for distinction. One perspective might suggest that the splintering of styles noticed in all areas of music tends to encourage the 
idea that all music exhibits elite, or pseudo-elite tendencies. Indie-rock or emo-rock are particular forms of popular culture, but many of thier fans and practitioners spurn the mainstream channels of the popular music industry, feeling themselves to be part of a more legitimate alternative culture. Rock music as a whole, therefore, exhibits both popular and elite tendencies; it has some artists who are very widely disseminated, and others who are only known by an initiated circle. The large popular culture is therefore broken down into smaller subcategories: hard rock, soft rock, oldies/classic, emo-rock, etc. This tendency towards sub-distinction requires definitions (to distinguish hard rock from emo-rock, new rock sounds from older rock sounds, etc.), and definitions have been shown to function as one of the key criteria of elite culture. Yet, it is important to note the difference between a change in strictly formal features of the culture (studied by the cultural studies model), and a change at the level of the pathways of distribution (studied by pathways analysis). Nevertheless, the range and penetration of this sub-distinctive tendency is another idea which future research might explore, as well as drawing further clarity upon the sense of distinction.

A second direction for future research does not look towards the proposed theory, nor the cultural object of study, but instead concerns itself with the implications of culture created as a process of communication. Using the tool of pathways analysis, further research might visit the subjects and objects traditionally considered by the cultural studies paradigm, but cast them in a slightly different light. Pathways analysis offers the chance to apply Lasswell's question of "Who says What to Whom through What Channels with What Effects?" in a variety of cultural settings. Rather than the perspectives and questions of cultural meaning and significance which cultural studies offers, further pathways 
analysis would seek to understand how the pathways themselves influence the creation and reception of culture. It would seek out the process by which the cultural form gains access to different audiences. Further research might therefore be able to offer alternative histories of rock, blues, rap, or country music, which differ from standard histories in their examination of the channels along which the music passes from artist to audience.

The implications of the theory of cultural flows and the insights about culture based on a pathways analysis are several. It is not enough to consider culture as the by-product only of great actors; artists who are able to transform our very understanding of culture with the strength of their vision. Rather, as the previous chapters have demonstrated, there are a host of other factors that influence the processes of popularizing and accessing certain types of culture. This is what this theory of cultural flows has attempted to dodemonstrate both the factors which contribute to the popularity of cultural forms, as well as the conditions under which a cultural form accesses certain audiences. Cultures may be either folk, popular, or elite (each term signifing the different types of pathways the culture utilizes). These pathways are the technologies which disseminate the cultural form, the cultural industry, the use of critics (who structure the discourse about the cultural form), and the institutions within which people experience the cultural form. Each pathway is more likely to transmit certain types of cultural forms, and cultural forms are adapted in order to be more communicable through the different pathways. This negotiation of the form allows the culture to access a certain type of audience, and by changing the pathways along which the culture is transmitted, a culture becomes accessible/popular by a different audience. 
This theory suggests that certain crucial pathways must be negotiated for the culture to operate at a certain level. Because of its dominance in controlling mass media outlets and popular opinion, the pathway of the culture industry must be successfully negotiated by the cultural form, if that form is to be allowed to operate as a popular culture. Likewise, at the elite level, a cultural form must demonstrate support from both an established body of critics, and, still further, must be compared favourably with other elite cultures. Most elite cultures operate within the institution of the Academy, and so a cultural form must negotiate its relationship with this institution in order to operate as an elite culture. These pathways therefore play a major role in the operation of a cultural form at a certain level. Furthermore, just as a successful negotiation of these pathways is necessary for a cultural form to be accepted into a certain level, a neglect of these pathways is also required in order to allow the cultural form to transform to a different level.

It has never been my purpose to claim a new, definitive model for cultural understanding that reduces all previous modes of understanding to meaninglessness. Pathways analysis promotes a certain set of questions (questions about transmission and access, questions about the way channels of communication exert pressure) that it privileges above other questions. While it does allow certain claims about the nature of culture, when taken as a whole, it posits another mode of understanding that stands counter to the model proposed by cultural studies. Therefore, with this model of pathways analysis, I am able to suggest a multi-dimensional approach to understanding culture. Culture can be understood from a variety of perspectives, be it a concentration on the cultural form and its creators, the socio-economic background of audience participants, or 
the pathways along which the cultural form travels. Culture remains, as Raymond Williams once suggested, one of the most complex terms in the English language; however, it is one that remains an interesting and exciting topic of study, no matter what terms or theories one studies it under. 


\section{Endnotes - Introduction}

i "The Goodman of Wastness." Obtained online at www.orkneyjar.com/folklore/selkiefolk. November 7, 2005.

ii Andrew Bauck, "Loser: The Real Seattle Music Story," in Popular Music, (Vol. 16, No. 2, May, 1997), 231-234.

iii Cultural Studies, as the name suggests, has long been interested in culture. Yet it has come to grant the pathways through which messages travel secondary importance, preferring to concentrate on the ways in which people interpret, select, and utilize cultural forms in order to create identities. Bourdieu (1984), for example, argues that people use culture to create networks of inclusion and exclusion through the concept of taste. This is a classic example of the search for homologies between cultural forms and the groups which value them; it typically understands the cultural form as functionally expressive of the groups' prior attitudes, beliefs, aspirations, impulses, etc.

iv Jurgen Grandt, Kinds of Blue, (Columbus, OH: Ohio State University Press, 2004), xiii.

${ }^{v}$ Chris Barker, The Cultural Studies Reader, (Routledge, New York: NY, 2000), 50.

${ }^{v i}$ Howard Becker, Art Worlds, (Los Angeles, CA: University of California Press, 1982), 34-39.

${ }^{\text {vii }}$ Richard Peterson \& Roger Kern, "Changing Highbrow Taste: From Snob to Omnivore," American Sociological Review, (Vol. 61, October, 1996), 900-907.

viii David Brooks, Bobos in Paradise, (New York, NY: Touchstone, 2000), 256-273.

${ }^{\text {ix }}$ Simon Frith and Howard Horne, Art Into Pop, (New York, NY: Methuen, 1987), 12.

${ }^{x}$ Kelly Hill, "Performing Arts Attendance in Canada and the Provinces," (Statistical Insights on the Arts, Vol. 1, No. 1, Hill Strategies Research, Inc., January, 2003), found online at www.hillstrategies.com.

\section{Endnotes - Chapter 1}

${ }^{x i}$ Marshall Sterns, The Story of Jazz, (New York, NY: Oxford University Press, 1956), 11.

xii Scott DeVeaux, "Constructing the Jazz Tradition: Jazz Historiography," in Black American Literature Forum, (Vol. 25, No. 3, Fall 1991), 528.

xiii Paul Ostransky, Understanding Jazz, (Englewood Cliffs, NJ: Prentice-Hall, Inc. 1977), 26-28.

${ }^{x i v}$ There are still examples of writing which suggest that swing was not Jazz (see Thomas Hennessey's From Swing to Jazz for example), however, this further demonstrates the fact that jazz is a disputed term.

${ }^{\mathrm{xv}}$ Ostransky, 40.

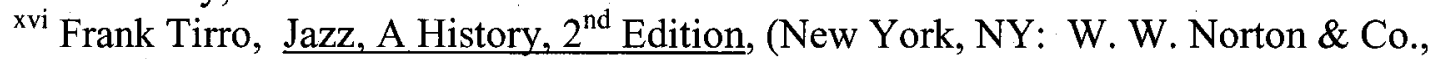
1993), 3.

xvii Martin Williams, The Jazz Tradition, (New York, NY: Oxford University Press, 1993), 3-8.

xviii DeVeaux, "Constructing the Jazz Tradition," 530. 
${ }^{x i x}$ Paul Lopes, The Rise of a Jazz Art World, (Cambridge, UK: Cambridge University Press, 2002), 3.

${ }^{x x}$ Ted Gioia, The History of Jazz, (New York, NY: Oxford University Press, 1997), 413425.

${ }^{x x i}$ Donald Megill, and Richard Demory, Introduction to Jazz History, $2^{\text {nd }}$ Ed. (Englewood Cliffs, New Jersey: Prentice Hall, 1989), 175. In a chapter ambiguously titled - Bebop: Extended Techniques.

${ }_{\text {xxii }}$ Scott DeVeaux, The Birth of Bebop, (Berkeley, CA: University of California Press, 1997), 1-3.

xxiii Hughes Panassie, Hot Jazz: the Guide to Swing Music, (New York, NY: Whitmark, 1936), 235.

xxiv Lopes, 4-12.

${ }^{\mathrm{xxv}}$ Sterns, 155.

xxvi DeVeaux, "Constructing the Jazz Tradition," 526.

xxvii DeVeaux, "Constructing the Jazz Tradition," 542-545.

xxviii Eric Lott, "Double V, Double Time," in Robert O'Meally, Ed., The Jazz Cadence of

American Culture, (New York, NY: Columbia University Press, 1998), 457.

${ }^{\mathrm{xxix}}$ Tirro, 330 .

${ }^{\mathrm{xxx}}$ For the interested reader cool jazz can be embodied by the work of Stan Getz, modal jazz by Miles Davis' Kind of Blue, Third Stream by Gunther Schuller, and hard bop by Horace Silver.

${ }^{x x x i}$ For the interested reader free jazz is perhaps most famously embodied by the work of Ornette Coleman, while Fusion can be found in the sound of Chick Corea.

xxxii Neoclassicism is heralded both musically and intellectually by Wynton Marsalis.

${ }^{x x x i i i}$ Eric Porter, What is this thing called Jazz?, (Los Angeles, CA: University of

California Press, 2002), 306.

${ }^{x x x i v}$ DeVeaux, "Constructing the Jazz Tradition," 526-528.

${ }^{x x x v}$ Mervyn Cooke, Jazz, (London, UK: Thames \& Hudson, Ltd., 1998), 171-190.

${ }^{x x x v i}$ Michel Foucault, The Order of Things, (New York, NY: Routledge, 2002), Pg. 20-21.

xxxvii Lopes, 1-9.

xxxviii Williams, The Jazz Tradition, Foreward, vi.

${ }^{x x x i x}$ George Lipsitz, "Songs of the Unsung," in Robert O'Meally, Brent Edwards, \& Farah Griffin, Eds., Uptown Conversations, (New York, NY: Columbia University Press, 2004), Pg. 14-15.

${ }_{\mathrm{xl}}$ Vulliamy, 79-80.

xli James Collier, Jazz: The American Theme Song, (New York, NY: Oxford University Press, 1993), 120.

xlii Tirro, 155-161.

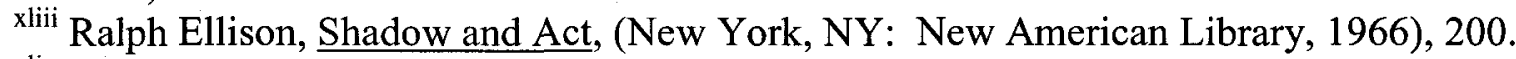

xliv DeVeaux, "Constructing the Jazz Tradition," 525.

${ }^{x l v}$ Thomas Hennessey, From Jazz to Swing, (Detroit, MN: Wayne State University, 1994).

${ }^{x l v i}$ DeVeaux, Birth of the Bebop.

xlvii DeVeaux's work should not be mis-interpreted as the creation of continuity; rather, he focuses on the transformative factors that catapult jazz into an art form. 
xlviii This also points to another problem with standard history. Presumably, the history of a popular form would have to take account of its methods of diffusion, economic reproduction, etc. Unfortunately, all of our models tell us how to evaluate high art. Therefore, even with the best will in the world, most jazz historians simply do not have a model for the study of a popular form.

xlix Lopes.

${ }^{1}$ This is an interesting distinction of approach between a sociological and a communications perspective. Whereas sociologists (such as Gans) focus on the behavior of individuals clustered around indissoluble cultural levels, the communications perspective recognizes the ability of art forms to adapt themselves to become part of a different cultural level.

\section{Endnotes - Chapter 2}

li John Berger, Ways of Seeing, (London, UK: Penguin, 1977), 7.

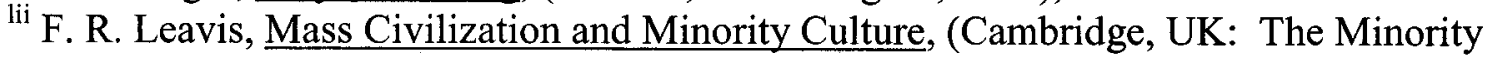
Press, 1930), 4-5.

liii Matthew Arnold, Culture and Anarchy, (Cambridge, UK: University Press, 1935), $43-$ 48.

${ }^{\text {liv }}$ Arnold, 34-35.

Iv Dwight MacDonald, "A Theory of Mass Culture," in Bernard Rosenberg \& David Manning White, Eds., Mass Culture: The Popular Arts in America. (Glencoe, IL: The Free Press, 1957), 59.

lvi Theodor Adorno \& Max Horkheimer, Dialectic of Enlightenment, (New York, NY: Verso, 1997/1979), 3-42.

lvii Lawrence Levine, Highbrow/Lowbrow: The Emergence of Cultural Hierarchy in America, (Cambridge, MS: Harvard University Press, 1988), 221-223.

Iviii Walter Benjamin, "The work of art in the age of mechanical reproduction," Illuminations, (London, UK: Fontana, 1973), 848-870.

${ }^{l i x}$ Benjamin's writings here may be used to suggest that the pathways along which a cultural form travels are extremely important, that a different experience of the object will occur if it is presented in a different format. While it is probable that Benjamin would have thought equally poorly of any sort of mechanized reproduction of culture, a kernel of distinction remains between the diffusion of the cultural object via direct experience as counter to the diffusion of the cultural object via a mediated experience.

${ }^{\mathrm{lx}}$ Levine, 85-86.

lxi Ibid., 96-104.

lxii Raymond Williams, "Culture," in Keywords, (New York, NY: Oxford University Press, 1983), 80.

lxiii Herbert Gans, Popular Culture and High Culture, (New York, NY: Basic Books, 1999), 70-71.

lxiv Stuart Hall, "Cultural Studies: Two Paradigms," in Oliver Boyd-Barrett \& Chris Newbold, Eds., Approaches to Media, (New York, NY: Arnold, 1995), 340-343. 
${ }^{1 x v}$ Pierre Bourdieu, On Distinction, (Cambridge, MS: Harvard University Press, 1984), 169-175.

${ }^{1 x v i}$ Gans, 5-13.

lxvii MacDonald, "A Theory of Mass Culture," 59.

lxviii Edward Shils, "Mass Society and its Culture," in Oliver Boyd-Barrett \& Chris

Newbold, Eds., Approaches to Media: A Reader, (London, UK: Arnold, 1995), 83-86.

Ixix Diana Crane, The Production of Culture, (London, UK: SAGE Publications, 1992), 109-121.

${ }^{1 x x}$ Keith Negus, Popular Music in Theory, (Hanover, NH: Wesleyan University Press, 1996), 107-108.

${ }^{1 x i}$ Keith Negus, Music Genres and Corporate Culture, (New York, NY: Routledge, 1999), 25.

lxxii Scott DeVeaux, "Bebop and the Recording Industry," Journal of the American Musicological Society, (Vol. 41, No. 1, Spring 1988), 134-135.

Ixxiii Oliver Boyd-Barrett, "Early Theories in Media Research," in Boyd-Barrett \& Newbold, Eds., 68-73.

${ }^{\text {Ixxiv }}$ We should be hesitant, however, to adopt this criticism unreservedly because the wealth of biological metaphors in Lasswell's 1948 article, as well as his foreshadowing of developments within systems theory, indicate clearly enough that he himself took a rather expansive view of each of the elements contained within his question. Furthermore, he explicitly recognized that communication could accomplish surveillance, transmission, systems-maintaining, and other functions.

${ }^{1 \times x v}$ Elihu Katz and Paul Lazarsfeld, "Between media and mass/the part played by people/the two-step flow of communication," in Oliver Boyd-Barrett \& Chris Newbold, Eds., Approaches to Media: A Reader, (London, UK: Arnold, 1995), 124-133.

lxxvi Joseph Klapper, "The Effects of Mass Communication," in Boyd-Barrett \& Newbold, Eds., 136.

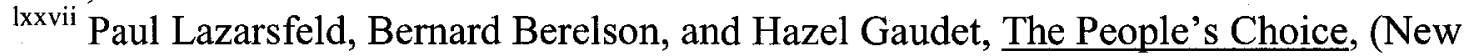
York, NY: Columbia University Press, 1944), 137-158.

lxxviii Harold Lasswell, "The Structure and Function of Communication in Society," in Boyd-Barrett \& Newbold, Eds., 93-94.

${ }_{\text {1xxix }}$ Harold Lasswell, "The Structure and Function of Communication in Society," in Wilbur Schramm, Ed., Mass Communications, (Urbana, IL: University of Illinois Press, 1960), 123.

1xxx John Storey, Cultural Studies \& The Study of Popular Culture, (Athens, GA:

University of Georgia Press, 1996), 9-14.

lxxxi Ibid., 121-122.

1xxxii Hennessey, Pg. 33-34.

1xxxiii Keith Negus, Popular Music in Theory, (Hanover, NH: Wesleyan University Press, 1996), 48-55.

lxxxiv Paul DiMaggio and Paul Hirsch, "Productions Organizations in the Arts," in Richard Peterson, Ed., The Production of Culture, (Beverly Hills, CA: SAGE Publications, 1976), 77.

${ }^{\text {lxxxv }}$ Ron Welburn, "Jazz Criticism," in Bill Kirchner, Ed., The Oxford Companion to Jazz, (New York, NY: Oxford University Press, 2000), 745-747. 


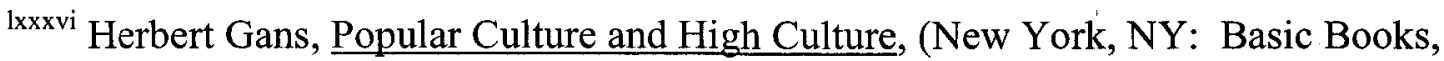
1999), 103.

lxxxvii Stevens, Charles, "Traditions and Innovations in Jazz," in Popular Music and Society, (Vol. 18, 1994), 63-65.

Ixxxviii See Baraka's article, for example, "Jazz and the White Critic," in Robert O'Meally, Ed., The Jazz Cadence of American Culture, (New York, NY: Columbia University Press, 1998), 137-142.

${ }^{1 x x x i x}$ Frank Kofsky, Black Music, White Business, (Montreal, QC: Pathfinder Press, 1998), 25-83.

${ }^{\mathrm{xc}}$ Simon Frith, "The Industrialization of Popular Music," in James Lull, Ed., Popular Music and Communication, (London, UK: SAGE Publications, 1992), 49-67.

${ }^{x c i}$ DeVeaux, Pg. 8.

\section{Endnotes - Chapter 3}

xcii Graham Vulliamy, Jazz and Blues, (Boston, MS: Routledge \& Kegan Paul, Ltd, 1982), 27-33.

${ }^{\text {xciii }}$ Frank Tirro, Jazz, A History, $2^{\text {nd }}$ Edition, (New York, NY: W. W. Norton \& Co., 1993), 117-120.

${ }^{\text {xciv }}$ Gioia, 32-33.

${ }^{x c v}$ Thomas Hennessey, From Jazz to Swing, (Detroit, MN: Wayne State University, 1994), 20.

${ }^{x c v i}$ Marshall Sterns, The Story of Jazz, (New York, NY: Oxford University Press, 1956), 55.

xcvii Ibid., 56.

xcviii Mervyn Cooke, Jazz, (London, UK: Thames \& Hudson, Ltd., 1998), 49.

${ }^{x c i x}$ Ted Gioia, The History of Jazz, (New York, NY: Oxford University Press, 1997), 36.

${ }^{\mathrm{c}}$ Hennessey, 15.

ci William Schafer, "Breaking into 'High Society," In Journal of Jazz Studies, (June 1975), 53-59.

cii It may be argued that I appear to be providing an 'essential' characteristic of jazz, in the practice of innovation. I would like to disagree. I merely note that the practice of altering and adapting a variety of musical cultures may result in a new form of music. This is not specific to jazz, but can be found in the beginnings of reggae, rap, rock, and other contemporary musics.

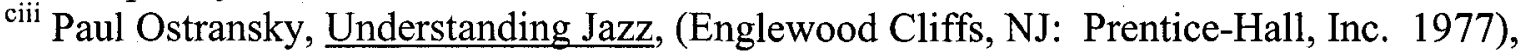
127.

${ }^{\text {civ }}$ Charles Nanry, The Jazz Text, (Toronto, ON: Litton Educational Publishing, Inc., 1979), 79-80.

${ }^{c v}$ William Schafer, Brass Bands and New Orleans Jazz, (Baton Rouge, LA: Louisiana State University Press, 1977), 26.

${ }^{\text {cvi }}$ Robert Walser, Keeping Time: Readings in Jazz History, (New York: NY: Oxford University Press, 1999), 8.

cvii Tirro, 19. 
cviii Eric Hobsbawm, The Jazz Scene, (New York, NY: Pantheon Books, 1993), 11-19.

${ }^{\text {cix }}$ Nicholas Tawa, The Way to Tin Pan Alley, (New York, NY: Schirmer Books, 1990), 12-13.

cx John Shepherd, Tin Pan Alley, (Boston, MS: Routledge \& Kegan Paul, 1982), 12-17.

cxi Cooke, 27-39.

cxii Some might point out that most of these 'authentic' folk musics were the result of black people imitating white people imitating black people - as in black minstrelsy and the cakewalk. This is an excellent and interesting point, however the imitation contained in these examples is one of dance, not within the rhythm or within the music itself. The origins of the rhythmic practice of syncopation are generally ascribed to the use of complex polyrhythms in West African drumming culture, and are quite different from European musical practice of the time.

cxiii Tirro, 29.

cxiv Donald MeGill, and Richard Demory, Introduction to Jazz History, $2^{\text {nd }}$ Ed. (Englewood Cliffs, New Jersey: Prentice Hall, 1989), 36.

${ }^{\mathrm{cxv}}$ Stearns, 104-110.

cxvi Gioia, 29-34.

cxvii Gioia, 32.

cxviii Schafer, 41.

cxix James Collier, Jazz: The American Theme Song, (New York, NY: Oxford University Press, 1993), 12-17.

${ }^{\mathrm{cxx}}$ Indeed, the lack of written music within the brass band culture (especially the Black bands) parallels the musicians' inability to read music. Many musicians learnt and played completely by ear. This also suggests that this folk music had not penetrated a massproduced market yet, where a demand for the printed music would make its production financially lucrative.

cxxi Vuillamy, 16-26.

cxxii Diana Crane, The Production of Culture, (London, UK: SAGE Publications, 1992), 109-121.

cxxiii Shirley Biagi and Craig McKie, Media Impact, (Scarborough, ON: ITP Nelson, 1999), 127.

cxxiv The Original Dixieland Jazz Band, who will be discussed in more detail later in this chapter.

${ }^{c x x v}$ Dave Laing, "A Voice without a face: Popular music and the phonograph in the 1890s," in Popular Music, (Vol. 10/1, 1991), 6-7.

cxxvi Stearns, 138.

cxxvii Jed Rasula, "The Media of Memory: Records and Jazz History," in Krin Gabbard,

Ed., Jazz Among the Discourses, (Durham, NC: Duke University Press, 1995), 134-137.

cxxviii Hennessey, 33.

cxxix Rasula, 135.

cxxx Michele Martin, Communication and Mass Media, (Scarborough, ON: Prentice Hall Allyn, 1997), 22-26.

cxxxi Gioia, 136.

cxxxii Stearns, 130-139.

cxxxiii Hennessey, 134-135. 
cxxxiv Keith Negus, Popular Music in Theory, (Hanover, NH: Wesleyan University Press, 1996), 36-42.

${ }^{\text {cxxxv }}$ Nanry, 80.

cxxxvi Tirro, $158-159$.

cxxxvii Stearns, 125

cxxxviii MeGill and Demory, 89.

cxxxix Hennessey, 87-95.

${ }^{\mathrm{cxl}}$ Gunther Schuller, Early Jazz, (New York, NY: Oxford University Press, 1968), 286.

cxli Theodor Adorno, The Culture Industry, (New York, NY: Routledge, 1991), 52.

cxlii Neil Leonard, "The Reactions to Ragtime," in Ragtime: Its History, Composers, and

Music, John Hasse, Ed. (New York, NY: Schirmer Books, 1985), 107.

cxliii Interestingly, this was exactly how the popular producer Mitch Miller reacted to rock'n'roll in the 1950s, further demonstrating that this kind of critical repulsion is characteristic of all new popular musics.

cxliv Neil Leonard, Jazz: Myth and Religion, (New York, NY: Oxford University Press, 1987), 3-16.

${ }^{c x l v}$ Paul Lopes, The Rise of a Jazz Art World, (Cambridge, UK: Cambridge University Press, 2002), 46-49.

cxlvi James Collier, The Reception of Jazz in America, (Brooklyn, NY: The Institute for Studies in American Music, 1988), 12.

cxlvii Lopes, 98-105.

cxlviii Tirro, 208-209.

cxlix Neil Leonard, Jazz: Myth and Religion, (New York, NY: Oxford University Press, 1987),

${ }^{\mathrm{cl}}$ Stearns, 142-143.

cli Lewis Erenberg, Swingin' the Dream, (Chicago, IL: University of Chicago Press, 1998), 136-137.

clii Vulliamy, 39-42.

cliii Hennessey, 49-66.

cliv Hennessey, 82-102.

${ }^{c l v}$ Lewis Erenberg, Steppin' Out, (Westport, CT: Greenwood Press, 1981), 250-259.

clvi Hennessey, 67-81.

\section{Endnotes - Chapter 4}

clvii John Hammond, "An Experience in Jazz History," in Robert Walser, Ed., Keeping Time: Readings in Jazz History, (New York, NY: Oxford University Press, 1999), 92. clviii Paul Ostransky, Understanding Jazz, (Englewood Cliffs, NJ: Prentice-Hall, Inc. 1977), 178.

clix Ted Gioia, The History of Jazz, (New York, NY: Oxford University Press, 1997), 136. ${ }^{c l x}$ Burton Peretti, The Creation of Jazz, (Chicago, IL: University of Illinois Press, 1992), 145-146.

${ }^{c 1 x i}$ Philip Ennis, The Seventh Stream: The emergence of Rocknroll in American Popular Music, (Hanover, NJ: Wesleyan University Press, 1992), 114-115. 
clxii Such as Louis Armstrong's recognizable gravelly voice, or Cab Calloway's phrase "Hi De Ho," and on-stage gymnastics.

clxiii Ennis, 116.

clxiv Scott DeVeaux, The Birth of Bebop, (Berkeley, CA: University of California Press, 1997), 122-131.

clxv James Collier, Jazz: The American Theme Song, (New York, NY: Oxford University Press, 1993), 107.

clxvi Marshall Sterns, The Story of Jazz, (New York, NY: Oxford University Press, 1956), 148-151.

clxvii Gioia, 136-137.

clxviii Lewis Erenberg, Swingin' the Dream, (Chicago, IL: University of Chicago Press, 1998), 41.

${ }^{\text {cxix }}$ Paul Lopes, The Rise of a Jazz Art World, (Cambridge, UK: Cambridge University Press, 2002), 117-122.

${ }^{c 1 x x}$ Lopes, 155-156.

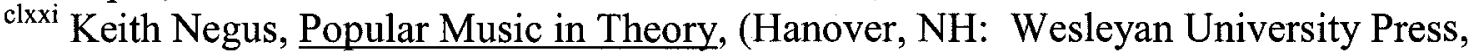
1996), 110-112.

clxxii Lopes, 93.

clxxiii Stearns, 137-143.

clxxiv Erenberg, Swingin' the Dream, 69.

clxxv Ostransky, 193-194.

clxxvi Graham Vulliamy, Jazz and Blues, (Boston, MS: Routledge \& Kegan Paul, Ltd, 1982), 38-42.

clxxvii Lopes, 110-112.

clxxviii Erenberg, Swingin' the Dream, 35.

clxxix Collier, 137.

${ }^{c l x x x}$ Erenberg, Swingin' the Dream, 61.

clxxxi Ostransky, 179.

clxxxii Lewis Erenberg, Steppin' Out, (Westport, CN: Greenwood Press, 1981), 250-259.

clxxxiii Ostransky, 178-179.

clxxxiv Lewis Erenberg, "Things to Come: Swing Bands, Bebop, and the Rise of a Postwar

Jazz Scene," Lary May, Ed., Recasting America: Culture and Politics in the Age of Cold

War, (Chicago, IL: University of Chicago Press, 1989), 124-136.

${ }^{c l x x x v}$ Erenberg, Swingin' the Dream, 35-37.

clxxxvi Vulliamy, 66.

clxxxvii Gioia, 201-216.

clxxxviii Vulliamy, 85.

clxxxix DeVeaux, Birth of the Bebop, 299.

${ }^{\text {cxc }}$ DeVeaux, Birth of the Bebop, 338-340.

cxci Lopes, 219-221.

cxcii Charles Nanry, The Jazz Text, (Toronto, ON: Litton Educational Publishing, Inc., 1979), 183.

cxciii DeVeaux, Birth of the Bebop, 238-244.

cxciv Lopes, 220. 
cxcv Scott DeVeaux, "Bebop and the Recording Industry," in Journal of the American Musicological Society, (Vol. 41, No. 1. Spring, 1988), 130.

${ }^{\text {cxcvi Stearns, } 160 .}$

${ }^{\text {cxcvii }}$ Frank Tirro, Jazz, A History, $2^{\text {nd }}$ Edition, (New York, NY: W. W. Norton \& Co., 1993), 291.

cxcviii Charles Hamm, Yesterdays: Popular Song in America, (New York, NY: W.W.

Norton \& Co., 1979), 386-387.

cxcix Gary Giddens, "How Come Jazz Isn't Dead?" in Eric Weisbard, Ed., this is POP, (Cambridge, MS: Harvard University Press, 2004), 45.

${ }^{\mathrm{cc}}$ Hamm, 394.

cci Philip Ennis, The Seventh Stream, (Hanover, NH: Wesleyan University Press, 1992), 124-128.

ccii Ennis, 160-176.

cciii Michael Levin and John Wilson, "No Bop Roots in Jazz: Parker," Down Beat, (September 9, 1949), 67.

cciv Robert Goffin, "Defining 'Hot' Jazz," in Robert Walser, Ed., Keeping Time, (New

York, NY: Oxford University Press, 1999), 84.

${ }^{\mathrm{ccv}}$ Lopes, 157-160.

ccvi Collier, 134-135.

ccvii Bill Gottlieb, "Delauney on First Visit to America," Down Beat, (August 26, 1946),

59.

ccvii Steven Elworth, "Jazz in Crisis: 1948-1958," in Krin Gabbard, Ed., Jazz Among the

Discourses, (Durham, NC: Duke University Press, 1995), 64.

${ }^{\text {ceix }}$ Lopes, 163-171.

${ }^{\mathrm{ccx}}$ Collier, 134-135.

ccxi Elworth, 67.

ccxii Lopes, 179.

ccxiii Herbert Gans, Popular Culture and High Culture, (New York, NY: Basic Books, 1999/1974), 103.

${ }^{c c x i v}$ Howard Becker, "The Professional Dance Musician and His Audience," in Robert

Walser, Ed., Keeping Time, (New York, NY: Oxford University Press, 1999), 185-186. A spirited rebuttal.

${ }^{c c x v}$ Lopes (2002), and Levine (1988), both note how the development of jazz criticism replicates the development of "serious" classical enthusiasts a century earlier, who attempted to enfranchise classical music within a specific set of criteria for approval and enjoyment.

${ }^{c c x v i}$ It should be noted that the previous recollection should be subtly contrasted with the traditional telling of this event, which focuses on musical styles. Ostransky (26-27) recounts how swing had supplanted real jazz with its written arrangements, whereas real jazz was improvised. But it was not as Ostransky suggests. It was because written swing arrangements fulfilled a type of pathway different from the original folk means of transmission that it was vilified by the traditionalists, not that written music was bad in and of itself. Indeed, many celebrated "folk" black musicians, including Louis Armstrong, learned to read notes to expand their opportunities to perform. 
ccxvii Bernard Gendron, "Moldy Figs and Modernists: Jazz at War," in Krin Gabbard, Ed., Jazz Among the Discourses, (Durham, NC: Duke University Press, 1995), 33.

ccxviii Ibid., 42-51.

cexix Lopes, 192-193.

${ }^{c c x x}$ Recognizably, this begs the pertinent question of if it is indeed possible for a popular culture to return to a folk culture. In this example, after jazz had become a popular culture, could it ever return to function again as a folk culture? This concept will be explored a little further in Chapter 6, but unfortunately, given the limitations of the current case study (jazz did not return to become a folk music), a full explanation of the possibility of a return to folk culture status would require the study of another cultural phenomenon.

cexxi Lopes, 177.

ccxiii Lopes, 176.

ccxxiii Howard Becker, Art Worlds, (Los Angeles, CA: University of California Press, 1982), 228-233.

cexxiv Tirro, 286-291.

${ }^{c c x x v}$ DeVeaux, Birth of the Bebop, 169-171.

ccxxvi Nanry, 96.

cexxvii DeVeaux, Birth of the Bebop, 202-204.

ccxuviii Gioia, 169.

ccxxix Scott DeVeaux, "The Emergence of the Jazz Concert," (American Music. [Spring 1989]), 20.

${ }^{\text {ccxxx }}$ Lopes, 151.

${ }^{\text {ccxxxi }}$ Lopes, 167.

ccxxxii Vulliamy, 77-80. Vulliamy even names his chapter introducing bebop, "Disturbance at Minton's."

cexxxiii Lopes, 167.

ccxxxiv Scott DeVeaux, "The Emergence of the Jazz Concert," 6.

${ }^{c c x x x v}$ Mervyn Cooke, Jazz, (London, UK: Thames \& Hudson, Ltd., 1998), 80-82.

ccxxxvi DeVeaux, "The Emergence of the Jazz Concert," 8.

ccxxxvii James Dugan and John Hammond, "Jazz at Carnegie Hall," in Robert Walser, Ed., Keeping Time, (New York, NY: Oxford University Press, 1999), 101-105.

ccxxxviii Lopes, 166.

ccxxxix DeVeaux, "The Emergence of the Jazz Concert," 17.

${ }^{c c x l}$ Theodor Adorno, The Culture Industry, (New York, NY: Routledge, 1991/2001), 53.

ccxli DeVeaux, Birth of the Bebop, 442-443.

ccxlii Lopes, 177.

\section{Endnotes - Chapter 5}

ccxliii Paul Lopes, The Rise of a Jazz Art World, (Cambridge, UK: Cambridge University Press, 2002),

${ }^{\text {ccxliv }}$ Frank Tirro, Jazz, A History, $2^{\text {nd }}$ Edition, (New York, NY: W. W. Norton \& Co., 1993), 330-331. 
ccxlv Ted Gioia, The History of Jazz, (New York, NY: Oxford University Press, 1997), 278-292.

ccxlvi Lopes, 235-237.

ccxlvii Steven Elworth, "Jazz in Crisis: 1948-1958," in Krin Gabbard, Ed., Jazz Among the Discourses, (Durham, NC: Duke University Press, 1995), 65.

ccxlviii Lopes, 243.

ccxlix For further discussion of all elements contained within the elusive term "Hard Bop," see David Rosenthal, Hard Bop, (New York, NY: Oxford University Press, 1992), 44-49. ccl Tirro, 341-364.

ccli Thomas Hennessey, From Jazz to Swing, (Detroit, MN: Wayne State University, 1994). Hennessey's basic argument is that jazz in the US during the 1910s was performed by a wide variety of different territory bands which operated in a distinct region. Because there was no standard set for the sound of jazz, nor any popular jazz stars, jazz developed differently in each region. This was, of course to become standardized by the onset of radio and the jazz craze of the 1920 s.

cclii Lopes, 229.

ccliii Gioia, 278.

ccliv Alice Goldfarb Marquis, "Jazz goes to College," in Popular Music and Society, (Vol. $22,1998), 117-122$.

cclv Iain Anderson, "Jazz outside the Marketplace," in American Music, (Vol. 20, No. 2, Summer, 2002), 131-167.

cclvi Joe Gallagher, "Lee Morgan: Jazz can be Sold," in Frank Alkyer, Ed., Down Beat: 60 years of Jazz, (Winona, MN: Hal Leonard Corporation, 1995), 151-152,

cclvii Lopes, 226.

cclviii Tirro, 369.

cclix Newsweek, (August 2, 1954).

${ }^{\text {cclx }}$ Lopes, 234-235.

cclxi Tirro, 405.

cclxii Lopes, 233.

cclxiii Lopes, 237.

cclxiv Darius Brubeck, “1959: The Beginning of Beyond,” in Mervyn Cooke \& David Horn, The Cambridge Companion to Jazz, (New York, NY: Cambridge University Press, 2002), 188-192. Darius Brubeck is the son of Dave Brubeck, jazz musician.

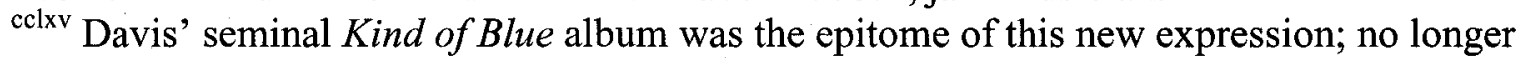
were the musicians playing compositions based strictly on harmonic progressions, but soloing on modal and scalar themes and patterns. This maturity of harmonic choice and intellectual application was further expanded by John Coltrane in 1959, on his album Giant Steps, which probably remains the jazz standard for complexity of chord progressions.

cclxvi Brubeck, 189.

cclxvii Lopes, 237.

cclxviii Ekkehard Jost, Free Jazz, (New York, NY: Da Capo Press, 1981), 44-66.

cclxix Tirro, 378.

cclxx Lopes, 235-236.

cclxxi Charles Beale, "Jazz Education," in Bill Kirchner, Ed., The Oxford Companion to $\mathrm{Jazz}_{2}$ (New York, NY: Oxford University Press, 2000), 756-762. 


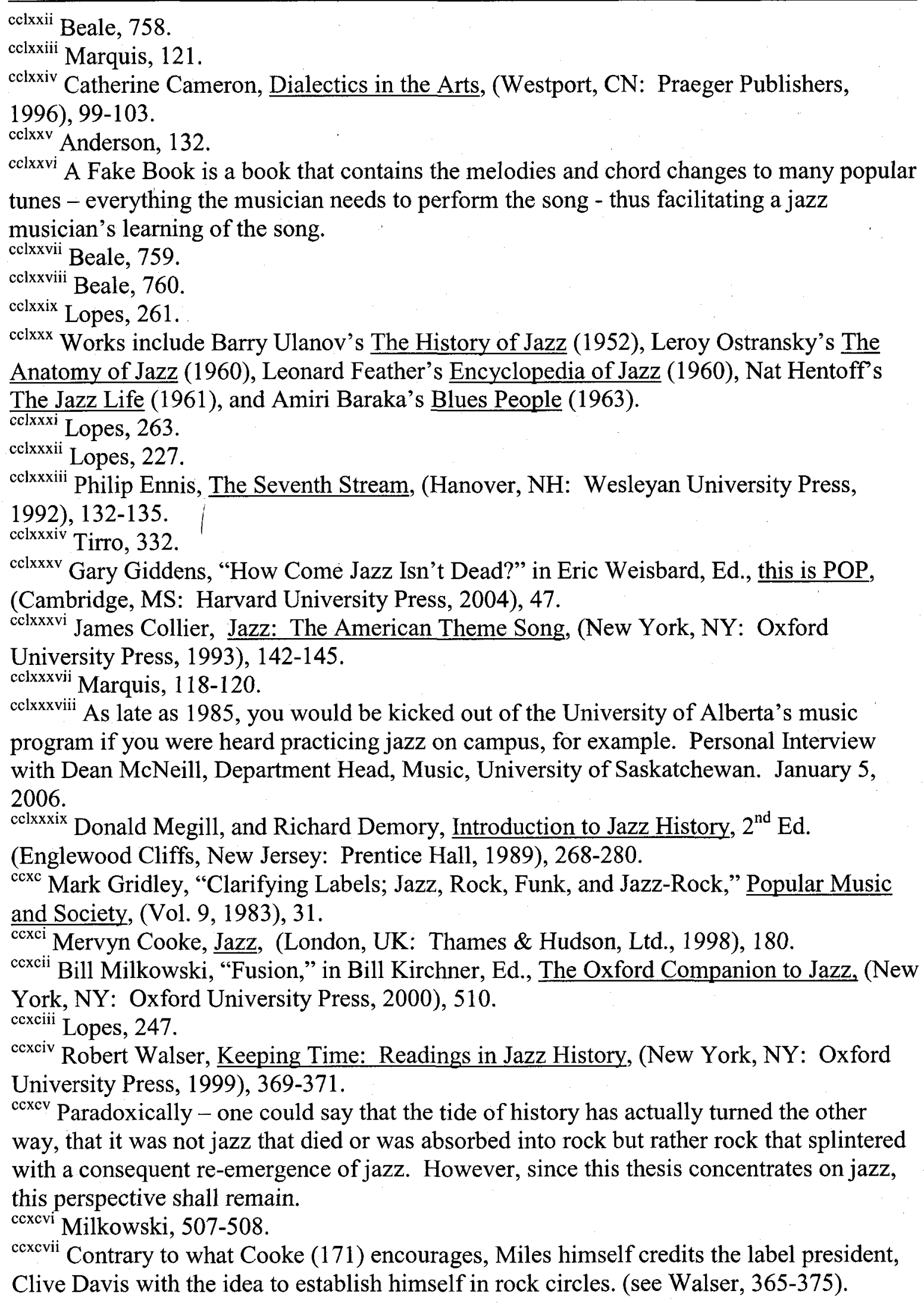


cexcviii Walser, 373-374.

ccxcix Stuart Nicholson, "Fusions and crossovers," in Mervyn Cooke and David Horn, Eds., The Cambridge Companion to Jazz, 232.

${ }^{c c c}$ Lopes, 241.

${ }^{\text {ccci }}$ Gridley, 30-31.

cceii Nicholson, "Fusions and crossovers," 230-232.

ccciii Lewis Porter, Jazz; a Century of Change, (New York, NY: Schirmer Books, 1997), 239-240.

ccciv Lopes, 263.

${ }^{\text {cccv }}$ Porter, 236.

${ }^{c c c v i}$ Walser, Keeping Time: Readings in Jazz History.

cccvii Nicholson, "Fusions and crossovers," 217-218.

cccviii There are those who would claim that the denouncement of inertia is one of the hallmarks of academia, and therefore, my argument that undoing the castigation of fusion away from the church of jazz would be both possible and encouraged within the academic realm. And while I do not dispute the ability of academia to reconsider its positions, my thought is that even a dialogical approach that would seek to reclaim fusion as part of the "proper" definition of jazz would require a great deal of critical scrutiny and discussion the very thing that reinforces a critical pathway and jazz as an elite culture. I therefore stand by my claim that if fusion were to be successful in returning jazz to a popular form of culture, it would need to undo the work of academic criticism - a very difficult, if not impossible task.

${ }^{\text {cccix }}$ Stuart Nicholson, Jazz-Rock: A History, (New York, NY: Schirmer Books, 1998), 326-328.

cccx Peter Keepnews, "Jazz after 1968," in Bill Kirchner, Ed., The Oxford Companion to $\mathrm{Jazz}_{2}$ (New York, NY: Oxford University Press, 2000), 497-498.

cccxi Wynton Marsalis and Herbie Hancock, "Soul, Craft, and Cultural Hierarchy," in

Robert Walser, Keeping Time: Readings in Jazz History, 339-351.

ccexii Wynton Marsalis, "The Neo-Classical Agenda," in Robert Walser, Keeping Time:

Readings in Jazz History, 337-338.

cccxiii Keepnews, 499.

cccxiv Tirro, 467.

cccxv Art Lange, "The 80s," in Frank Alkyer, Ed., Down Beat: 60 years of Jazz, (Winona, MN: Hal Leonard Corporation, 1995), 188-189.

ccexvi Lange, 189.

cccxvii Scott DeVeaux, Jazz In America: Who's Listening? (National Endowment for the

Arts Publication, Research Division Report \#31, 2002), 1-4.

cccxviii Frank Alkyer, "The 90s," in Frank Alkyer, Ed., Down Beat: 60 years of Jazz,

(Winona, MN: Hal Leonard Corporation, 1995), 231.

cccxix Marsalis, "The Neo-Classical Agenda," 337.

cccxx Marsalis, "The Neo-Classical Agenda," 335.

cccxxi Marquis, 120.

cccxii Porter, 253

cccxiii Personal Interview with Dean McNeill, Department Head, Music, University of Saskatchewan. January 5, 2006. 
cccxxiv Porter, 282.

cccxxv Keepnews, 499-500.

cccxxvi Parenthetically, the fact that bebop has now become 'traditional' speaks volumes about its progress within elite circles.

cccxxvii André Mayer, "Crossing over with Michael Bublé," (March 31, 2005), found online at www.cbc.ca.

cecxxviii Greg Buium, "Name Brand: How Diana Got Her Groove Back," (December 5, 2005), found online at www.cbc.ca.

cecxxix Jack Massarik, "Diana Krall,” Evening Standard, London, UK, October 28, 2004.

cccxxx Keepnews, 500.

cccxxxi Porter, 249.

cccxxxii Porter, 246.

cccxxxiii Larry Kart, "Provocative Opinion: The Death of Jazz," Black Music Research

Journal, (Vol. 10, No. 1. Spring, 1990), 76-81.

cccxxxiv Porter, 260-264.

cccxxxv Samuel Floyd, "Ring Shout, Signifyin(g) and Jazz Analysis," in Robert Walser, Keeping Time: Readings in Jazz History, 401-410.

cccxxxvi Alan Stanbridge, Who Could Ask For Anything More? (Ottawa, ON: Carleton University Doctoral Dissertation, 2000), 340-360.

\section{Endnotes - Chapter 6}

cccxxxvii The term "culture industry" is an attempt to speak of those commercial and corporate popularizing interests which are embodied in jazz music by the pathway of the popular music industry. It is used in an attempt to generalize from the case study's music industry to talk about other (perhaps non-musical) cultural processes in general. While the term has been most famously popularized by Theodor Adorno and the work of the Frankfurt School, and attached to a very negative, Marxist image, it is hoped that it can also function under a more neutral connotation. It is simply meant to refer to the commercializing and popularizing interests of an industrial pathway, not to decry them as befouling an authentic art form or vernacular music.

cccxxviii Kelefa Sanneh, "Rapping about Rapping," in Eric Weisbard, Ed., This is Pop, (Cambridge, MS: Harvard University Press, 2004), 223-232.

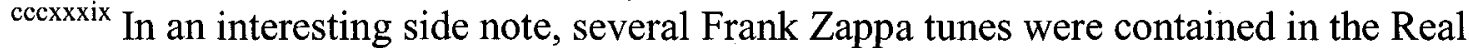
Book (the title of the previously discussed fake book - a deliberate ironic titling) commonly used by jazz musicians, further demonstrating the close ties between elite musics.

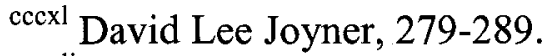

cccxli Stephen Davies, "Rock Verses Classical Music," in Journal of Aesthetics and Art Criticism, (Vol. 57, No. 2, Spring, 1999), 193-204.

cccxlii Scott DeVeaux, "Constructing the Jazz Tradition," in Black American Literature Forum, (Vol. 25, No. 3, Fall, 1991), 528.

cccxliii Michael Brooke, The Concrete Wave, (Toronto, ON: Warwick Books, 1999).

cccliv I would even argue that the current reliance of the sport on extremely technical tricks would support its candidacy as an elite culture (due to this nature of exclusion through 
virtuosity), but it has not developed a relationship with the pathways of critical contemplation and elite institutional support that are required for the form to function as an elite culture.

${ }^{\text {cccxlv }}$ Now from a cultural studies perspective the answer to this question "How can I be sure that my message will be understood?" is easily answered. The message is understood because of the ideological framework in which it is produced and circulated; that framework reduces uncertainty. It asks not "what do I, creator, intend to communicate and how?", it asks "what does the system impose upon the creator and how?"

\section{Endnotes - Conclusion}

cccxlvi George Boas, "The Mona Lisa in the History of Taste," in Journal of the History of Ideas, (Vol. 1, No. 2, April 1940), 207-224.

cccxlvii Michel Foucault, The Order of Things, (New York, NY: Routledge, 2002), 19. cccxlviii Indeed, one wonders if Benjamin's concept of aura holds up for works of art in similar ways, if they are not immediately accorded value.

cccxlix Boas, 207-208, 224.

${ }^{c c c l}$ Paul Lazarsfeld, Bernard Berelson, and Hazel Gaudet, The People's Choice, (New York, NY: Columbia University Press, 1944), 137-158.

cccli Allan Gedalof, Cultural Subjects: A Popular Culture Reader, (Toronto, ON: Nelson, 2005), 64-65. 


\section{Bibliography}

Adorno, Theodor, \& Horkheimer, Max. Dialectic of Enlightenment. New York, NY: Verso, 1997/1979.

Adorno, Theodor. "Perennial Fashion - Jazz." In Prisms. Cambridge, MS: MIT Press, 1981.

Alkyer, Frank. Downbeat: 60 years of Jazz. Milwaukee, WI: Hal Leonard Corporation, 1995.

Anderson, Iain. "Jazz outside the Marketplace: Free Improvisation and Nonprofit Sponsorship of the Arts, 1965-1980." In American Music. Vol. 20, No. 2. Summer, 2002.

Arnold, Matthew. Culture and Anarchy. Cambridge, UK: University Press, 1935.

Baker, David, Ed. New Perspectives on Jazz. Washington, DC: Smithsonian Institution Press, 1990.

Barker, Chris. The Cultural Studies Reader. New York, NY: Routledge, 2000.

Bauck, Andrew. "Loser: The Real Seattle Music Story." In Popular Music. Vol. 16, No. 2, May, 1997.

Becker, Howard S. Art Worlds. Los Angeles, CA: University of California Press, 1982.

Benjamin, Walter. "The work of art in the age of mechanical reproduction." In Illuminations. London, UK: Fontana, 1973.

Bergeron, Katherine \& Bohlman, Philip, Eds. Disciplining Music. Chicago, IL: University of Chicago Press, 1992.

Berliner, Paul. Thinking in Jazz. Chicago, IL: University of Chicago Press, 1994.

Biagi, Shirley \& McKie, Craig. Media Impact. Scarborough, ON: ITP Nelson, 1999.

Billboard Magazine. Vol. 103, No. 4. February 18, 2004.

Blacking, John. "Making Artistic Popular Music: the goal of true folk." In Popular Music. 1981.

Bloom, Allan. The Closing of the American Mind. New York, NY: Simon \& Schuster, 1987.

Boas, George. "The Mona Lisa in the History of Taste." In Journal of the History of Ideas. Vol. 1, No. 2, April 1940.

Bourdieu, Pierre. On Distinction. Cambridge, MS: Harvard University Press, 1984.

Boyd-Barrett, Oliver \& Chris Newbold, Eds. Approaches to Media: A Reader. London, UK: Arnold, 1995.

Brooks, David. Bobos in Paradise. New York, NY: Touchstone, 2000.

Buckner, Reginald T. \& Weiland, Steven, Eds. Jazz in Mind. Detroit, MN: Wayne State University Press, 1991.

Budds, Michael. Jazz in the Sixties. Iowa City, IO: University of Iowa Press, 1978.

Buium, Greg. "Name Brand: How Diana Got Her Groove Back." Found online at www.CBC.ca. December 5, 2002.

Byler, Robert. "Traditional Jazz Resurgence is Illustrated by Representative Profiles of Current Bands." In Popular Music and Society. Vol. 10, 1985.

Cameron, Catherine M. Dialectics in the Arts. Westport, CN: Praeger Publishers, 1996.

Collier, James Lincoln. The Reception of Jazz in America: A New View. Brooklyn, NY: The Institute for Studies in American Music, 1988. 
Collier, James Lincoln. Jazz: The American Theme Song. New York, NY: Oxford University Press, 1993.

Cooke, Mervyn, and Horn, David, Eds. The Cambridge Companion to Jazz. Cambridge, UK: Cambridge University Press, 2002.

Cooke, Mervyn. Jazz. London, UK: Thames and Hudson, Ltd., 1998.

Crane, Diana. The Production of Culture. London, UK: SAGE Publications, 1992.

Culver, Dick. "Jazz Education: We've come a long way, maybe." In The Instrumentalist. Vol. 33, August 1978.

Davis, Ronald L. The Social and Cultural Life of the 1920s. Chicago, IL: Holt Rinehart and Winston, Inc. 1972.

De Montesquieu, Charles. An Essay on Taste. New York, NY: Garland Publishing, $1757 / 1970$.

DeVeaux, Scott. "Bebop and the Recording Industry: The 1942 AFM Recording Ban Reconsidered." In Journal of the American Musicological Society. Vol. 41, No. 1. Spring, 1988.

DeVeaux, Scott. "The Emergence of the Jazz Concert." In American Music. Spring 1989.

DeVeaux, Scott. "Constructing the Jazz Tradition: Jazz Historiography." In Black American Literature Forum. Vol. 25, No. 3. Fall 1991.

DeVeaux, Scott. The Birth of Bebop. Berkeley, CA: University of California Press, 1997.

DeVeaux, Scott. Jazz In America: Who's Listening? National Endowment for the Arts Publication, Research Division Report \#31, 2002.

Dinerstein, Joel. Swinging the Machine. Boston, MS: University of Massachusetts Press, 2003.

Duncombe, Stephen, Ed. The Cultural Resistance Reader. New York, NY: Verso, 2002.

Ellison, Mary. "Subverting Commodification: Delfeayo Marsalis and Jazz." In Popular Music and Society. Vol. 24. 2000.

Ellison, Ralph. Shadow and Act. New York, NY: New American Library, 1966.

Ennis, Philip. The Seventh Stream. Hanover, NH: Wesleyan University Press, 1992.

Erenberg, Lewis. Steppin' Out. Westport, CN: Greenwood Press, 1981.

Erenberg, Lewis. Swingin' the Dream. Chicago, IL: University of Chicago Press, 1998. Foucault, Michel. The Order of Things. New York, NY: Routledge, 2002.

Frith, Simon, and Horne, Howard. Art Into Pop. New York, NY: Methuen, 1987.

Frith, Simon, Ed. Facing the Music. New York, NY: Pantheon Books, 1988.

Gabbard, Krin. "The Jazz Canon and its Consequences." In Annual Review of Jazz Studies. Vol. 7, 1993.

Gabbard, Krin, Ed. Jazz Among the Discourses. Durham, NC: Duke University Press, 1995.

Gabbard, Krin, Ed. Representing Jazz. Durham, NC: Duke University Press, 1995.

Gans, Herbert. Popular Culture and High Culture. New York, NY: Basic Books, 1999.

Gedalof, Allan. Cultural Subjects: A Popular Culture Reader. Toronto, ON: Nelson, 2005.

Gennari, John. "Jazz Criticism: Its development and ideologies." Black American Literature Forum. Vol. 25, No. 3. Autumn, 1991.

Gioia, Ted. The History of Jazz. New York, NY: Oxford University Press, 1997. 
Gitler, Ira. Swing to Bop. New York, NY: Oxford University Press, 1985.

Gracyk, Theodore. "Adorno, Jazz, and the Aesthetics of Popular Music." In The

Musical Quarterly. Vol. 76, No. 4, Winter, 1992.

Grandt, Jurgen. Kinds of Blue. Columbus, OH: Ohio State University Press, 2004.

Gridley, Mark. "Clarifying Labels: Jazz Rock, Funk and Jazz Rock." In Popular Music and Society. Vol. 9, 1983.

Gridley, Mark. "Why have Modern Jazz Combos Been Less Popular than Swing Big Bands?" In Popular Music and Society. Vol. 9, 1984.

Hall, Stuart, Critcher, Charles, et al. Policing the Crisis. London, UK: MacMillan, 1978.

Hamm, Charles. Yesterdays: Popular Song in America. New York, NY: W.W. Norton \& Co., 1979.

Hasse, John, Ed. Ragtime: Its History, Composers, and Music. New York, NY:

Schirmer Books, 1985.

Hennessey, Thomas. From Jazz to Swing. Detroit, MN: Wayne State University, 1994.

Hobsbawm, Eric. The Jazz Scene. New York, NY: Pantheon Books, 1993.

Hobsbawm, Eric. Behind the Times; the Decline and Fall of the Twentieth-Century Avant Gardes. London, UK: Thames and Hudson, 1998.

Hodeir, Andre. Jazz: Its Evolution and Essence. New York, NY: Grove Press, Inc., 1956.

Holbrook, Morris and Huber, Joel. "The Spatial Representation of Responses toward Jazz." In Journal of Jazz Studies, Summer, 1979.

Horowitz, Irving Louis. "Style and Stewardship: Sociological Considerations on the Professionalization of Music." In Journal of Jazz Studies. Winter, 1978.

Innis, Harold Adams. Empire and Communication. Oxford, UK: Clarendon Press, 1950.

Johnson, Bruce. "Hear me talkin' to ya: problems of jazz discourse." In Popular Music. Vol. 12, No. 1. 1993.

Jones, LeRoi. Blues People. New York, NY: William Morrow \& Company, 1963.

Jones, Steve, Ed. Pop Music and the Press. Philadelphia, PA: Temple University Press, 2002.

Jost, Ekkehard. Free Jazz. New York, NY: Da Capo Press, 1981.

Kammen, Michael. American Culture, American Tastes. New York, NY: Alfred A. Knopf, 1999.

Kart, Larry. "Provocative Opinion: The Death of Jazz." In Black Music Research Journal. Vol. 10, No. 1. Spring, 1990.

Kirchner, Bill, Ed. The Oxford Companion to Jazz. New York, NY: Oxford University Press, 2000.

Kofsky, Frank. Black Music, White Business. Montreal, QC: Pathfinder Press, 1998.

Laing, Dave. "A Voice without a face: Popular music and the phonograph in the 1890 s." In Popular Music. Vol. 10/1, 1991.

Lamont, Michele, \& Fournier, Marcel. Cultivating Differences: Symbolic Boundaries and the Making of Inequality. Chicago, IL: University of Chicago Press, 1992.

Landy, Marcia. "Culture and Politics in the Work of Antonio Gramsci." In Boundary 2. Vol. 14, No. 3, (Spring 1986). 
Lazarsfeld, Paul, Berelson, Bernard, and Gaudet, Hazel. The People's Choice. New York, NY: Columbia University Press, 1944.

Leavis, F. R. Mass Civilization and Minority Culture. Cambridge, UK: The Minority Press, 1930.

Leonard, Neil. Jazz: Myth and Religion. New York, NY: Oxford University Press, 1987.

Levine, Lawrence. Highbrow/Lowbrow: The Emergence of Cultural Hierarchy in America. Cambridge, MS: Harvard University Press, 1988.

Litweiler, John. The Freedom Principle: Jazz after 1958. New York, NY: Da Capo Press, 1984.

Lopes, Paul, The Rise of a Jazz Art World. Cambridge, UK: Cambridge University Press, 2002.

Lull, James, Ed. Popular Music and Communication. London, UK: SAGE Publications, 1992.

MacDonald, Dwight. “On Selling Out.” Discriminations. New York, NY: Grossman Publishers, 1974.

Marquis, Alice Goldfarb. “Jazz goes to College: Has Academic Status Served the Art?" In Popular Music and Society. Vol. 22, 1998.

May, Lary, Ed. Recasting America: Culture and Politics in the Age of Cold War. Chicago, IL: University of Chicago Press, 1989.

Mayer, Andre. "Crossing over with Michael Bublé." Found online at www.cbc.ca. March 31, 2005.

Megill, Donald and Demory, Richard. Introduction to Jazz History, $2^{\text {nd }}$ Ed. Englewood Cliffs, NJ: Prentice Hall, 1989.

Merriam, Alan and Mack, Raymond. "The Jazz Community." In Social Forces. Vol. 38, No. 3, March, 1960.

Nanry, Charles. The Jazz Text. Toronto, ON: Litton Educational Publishing, Inc., 1979.

Nanry, Charles. "Jazz and Modernism: Twin Born Children of the Age of Invention?" In Annual Review of Jazz Studies. Vol. 1, 1982.

Negus, Keith. Music Genres and Corporate Culture. New York, NY: Routledge, 1999.

Negus, Keith. Popular Music in Theory. Hanover, NH: Wesleyan University Press, 1996.

Nicholson, Stuart. Jazz-Rock: A History. New York, NY: Schirmer Books, 1998.

Ogren, Kathy. The Jazz Revolution: Twenties America and the Meaning of Jazz. New York, NY: Oxford University Press, 1989.

O'Meally, Robert, Ed. The Jazz Cadence of American Culture. New York, NY: Columbia University Press, 1998.

O'Meally, Robert, Ed. Uptown Conversation: The New Jazz Studies. New York, NY: Columbia University Press, 2004.

Ostransky, Paul. Understanding Jazz. Englewood Cliffs, NJ: Prentice-Hall, Inc., 1977.

Owens, Thomas. Bebop: The Music and its Players. New York, NY: Oxford University Press, 1995.

Panassie, Hughes. Hot Jazz: the Guide to Swing Music. New York, NY: Whitmark, 1936.

Peterson, Richard \& Kern, Roger. "Changing Highbrow Taste: From Snob to Omnivore." In American Sociological Review. Vol. 61, October, 1996. 
Peterson, Richard A. Creating Country Music: Fabricating Authenticity. Chicago, IL: University of Chicago Press, 1997.

Peterson, Richard A., Ed. The Production of Culture. Beverly Hills, CA: SAGE Publications, 1976.

Peretti, Burton. The Creation of Jazz. Chicago, IL: University of Illinois Press, 1992.

Peretti, Burton. Jazz in American Culture. Chicago, IL: Ivan R. Dee, Inc. 1997.

Porter, Eric. "'Dizzy Atmosphere:' The Challenge of Bebop." In American Music. Winter 1999.

Porter, Eric. What is This Thing Called Jazz? Los Angeles, CA: University of California Press, 2002.

Porter, Lewis. "Some Problems in Jazz Research." In Black Music Research Journal. Vol. 8, No. 2. Autumn, 1988.

Porter, Lewis. Jazz; a Century of Change. New York, NY: Schirmer Books, 1997.

Pratt, Ray. "The Politics of Authenticity in Popular Music." In Popular Music and Society. Vol. 10, 1986.

Rimler, Walter. Not Fade Away. Ann Arbour, MN: Pierian Press, 1984

Rosenberg, Bernard \& Manning White, David, Eds. Mass Culture: The Popular Arts in America. Glencoe, IL: The Free Press, 1957.

Rosenthal, David. Hard Bop: Jazz and Black Music 1955-1965. New York, NY: Oxford University Press, 1992.

Rosenthal, David. "Jazz in the Ghetto, 1950-1970." In Popular Music. Vol. 7, No. 1. January, 1988.

Rosenthal, David. "Hard Bop and Its Critics." In The Black Perspective in Music. Vol. 16, No. 1. Spring, 1988.

Ross, Andrew. No Respect: Intellectuals \& Popular Culture. New York, NY: Routledge, 1989.

Rubin, Rachel, and Jeffrey Melnick, Eds. American Popular Music. Amherst, MS: University of Massachusetts Press, 2001.

Sargeant, Winthrop. Jazz: Hot and Hybrid. NewYork, NY: Da Capo Press. 1936.

Schafer, William. "Breaking into 'High Society'." In Journal of Jazz Studies. June 1975.

Schafer, William. Brass Bands and New Orleans Jazz. Baton Rouge, LA: Louisiana State University Press, 1977.

Schick, Robert D. Classical Music Criticism. New York, NY: Garland Publishing, Inc., 1996.

Schramm, Wilbur, Ed. Mass Communications. Urbana, IL: University of Illinois Press, 1960.

Schuller, Gunther. Early Jazz. New York, NY: Oxford University Press, 1968.

Scott, Derek. "Music and Sociology for the 1990's: A Changing Critical Perspective." In The Musical Quarterly. Vol. 74, No. 3. 1990.

Shapiro, Nat \& Hentoff, Nat. Hear Me Talkin' To Ya. New York, NY: Dover Publications, Inc., 1955/1965.

Shaw, Arnold. The Jazz Age: Popular Music in the 1920s. New York, NY: Oxford University Press, 1987.

Shepherd, John. Tin Pan Alley. Boston, MS: Routledge \& Kegan Paul, 1982.

Stanbridge, Alan. Of Sunshine and Happy Endings: Jazz, Parody, and the Limits of Interpretation. Publication Pending, University of Toronto, 2005. 
Stanbridge, Alan. Who Could Ask For Anything More? Ottawa, ON: Carleton University Doctoral Dissertation, 2000.

Sterns, Marshall. The Story of Jazz. New York, NY: Oxford University Press, 1956.

Stevens, Charles. "Traditions and Innovations in Jazz." In Popular Music and Society. Vol. 18, 1994.

Storey, John. An Introduction to Cultural Theory and Popular Culture. Athens, GE: University of Georgia Press, 1998.

Tawa, Nicholas. The Way to Tin Pan Alley. New York, NY: Schirmer Books, 1990.

Taylor, Billy. "Jazz." The Musical Quarterly. Vol. 68, No. 2. April 1982.

"The Goodman of Wastness." Found online at www.orkneyjar.com/folklore/selkiefolk. November 7, 2005.

Tirro, Frank. Jazz, A History, $2^{\text {nd }}$ Edition. New York, NY: W. W. Norton \& Co., 1993. Vulliamy, Graham. Jazz \& Blues. Boston, MS: Routledge \& Kegan Paul, Ltd, 1982.

Walser, Robert. Keeping Time: Readings in Jazz History. New York, NY: Oxford University Press, 1999.

Weiland, Steven, and Buckner, Reginald, Eds. Jazz in Mind: Essays on the History and Meanings of Jazz. Detroit, MN: Wayne State University Press, 1991.

Weisbard, Eric, Ed. this is POP. Cambridge, MS: Harvard University Press, 2004.

Welburn, Ron. "Duke Ellington's Music: The Catalyst for a True Jazz Criticism." IRASM 17, 1986.

Williams, Martin. The Jazz Tradition. New York, NY: Oxford University Press, 1993. Williams, Martin. Jazz in its Time. New York, NY: Oxford University Press, 1993.

Williams, Raymond. "Culture." Keywords. New York, NY: Oxford University Press, 1983.

Witkin, Robert. "Why did Adorno Hate Jazz?" In Sociological Theory. Vol. 18, No. 1, March 2000. 